Allan Nogueira de Albuquerque

\title{
Dinâmica e Controle de Mecanismos Paralelos: Integração Modelo Analítico Fechado, Transdutores Inerciais e Atuadores Elétricos Lineares
}

Tese de Doutorado

Tese apresentada como requisito parcial para obtenção do grau de Doutor pelo Programa de Pós-graduação em Engenharia Mecânica da PUC-Rio.

Orientador: Prof. Marco Antonio Meggiolaro 
Allan Nogueira de Albuquerque

\section{Dinâmica e Controle de Mecanismos Paralelos: Integração Modelo Analítico Fechado, Transdutores Inerciais e Atuadores Elétricos Lineares}

Tese apresentada como requisito parcial para obtenção do grau de Doutor pelo Programa de Pós-graduação em Engenharia Mecânica da PUC-Rio. Aprovada pela Comissão Examinadora abaixo assinada.

Prof. Marco Antonio Meggiolaro Orientador Departamento de Engenharia Mecânica - PUC-Rio

Prof. Mauro Speranza Neto Departamento de Engenharia Mecânica - PUC-Rio

Prof. Jaime Tupiassú Pinho de Castro Departamento de Engenharia Mecânica - PUC-Rio

Prof. Fernando Ribeiro da Silva CEFET/RJ

Prof. José Geraldo Telles Ribeiro UERJ

Prof. Márcio da Silveira Carvalho Coordenador Setorial do Centro Técnico Científico - PUC-Rio

Rio de Janeiro, 25 de Maio de 2017 
Todos os direitos reservados. É proibida a reprodução total ou parcial do trabalho sem autorização da universidade, do autor e do orientador.

\section{Allan Nogueira de Albuquerque}

É formado em Engenharia Mecânica (2009) e possui Mestrado em Engenharia Mecânica pela Pontifícia Universidade Católica do Rio de Janeiro (2012). Já atuou nas áreas de ensaios mecânicos e desenvolvimento de veículos robóticos de inspeção. Atualmente trabalha no desenvolvimento de equipamentos para o setor de petróleo e gás. Paralelamente, atua em pesquisa sobre mecanismos articulados para reprodução de movimentos.

Ficha Catalográfica

Albuquerque, Allan Nogueira de

Dinâmica e controle de mecanismos paralelos : integração modelo analítico fechado, transdutores inerciais e atuadores elétricos lineares / Allan Nogueira de Albuquerque ; orientador: Marco Antonio Meggiolaro. - 2017.

202 f. : il. (color.) ; $30 \mathrm{~cm}$

Tese (doutorado)-Pontifícia Universidade Católica do Rio de Janeiro, Departamento de Engenharia Mecânica, 2017.

Inclui referências bibliográficas.

1. Engenharia Mecânica - Teses. 2. Mecanismos paralelos. 3. Cinemática inversa. 4. Dinâmica direta. 5. Fluxo de potência. 6. Grafos de ligação. I. Meggiolaro, Marco Antonio. II. Pontifícia Universidade Católica do Rio de Janeiro. Departamento de Engenharia Mecânica. III. Título. 


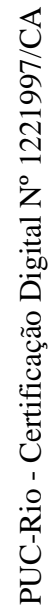

Para Alice. 


\section{Agradecimentos}

Ao Prof. Marco Antonio Meggiolaro, orientador do trabalho, pela orientação e apoio durante o desenvolvimento deste trabalho.

Ao Prof. Mauro Speranza Neto, pelos mais de dez anos de amizade e por todos os seus ensinamentos, sem os quais eu não seria o profissional que me tornei.

Ao CNPq e à PUC-Rio, pelos auxílios concedidos, sem os quais este trabalho não poderia ter sido realizado.

Aos funcionários do Instituto Tecnológico (ITUC), pelo apoio técnico.

Aos alunos e colaboradores do Laboratório de Desenvolvimento de Sistemas Mecatrônicos (LDSM) e da Oficina de Desenvolvimento de Protótipos (ODP), Marília Maurell Assad, Lucas Maciel Ribeiro, Alessandro Soares da Silva Junior

e Edson Gonçalves dos Santos, pelo suporte em diversas etapas do projeto, pela amizade e pelo companheirismo.

Aos amigos e entes queridos, que de alguma forma, contribuíram para este trabalho.

À minha família, por todo o amor. 


\section{Resumo}

Albuquerque, Allan Nogueira; Meggiolaro, Marco Antonio (Orientador). Dinâmica e Controle de Mecanismos Paralelos: Integração Modelo Analítico Fechado, Transdutores Inerciais e Atuadores Elétricos Lineares. Rio de Janeiro, 2017. 202p. Tese de Doutorado - Departamento de Engenharia Mecânica, Pontifícia Universidade Católica do Rio de Janeiro.

Mecanismos são essencialmente (mas não exclusivamente) compostos por vários corpos rígidos que possuem movimento relativo entre si. Cada corpo rígido está ligado através de uma junta a um ou mais corpos, sendo a sequência de corpos conectados chamada de cadeia cinemática. Cadeias cinemáticas abertas (ou em série) não têm restrições sobre uma de suas extremidades, já cadeias fechadas (ou paralelas) têm restrições em ambas as extremidades. $\mathrm{O}$ foco neste trabalho será dado no estudo de mecanismos com cadeias cinemáticas fechadas ou mecanismos paralelos. Assim, este trabalho apresenta a determinação da solução analítica do modelo dinâmico de um mecanismo paralelo plano com três graus de liberdade através da caracterização do fluxo de potência entre os seus componentes. A partir das relações geométricas associadas ao deslocamento dos seus graus de liberdade, as relações cinemáticas associadas às suas velocidades são determinadas. Considerando o fluxo de potência entre os graus de liberdade, e também entre estes e os elementos de atuação (atuadores lineares elétricos), as relações de equilíbrio das forças e torques são obtidas. Levando em consideração os efeitos inerciais dos componentes do sistema, a rigidez e efeitos de amortecimento, as equações de movimento ou as equações de estado são analiticamente determinadas e representadas em qualquer sistema de referência, local ou global. Além disso, as relações entre a cinemática inversa e a dinâmica direta são apresentadas. Esta abordagem adota os mesmos fundamentos, conceitos e elementos da técnica dos grafos de ligação, com a sua notação simbólica e representação gráfica. A metodologia proposta é generalizada e aplicável em qualquer tipo de mecanismo (aberto ou fechado, plano ou espacial). O modelo cinemático inverso do mecanismo de cadeia fechada, que tem uma solução fácil quando comparado com o modelo direto, pode ser desenvolvido por qualquer metodologia conhecida. Neste trabalho, a técnica da cadeia vetorial é usada para determinar o modelo geométrico inverso, e com a sua derivação, as relações 
cinemáticas são obtidas, e, portanto, a matriz Jacobiana inversa. Desse modo, é construída a estrutura em grafos de ligação da cinemática inversa e, a partir das relações de causa e efeito, encontra-se o modelo dinâmico direto do mecanismo. Assim, esta metodologia (grafos de ligação ou fluxo de potência) é mais eficiente e segura para determinar os modelos dinâmicos analíticos (fechados) de mecanismos paralelos. Um conjunto de simulações foi realizado para validar esta abordagem, usando os dados reais (geometria, inércia, amortecimento, forças de atuação, etc.) a partir de um mecanismo plano projetado e construído especialmente para a finalidade de comparar os resultados simulados e experimentais. Uma estratégia de controle de malha fechada usando a cinemática inversa e os modelos dinâmicos diretos é proposta. Finalmente, testes experimentais validam esta estratégia. As equações analíticas levam a um processo de simulação e controle em tempo real mais eficientes destes sistemas.

\section{Palavras-chave}

Mecanismos Paralelos; Cinemática Inversa; Dinâmica Direta; Fluxo de Potência; Relações Causais; Grafos de Ligação. 


\section{Abstract}

Albuquerque, Allan Nogueira; Meggiolaro, Marco Antonio (Advisor). Dynamics and Control of Parallel Mechanisms: Closed Analytical Model, Inertial Transducers and Linear Electric Actuators Integration. Rio de Janeiro, 2017. 202p. Tese de Doutorado Departamento de Engenharia Mecânica, Pontifícia Universidade Católica do Rio de Janeiro.

Mechanisms are essentially (but not exclusively) made up of multiple rigid bodies that have relative motion between themselves. Each rigid body is connected through a joint to one or more bodies, wherein the sequence of connected bodies is called kinematic chain. Open (or serial) kinematic chains have no restrictions on one of their ends, as closed (or parallel) chains have restrictions on both ends. The focus in this work will be given on the study of mechanisms with closed kinematic chains or parallel mechanisms. Thus, this work presents the analytical form determination of the dynamic model of a parallel planar mechanism with three degrees of freedom through the characterization of the power flow between its components. From the geometrical relations associated to the displacement of their degrees of freedom, the kinematic relations associated to their speeds are determined. Considering the power flow between the degrees of freedom, and also between these and the actuating elements (linear electric actuators) the equilibrium relations of the forces and torques are obtained. Accounting for inertial effects of system components, the stiffness and damping effects, the equations of motion or the state equations are analytically determined and represented in any reference frame, local or global. Besides, the relation between the inverse kinematics and the direct dynamics is presented. This approach adopts the same fundamentals, concepts and elements of the Bond Graph Technique, with its symbolic notation and graphical representation. The proposed methodology is generalized and applicable in any type of mechanism (open or closed, planar or spatial). The inverse kinematic model of the closed chain mechanism, which has easy solution when compared to the direct model, can be developed by any known methodology. In this work, the vector loop technique is used to determine the inverse geometric model, and with its derivation, the kinematic relations are obtained, and therefore the inverse Jacobian matrix. Thereby, the inverse kinematics bond graph is built and, from the cause 
and effect relations, the direct dynamic model of the mechanism is found. Thus, this methodology (bond graphs or power flow) is more efficient and secure to achieve the dynamic analytical (closed) models of parallel mechanisms. A set of simulations are performed to validate this approach, using the real data (geometry, inertia, damping, actuators forces, etc.) from a planar mechanism designed and built especially for the purpose to compare the simulated and experimental results. A closed-loop control strategy using the inverse kinematic and the direct dynamic models is proposed. Finally, experimental tests validate this strategy. The analytical equations lead to a more efficient simulation process and real-time control of these systems.

\section{Keywords}

Parallel Mechanisms; Inverse Kinematic; Direct Dynamic; Power Flow; Causal Relations; Bond Graphs. 


\section{Sumário}

1 Introdução $\quad 24$

1.1 Objetivos 24

1.2 Motivação 25

1.3 Contribuições da presente Tese 26

1.4 Organização do trabalho 28

2 Revisão bibliográfica 29

2.1 Mecanismos de cadeia fechada 32

2.1.1 Graus de liberdade 34

2.1.2 Notação de Denavit-Hartenberg 38

2.1.3 Cinemática via cadeia vetorial 40

2.2 Dinâmica via fluxo de potência 44

2.3 Estruturas HIL - Hardware In the Loop 46

2.4 Curvas de desempenho de motores DC 51

2.5 Calibração de IMU 54

3 Modelo dinâmico do mecanismo paralelo plano 57

3.1 Cinemática inversa do mecanismo paralelo plano 57

3.1.1 Geometria inversa via cadeia vetorial 57

3.1.2 Cinemática inversa via cadeia vetorial 58

3.1.3 Cinemática inversa via fluxo de potência 63

3.2 Dinâmica do mecanismo paralelo plano via fluxo de potência 65

3.2.1 Relações de causa e efeito 65

3.2.2 Dinâmica direta 66

$\begin{array}{lll}3.3 & \text { Condições de singularidade } & 73\end{array}$

4 Modelo dinâmico do sistema de atuação $\quad 77$

4.1 Modelo dinâmico de motores elétricos 77

4.2 Descrição do sistema de atuação 82

4.3 Modelo dinâmico do sistema de atuação 84 
4.3.1 Modelo dinâmico acoplado 87

4.4 Curvas de desempenho do motor elétrico 91

4.5 Caracterização do atuador linear elétrico 101

4.5.1 Calibração do transdutor de deslocamento linear 101

4.5.2 Ensaios com tensão de alimentação constante 103

4.5.3 Ensaios usando o controlador de velocidade 107

5 Estratégias de controle $\quad 112$

5.1 Arquitetura de controle via transdutores lineares elétricos $\quad 112$

5.2 Controle via transdutores lineares elétricos e central inercial 116

5.3 Controle via central inercial 119

6 Simulações para avaliação dos modelos desenvolvidos 122

6.1 Atuador linear elétrico 122

6.1.1 Simulações em MatLab/Simulink 122

6.1.2 Simulações em SolidWorks Motion Analysis 124

6.2 Modelo cinemático do mecanismo paralelo plano 127

6.2.1 Simulações em MatLab/Simulink 127

6.2.2 Simulações em SolidWorks Motion Analysis $\quad 129$

6.3 Modelo dinâmico do mecanismo paralelo plano 131

6.3.1 Simulações em MatLab/Simulink 131

6.3.2 Simulações em SolidWorks Motion Analysis 134

6.4 Validação das estratégias de controle 135

7 Resultados experimentais 141

7.1 Descrição da bancada experimental 141

7.2 Validação da Geometria Inversa 145

7.3 Validação da Cinemática Inversa 148

7.3.1 Modelo da matriz Jacobiana (relação de velocidades) 148

7.3.2 Modelo dos derivativos da matriz Jacobiana (relação de acelerações) 155

7.4 Estratégias de controle 157

7.4.1 Controle via transdutores de deslocamento 157

$\begin{array}{ll}\text { 7.4.2 Calibração da central inercial } & 161\end{array}$ 
8 Conclusões 164

8.1 Conclusões 164

8.2 Principais contribuições 165

8.3 Trabalhos futuros 166

$\begin{array}{lc}\text { Referências bibliográficas } & 168\end{array}$

Apêndice A Análise cinemática de um mecanismo de quatro barras

usando o método de Denavit-Hartenberg

Índice do CD Anexo: I Códigos usados nas simulações

Índice do CD Anexo: II CAD e desenhos técnicos

Índice do CD Anexo: III Virtual Instruments (.vi) do programa LabView 200 Índice do CD Anexo: IV Catálogos dos elementos da plataforma

plana 3-RㅁR

201

CD Anexo

202 


\section{Lista de figuras}

Figura 2.1: Tipos de cadeia cinemática. a) aberta; b) em árvore; c) fechada.

Figura 2.2: Exemplos de mecanismos paralelos baseados na plataforma

de Stewart. a) Simulador de voo; b) Robô montador.

Figura 2.3: Classificação de manipuladores paralelos de acordo com seus movimentos: a) plano; b) esférico; c) espacial.

Figura 2.1.1: Transformação do mecanismo com cadeia fechada (a) em um aberto equivalente com estrutura tipo 'árvore' (b).

Figura 2.1.2: Mecanismo paralelo plano com três graus de liberdade.

Figura 2.1.3: Mecanismo de cadeia fechada e seus parâmetros de

Denavit-Hartenberg.

Figura 2.1.4: Diagrama esquemático da Plataforma Stewart.

Figura 2.3.1: Arquitetura da plataforma HIL para simulação de um

guindaste (Pedersen, M. M., et al., 2012).

Figura 2.3.2: (a) Processo de validação da ECU Ford; (b) Diagrama com a arquitetura do sistema HIL usado (Ramaswamy, D. et al., 2004).

Figura 2.3.3: Conceito HIL usado em sistemas hidráulicos offshore

(Pawluls, W., et al., 2015).

Figura 2.3.4: Ambiente de simulação HIL para VANT

(Gans, N. R., et al., 2009).

Figura 2.3.5: Arquitetura HIL empregada no teste de um controlador de aleta de míssil (Pritsker, D., 2013).

Figura 2.3.6: Simulador de treinamento para um guindaste (Kleijn, C., 2016). 50

Figura 2.4.1: Diagrama de um motor DC com escovas

(Harrington, A. M., e Kroninger, C., 2013).

Figura 2.4.2: Curvas de torque $\mathrm{x}$ velocidade angular para um motor com escovas (Harrington, A. M., e Kroninger, C., 2013).

Figura 2.4.3: Curvas de eficiência x potência mecânica para um motor

com escovas (Harrington, A. M., e Kroninger, C., 2013).

Figura 2.4.4: Curvas de eficiência $\mathrm{x}$ velocidade angular para um motor com escovas (Harrington, A. M., e Kroninger, C., 2013). 
Figura 2.5.1: (a) Plano inclinado para teste estático e (b) Rate test

(Wang, L. e Wang, F., 2011).

Figura 2.5.2: Plataforma de Stewart usada na calibração de IMU embarcada em UAV (Magnussen, O. et al., 2012).

Figura 2.5.3: Plataforma de Stewart usada na validação de IMU

(Costa, M. S. M.. et al., 2015). 56

Figura 3.1.1: Plataforma plana com três graus de liberdade. 58

Figura 3.1.2: Cinemática inversa da plataforma plana via grafos de ligação. $\quad 64$

Figura 3.1.3: Cinemática inversa da plataforma plana via grafos multi-ligação. 64

Figura 3.2.1: Relações de causa e efeito da plataforma plana. 65

Figura 3.2.2: Dinâmica da plataforma plana via grafos de ligação. 67

Figura 3.2.3: Dinâmica da plataforma plana via grafos multi-ligação. $\quad 68$

Figura 3.2.4: Velocidades envolvidas em detalhe (a) e parte do grafo de ligação do modelo que considera o atrito viscoso das juntas rotativas da base $B_{i}(\mathrm{~b})$.

Figura 4.1.1: Variáveis de entrada e de saída do modelo de um motor elétrico CC com escovas.

Figura 4.1.2: Esquema da parte elétrica (a) e da parte mecânica (b) do motor CC.

Figura 4.1.3: Curvas de comportamento de um motor CC com escovas.

Figura 4.1.4: Relações de parâmetros das curvas de comportamento de um motor CC com escovas.

Figura 4.2.1: Atuador linear elétrico LINAK LA12.

Figura 4.2.2: Esquema do atuador elétrico.

Figura 4.2.3: Curva velocidade $(\mathrm{mm} / \mathrm{s}) \times$ força $(\mathrm{N})$ do atuador LINAK LA12. 83 Figura 4.2.4: Curva corrente elétrica $(\mathrm{A}) x$ força $(\mathrm{N})$ do atuador LINAK

LA12.

Figura 4.3.1: Grafos de ligação do modelo dinâmico do atuador linear elétrico. 84 Figura 4.3.2: Representação completa do mecanismo paralelo 3-RPR em grafos de ligação.

Figura 4.3.3: Representação completa do mecanismo paralelo 3-RPR em grafos multi-ligação.

Figura 4.4.1: Dinamômetro de motores de corrente contínua. 
Figura 4.4.2: Curvas características do motor elétrico para 6 VDC. 92

Figura 4.4.3: Curvas características do motor elétrico para 12 VDC. 93

Figura 4.4.4: Curvas características do motor elétrico para 18 VDC. 93

Figura 4.4.5: Curvas características do motor elétrico para 24 VDC. 93

Figura 4.4.6: Curvas torque x velocidade angular para o controle do motor elétrico usando uma fonte CC. 94

Figura 4.4.7: Controlador MC33926, da Pololu. 95

Figura 4.4.8: Painel de controle usado nos testes. 95

Figura 4.4.9: Sensor de corrente ACS714, da Allegro. 96

Figura 4.4.10: Curva de calibração do sensor ACS714. 96

Figura 4.4.11: Respostas no tempo obtidas nos testes do motor elétrico. 97

Figura 4.4.12: Curvas características do motor elétrico para $\mathrm{D}=0,25$ (6 VDC). 98

Figura 4.4.13: Curvas características do motor elétrico para $\mathrm{D}=0,50$

(12 VDC).

Figura 4.4.14: Curvas características do motor elétrico para $\mathrm{D}=0,75$

(18 VDC).

Figura 4.4.15: Curvas características do motor elétrico para $\mathrm{D}=1,00$

(24 VDC).

Figura 4.4.16: Curvas torque x velocidade angular para o controle do motor elétrico usando o controlador de velocidade.

Figura 4.4.17: Comparação das curvas torque x velocidade angular para

o controle do motor elétrico usando fonte CC e controlador de velocidade. 100

Figura 4.5.1: Curva de calibração do atuador linear elétrico. 101

Figura 4.5.2: Bancada para testes experimentais. 103

Figura 4.5.3: Esquema de ligação do atuador, transdutor e módulo de $\begin{array}{ll}\text { aquisição de dados. } & 103\end{array}$

Figura 4.5.4: Testes para escolha do tipo de filtro. 104

Figura 4.5.5: Testes horizontal e vertical com carga. 105

Figura 4.5.6: Teste horizontal com carga. 105

Figura 4.5.7: Teste horizontal sem carga. 106

Figura 4.5.8: Teste vertical com carga. 106

Figura 4.5.9: Teste vertical sem carga. 106

Figura 4.5.10: Extensão do atuador sem carga. 108 
Figura 4.5.11: Retração do atuador sem carga.

Figura 4.5.13: Extensão do atuador para $m_{h}=759,8 \mathrm{~g}$.

Figura 4.5.14: Retração do atuador para $m_{h}=759,8 \mathrm{~g}$.

Figura 4.5.14: Extensão e retração do atuador para $m_{h}=5327,8 \mathrm{~g}$.

Figura 4.5.15: Teste horizontal com carga $m_{h}=759,8 \mathrm{~g}$ (a) e

$\mathrm{m}_{\mathrm{h}}=5327,8 \mathrm{~g}(\mathrm{~b})$.

Figura 4.5.16: Painel de controle para os ensaios usando o controlador.

Figura 5.1.1: Esquema do acionamento do motor elétrico.

Figura 5.1.2: Estratégia para validação da geometria inversa e controle convencional de posição.

Figura 5.1.3: Estratégia para validação para modelo da Jacobiana inversa.

Figura 5.1.4: Estratégia para validação para modelo dos derivativos da

Jacobiana inversa.

Figura 5.1.5: Estratégia para controle convencional de velocidade e posição. 116

Figura 5.1.6: Estratégia para controle convencional de aceleração,

velocidade e posição.

Figura 5.2.1: Central inercial Pixhawk, da 3D Robotics.

Figura 5.2.2: Estratégia não convencional de aceleração, velocidade e posição. 118

Figura 5.3.1: Sistema em malha fechada.

Figura 5.3.2: Esquema dos modelos cinemáticos da malha de controle.

Figura 5.3.3: Diagrama de blocos da malha de controle.

Figura 5.3.4: Estratégia de controle via central inercial.

Figura 6.1.1: Modelo do atuador simplificado.

Figura 6.1.2: Torque fornecido pelo motor (a), aceleração (b), velocidade

(c) e deslocamentos do atuador (d).

Figura 6.1.3: Modelo simplificado (a) e detalhado (b) do atuador linear elétrico.

Figura 6.1.4: Torque aplicado no modelo.

Figura 6.1.5: Velocidade da haste do atuador no tempo.

Figura 6.2.1: Manipulador paralelo 3-RPR: (a) $X=0.0 \mathrm{~mm}, Y=0.0 \mathrm{~mm}$ e $\theta=0.000 \mathrm{rad}$; (b) $X=20.0 \mathrm{~mm}, Y=30.0 \mathrm{~mm}$ e $\theta=0.262 \mathrm{rad}\left(15.0^{\circ}\right)$.

Figura 6.2.2: Deslocamento e velocidades lineares e angulares dos atuadores. 128

Figura 6.2.3: Velocidades e acelerações lineares e angulares dos atuadores. 
Figura 6.2.1: Modelo em CAD da plataforma paralela plana usada nas simulações.

Figura 6.2.4: Respostas no tempo para as entradas $v_{X}(t)=10 \mathrm{~mm} / \mathrm{s}$ (a) e $v_{Y}(t)=10 \mathrm{~mm} / \mathrm{s}$.

Figura 6.2.5: Respostas no tempo dos deslocamentos (a) e velocidades (b) para as entradas da Equação 6.2.1.

Figura 6.2.6: Respostas no tempo das velocidades (a) e acelerações (b) para as entradas da Equação 6.2.2.

Figura 6.3.1: Forças geradas pelos atuadores.

Figura 6.3.2: Acelerações, velocidades e deslocamentos lineares e angulares da plataforma móvel.

Figura 6.3.3: Simulação com entradas $a_{X}(t)=1 \mathrm{~mm} / \mathrm{s}^{2}$ (a), $a_{X}(t)=5 \mathrm{~mm} / \mathrm{s}^{2}$

(b), $a_{X}(t)=10 \mathrm{~mm} / \mathrm{s}^{2}$ (c) e $a_{X}(t)=15 \mathrm{~mm} / \mathrm{s}^{2}$ (d).

Figura 6.3.4: Respostas no tempo das velocidades (a) e acelerações (b) para as entradas da Figura 6.3.1.

Figura 6.4.1: Respostas no tempo para a entrada $X(t)=20 \mathrm{~mm}$. (a) $k_{p}=0,5$;

(b) $k_{p}=1,0$.

Figura 6.4.2: Respostas no tempo para a entrada $Y(t)=20 \mathrm{~mm}$. (a) $k_{p}=0,5$;

(b) $k_{p}=1,0$.

Figura 6.4.3: Respostas no tempo para a entrada $v_{X}(t)=10 \mathrm{~mm} / \mathrm{s}$. (a) $k_{p}=0,8$ e $k_{v}=0,01$; (b) $k_{p}=0,8$ e $k_{v}=1,00$.

Figura 6.4.4: Respostas no tempo para ganhos $k_{p}=0,8$ e $k_{v}=0,01$. (a)

$v_{X}(t)=10 \mathrm{~mm} / \mathrm{s} ;$ (b) $v_{X}(t)=30 \mathrm{~mm} / \mathrm{s} ;$ (c) $v_{Y}(t)=10 \mathrm{~mm} / \mathrm{s}$; (d) $v_{Y}(t)=20 \mathrm{~mm} / \mathrm{s} .138$

Figura 6.4.5: Respostas no tempo para a entrada $a_{X}(t)=5 \mathrm{~mm} / \mathrm{s}^{2}, k_{p}=0,8$

e $k_{v}=0,05$. (a) $k_{i}=10^{-4}$; (b) $k_{i}=10^{-5}$; (c) $k_{i}=10^{-6}$.

Figura 6.4.6: Respostas no tempo dos deslocamentos dos atuadores para a entrada $a_{X}(t)=5 \mathrm{~mm} / \mathrm{s}^{2}$. (a) $k_{p}=4, k_{v}=1$ e $k_{i}=1,2.10^{-4}$; (b) $k_{p}=4, k_{v}=1$ e $k_{i}=1,5.10^{-4}$; (c) $k_{p}=4, k_{v}=1$ e $k_{i}=1,7.10^{-4}$; (d) $k_{p}=5, k_{v}=1,5$ e $k_{i}=1,5 \cdot 10^{-4}$.

Figura 6.4.7: Respostas no tempo das velocidades dos atuadores para a entrada $a_{X}(t)=5 \mathrm{~mm} / \mathrm{s}^{2}$. (a) $k_{p}=4, k_{v}=1$ e $k_{i}=1,2.10^{-4}$; (b) $k_{p}=4, k_{v}=1$ e $k_{i}=1,5.10^{-4}$; (c) $k_{p}=4, k_{v}=1$ e $k_{i}=1,7.10^{-4}$; (d) $k_{p}=5, k_{v}=1,5$ e $k_{i}=1,5 \cdot 10^{-4}$. 
Figura 7.1.1: Modelo em CAD do acoplamento do rolamento à base fixa (a) e da junta rotativa da base fixa (b).

Figura 7.1.2: Modelo em CAD de uma das peças da plataforma móvel (a) e da plataforma montada (b).

Figura 7.1.3: Modelo em CAD da plataforma plana para simulação de movimentos.

Figura 7.1.4: Modelo em CAD da bancada (base fixa) com a plataforma.

Figura 7.1.5: Eletrônica de controle da plataforma.

Figura 7.1.6: Bancada experimental.

Figura 7.1.7: Configurações distintas da plataforma móvel.

Figura 7.2.1: Painel de controle para os testes de validação da geometria inversa.

Figura 7.2.2: Respostas no tempo nos testes para validação da geometria inversa com entrada em $X(t)$.

Figura 7.2.3: Respostas no tempo nos testes para validação da geometria inversa com entrada em $Y(t)$.

Figura 7.2.4: Respostas no tempo nos testes para validação da geometria inversa com entrada em $\theta(t)$.

Figura 7.2.5: Respostas no tempo nos testes para validação da geometria inversa com entradas em $X(t), Y(t)$ e $\theta(t)$.

Figura 7.3.1: Teste com entrada $v_{X}(t)=10 \mathrm{~mm} / \mathrm{s}$.

Figura 7.3.2: Teste com entrada $v_{X}(t)=20 \mathrm{~mm} / \mathrm{s}$.

Figura 7.3.3: Teste com entrada $v_{X}(t)=30 \mathrm{~mm} / \mathrm{s}$.

Figura 7.3.4: Teste com entrada $v_{Y}(t)=10 \mathrm{~mm} / \mathrm{s}$.

Figura 7.3.5: Teste com entrada $v_{Y}(t)=20 \mathrm{~mm} / \mathrm{s}$.

Figura 7.3.6: Teste com entrada $v_{Y}(t)=30 \mathrm{~mm} / \mathrm{s}$.

Figura 7.3.7: Teste com entrada $v_{X}(t)=20 . \operatorname{sen}(2 \pi t)[\mathrm{mm} / \mathrm{s}]$.

Figura 7.3.8: Teste com entrada $v_{X}(t)=20 . \operatorname{sen}(6 \pi t)[\mathrm{mm} / \mathrm{s}]$.

Figura 7.3.9: Teste com entrada $v_{Y}(t)=20 . \operatorname{sen}(2 \pi t)[\mathrm{mm} / \mathrm{s}]$.

Figura 7.3.10: Teste com entrada $v_{Y}(t)=20 \cdot \operatorname{sen}(6 \pi t)[\mathrm{mm} / \mathrm{s}]$.

Figura 7.3.11: Teste com entradas $v_{X}(t)=20 \cdot \operatorname{sen}(6 \pi t)$ e $v_{Y}(t)=20 \cdot \operatorname{sen}(6 \pi t)$ $[\mathrm{mm} / \mathrm{s}]$.

Figura 7.3.12: Teste com entradas $v_{X}(t)=30 \cdot \operatorname{sen}(10 \pi t) \mathrm{e}$ 
$v_{Y}(t)=30 \cdot \operatorname{sen}(10 \pi t)[\mathrm{mm} / \mathrm{s}]$.

Figura 7.3.13: Teste com entradas $a_{X}(t)=1 \mathrm{~mm} / \mathrm{s}^{2}(\mathrm{a}), a_{X}(t)=5 \mathrm{~mm} / \mathrm{s}^{2}(\mathrm{~b})$, $a_{X}(t)=10 \mathrm{~mm} / \mathrm{s}^{2}(\mathrm{c})$ e $a_{X}(t)=15 \mathrm{~mm} / \mathrm{s}^{2}(\mathrm{~d})$.

Figura 7.3.14: Teste com entradas $a_{Y}(t)=1 \mathrm{~mm} / \mathrm{s}^{2}(\mathrm{a}), a_{Y}(t)=5 \mathrm{~mm} / \mathrm{s}^{2}(\mathrm{~b})$, $a_{Y}(t)=10 \mathrm{~mm} / \mathrm{s}^{2}(\mathrm{c})$ e $a_{Y}(t)=15 \mathrm{~mm} / \mathrm{s}^{2}(\mathrm{~d})$.

Figura 7.4.1: Respostas no tempo para entrada $X(t)=20 \mathrm{~mm}$. (a) Atuador 1 e $k_{p}=0,5$ a 1,0; (b) atuador 2 e $k_{p}=0,5$ a 1,0 ; (c) atuador 1 e $k_{p}=1,0$ a 4,$0 ;$ (d) atuador 2 e $k_{p}=1,0$ a 4,0.

Figura 7.4.2: Entrada $Y(t)=20 \mathrm{~mm}$. (a) Atuador 1 e $k_{p}=0,5$ a 1,0; (b) atuador 3 e $k_{p}=0,5$ a 1,0; (c) atuador 1 e $k_{p}=1,0$ a 4,0; (d) atuador 3 e $k_{p}=1,0$ a $4,0$.

Figura 7.4.2: Respostas no tempo para entrada $v_{X}(t)=10 \mathrm{~mm} / \mathrm{s}$. (a) Atuador $1, k_{p}=0,5$ a 4,0 e $k_{v}=0,1$; (b) atuador $2, k_{p}=0,5$ a 4,0 e $k_{v}=0,1$.

Figura 7.4.3: Respostas no tempo para entrada $v_{X}(t)=10 \mathrm{~mm} / \mathrm{s}$. (a) Atuador

$1, k_{p}=0,8$ e $k_{v}=0,01$ a 0,09 ; (b) atuador $2, k_{p}=0,8$ e $k_{v}=0,01$ a 0,09 ;

(c) atuador $1, k_{p}=0,8$ e $k_{v}=0,01$ a 1,0 ; (d) atuador $2, k_{p}=0,8$ e

$k_{v}=0,01$ a 1,0 .

Figura 7.4.4: Respostas no tempo para entrada $v_{X}(t)=30 \mathrm{~mm} / \mathrm{s}$. (a)

Atuador $1, k_{p}=0,8$ e $k_{v}=0,01$ a 1,$0 ;$ (b) atuador $2, k_{p}=0,8$ e $k_{v}=0,01$ a $1,0.160$

Figura 7.4.5: Respostas no tempo para entrada $v_{Y}(t)=10 \mathrm{~mm} / \mathrm{s}$. (a)

Atuador $1, k_{p}=0,8$ e $k_{v}=0,01$ a 1,0 ; (b) atuador $3, k_{p}=0,8$ e $k_{v}=0,01$ a $1,0 . \quad 161$

Figura 7.4.6: IMU fixada na plataforma móvel.

Figura 7.4.7: Painel do controle para os testes com IMU.

Figura 7.4.8: Exemplo de resposta no tempo obtida durante a calibração da IMU.

Figura 7.4.9: Respostas no tempo para entrada em degrau de $5^{\circ}$.

Figura 7.4.10: Respostas no tempo para entrada em degrau de $30^{\circ}$.

Figura 8.2.1: Aparatos desenvolvidos pela Quanser: mecanismo de quatro barras (a) e hexapod (b).

Figura 8.3.1: Uso do mecanismo paralelo desenvolvido como simulador de movimentos.

Figura A.1: Mecanismo de quatro barras.

Figura A.2: Seção esquerda do mecanismo de quatro barras apresentado 
e seus parâmetros de Denavit-Hartenberg.

Figura A.3: Seção direita do mecanismo de quatro barras apresentado

e seus parâmetros de Denavit-Hartenberg.

Figura A.4: Definição dos ângulos no mecanismo de quatro barras. 186

Figura A.5: Modelo cinemático do mecanismo de quatro barras. 192

Figura A.6: Detalhes do modelo cinemático do mecanismo de quatro barras. 192

Figura A.7: Entrada de -30 \% na barra $d_{4}$ após $1 \mathrm{~s}$.

Figura A.8: Deslocamentos do ponto $A_{2}$ para entrada de $-30 \%$ em $d_{4}$.

Figura A.9: Velocidades do ponto $A_{2}$ para entrada de $-30 \%$ em $d_{4}$.

Figura A.10: Variação dos ângulos $\theta 1, \theta 2 e \theta 4$ para entrada de $-30 \%$ em $d_{4} .194$

Figura A.11: Entrada de -30 \% na barra $d_{4}$ após $1 \mathrm{~s}$ (“cotovelo" para baixo). 194

Figura A.12: Deslocamentos do ponto $A_{2}$ para entrada de $-30 \% \mathrm{sem} d_{4}$ ("cotovelo" para baixo).

Figura A.13: Velocidades do ponto $A_{2}$ para entrada de $-30 \%$ em $d_{4}$ ("cotovelo" para baixo).

Figura A.14: Variação dos ângulos $\theta 1, \theta 2$ e $\theta 4$ para entrada de $-30 \%$ em $d_{4}$ ("cotovelo" para baixo).

Figura A.15: Entrada de $30 \%$ na barra $d_{4}$ após $1 \mathrm{~s}$.

Figura A.16 Entrada de $30 \%$ s na barra $d_{4}$ após 1 s ("cotovelo" para baixo).

Figura A.17: Deslocamentos do ponto $A_{2}$ para entrada senoidal em $\theta 4$.

Figura A.18: Velocidades do ponto $A_{2}$ para entrada senoidal em $\theta 4$.

Figura A.19: Variação dos ângulos $\theta 1, \theta 2$ e $\theta 4$ para entrada senoidal em $\theta 4.197$ 


\section{Lista de tabelas}

Tabela 2.1: Comparação entre manipuladores seriais e paralelos

(Wang, Y., 2008). 30

Tabela 2.1.1: Classificação do mecanismo plano paralelo. 37

Tabela 4.4.1: Dados da calibração da medição de velocidade angular. 96

Tabela 4.5.1: Séries de leitura para curva de calibração. 102

Tabela 4.5.2: Faixas de incerteza nos pontos da curva de calibração. 102

Tabela 4.5.3: Resultados dos testes com carga. $\quad 107$

Tabela 4.5.4: Resultados dos testes sem carga. 107

Tabela 4.5.5: Resultados dos testes com controlador de velocidade. 111

Tabela 6.1.1: Parâmetros usados na simulação do atuador linear elétrico. 123

Tabela A.1: Parâmetros de Denavit-Hartenberg do mecanismo serial da esquerda.

Tabela A.2: Parâmetros de Denavit-Hartenberg do mecanismo serial da direita. 


\title{
Sumário das notações
}

\author{
Lista de símbolos \\ DOF, \\ Graus de liberdade (degree of freedom) \\ $O$, \\ Origem do sistema de referência fixo \\ $u$, \\ Coordenada horizontal (perpendicular ao plano $v w$ ) no \\ sistema de referência $\mathrm{B}, \mathrm{mm}$ \\ $v$, \\ Coordenada horizontal (perpendicular ao plano $u w$ ) no \\ $w$, \\ sistema de referência $\mathrm{B}, \mathrm{mm}$ \\ $x$, \\ Coordenada vertical no sistema de referência B, mm \\ Coordenada horizontal (perpendicular ao plano $y z$ ) no \\ sistema de referência $\mathrm{A}, \mathrm{mm}$ \\ $y$, \\ Coordenada horizontal (perpendicular ao plano $x z$ ) no \\ sistema de referência A, mm \\ $z$ \\ Coordenada vertical no sistema de referência A, mm \\ $m$, \\ Número de encadeamentos \\ $F$, \\ Número de graus de liberdade do mecanismo \\ $L$, \\ Número de cadeias cinemáticas do mecanismo \\ $P$, \\ Junta prismática \\ $R$, \\ Junta rotacional \\ $S$ \\ Junta esférica \\ $C_{k}$ \\ Conectividade do membro $k$ \\ $f_{i}$, \\ Graus de liberdade já junta $i$ \\ $A_{h}$, \\ Matriz de transformação resultante (Denavit-Hartenberg) \\ $I$, \\ Matriz Identidade \\ $R$ \\ Junta rotacional \\ $t$ \\ Tempo, s
}

Símbolos gregos

$\varphi$

Ângulo de arfagem (pitch) da plataforma móvel, rad 
$\theta$,

$\psi$

$\tau$,

$\omega$,

$\Lambda$,

Ângulo de rolagem (roll) da plataforma móvel, rad

Ângulo de guinada (yaw) da plataforma móvel, rad

Constante de tempo, $\mathrm{s}$

Frequência, $\mathrm{rad} / \mathrm{s}$

Graus de liberdade do espaço onde atua o mecanismo

\section{Subscritos}
A,
Referente ao sistema de referência A
$\mathrm{B}$,
Referente ao sistema de referência B
$\mathrm{O}$,
Referente ao sistema de referência $\mathrm{O}$
$d$
Referente à trajetória desejada
$i$,
Relativo ao $i$-ésimo membro
$u$,
Referente à coordenada $u$
1 ,
Referente ao atuador, membro ou sistema de referência 1
2 ,
Referente ao atuador, membro ou sistema de referência 2
3 ,
Referente ao atuador, membro ou sistema de referência 3
4 ,
Referente ao atuador, membro ou sistema de referência 4
5 ,
Referente ao atuador, membro ou sistema de referência 5
6 ,
Referente ao atuador, membro ou sistema de referência 6
$\infty$,
Referente ao regime permanente
$a$,
Referente à aceleração
Referente à velocidade
$p$,
Referente à posição
$n$,
Referente à frequência natural ou sistema de referência $n$

\section{Sobrescritos}
A,
Referente ao sistema de referência A
$\mathrm{B}$,
Referente ao sistema de referência B
$\mathrm{O}$,
Referente ao sistema de referência $\mathrm{O}$ 


\title{
1
}

\section{Introdução}

\begin{abstract}
Neste capítulo serão apresentados os objetivos, motivações e posicionamentos com relação às contribuições deste trabalho, além da organização do presente documento.
\end{abstract}

\subsection{Objetivos}

Mecanismos são essencialmente (mas não exclusivamente) compostos por vários elos que possuem movimento relativo entre si. Cada elo está ligado através de juntas a um ou mais corpos, sendo a sequência de corpos conectados chamada de cadeia cinemática. Cadeias cinemáticas abertas (ou em série) não têm restrições sobre uma de suas extremidades, já cadeias fechadas (ou paralelas) têm restrições em ambas as extremidades. O foco neste trabalho será dado no estudo de mecanismos paralelos, que são mecanismos com cadeias cinemáticas fechadas.

O modelo cinemático inverso de um mecanismo de cadeia fechada, que tem uma solução fácil quando comparado com o modelo direto, pode ser desenvolvido por qualquer metodologia conhecida, sendo possível usar notações como as de Denavit-Hartenberg, de Sheth-Uicker ou de Kleinfinger-Khalil. Neste trabalho foi usada a técnica da cadeia vetorial. Assim, a partir das relações geométricas associadas ao deslocamento dos seus graus de liberdade, as relações cinemáticas associadas às suas velocidades são determinadas.

Com o modelo cinemático fechado, será aplicado um método baseado no acoplamento de modelos dinâmicos usando a técnica dos grafos de ligação. Considerando o fluxo de potência entre os graus de liberdade, e também entre estes e os elementos de atuação (atuadores lineares elétricos), as relações de equilíbrio das forças e torques são obtidas. Levando em consideração os efeitos inerciais dos componentes do sistema, a rigidez e efeitos de amortecimento, as equações de movimento ou as equações de estado são analiticamente determinadas e representadas em qualquer sistema de referência, local ou global. 
Esta abordagem adota os mesmos fundamentos, conceitos e elementos da técnica dos grafos de ligação, com a sua notação simbólica e representação gráfica. Assim, este trabalho apresenta a determinação da solução analítica do modelo dinâmico de um mecanismo paralelo plano com três graus de liberdade através da caracterização do fluxo de potência entre os seus componentes e também apresenta as relações entre a cinemática inversa e a dinâmica direta. A metodologia proposta é generalizada e aplicável em qualquer tipo de mecanismo (aberto ou fechado, plano ou espacial), além de ser eficiente e segura para determinar os modelos dinâmicos analíticos (fechados) de mecanismos paralelos.

Com o modelo dinâmico acoplado fechado, este será inserido em uma estratégia de controle não convencional, integrando o uso de transdutores inerciais e atuadores lineares elétricos. Um conjunto de simulações é realizado para validar esta abordagem, usando os dados reais (geometria, inércia, amortecimento, atuadores forças, etc.) a partir de um mecanismo plano projetado e construído especialmente para a finalidade de comparar os resultados simulados e experimentais e testes validam esta estratégia. As equações analíticas levam a um processo de simulação e controle em tempo real mais eficientes destes sistemas.

\subsection{Motivação}

Sistemas paralelos apresentam grandes vantagens quando comparados aos manipuladores seriais, como melhor estabilidade e precisão, capacidade de manipular cargas relativamente grandes, altas velocidades e acelerações e baixa força de atuação. O projeto de manipuladores robóticos paralelos remonta há várias décadas atrás, em 1962, quando Gough e Witehall desenharam um sistema paralelo para ser usado em uma máquina de provas universais. Stewart em 1965 projetou uma plataforma para ser usada em simuladores de voo. Desde então vão se desenrolando inúmeros estudos por diversos pesquisadores.

Assim, a obtenção de modelos dinâmicos analíticos fechados destes tipos de mecanismos pode contribuir significativamente para o desenvolvimento de manipuladores robóticos, simuladores de movimentos, sistemas de calibração de centrais inerciais, aparatos educacionais e quaisquer outros equipamentos que sejam baseados neste tipo de arquitetura. Além da obtenção de tais modelos, este trabalho visa implementar uma estratégia de controle usando uma central inercial 
de baixo custo para controlar posição, velocidade e aceleração de um mecanismo paralelo plano projetado e construído para os fins deste trabalho.

O desenvolvimento de tal bancada de testes leva a diversas aplicações diretas em pesquisas futuras, tais como seu uso no processo de calibração de centrais inerciais, seu uso como simulador de movimentos de veículos em escala e como ferramenta de auxílio ao ensino de engenharia, como outros equipamentos desenvolvidos no Laboratório de Desenvolvimento de Sistemas Mecatrônicos Estes aparatos são em escala reduzida e de baixo custo, com o intuito de auxiliar a prática do ensino, aprendizado e pesquisa em engenharia. Equipamentos deste tipo podem ser usados por outras instituições como kits educacionais, além de serem usados para ilustrar conceitos de Física e Matemática, por exemplo, gerando um ganho de qualidade no treinamento de futuros técnicos e engenheiros (Speranza Neto, M. et al., 2016).

Nos tipos de mecanismos em questão, o uso de centrais inerciais de baixo custo para estimativa do estado cinemático da plataforma móvel é importante porque representa uma redução da inércia (efeito de carga) e custo devido à substituição dos transdutores não inerciais em cada um dos membros instrumentados no mecanismo (El-Fatatry, A., 2003).

\subsection{Contribuições da presente Tese}

Como será descrito em detalhes na pesquisa apresentada na Seção 2.1, a modelagem dinâmica destes tipos de mecanismos é necessária para a solução de diversos problemas na área de robótica, como o controle da caminhada de um robô bípede (Khandelwal, S. et al., 2013) ou o controle de robôs trabalhando em cooperação (Bennett, D. J. et al., 1991). Estabelecer uma metodologia para a modelagem de tais mecanismos também trará benefícios ao projeto e análise de sistemas como os de suspensão veicular (Costa Neto, R. T., 2008).

Também é notório o esforço na modelagem cinemática de tais mecanismos, o que pode ser observado em Mohamed, M. G. et al. (2005), por exemplo, onde foi modelada a cinemática de mecanismos paralelos com até nove cadeias usando o método da cadeia vetorial. Porém, já existem muitos trabalhos na obtenção das relações cinemáticas inversa e direta de mecanismos com cadeias fechadas. Além da técnica da cadeia vetorial, são usadas diversas técnicas e 
notações como as de Denavit-Hartenberg (Mavroidis, C. et al., 1995), de ShethUicker (Sheth, P., N. et al., 1971) ou de Kleinfinger-Khalil (Khalil, W. et al., 1986). Derivações destes métodos também vêm sendo desenvolvidas (Rodrigues, F. H. et al., 2013). Assim, não é escopo deste trabalho apresentar uma nova técnica ou notação para o desenvolvimento do modelo cinemático inverso do mecanismo estudado, mas sim obter o modelo dinâmico direto deste mecanismo a partir do modelo cinemático inverso obtido por um método consagrado, como o da cadeia vetorial.

Sobre o método para obtenção do modelo dinâmico, o método de fluxo de potência já foi usado em Costa Neto, R. T. (2008) para um mecanismo paralelo plano. Em Zhao, Q. et al. (2012) e Yildiz, I. et al. (2008) o método dos Grafos de Ligação foi usado para um mecanismo paralelo espacial (plataforma de Stewart). Contudo, estes modelos dinâmicos diretos não são acoplados com as soluções analíticas dos modelos cinemáticos inversos de tais mecanismos, como feito neste trabalho.

A validação de uma estratégia de controle baseada no uso de centrais inerciais de baixo custo, além de trazer vantagens no projeto mecânico destes mecanismos, pode contribuir na redução dos custos com instrumentação, dependendo do número de atuadores. Além disso, este trabalho contribui no estudo do uso de tais mecanismos para a calibração destas centrais inerciais. Muitos trabalhos estão sendo desenvolvidos sobre este tipo de procedimento, como os descritos em Magnussen, O. et al., (2012) e Costa, M. S. M.. et al. (2015).

Inspirado na corrente de aprendizagem ativa de maior sucesso atualmente, que é o Aprendizado Baseado em Problemas (Problem Based Learning - PBL), foram desenvolvidos vários aparatos educacionais no Laboratório de Desenvolvimento de Sistemas Mecatrônicos (LDSM). São equipamentos em escala reduzida e de baixo custo, com o intuito de auxiliar a prática do ensino, aprendizado e pesquisa em engenharia (Martins, G. N., 2016). A bancada experimental desenvolvida nesta Tese também poderá servir como objeto de ensino de diversas disciplinas dos cursos de Graduação em Engenharia Mecânica e Engenharia de Controle e Automação da PUC-Rio, como Introdução à Engenharia, Modelagem de Sistemas Dinâmicos, Controle de Sistemas 
Dinâmicos, entre outras, além de poder ser usada por alunos de Iniciação Científica e Projeto de Fim de Curso destas habilitações.

\subsection{Organização do trabalho}

O Capítulo 2 apresenta a revisão bibliográfica, na qual são apresentados os conceitos fundamentais e descritas pesquisas recentes sobre a modelagem cinemática e dinâmica de mecanismos de cadeia fechada, arquiteturas de controle usando estruturas do tipo HIL (Hardware In the Loop), curvas de desempenho de motores elétricos de corrente contínua e procedimentos para calibração de centrais inerciais.

O Capítulo 3 apresenta o modelo dinâmico do mecanismo paralelo plano com três graus de liberdade, descrevendo a obtenção de sua cinemática inversa pelo método da cadeia vetorial e de sua dinâmica direta pelo método do fluxo de potência. Já o Capítulo 4 apresenta o modelo dinâmico do sistema de atuação, descrevendo o processo de obtenção de sua dinâmica via grafos de ligação, além dos testes experimentais para caracterização do sistema, dos quais são extraídos os parâmetros para a calibração de tal modelo. Também é apresentado o modelo dinâmico acoplado do sistema.

No Capítulo 5 são apresentadas as arquiteturas usadas na bancada experimental para validação das simulações com os modelos dinâmicos do mecanismo e as estratégias de controle propostas, tanto as convencionais, que usam transdutores lineares elétricos, quanto as ditas não convencionais, baseadas no uso de sensores inerciais. Já o Capítulo 6 apresenta os resultados das simulações feitas nos programas SolidWorks Motion Analysis e MatLab/Simulink para validação dos modelos dinâmicos do atuador linear elétrico, do mecanismo paralelo plano e da estratégia de controle proposta.

No Capítulo 7 é apresentada a bancada experimental, que consiste de um mecanismo paralelo com três graus de liberdade com geometria simétrica. Também são apresentados os resultados dos testes experimentais para validação dos modelos desenvolvidos e das estratégias de controle propostas.

Por fim, o Capítulo 8 descreve as conclusões deste trabalho e indica seus desdobramentos, enumerando possíveis trabalhos futuros e aplicações diretas do equipamento desenvolvido nesta Tese. 


\section{2 Revisão bibliográfica}

Neste capítulo são apresentados conceitos fundamentais e descritas pesquisas recentes sobre a modelagem cinemática e dinâmica de mecanismos de cadeia fechada.

Mecanismos são essencialmente (mas não exclusivamente) formados por múltiplos elos que possuem movimento relativo entre si. Cada elo é conectado via uma junta a um ou mais corpos, sendo que a sequência serial de corpos conectados é chamada de cadeia cinemática. Cadeias cinemáticas abertas não possuem restrições em suas extremidades, já as cadeias fechadas possuem restrições em ambas as extremidades. A Figura 2.1 apresenta as diferenças entre os tipos de cadeia cinemática. Neste trabalho, o foco será dado no estudo de mecanismos com cadeias cinemáticas fechadas.

Manipuladores seriais apresentam diversas desvantagens, sendo as mais importantes: a) apenas um motor é fixo, logo, todos os outros, além de uma parcela substancial da inércia do manipulador, se movem; b) devido à estrutura tipo cantiléver de seus elos, possuem alta flexibilidade, o que introduz imprecisões de posicionamento e efeitos dinâmicos secundários não desejados (Gosselin, C. e Angeles, J., et al., 1988).

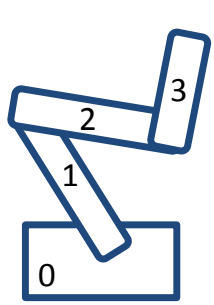

Cadeia serial

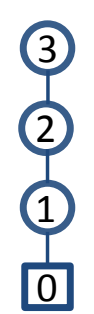

a)

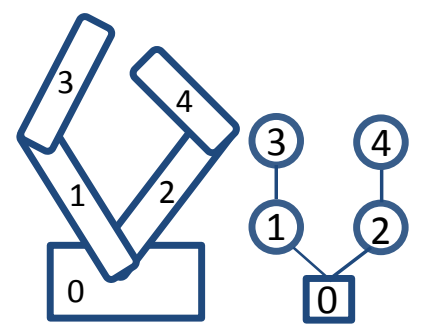

Cadeia bifurcada (árvore)

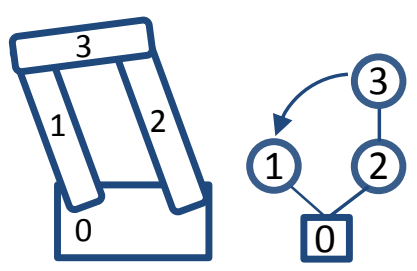

Cadeia paralela

b)

c)

Figura 2.1: Tipos de cadeia cinemática. a) aberta; b) em árvore; c) fechada. 
Apesar de ter um espaço de trabalho menor, maior inércia e uma análise dinâmica mais difícil, sistemas paralelos apresentam grandes vantagens quando comparado aos manipuladores seriais, como melhor estabilidade e precisão, capacidade de manipular cargas relativamente grandes, altas velocidades e acelerações e baixa força de atuação (Wang, Y., 2008). A Tabela 2.1 apresenta a comparação de algumas características destes dois tipos de manipuladores.

Tabela 2.1: Comparação entre manipuladores seriais e paralelos (Wang, Y., 2008).

\begin{tabular}{ccc} 
Característica comparada & \multicolumn{2}{c}{ Tipo de manipulador } \\
\cline { 2 - 3 } & Serial & Paralelo \\
\hline Capacidade de carga & Baixa & Alta \\
Rigidez & Baixa & Alta \\
Espaço de trabalho & Maior & Menor \\
Análise de singularidade & Menos complicada & Mais complicada \\
Análise cinemática/ dinâmica & Mais fácil & Mais difícil \\
Razão potência/carga & Alta & Baixa \\
Inércia & Baixa & Alta \\
Reconfigurabilidade & Fácil & Difícil
\end{tabular}

O projeto de manipuladores robóticos paralelos remonta há várias décadas atrás, em 1962, quando Gough e Witehall desenharam um sistema paralelo para ser usado em uma máquina de provas universais. Segundo Goselin, C. (1985), o conceito de um mecanismo com múltiplas cadeias cinemáticas fechadas ficou popular com seu uso em um simulador de voo (Stewart, D., 1965). Apesar disto, a ideia de considerar a inclusão de cadeias cinemáticas fechadas em manipuladores robóticos começou na década de 1980 (Asada, H. e Youcef-Toumi, K., 1984; Bajpai, A. e Roth, B., 1986), assim como a construção de manipuladores com uma arquitetura totalmente paralela (Yang, D. C. H. e Lee, T. W., 1984; Mohamed, M. G. e Duffy, J., 1985; Fichter, E. F., 1986). A Figura 2.2.a mostra o primeiro simulador de voo com uma estrutura de seis graus de liberdade e a Figura 2.2.b mostra um manipulador paralelo empregado na montagem de peças, também com seis graus de liberdade (Tapia, B. C. e Méndez, S. J. T, 2009). 


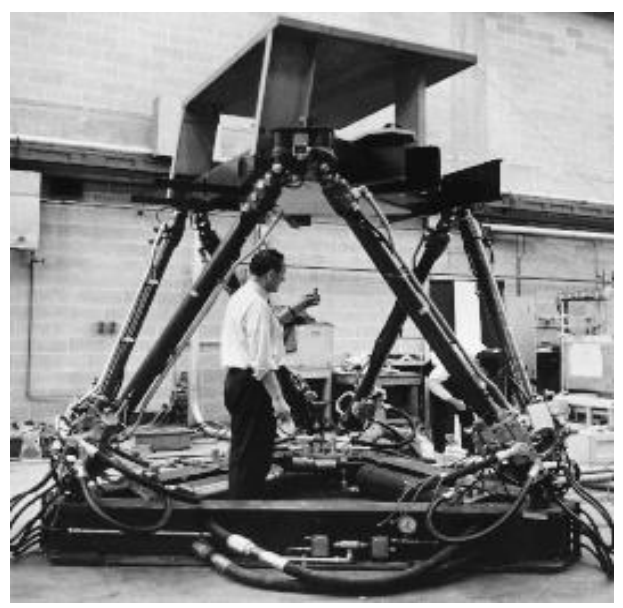

a)

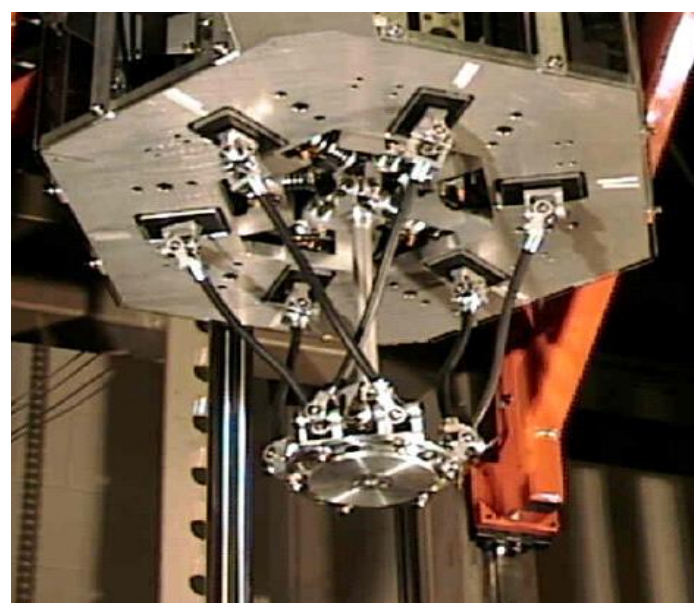

b)

Figura 2.2: Exemplos de mecanismos paralelos baseados na plataforma de Stewart. a) Simulador de voo; b) Robô montador.

Os manipuladores paralelos podem ser classificados como planos, esféricos ou espaciais de acordo com as características geométricas e de movimento. Na Figura 2.3 pode-se distinguir esta classificação.

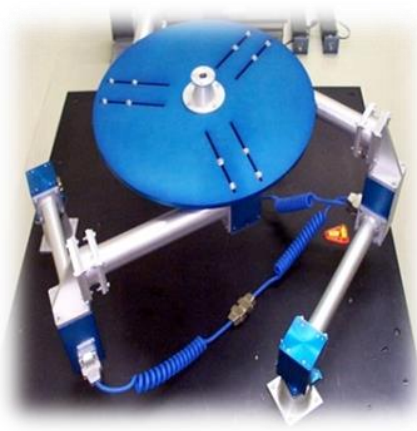

a)

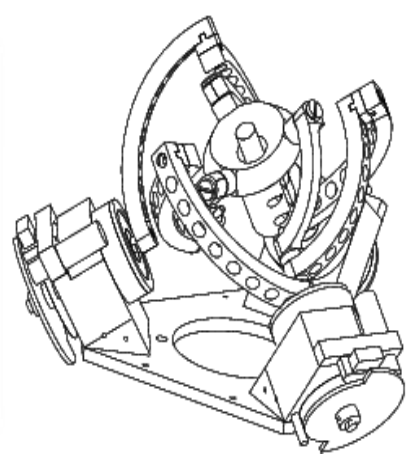

b)

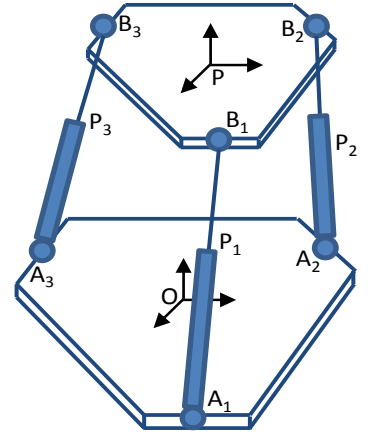

c)

Figura 2.3: Classificação de manipuladores paralelos de acordo com seus movimentos: a) plano; b) esférico; c) espacial.

Também pode se classificar de acordo com suas características estruturais como simétricos e assimétricos. Um manipulador paralelo é chamado de simétrico se segue as seguintes condições: o número de encadeamentos (membros) deve ser igual ao número de graus de liberdade da plataforma móvel; o tipo e número das articulações (juntas) em todos os encadeamentos devem estar fixos em um padrão idêntico; o número e a localização das articulações e dos atuadores devem ser os 
mesmos. Quando as condições mencionadas não se cumprem, o manipulador é chamado assimétrico. Pode-se observar então que nos manipuladores paralelos simétricos o número de encadeamentos, $m$, é igual ao número de graus de liberdade $F$, que é igual ao número total de cadeias cinemáticas, $L+1$ (incluindo a malha externa; Tsai, L. W., 1999). Isto pode se expressar como apresentado na Equação 2.1.

$$
m=F=L+1
$$

\subsection{Mecanismos de cadeia fechada}

Mecanismos são dispositivos mecânicos compostos de elos ligados por juntas, formando cadeias móveis abertas ou fechadas. São usados em quase todas as máquinas para transferência de movimento ou força, como esteiras transportadoras, sistemas de posicionamento de peças, impressoras e sistemas de suspensão de veículos (Mavroidis, C. et al, 1995). No entanto, existem sistemas articulados, que têm grau(s) de liberdade(s) mesmo sendo tidos como estruturas de acordo com o critério da mobilidade (Critério de Grübler). Estes sistemas articulados são chamados de mecanismos sobre-restritos. Sua mobilidade é devido à existência de condições geométricas especiais entre os eixos das juntas do mecanismo que são chamados de condições de sobre-restrição. O problema de determinar de uma forma geral e sistemática todas as condições geométricas especiais que transformam uma estrutura em um mecanismo tem sido um problema sem solução por um longo tempo. Assim, em Mavroidis, C. et al, (1995) é proposto um método geral e sistemático para provar a condição de restrição e obter as equações de entrada-saída de qualquer mecanismo de cadeia fechada com sobre-restrição. Em Jalón, J. G. et al (1994) é apresentada uma breve análise da influência da escolha dos sistemas de coordenadas nestas equações de restrição em um mecanismo de quatro barras.

Mohamed, M. G. et al (2005) trata a cinemática de mecanismos paralelos com diversas cadeias fechadas separando as matrizes Jacobianas das juntas ativas e passivas do mecanismo. Já Kim, J. et al (2001) propõe um processo de solução de duas etapas: operação de cortar e operação de colar, ou seja, remove-se uma restrição e trabalha-se como se a cadeia cinemática fosse aberta, para depois achar 
a solução que atende à cadeia fechada original. Nakamura, Y. et al. (1989) usa um método semelhante, no qual o cálculo da dinâmica inversa de mecanismos fechados consiste nos seguintes passos: 1) Transformar os mecanismos de cadeia fechada em mecanismos com cadeias abertas tipo 'árvore' e assumir que as juntas não atuadas têm atuadores virtuais (Figura 2.1.1); 2) Calcular os torques nas juntas deste novo mecanismo para o movimento equivalente requerido para o mecanismo fechado; 3) Calcular os torques das juntas atuadas do mecanismo original a partir dos torques obtidos para o mecanismo tipo 'árvore' levando agora as restrições em consideração. Este método também é semelhante ao princípio usado por Kleinfinger e Khalil em Khalil, W. et al. (1986). Em Fischer, I. S. et al. (2001) as notações de Denavit-Hartenberg e Sheth-Uicker foram usadas para a modelagem cinemática de diversos tipos de mecanismos paralelos, como o mecanismo de retorno rápido de Whitworth.

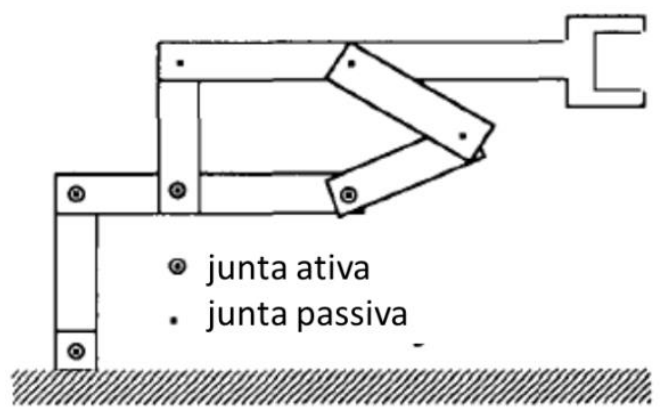

a)

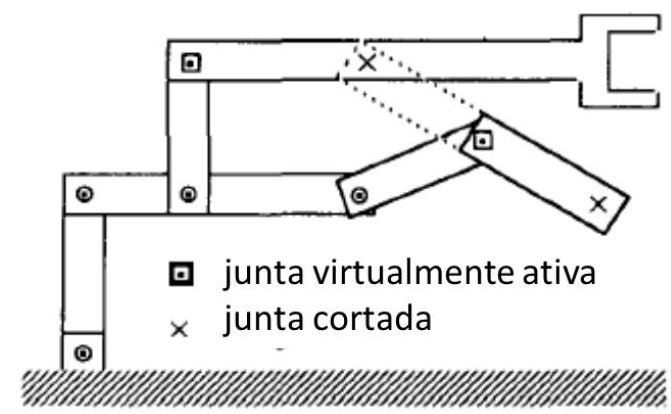

b)

Figura 2.1.1: Transformação do mecanismo com cadeia fechada (a) em um aberto equivalente com estrutura tipo 'árvore' (b).

$\mathrm{O}$ aprimoramento na modelagem de mecanismos paralelos também contribui para solucionar problemas associados a algumas tarefas de robôs seriais. Em algumas tarefas, como quando um braço robótico serial abre uma porta ou acopla seu efetuador final a uma superfície ou objeto, a cadeia cinemática, devido ao surgimento de restrições nos graus de liberdade do efetuador final, fica momentaneamente fechada (Bennett, D. J. et al., 1991). Outro caso no qual um mecanismo serial passa a possuir uma cadeia cinemática fechada é o das pernas de um robô antropomórfico. Quando os dois pés encontram uma restrição (como o chão, por exemplo), a cadeia cinemática se fecha e assim, para estimar o 
movimento do quadril do robô, a fim de equilibrá-lo, são usadas técnicas para a modelagem de mecanismos com estrutura em árvore ou de mecanismos paralelos (Khandelwal, S. et al., 2013).

Alguns mecanismos paralelos, como o octaedro de Bricard, se assemelham, em certas configurações, às estruturas moleculares de certos compostos, como o esqueleto de carbono da molécula de cicloexano (W. H. Chai, et al., 2009). Desta maneira, o desenvolvimento de um procedimento para a modelagem de mecanismos paralelos poderá auxiliar no estudo do comportamento destas moléculas e até no desenvolvimento de novos materiais e substâncias.

A importância dos modelos cinemáticos inversos e diretos no controle de sistemas compostos por mecanismos paralelos, como robôs e simuladores de movimentos, é também descrita em Albuquerque, A. N. (2012). Uma vez obtido o modelo cinemático inverso dos mecanismos de cadeia fechada, a dinâmica pode ser descrita através do método do fluxo de potência.

\subsubsection{Graus de liberdade}

Um mecanismo é constituído de diversos elos conectados por juntas. O número de graus de liberdade de um mecanismo depende do número de elos e juntas e dos tipos de juntas empregadas na construção do mesmo. Neste trabalho, todos os elos serão considerados como corpos rígidos em seus modelos.

Do ponto de vista cinemático, dois ou mais membros conectados de forma que não haja movimento relativo entre eles são considerados como um elo. A conexão entre os elos é chamada de junta. Uma junta provê algumas restrições ao movimento relativo entre os dois membros. Estas restrições dependem do tipo de junta empregada para fazer a união entre os elos. No mecanismo paralelo de três graus de liberdade apresentado são empregados dois tipos de juntas: juntas rotativas e juntas prismáticas (Tsai, L. W., 1999).

Juntas rotativas $(\mathrm{R})$ permitem que os dois elementos acoplados a ela tenham uma rotação, um em relação ao outro, em torno de um eixo definido pela geometria da junta. Estas juntas impõem cinco restrições de movimento aos elos e é então uma junta de um grau de liberdade. Uma junta prismática $(\mathrm{P})$ permite que os dois elementos unidos deslizem um em relação ao outro ao longo de um eixo 
definido pela geometria da junta. Impõe cinco restrições ao movimento, formando uma junta com um grau de liberdade (Tsai, L. W., 1999).

O número de graus de liberdade de um mecanismo consiste no número de parâmetros independentes ou entradas necessárias para especificar a configuração completa do mecanismo. Exceto em alguns casos especiais, o Critério de Grübler define o número de graus de liberdade de um mecanismo (Tsai, L. W., 1999). Este é definido como

$$
F=\Lambda(n-j-1)+\sum_{i=1}^{j} f_{i}-f_{p}
$$

na qual

$F$ é o número de graus de liberdade do mecanismo;

$f_{i}$ é o número de graus de movimento relativo associados à junta i;

$f_{p}$ é o número de graus de liberdade passivos do mecanismo;

$j$ é o número de juntas do mecanismo;

$j_{f}$ é o número de juntas com $f$ graus de liberdade;

$n$ é o número de elos do mecanismo;

$\Lambda$ é o número de graus de liberdade do espaço no qual o mecanismo irá atuar (é igual a 3 em subsistemas esféricos ou planares e igual a 6 em subsistemas espaciais).

A Figura 2.1.2 mostra um mecanismo paralelo no qual uma plataforma móvel é conectada a uma base fixa com três membros extensíveis por juntas rotativas. Cada membro é constituído por dois elos conectados por uma junta prismática. Esta construção é denominada 3-RPR (Tsai, L. W., 1999). Nesta configuração há um grau de liberdade passivo associado a cada membro. Assim, tem-se $\Lambda=3$ (mecanismo planar), $n=8, j_{1}=3$ (juntas prismáticas), $j_{3}=6$ (juntas rotativas) e $f_{p}=0$. O valor dos graus de liberdade do manipulador é dado por $F=$ $3(8-9-1)+(3+6)-0=3$. Estes três graus de liberdade achados estão associados à translação nas duas direções do plano vetorial $(x$ e $z)$ e à rotação ao redor do eixo $y(\theta)$. 


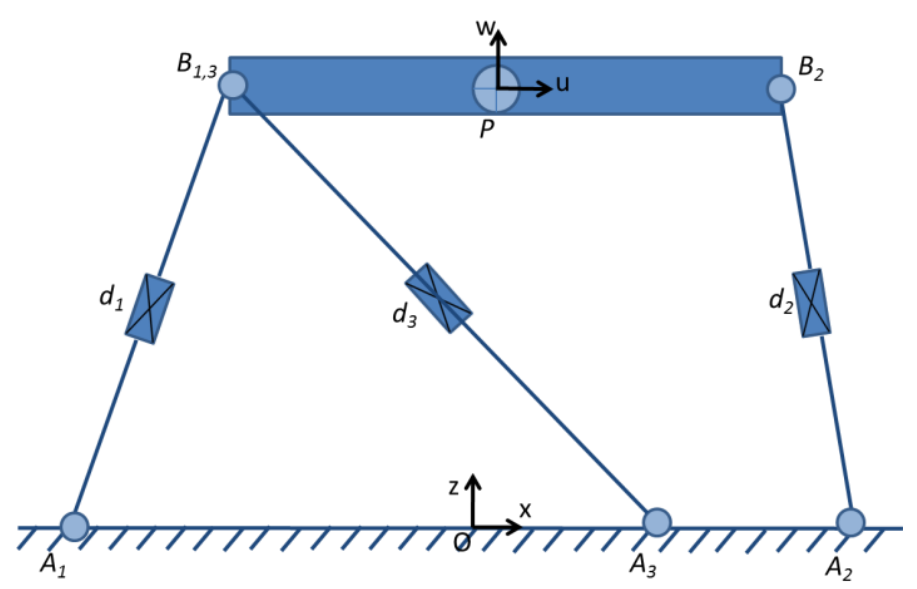

Figura 2.1.2: Mecanismo paralelo plano com três graus de liberdade.

O número de malhas independentes em uma cadeia cinemática é dado pela relação

$$
L=j-n+1
$$

A Equação 2.1.2, conhecida como Equação de Euler indica que este número de malhas independentes excede a diferença entre o número de juntas e o número de elos por um (Tsai, L. W., 1999). Combinando esta com a Equação 2.1.1 e eliminando o termo $f_{p}$ da relação, tem-se

$$
\sum f_{i}=F+\Lambda L
$$

A Equação 2.1.3 é conhecida como o critério da mobilidade de malha $\mathrm{e}$ também é usada para prever o número de malhas independentes em uma cadeia cinemática. No mecanismo em estudo tem-se $\Lambda=3, \mathrm{n}=8, j=9$. Assim, existem $L=9-8+1=2$ malhas independentes. O lado direito da Equação 2.1.3 leva a $F+\Lambda L=3+6 \times 1=9$, enquanto que o lado esquerdo nos dá $\sum f i=1 \times 6+3=9$. A diferença é nula devido à inexistência de graus de liberdade passivos (valor de $f_{p}$ ).

Definindo a conectividade $C_{k}$ de um membro como o número de graus de liberdade associados com todas as juntas do encadeamento, tem-se

$$
\sum_{k=1}^{m} C_{k}=\sum_{i=1}^{j} f_{i}
$$


na qual $j$ é o número de juntas no mecanismo. Substituindo a Equação 2.1.3 na Equação 2.1.4, eliminando $L$ e usando a Equação 2.1.1, obtém-se

$$
\sum_{k=1}^{m} C_{k}=(\Lambda+1) F-\lambda
$$

Além disso, a conectividade de cada membro não deve ser maior que o parâmetro de movimento (graus de liberdade do ambiente de trabalho do manipulador) e menor que o número de graus de liberdade da plataforma móvel (Tsai, L. W., 1999). Assim, tem-se

$$
\Lambda \geq C_{k} \geq F
$$

As Equações 2.1.5 e 2.1.6 são usadas na enumeração e classificação dos manipuladores paralelos. Em manipuladores paralelos planos substitui-se $\Lambda=3$ (Tsai, L. W., 1999) e assim, obtém-se

$$
\begin{aligned}
& \sum_{k=1}^{m} C_{k}=4 F-3 \\
& 3 \geq C_{k} \geq F
\end{aligned}
$$

Resolvendo as Equações 2.1.7 e 2.1.8 simultaneamente para valores inteiros positivos de $C_{k}, k=1,2,3, \ldots$, pode-se classificar este manipulador paralelo de acordo com seus graus de liberdade e conectividade (Tsai, L. W., 1999), como mostra a Tabela 2.1.1.

Tabela 2.1.1: Classificação do mecanismo plano paralelo.

\begin{tabular}{c|c|c|c}
$\begin{array}{c}\text { Graus de } \\
\text { liberdade }(F)\end{array}$ & $\begin{array}{c}\text { Número de } \\
\text { malhas }(L)\end{array}$ & $\begin{array}{c}\text { Somatório dos graus de liberdade } \\
\text { de todas as juntas }\left(\sum f_{i}\right)\end{array}$ & $\begin{array}{c}\text { Conectividade }\left(C_{k}\right) \\
\text { para } k=[1,3]\end{array}$ \\
\hline 3 & 2 & 9 & $3,3,3$
\end{tabular}




\subsubsection{Notação de Denavit-Hartenberg}

Um dos métodos que podem ser usados na análise da geometria e da cinemática dos manipuladores paralelos é o método matricial de DenavitHartenberg (H. Asada, 1986). Em mecanismos com malhas cinemáticas fechadas, podem ser definidos sistemas de coordenadas cartesianas em cada elo, de acordo com a notação de Denavit-Hartenberg, como mostra a Figura 2.1.3. Nestes casos, o sistema de coordenadas da extremidade do manipulador coincide com o sistema de coordenadas da base, em cada malha. Nesta notação, juntas universais podem ser modeladas como duas juntas rotativas que se interceptam e juntas esféricas como três (Tsai, L. W., 1999).

Realizando as mudanças de coordenadas sucessivamente, as matrizes correspondentes a cada transformação são multiplicadas. Quando todas as mudanças são feitas, parte-se do sistema inicial $\left(x_{0}, y_{0}, z_{0}\right)$, dá-se a volta pela malha e então se retorna ao sistema $\left(x_{0}, y_{0}, z_{0}\right)$. Quando isto ocorre, a matriz resultante de transformação é dada por ${ }^{0} A_{1}{ }^{1} A_{2} \ldots{ }^{n-2} A_{n-1}{ }^{n-1} A_{n}$. Porém, esta transformação é uma matriz identidade, uma vez que ela retorna ao sistema original (Tsai, L. W., 1999). Logo, pode-se escrever

$$
{ }^{0} A_{1}{ }^{1} A_{2} \ldots{ }^{n-2} A_{n-1}{ }^{n-1} A_{n}=A_{h}=I
$$

na qual $I$ é uma matriz identidade $4 \times 4$.

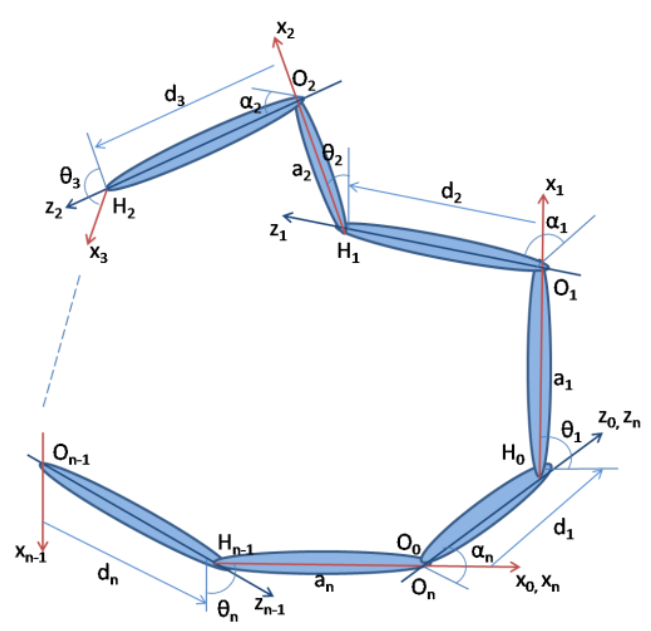

Figura 2.1.3: Mecanismo de cadeia fechada e seus parâmetros de DenavitHartenberg. 
Para um mecanismo com múltiplas malhas, forma-se o equacionamento dado acima para cada malha independente do mecanismo a fim de obter um conjunto de equações de restrições. Apesar de este ser um método bem geral, ele se torna complicado à medida que o número de malhas fechadas na cadeia cinemática aumenta (Tsai, L. W., 1999).

Após estabelecer $A_{h}$, usa-se o método de Raghavan-Roth (Ragavhan, M. et al., 1990) para obter a cinemática inversa do manipulador. Como exemplo, a metodologia será apresentada para uma cadeia fechada semelhante à da Figura 2.1.3, porém, com seis elos e seis juntas rotativas (6R). Desta forma, a equação da malha fechada se torna

$$
{ }^{2} A_{3} \cdot{ }^{3} A_{4}{ }^{4} A_{5}=\left({ }^{1} A_{2}{ }^{-1}\right) \cdot\left({ }^{0} A_{1}{ }^{-1}\right) \cdot A_{h \cdot}\left({ }^{5} A_{6}{ }^{-1}\right)
$$

Desta relação, desmembram-se 14 equações escalares que podem ser escritas na forma

$$
M . X_{1}=N . Y
$$

onde $M$ é uma matriz 14 x 9 e $N$, uma 14 x 8 de valores constantes. Usando oito das quatorze equações, elimina-se $Y$ e passa-se a ter a seguinte relação

$$
\Sigma . X=0
$$

que forma um sistema homogêneo $12 \times 12$, sendo que a condição det $\Sigma=0$ gera o polinômio característico em termos de $\theta_{3}$.

É importante notar que, quando $A_{h}=I$, os parâmetros estruturais $\alpha_{i}, a_{i}, d_{i}$ (ou $\theta_{i}$ ) descrevem a posição relativa de duas juntas ativas da cadeia cinemática. Estes parâmetros têm um papel importante na determinação das propriedades cinemáticas do sistema articulado, como a mobilidade e as configurações de montagem. Quando $A_{h}=I$ existem três possibilidades para o problema da cinemática (Mavroidis, C. et al., 1995):

- O polinômio característico do manipulador não tem raízes reais: Isto significa que a posição e a orientação do efetuador final estão fora do espaço de 
trabalho do manipulador ou, de forma equivalente, que não existe cadeia fechada que satisfaça a estes parâmetros estruturais;

- O polinômio característico do manipulador tem raízes reais: Estas raízes levam à configuração do manipulador para chegar nesta posição e orientação do efetuador final;

- $\Sigma$ possui linhas linearmente dependentes: Isto ocorre quando o movimento do efetuador final do manipulador (considerando apenas uma cadeia fechada) perde algum ou alguns graus de liberdade. Acontece instantaneamente (em uma configuração singular) se ocorre para um $A_{h}$ específico ou permanentemente, caso ocorra para qualquer valor de $A_{h}$. Em ambos os casos existem mais incógnitas que equações e assim, obviamente, é impossível obter um número finito de soluções para o problema da cinemática inversa.

\subsubsection{Cinemática via cadeia vetorial}

Em Albuquerque, A. N. (2012) foi realizado um estudo sobre a modelagem cinemática inversa e direta de manipuladores paralelos usando o método da cadeia vetorial (comumente usado neste tipo de manipuladores). Para exemplificar o procedimento adotado, será descrita a modelagem de um manipulador paralelo espacial com seis graus de liberdade.

A Figura 2.1.4 mostra um manipulador paralelo com configuração 6 S-P-S conhecido como Plataforma Stewart-Gough. Seis membros idênticos conectam a plataforma móvel à base fixa por juntas esféricas nos pontos $B_{i}$ e $A_{i}$, com $i=1,2$, 3, 4, 5 e 6. Usando o sistema de coordenadas mostrado na Figura 2.1.4, adicionase um referencial $\mathrm{A}(x, y, z)$ fixado à base da plataforma e outro, $\mathrm{B}(u, v, w)$ acoplado à plataforma móvel. Outro sistema de referências $\mathrm{C}\left(x_{i}, y_{i}, z_{i}\right)$ é fixado a cada junta universal, tendo assim, sua origem no ponto $A_{i}$ (sendo $i$ referente à $i$ ésima junta universal; $i=1,2, \ldots, 6)$. O eixo $\mathrm{z}_{i}$ deste sistema aponta de $A_{i}$ para $B_{i}$ (direção do atuador $i$ ), o eixo $y_{i}$ é paralelo ao produto interno dos dois vetores unitários definidos ao longo dos eixos $z_{i}$ e $z$ e o eixo $x_{i}$ é então obtido pela regra da mão direita. Por conveniência, a origem do sistema B é localizada no centro de massa da plataforma móvel (na direção de $P$ ). 


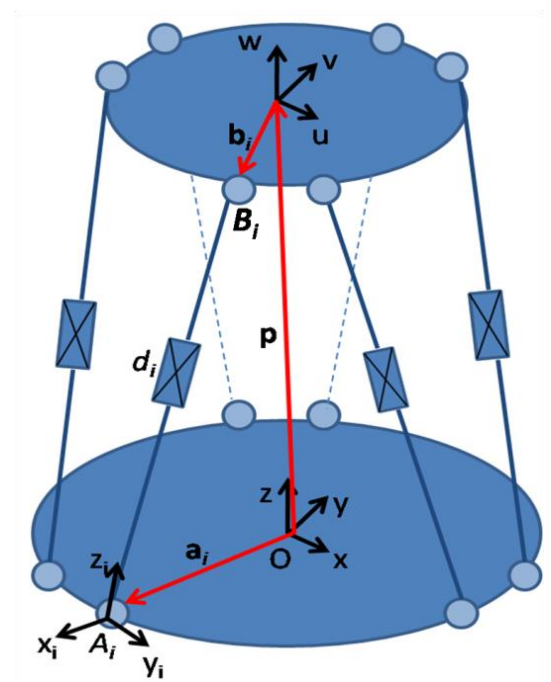

Figura 2.1.4: Diagrama esquemático da Plataforma Stewart.

Sendo $\mathbf{a}_{\mathrm{i}}=\left[a_{i x}, a_{i y}, a_{i z}\right]^{\mathrm{T}} \mathrm{e}^{\mathrm{B}} \mathbf{b}_{\mathrm{i}}=\left[b_{i u}, b_{i v}, b_{i w}\right]^{\mathrm{T}}$ as posições vetoriais dos pontos $A_{i}$ e $B_{i}$ nos sistemas coordenados $A$ e $B$, respectivamente, pode-se escrever uma equação de malha para o $i$-ésimo membro do manipulador, como segue

$$
\overline{A_{\imath} B_{\imath}}=\mathbf{p}+{ }^{A} R_{B}{ }^{B} \mathbf{b}_{i}-\mathbf{a}_{i}
$$

O comprimento do i-ésimo membro é obtido pelo produto escalar do vetor $A_{i} B_{i}$ com ele mesmo, como mostra a Equação 2.1.14.

$$
d_{i}^{2}=\left[\mathbf{p}+{ }^{A} R_{B}{ }^{B} b_{i}-\mathbf{a}_{i}\right]^{T}\left[\mathbf{p}+{ }^{A} R_{B}{ }^{B} b_{i}-\mathbf{a}_{i}\right] \text { para } i=1,2,3,4,5,6 .
$$

Lembrando que ${ }^{\mathrm{B}} \mathbf{b}_{\mathrm{i}}$ e $\mathbf{a}_{\mathrm{i}}$ são vetores constantes definidos pela geometria do manipulador. Neste caso, se o vetor $\mathbf{p}$ e a matriz de transformação ${ }^{A} R_{B}$ do sistema $B$ em relação ao $A$ são dados, a solução do problema da cinemática inversa se resume a

$$
\begin{array}{r}
d_{i}= \pm \sqrt{\mathbf{p}^{T} \mathbf{p}+{ }^{B} \mathbf{b}_{i}^{T}{ }^{B} \mathbf{b}_{i}+\mathbf{a}_{i}^{T} \mathbf{a}_{i}+2 \mathbf{p}^{T}{ }^{A} R_{B}{ }^{B} \mathbf{b}_{i}-2 \mathbf{p}^{T} \mathbf{a}_{i}-2\left[{ }^{A} R_{B}{ }^{B} \mathbf{b}_{i}\right]^{T} \mathbf{a}_{i}} \\
\text { para i }=1,2,3,4,5,6 .
\end{array}
$$


Geralmente, o vetor velocidade de um ponto é formulado a partir de duas direções diferentes de uma cadeia fechada. Cada cadeia fechada consiste em uma base fixa, uma plataforma móvel e todos os elos de um membro. As velocidades das juntas passivas (não atuadas) em cada membro são eliminadas pelo produto escalar da equação da cadeia de vetores de velocidade com o vetor apropriado normal a todos os vetores das velocidades das juntas passivas. Finalmente, as equações resultantes são agregadas na matriz Jacobiana (Tsai, L. W., 1999).

Por consistência, define-se o estado de velocidades da plataforma móvel da Jacobiana convencional como um vetor de seis dimensões com a velocidade linear de um ponto, seguido pela velocidade angular da plataforma móvel

$$
\dot{\mathbf{x}}=\left[\begin{array}{c}
\mathbf{v}_{p} \\
\mathbf{\omega}_{P}
\end{array}\right]
$$

Para este manipulador o vetor de entrada é dado por $\dot{\mathbf{q}}=\left[\dot{\mathbf{d}_{1}}, \dot{\mathbf{d}_{2}}, \ldots \dot{\mathbf{d}_{\mathbf{6}}}\right]^{T} \mathrm{e}$ o vetor de saída pode ser descrito pela velocidade do centroide $P$ e a velocidade angular da plataforma móvel (Equação 2.1.16).

A partir da definição da geometria inversa, será apresentado o procedimento para obtenção da cinemática inversa. Reescrevendo a Equação 2.1.13, tem-se

$$
\overline{O P}+\overline{P B_{l}}=\overline{O A_{\iota}}+\overline{A_{l} B_{l}} \therefore \mathbf{p}+\mathbf{b}_{i}=\mathbf{d}_{i}+\mathbf{a}_{i}
$$

Aplicando o diferencial em relação ao tempo

$$
\mathbf{v}_{p}+\boldsymbol{\omega}_{P} \times \mathbf{b}_{i}=d_{i} \boldsymbol{\omega}_{i} \times \mathbf{s}_{i}+\dot{d}_{\imath} \mathbf{s}_{i}
$$

na qual $\mathbf{b}_{i}$ e $\mathbf{s}_{i}$ representam o vetor $\overline{P B_{l}}$ e um vetor unitário ao longo de $\overline{A_{l} B_{l}}$, respectivamente. $\boldsymbol{\omega}_{i}$ denota a velocidade angular do $i$-ésimo membro em relação ao sistema fixo $A$. Para eliminar $\boldsymbol{\omega}_{i}$, multiplica-se os dois lados da Equação 2.1.18 por $\mathbf{s}_{i}$ (Equação 2.1.19).

$$
\mathbf{s}_{i} \cdot \mathbf{v}_{P}+\mathbf{s}_{i}\left(\boldsymbol{\omega}_{P} \times \mathbf{b}_{i}\right)=d_{i} \mathbf{s}_{i}\left(\boldsymbol{\omega}_{i} \times \mathbf{s}_{i}\right)+\dot{d}_{l} \mathbf{s}_{i} \mathbf{s}_{i}
$$


Sendo que $\mathbf{s}_{i} \mathbf{s}_{i}=1$ (produto escalar de dois vetores unitários paralelos), $\mathbf{s}_{i}\left(\boldsymbol{\omega}_{i} \times \mathbf{s}_{i}\right)=0$ (produto escalar de dois vetores perpendiculares) e $\mathbf{s}_{i}\left(\boldsymbol{\omega}_{P} \times\right.$ $\left.\mathbf{b}_{i}\right)=\left(\mathbf{b}_{i} \times \mathbf{s}_{i}\right) \cdot \boldsymbol{\omega}_{P}(\mathbf{a} \cdot(\mathbf{b} \times \mathbf{c})=\mathbf{b} \cdot(\mathbf{c} \times \mathbf{a})=\mathbf{c} \cdot(\mathbf{a} \times \mathbf{b}))$. Assim,

$$
\begin{aligned}
& \mathbf{s}_{i} \cdot \mathbf{v}_{P}+\left(\mathbf{b}_{i} \times \mathbf{s}_{i}\right) \cdot \boldsymbol{\omega}_{P}=\dot{d}_{\iota} \\
& \mathbf{s}_{i} \cdot\left[\begin{array}{c}
\dot{x}_{d} \\
\dot{y}_{d} \\
\dot{z}_{d}
\end{array}\right]+\left(\mathbf{b}_{i} \times \mathbf{s}_{i}\right) \cdot \boldsymbol{\omega}_{P}=\dot{d}_{\iota}
\end{aligned}
$$

Os termos da esquerda estão associados às velocidades da plataforma e formam a matriz $J_{x}$ (Equação 2.1.22). Já à direita, estão os termos associados à velocidade das juntas, que formam $J_{q}$ (Equação 2.1.23).

$$
\begin{aligned}
& J_{x}=\left[\begin{array}{cc}
\mathbf{s}_{1}^{T} & \left(\mathbf{b}_{1} \times \mathbf{s}_{1}\right)^{T} \\
\mathbf{s}_{2}^{T} & \left(\mathbf{b}_{2} \times \mathbf{s}_{2}\right)^{T} \\
\vdots & \vdots \\
\mathbf{s}_{6}^{T} & \left(\mathbf{b}_{6} \times \mathbf{s}_{6}\right)^{T}
\end{array}\right] \\
& J_{q}^{-1}=I_{6 x 6}
\end{aligned}
$$

Assim, obtém-se a relação entre as variáveis que descrevem a velocidade linear e a angular da plataforma móvel e as velocidades dos elos da plataforma plana $\left(\dot{\mathbf{q}}=J^{-1} \dot{\mathbf{x}}\right)$. Com esta relação, monta-se a matriz Jacobiana inversa (por se tratar da cinemática inversa) deste manipulador.

Já o problema da cinemática direta consiste em encontrar a posição (vetor p) e orientação final (matriz de rotação ${ }^{A} R_{B}$ ) de um mecanismo a partir dos ângulos (ou deslocamentos lineares, no caso de juntas prismáticas) de entrada. A formulação deste problema leva a um sistema de equações algébricas não lineares acoplado (Boudreau, R. et al., 1994). Usualmente, não há uma solução fechada para este problema no caso deste mecanismo paralelo. Métodos por iteração numérica (como o de Newton-Raphson, por exemplo) e soluções polinomiais vêm sendo desenvolvidas (Tsai, L. W., 1999). 


\subsection{Dinâmica via fluxo de potência}

Segundo Speranza Neto, M. (1999), quando se consegue compatibilizar completamente as variáveis de potência dos subsistemas o modelo resultante é totalmente equivalente àquele que seria obtido analiticamente, o que permite a sua simulação a partir da simples conexão dos módulos. Desta forma, uma vez obtidos os modelos individuais de cada componente, para que estes possam ser conectados, deve-se inicialmente verificar se as variáveis de entrada e de saída destes modelos são compatíveis. A incompatibilidade da potência, ainda que ocorra, é simples de resolver, bastando para isso inverter o sinal de entrada (ou de saída) de uma das variáveis de potência de um dos módulos. Se as entradas dos módulos são ambas esforço ou ambas fluxo, diz-se que há conflito de causalidade, impedindo assim o acoplamento imediato dos módulos, ainda que a potência seja compatível. Isso implica na dependência matemática entre as variáveis que caracterizam a dinâmica do sistema acoplado, ou seja, há menos graus de liberdade físicos no modelo completo do que nos individuais. O resultado disso é uma malha algébrica, ou seja, equações algébricas dependentes, que deve ser resolvida.

A quebra da malha algébrica pode ser feita através da manipulação analítica das equações associadas, o que altera os modelos individuais desenvolvidos. Assim estará se modificando as variáveis de entrada e de saída e compatibilizando a causalidade. Esta é uma solução que pode ser inviável em alguns problemas, principalmente aqueles que envolvam equações não lineares ou sistemas de equações retangulares, cuja inversão é difícil ou até mesmo impossível por metodologias tradicionais (Speranza Neto, M., 1999).

Outra solução requer o conhecimento dos componentes que serão conectados, pois se deve alterar a natureza física do acoplamento, se for possível, através de elementos de inversão de causalidade. Estes elementos podem ser subsistemas especialmente desenvolvidos ou até mesmo simples equações adicionais que são introduzidas de modo a compatibilizar as variáveis no acoplamento. Tomando como exemplo os sistemas mecânicos, a introdução de um elemento mola adicional (de grande rigidez) entre duas inércias permite inverter a causalidade associada a uma delas, o que compatibiliza a conexão, evitando a manipulação que levaria ao elemento inércia equivalente, sem alteração 
significativa no desempenho do sistema acoplado. O mesmo procedimento pode ser generalizado para qualquer sistema físico e suas conexões (Speranza Neto, M., 1999).

Em Costa Neto, R. T. (2008) foram obtidos modelos matemáticos de subsistemas via fluxo de potência de forma que fosse possível implementá-los como módulos independentes e intercambiáveis em um diagrama de blocos, acoplando-os diretamente, na forma computacional. Os módulos independentes são testados individualmente, sendo possível separar cinemática e dinâmica. O método empregado para abrir os laços algébricos próprios dos mecanismos em cadeia fechada elimina as equações algébricas que caracterizam o laço. Uma vez criado o módulo, nenhuma adaptação precisa ser feita na estrutura global do sistema.

Zhao, Q. et al. (2012) usou técnica dos Grafos de Ligação para modelar a cinemática e a dinâmica de uma plataforma de Stewart. Após a modelagem cinemática, foram desenvolvidas as equações dinâmicas da plataforma superior usando o método de Newton-Euler e então, seu modelo em grafos de ligação foi estabelecido. Uma abordagem equivalente é empregada para tratar dos efeitos inerciais de cada atuador. A cada conjunto atuador-válvula do simulador é acoplada uma malha fechada de controle de posição independente. O modelo em grafos de ligação do simulador completo é feito usando o programa 20-Sim e então, são realizadas diversas simulações para verificação do modelo. A comparação com testes experimentais comprovou a viabilidade e a eficiência do modelo, cujo método pode ser usado na modelagem de outros tipos de mecanismos paralelos.

Já Yildiz, I. et al. (2008) representou em seu trabalho a dinâmica de uma plataforma de Stewart pelo método dos Grafos de Ligação usando uma nova forma de visualização espacial destas ligações. Este modelo dinâmico inclui todos os efeitos dinâmicos e gravitacionais, como a dinâmica do motor linear (usado como atuador) e o atrito viscoso das juntas. Além disto, neste trabalho é unificada a modelagem do sistema de atuação e da estrutura. Como este sistema tem muitas não linearidades, originadas pela sua geometria e pelas forças giroscópicas, o problema da causalidade derivativa resultante devido aos elementos de inércia rigidamente acoplados é abordado e as equações no espaço de estados são apresentadas. Para descrever a cinemática inversa da plataforma de Stewart, foi 
usada a metodologia da cadeia vetorial, a mesma usada em Tsai, L. W. (1999). Mais recentemente, Zhang, L., et al. (2016) também usou a técnica dos Grafos de Ligação para a obtenção do modelo dinâmico de um manipulador paralelo tipo 3UPS/S. O modelo acopla o mecanismo ao sistema de atuação e foi validado via simulações e testes usando um protótipo com atuação eletro-hidráulica.

\subsection{Estruturas HIL - Hardware In the Loop}

O teste de desenvolvimento de sistemas é feito principalmente usando duas abordagens. Primeiro, a funcionalidade e desempenho do sistema é observada e ajustada usando ferramentas de softwares de simulação. O nível de confiabilidade obtido é específico para cada aplicação e depende da disponibilidade e precisão dos modelos do sistema, segurança dos testes de bancada e duração dos testes executados. Segundo, o projeto é implantado em uma plataforma para verificação da funcionalidade e medição de desempenho sob condições mais realísticas. Esta abordagem é conhecida como teste em hardware (Pritsker, D., 2013).

Esta crescente necessidade de testar e prototipar projetos sob situações cada vez mais realistas resultou no desenvolvimento de novos tipos de simulação. Nesse cenário, um tipo de simulação que tem ganho grande notoriedade e aplicabilidade é a simulação Hardware In the Loop (HIL). Essa técnica permite que componentes reais e componentes simulados de um sistema sejam testados simultaneamente, de forma que o sistema possa ser submetido a condições mais realísticas ou extremas sem comprometer o sistema real ou um protótipo construído especificamente para testes (Farias, A. B. C., 2015). Isto também se deve a um crescente aumento da demanda por segurança em máquinas e equipamentos, conforme normas EU Machinery Directive (2006) e EN ISO 13849-1:2006 (Safety of machinery - Safety-related parts of control systems Part I: General principles for design). Portanto, cada vez mais sistemas eletrônicos de segurança e controle são implementados a fim de evitar perigos potenciais, tanto devido ao uso convencional quanto ao mau uso previsível (Pedersen, M. M., et al., 2012).

A ideia básica na simulação HIL é a de incluir parte do hardware real na malha de simulação durante o desenvolvimento do sistema ao invés de testar o algoritmo de controle em um modelo puramente matemático do sistema. Por 
exemplo, atuadores são notoriamente difíceis de modelar e, se disponível, este pode ser incluído na malha de simulação para aprimorar a validade desta. Além disso, o teste e a avaliação do sistema são realizados em tempo real (real-time). Apesar de ser usada há mais de cinquenta anos, não houve tentativa de formalizar a abordagem do assunto. A maioria dos projetos em HIL é feita de forma ad hoc, específica à aplicação (Bacic, M., 2005).

O processo que envolve a criação de novos algoritmos e técnicas de controle de sistemas envolve um alto custo de tempo e recursos econômicos. Por exemplo, para o teste em tempo real de um novo algoritmo de controle da suspensão de um carro, seria necessária a criação de um modelo real, às vezes em escala menor, do sistema de interesse do carro. Os resultados desses testes poderiam ser obtidos primordialmente utilizando-se um Simulador em Tempo Real (STR) do sistema, isto é, um dispositivo com entradas e saídas de sinais capaz de emular a reação do carro aos sinais de controle recebidos. No ajuste de um controlador para uma determinada aplicação, os testes desses algoritmos nas plantas reais podem ter custos demasiadamente proibitivos. Além disso, testar dispositivos de controle exige uma série de testes com diversas configurações que podem ser difíceis atingir com a planta em um laboratório comum (Souza, I. D. T. et al., 2015).

Para evitar alguns desses problemas, foi criado um tipo de teste que não utiliza a planta real, mas um modelo computacional da mesma, a simulação (ou teste) HIL (Harakawa, M. et al., 2005). Utilizando as mesmas interfaces de hardware que o controlador usaria para interagir com a planta, este teste trabalha como se estivesse interagindo com a planta real, sem alterações muito bruscas nos seus parâmetros internos. A simulação HIL se caracteriza pela operação de componentes reais em conjunto com elementos simulados. Por exemplo, o desenvolvedor pode desejar fazer o ajuste do dispositivo simulando somente a planta e os atuadores, mas mantendo os sensores reais interagindo com o modelo matemático.

A pesquisa envolvendo simulação em tempo real é um campo amplo que envolve não só o estudo de novas propostas de hardware e software, mas também novas técnicas de modelagem para sistemas comerciais existentes (Souza, I. D. T. et al., 2015). Plataformas anteriores de simulação HIL consideravam tipicamente apenas um único componente ou um sistema menor isolado para o teste do 
software de controle com saída visual limitada. Entretanto, avanços no poder computacional impulsionaram uma rápida evolução nas plataformas HIL, que agora consideram sistemas inteiros, tais como máquinas de construção e estruturas offshore, além de oferecerem saídas com ricas animações 3D, como mostra a arquitetura da plataforma HIL da Figura 2.3.1 (Pedersen, M. M., et al., 2012).

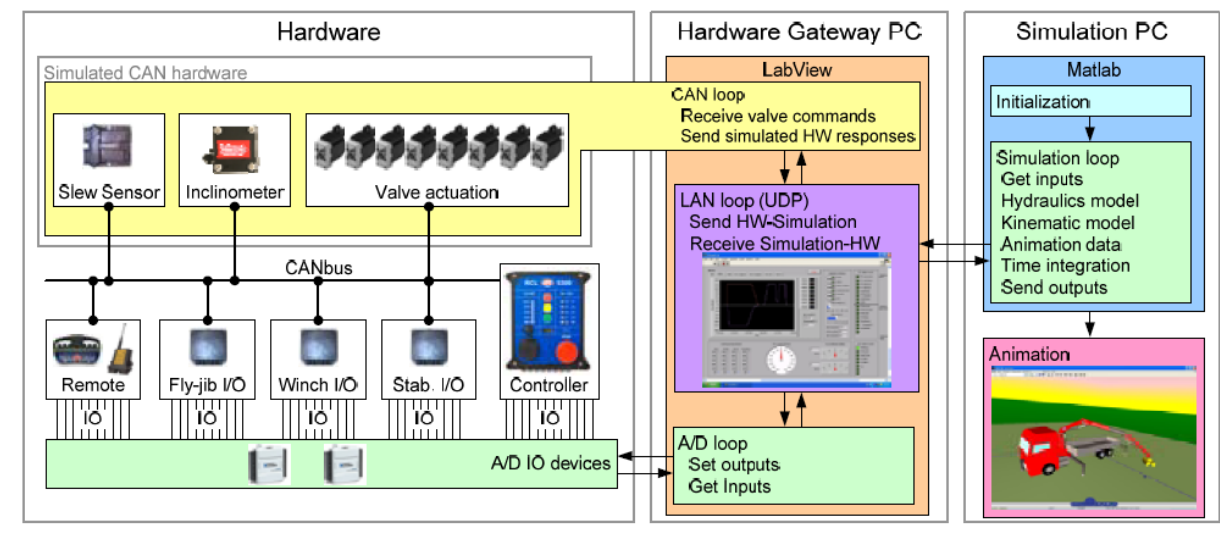

Figura 2.3.1: Arquitetura da plataforma HIL para simulação de um guindaste (Pedersen, M. M., et al., 2012).

Um dos primeiros usos da simulação HIL foi para simulações de voo (Isermann, R., et al. 1999). Na década de 70, a NASA usou a simulação HIL no projeto do Rockwell RPRV-870 HiMAT (Highly Maneuverable Aircraft Technology), desenvolvendo uma série de simulações HIL de alta fidelidade (Evans, M. B. e Schilling, L. J., 1984). Nos últimos trinta anos, a simulação HIL ganhou popularidade na indústria automotiva, sendo usada no projeto de sistemas ABS (Anti-lock Braking System), sistemas de controle de tração (TCS - Traction Control System), sistemas de suspensão entre outros.

A Ford recentemente implementou um sistema de testes usando HIL para o desenvolvimento de uma unidade de controle eletrônica (ECU - Electronic Control Unit) de um veículo elétrico híbrido (HEV - Hybrid Electric Vehicle). As Figuras 2.3.2.a e 2.3.2.b apresentam o processo de validação desta unidade de controle eletrônica e a o diagrama com a arquitetura do sistema HIL usado, respectivamente. (Ramaswamy, D. et al., 2004). A Figura 2.3.3 apresenta um esquema de conceito HIL usado em sistemas hidráulicos offshore (Pawluls, W., et al., 2015) e a Figura 2.3.4 apresenta o ambiente de simulação HIL para um veículo aéreo não tripulado (VANT) (Gans, N. R., et al., 2009). Já a Figura 2.3.5 
apresenta uma arquitetura HIL empregada no teste de um controlador de aleta de míssil (Pritsker, D., 2013). Outras aplicações se encontram principalmente no campo da geração de energia e em robótica (Bacic, M., 2005).

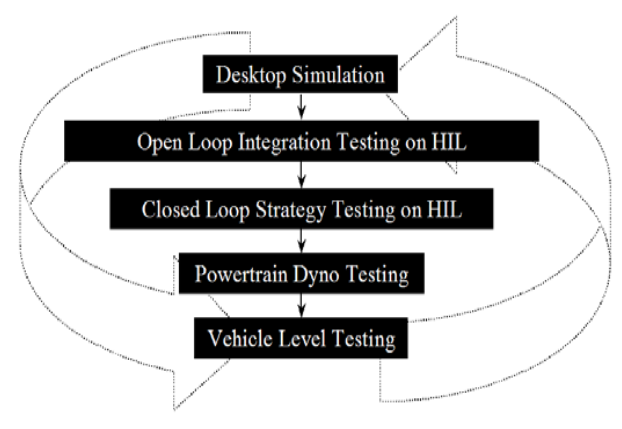

a)

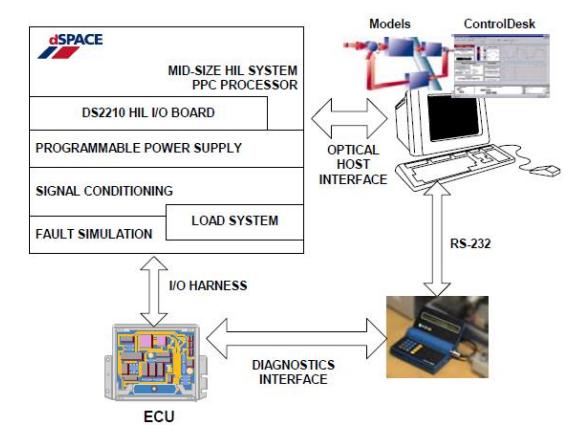

b)

Figura 2.3.2: (a) Processo de validação da ECU Ford; (b) Diagrama com a arquitetura do sistema HIL usado (Ramaswamy, D. et al., 2004).

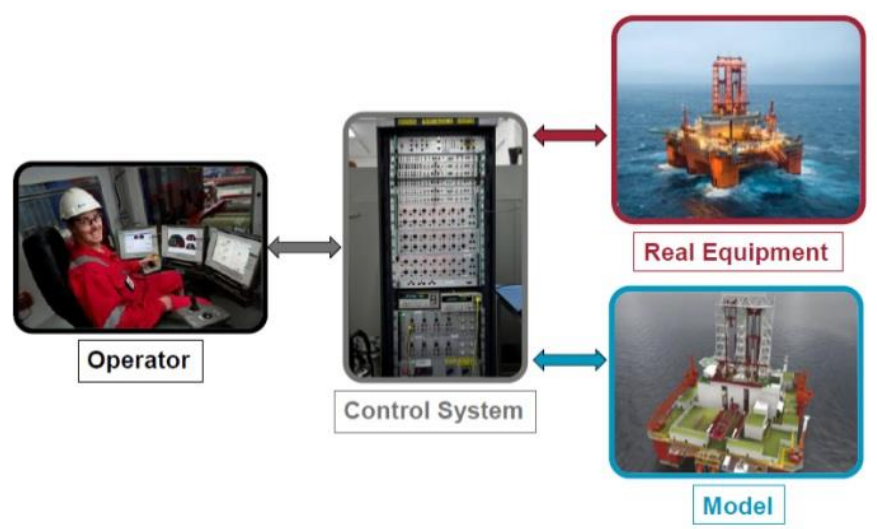

Figura 2.3.3: Conceito HIL usado em sistemas hidráulicos offshore (Pawluls, W., et al., 2015).

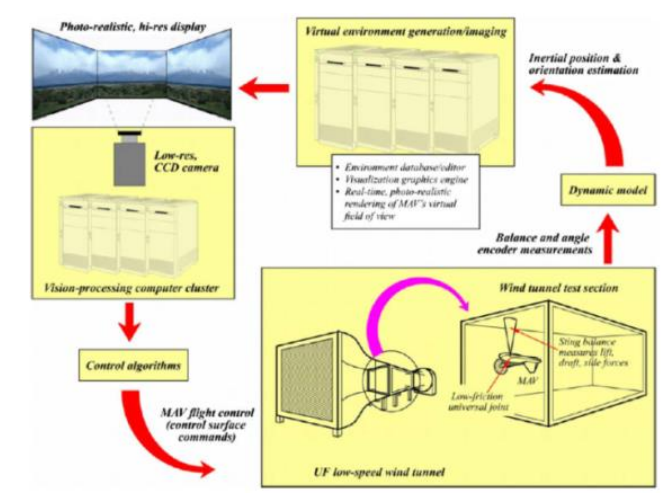

Figura 2.3.4: Ambiente de simulação HIL para VANT (Gans, N. R., et al., 2009). 


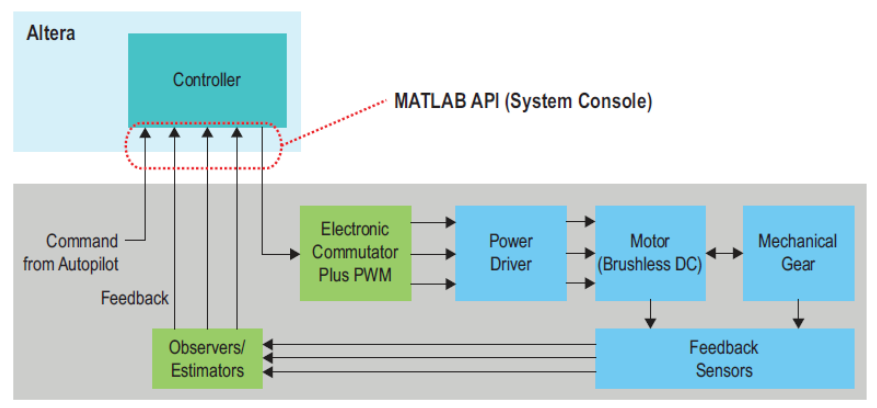

Figura 2.3.5: Arquitetura HIL empregada no teste de um controlador de aleta de míssil (Pritsker, D., 2013).

O modelo de um sistema consiste basicamente de dois componentes: um modelo da instalação (planta) física e um acoplamento com o ambiente. Estes dois componentes são normalmente conectados usando uma representação como a dos Grafos de Ligação. O modelo está sujeito a incertezas provenientes dos seus dois componentes: a instalação física é complexa e não pode ser modelada precisamente e o acoplamento que também gera incertezas. Com o sistema real interagindo com o ambiente local, não há incerteza associada à instalação física (Bacic, M., 2005). Além disso, as simulações em HIL fornecem ao engenheiro de testes a habilidade de simular uma variedade de cenários que seriam muito difíceis, demorados ou caros de se fazer em um protótipo. Esta metodologia reduz significantemente o tempo médio de desenvolvimento e melhora muito a qualidade e a confiabilidade do produto final (Ramaswamy, D. et al., 2004). Quando um simulador HIL é equipado com visualização 3D e é usado para treinamento, estas estruturas HIL, como as da Figura 2.3.6, são chamadas de simuladores para treinamento (Kleijn, C., 2016).

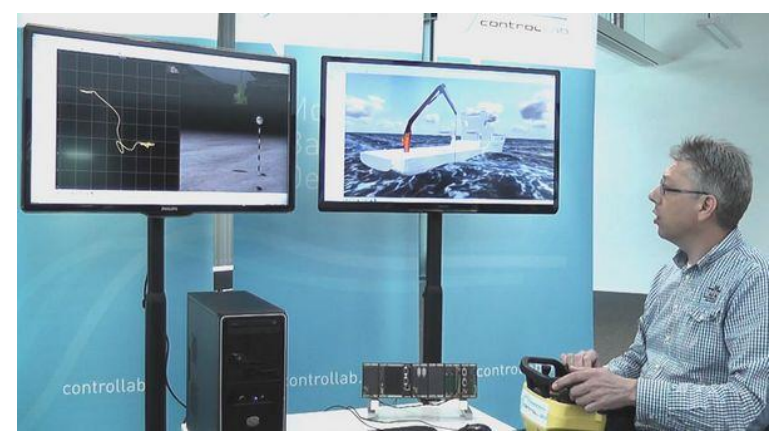

Figura 2.3.6: Simulador de treinamento para um guindaste (Kleijn, C., 2016). 


\subsection{Curvas de desempenho de motores DC}

O propósito de motores elétricos é o de converter potência elétrica em potência mecânica na forma de movimento rotacional. Este sistema eletromecânico é caracterizado por alguns parâmetros específicos, que conhecidos, ajudam a prever o comportamento do motor no sistema. Estes parâmetros incluem velocidades, torques, correntes e tensões elétricas sem carga e de stall (sistema travado ou na iminência de sair da inércia), assim como a eficiência, e podem ser obtidos usando um dinamômetro. Quando se trata de motores de pequena escala, muitos são fabricados para hobbistas e, portanto, os fornecedores não incluem todos estes dados em seus catálogos técnicos (Harrington, A. M., e Kroninger, C., 2013). Assim, torna-se necessário desenvolver equipamentos para a avaliação de desempenho de motores elétricos para uso em veículos autônomos ou outros projetos de robótica.

A potência de saída nestes motores é obtida pelo produto do torque pela velocidade angular. Em motores com escovas (brushed), uma vez que há apenas uma fase, a potência de entrada é simplesmente o produto da tensão de alimentação e da corrente elétrica que passa pelo motor. Já em motores sem escovas (brushless) tem que ser calculada a potência aparente, que é a relação da média da potência em cada fase multiplicada por um fator que, para três fases tem o valor de $\sqrt{ } 3$. A eficiência é a razão entre a potência de entrada e de saída (Harrington, A. M., e Kroninger, C., 2013).

Motores com escovas usam um comutador elétrico interno que inverte a polaridade da bobina ativa quando passam por ímãs de polaridade fixa. Vantagens deste tipo de motores é que possuem um baixo custo de fabricação. Além disso, podem facilmente ser fabricados em tamanhos reduzidos $(<1 \mathrm{~g})$. São compostos principalmente por três partes: estator, rotor e comutador/escovas. Esta construção é apresentada na Figura 2.4.1 (Harrington, A. M., e Kroninger, C., 2013). Em grandes motores com escovas, o estator usa bobinas, porém, em motores pequenos são usados ímãs permanentes por conta da dificuldade de obter fortes campos magnéticos com bobinas desta escala. Além disso, com a disponibilidade de ímãs permanentes de alto campo, como os ímãs de neodímio, estes se tornaram a opção 
preferida dos fabricantes de pequenos motores (Krishnan, R., 2010). Já o rotor contém uma armadura feita com uma bobina de cobre.

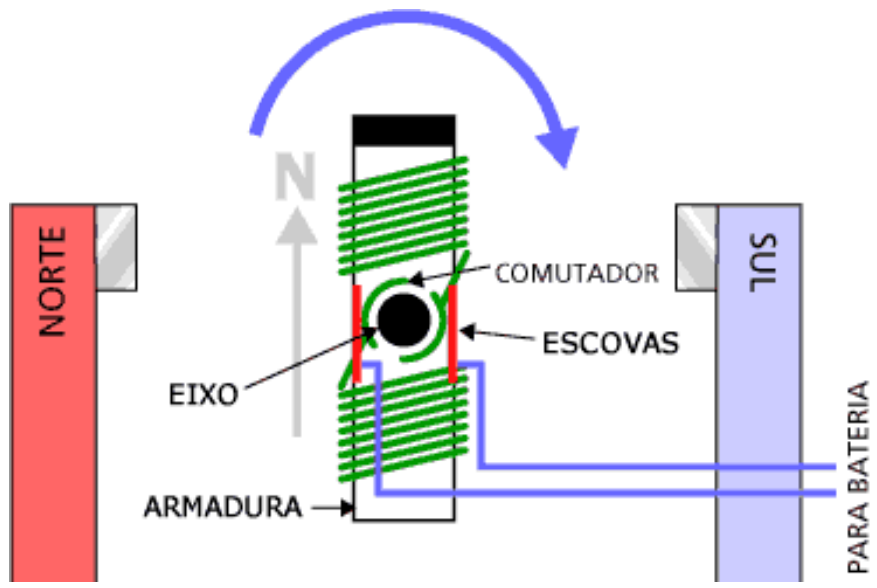

Figura 2.4.1: Diagrama de um motor DC com escovas (Harrington, A. M., e Kroninger, C., 2013).

Entretanto, a presença das escovas gera algumas desvantagens. Estas apresentam desgaste com o tempo de uso e eventualmente as escovas ou até o motor inteiro devem ser trocados (Bar-Cohen, Y., 2000). E além do calor gerado pela corrente que passa pelas bobinas, o atrito das escovas aumenta o calor produzido. Fora os efeitos negativos deste calor adicional, este arraste das escovas gera uma grande quantidade de ruído elétrico e interferência eletromagnética (electromagnetic interference - EMI). Isto pode causar alguns problemas em aplicações em robótica que requerem comunicação via rádio ou que possuem sensores eletronicamente sensíveis. Fora a questão do calor gerado, a força de atrito do movimento das escovas é uma carga para o motor, o que aumenta a ineficiência do sistema com o aumento da velocidade angular. Apesar de todas estas desvantagens, motores com escovas ainda são populares em projetos de veículos autônomos aéreos e terrestres (Harrington, A. M., e Kroninger, C., 2013).

Motores com escovas em geral possuem uma curva de torque $\mathrm{x}$ velocidade angular linear com inclinação constante em todas as tensões de entrada. Inserir uma tensão constante de entrada é o primeiro método para acelerar este tipo de motor, mas isto também pode ser feito com o uso de controladores de velocidade gerando ondas quadradas moduladas por largura de pulso (pulse-width modulation - PWM). Exemplos destas curvas são apresentados na Figura 2.4.2. Já a Figura 
2.4.3 mostra que a tensão de alimentação aumenta a potência de saída e que, para determinada tensão, a potência e a eficiência varia com o estado caracterizado pelo torque e velocidade angular (Harrington, A. M., e Kroninger, C., 2013).

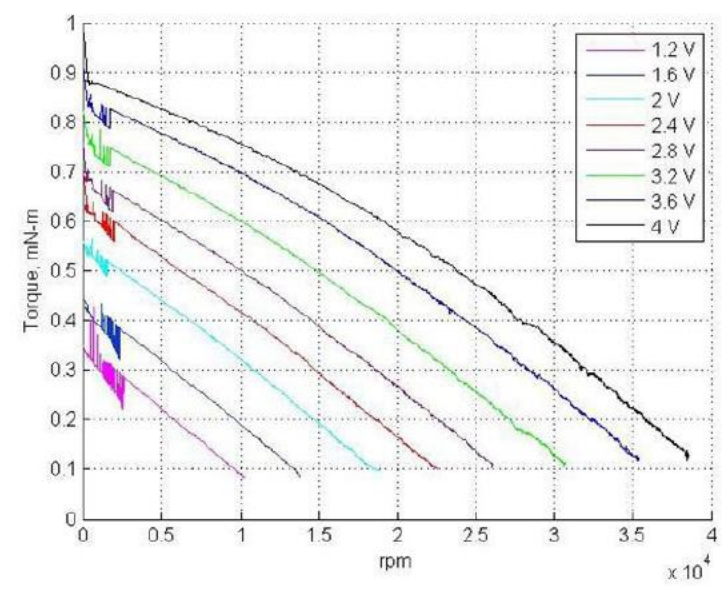

Figura 2.4.2: Curvas de torque $\mathrm{x}$ velocidade angular para um motor com escovas (Harrington, A. M., e Kroninger, C., 2013).

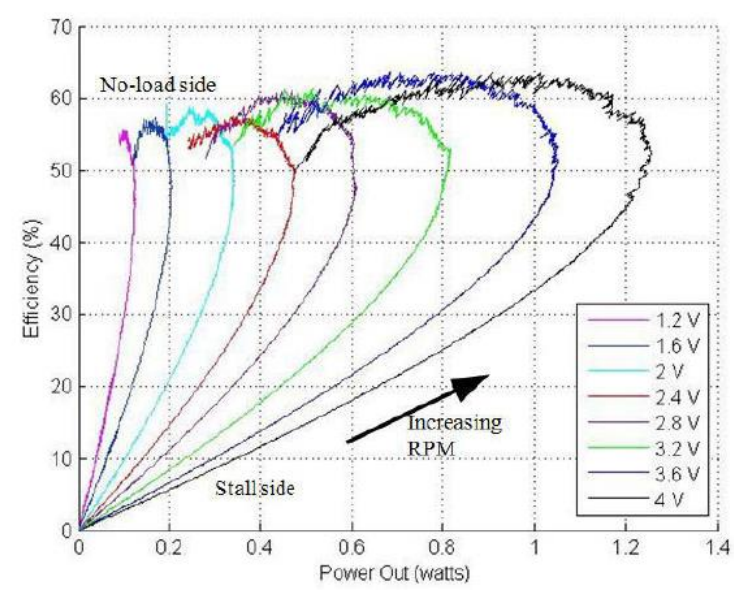

Figura 2.4.3: Curvas de eficiência x potência mecânica para um motor com escovas (Harrington, A. M., e Kroninger, C., 2013).

É interessante notar que para motores com escovas, os valores de eficiência próximos do pico cobrem apenas uma pequena faixa dos valores de velocidade angular e caem significativamente em rotações menores, como mostra a Figura 2.4.4. Estes valores baixos de velocidade angular correspondem a valores altos de torque. Para aplicações do tipo direct-drive (torque do motor aplicado diretamente ao eixo de saída) isto sugere que motores com escovas são boas 
escolhas para usos em situações de alta velocidade e baixo torque. Também sugere que a eficiência do sistema é muito afetada em regimes de operação fora da faixa de projeto. Isto pode ser amenizado pela escolha do sistema de transmissão que acompanha o motor (Harrington, A. M., e Kroninger, C., 2013).

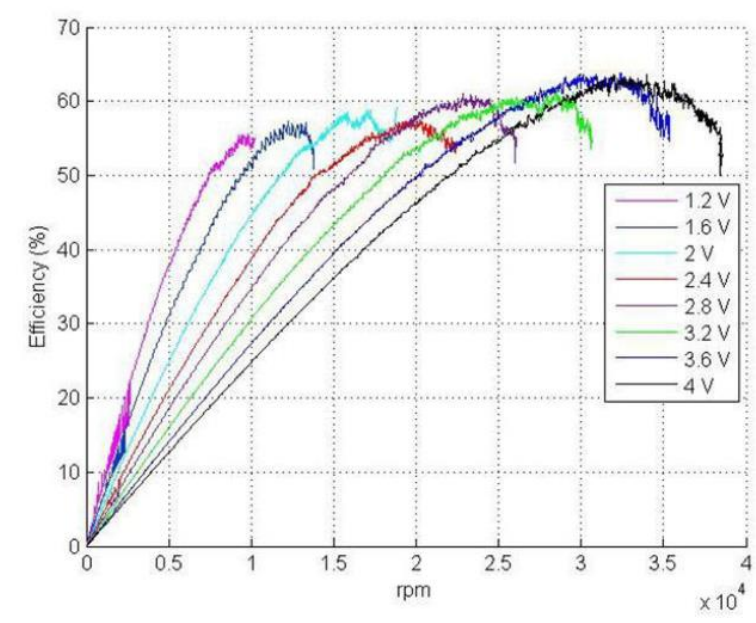

Figura 2.4.4: Curvas de eficiência x velocidade angular para um motor com escovas (Harrington, A. M., e Kroninger, C., 2013).

\subsection{Calibração de IMU}

Centrais inerciais, ou IMUs (Inertia Measurement Units) são conjuntos de sensores usados para medir acelerações lineares e velocidades angulares em três dimensões e são tipicamente encontrados em VANTs (Veículos Aéreos Não Tripulados ou UAV, e Unmanned Aerial Vehicle). Mesmo que IMUs com alta precisão sejam disponíveis pelos fornecedores, ainda é desejável executar uma calibração e verificação de desempenho independentes comparando com um dispositivo de medição mais preciso. O problema da filtragem dos sinais destas centrais inerciais para uso na estimativa de velocidades e deslocamentos já foi estudado por diversos autores, como por exemplo, em Ribeiro, J. G. T., et al. (2001), no qual foi proposto o uso do método FFT-DDI (Fast Fourier Transform Digital Double Integration) de filtragem, porém, ainda é um campo que demanda mais pesquisas.

Também é desejável calibrar uma IMU após a instalação desta no UAV, uma vez que a localização e a orientação do sensor relativas ao corpo do veículo são fontes adicionais de erro. Para minimizar estes erros na estimativa de atitude, 
tenta-se acoplar IMU no centro de gravidade destes veículos, porém, isto comumente não é possível (Magnussen, O. et al., 2012).

Muitos autores já propuseram diferentes métodos para calibração de IMUs (Sahawneh, L. e Jarrah, M. A., 2008), porém, comumente nestes métodos está o uso da ideia de que a norma da saída do acelerômetro e do giroscópio é igual à magnitude da força aplicada e da velocidade rotacional. Porém, nem todos os parâmetros dos sensores da IMU são observáveis, o que implica que estes parâmetros descalibrados devem ser levados em conta na integração da IMU usando algoritmos avançados de filtragem, por exemplo (Magnussen, O. et al., 2012).

Métodos comuns para calibração de IMUs usam equipamentos simples, como o plano inclinado da Figura 2.5.1.a (teste de posição estática), que verifica a sensibilidade da IMU ao valor da gravidade local, ou o aparato da Figura 2.5.1.b (rate test), que verifica os valores do giroscópico e da aceleração centrífuga sob velocidade rotacional constante para estimar bias, fator de escala e parâmetros não ortogonais no modelo do giroscópio (Wang, L. e Wang, F., 2011).

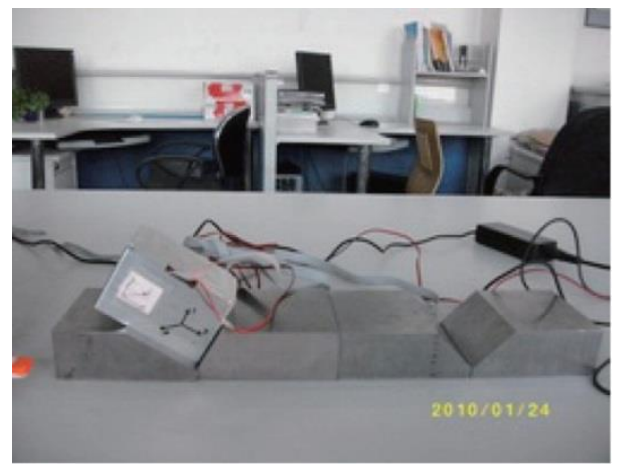

a)

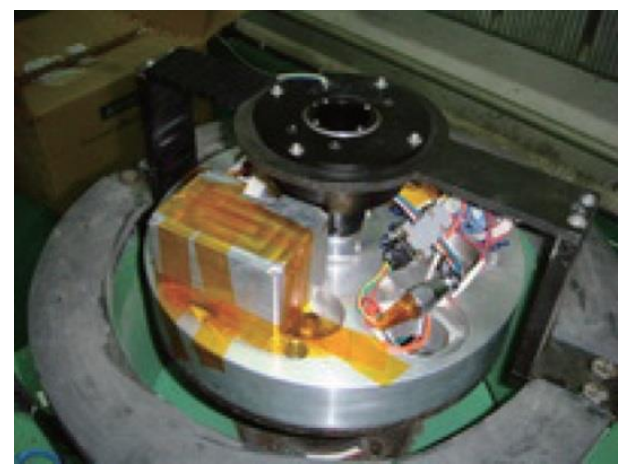

b)

Figura 2.5.1: (a) Plano inclinado para teste estático e (b) Rate test (Wang, L. e Wang, F., 2011).

Usando um mecanismo como uma Plataforma de Stewart, por exemplo, é possível gerar movimentos de translação e rotação puras em determinadas direções e assim, comparar estas respostas com as medidas pela IMU embarcada no UAV montado na plataforma móvel o mecanismo. A Figura 2.5.2 apresenta uma Plataforma de Stewart usada para este fim (Magnussen, O. et al., 2012). Em Costa, M. S. M., et al. (2015), a validação das medidas feitas por uma IMU é feita 
comparando estas com os valores medidos por uma Plataforma de Stewart com atuação pneumática desenvolvida no Laboratório de Desenvolvimento de Sistemas Mecatrônicos (LDSM) da PUC-Rio. A Figura 2.5.3 apresenta a plataforma em duas diferentes configurações.

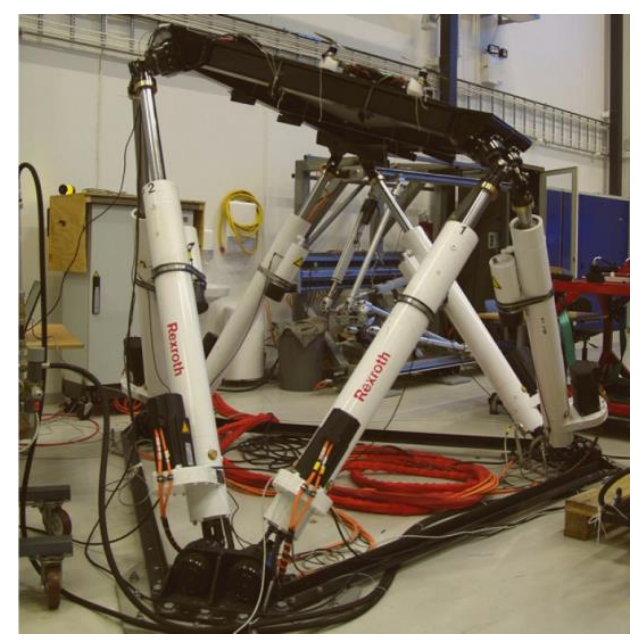

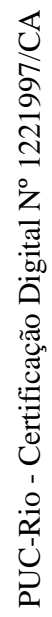

Figura 2.5.2: Plataforma de Stewart usada na calibração de IMU embarcada em UAV (Magnussen, O. et al., 2012).
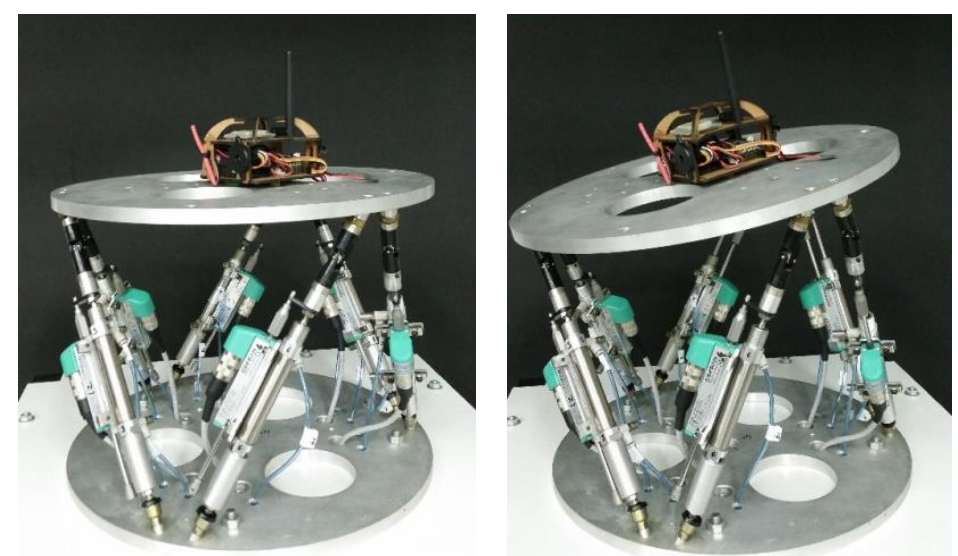

Figura 2.5.3: Plataforma de Stewart usada na validação de IMU (Costa, M. S. M.. et al., 2015). 


\section{3 Modelo dinâmico do mecanismo paralelo plano}

Neste capítulo será apresentado o processo para obtenção do modelo dinâmico do mecanismo paralelo plano. Primeiramente, a técnica da cadeia vetorial é usada para determinar o modelo geométrico inverso, e com a sua derivação, as relações cinemáticas são obtidas, e, portanto, a matriz Jacobiana inversa. Deste modo, é construída a estrutura em grafos de ligação da cinemática inversa e, a partir das relações de causa e efeito, encontra-se o modelo dinâmico direto do mecanismo.

\subsection{Cinemática inversa do mecanismo paralelo plano}

\subsubsection{Geometria inversa via cadeia vetorial}

A Figura 3.1.1 mostra um manipulador paralelo com configuração 3-RㅛRR. Três membros se conectam à plataforma móvel e à base fixa por juntas rotativas nos pontos $B_{i}$ e $A_{i}, i=1,2$ e 3 . Para descrever sua geometria, adiciona-se um referencial $\mathrm{A}(X, Y)$ fixado à base da plataforma e outro, $\mathrm{B}(x, y)$ acoplado à plataforma móvel. Outro sistema de referências $\mathrm{C}\left(x_{i}, y_{i}\right)$ é fixado à cada junta rotativa, tendo assim, sua origem no ponto $A_{i}$ (sendo $i$ referente à $i$-ésima junta rotativa; $i=1,2$ e 3 ). $\mathrm{O}$ eixo $\mathrm{z}_{i}$ deste sistema aponta de $A_{i}$ para $B_{i}$ (direção do atuador $i$ ). Por conveniência, a origem do sistema B é localizada no centro de massa da plataforma móvel. A localização da plataforma móvel pode ser descrita pela posição do vetor $\boldsymbol{p}=\left[p_{X}, p_{Y}\right]^{T}=[X, Y]^{T}$ e da matriz de rotação ${ }^{A} R_{B}$. Sendo $x e$ $y$ os eixos do sistema de coordenadas móvel, então a matriz de rotação pode ser escrita como apresentado na Equação 3.1.1.

$$
{ }^{A} R_{B}=\left[\begin{array}{cc}
\cos \theta & -\operatorname{sen} \theta \\
\operatorname{sen} \theta & \cos \theta
\end{array}\right]
$$


Sendo $\boldsymbol{a}_{i}=\left[a_{i X}, a_{i Y}\right]^{\mathrm{T}} \mathrm{e}^{B} \boldsymbol{b}_{i}=\left[b_{i x}, b_{i y}\right]^{\mathrm{T}}$ as posições vetoriais dos pontos $A_{i} \mathrm{e}$ $B_{i}$ nos sistemas coordenados A e B (com $i$ de 1 a 3 ), respectivamente, pode-se escrever uma equação de malha para o $i$-ésimo membro do manipulador (Equação 3.1.2),

$$
\overline{A_{l} B_{l}}=\boldsymbol{p}+{ }^{A} R_{B}{ }^{B} \boldsymbol{b}_{i}-\boldsymbol{a}_{i}
$$

, na qual $\left[b_{i X}, b_{i Y}\right]^{\mathrm{T}}$ é o vetor $\boldsymbol{b}_{i}$ descrito no referencial fixo.

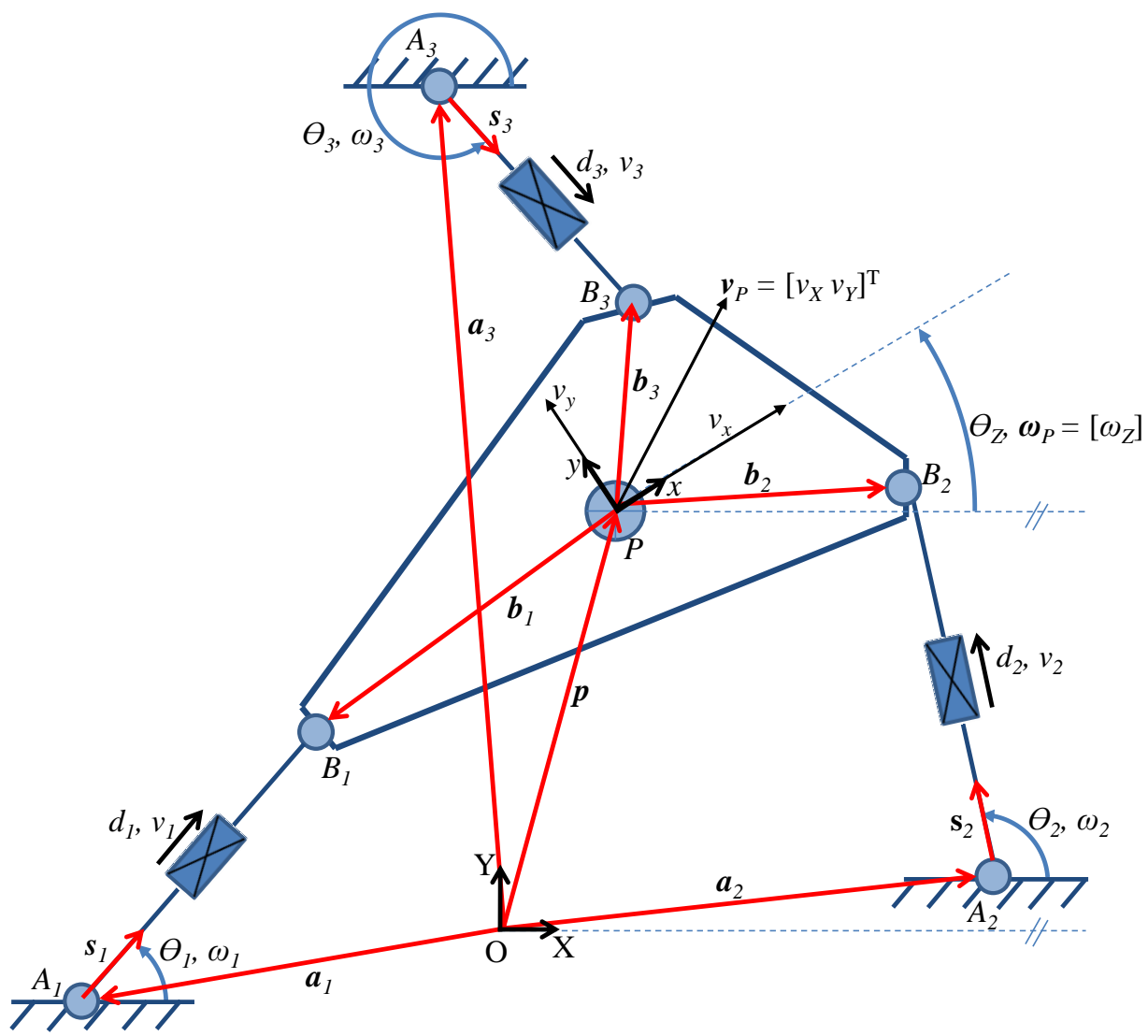

Figura 3.1.1: Plataforma plana com três graus de liberdade.

\subsubsection{Cinemática inversa via cadeia vetorial}

Define-se o estado de velocidades da plataforma móvel da Jacobiana convencional como um vetor de três dimensões com a velocidade linear absoluta, seguido pela velocidade angular da plataforma móvel. 


$$
\dot{\boldsymbol{x}}=\boldsymbol{v}=\left[\begin{array}{c}
\boldsymbol{v}_{P} \\
\boldsymbol{\omega}_{P}
\end{array}\right]=\left[\begin{array}{c}
\dot{X} \\
\dot{Y} \\
\dot{\theta}
\end{array}\right]=\left[\begin{array}{c}
v_{X} \\
v_{Y} \\
\omega_{Z}
\end{array}\right]
$$

Para este manipulador o vetor de entrada é dado por $\dot{\mathbf{q}}=\left[\dot{d_{1}}, \dot{d_{2}}, \dot{d_{3}}\right]^{T}$ e o vetor de saída pode ser descrito pela velocidade do centroide $P$ e a velocidade angular da plataforma móvel (Equação 3.1.3). Reescrevendo a Equação 3.1.2, tem-se

$$
\overline{O P}+\overline{P B_{l}}=\overline{O A_{l}}+\overline{A_{l} B_{l}} \therefore \boldsymbol{p}+\boldsymbol{b}_{i}=\boldsymbol{d}_{i}+\boldsymbol{a}_{i}
$$

Aplicando o diferencial em relação ao tempo, obtém-se

$$
\boldsymbol{v}_{p}+\boldsymbol{\omega}_{P} \times \boldsymbol{b}_{i}=d_{i}\left(\boldsymbol{\omega}_{i} \times \boldsymbol{s}_{i}\right)+\dot{d}_{\imath} \boldsymbol{s}_{i}
$$

, na qual $\mathbf{b}_{i}$ e $\mathbf{s}_{i}$ representam o vetor $\overline{P B_{l}}$ e um vetor unitário ao longo de $\overline{A_{l} B_{l}}$, respectivamente. $\boldsymbol{\omega}_{i}$ denota a velocidade angular do $i$-ésimo membro em relação ao sistema fixo $A$. Para eliminar $\boldsymbol{\omega}_{i}$, multiplicam-se os dois lados da Equação 3.1.5 por $\mathbf{s}_{i}$, obtendo

$$
\boldsymbol{s}_{i} \cdot \boldsymbol{v}_{P}+\boldsymbol{s}_{i}\left(\boldsymbol{\omega}_{P} \times \boldsymbol{b}_{i}\right)=d_{i} \boldsymbol{s}_{i}\left(\boldsymbol{\omega}_{i} \times \boldsymbol{s}_{i}\right)+\dot{d}_{l} \boldsymbol{s}_{i} \boldsymbol{s}_{i}
$$

Sendo $\mathbf{s}_{i} \mathbf{s}_{i}=1$ (produto escalar de dois vetores unitários paralelos), $\mathbf{s}_{i}\left(\boldsymbol{\omega}_{i} \times \mathbf{s}_{i}\right)=0$ (produto escalar de dois vetores perpendiculares) e $\mathbf{s}_{i}\left(\boldsymbol{\omega}_{P} \times\right.$ $\left.\mathbf{b}_{i}\right)=\left(\mathbf{b}_{i} \times \mathbf{s}_{i}\right) \cdot \boldsymbol{\omega}_{P}($ da propriedade $\mathbf{a} \cdot(\mathbf{b} \times \mathbf{c})=\mathbf{b} \cdot(\mathbf{c} \times \mathbf{a})=\mathbf{c} \cdot(\mathbf{a} \times \mathbf{b}))$, tem-se

$$
\boldsymbol{s}_{i} \cdot \boldsymbol{v}_{P}+\left(\boldsymbol{b}_{i} \times \boldsymbol{s}_{i}\right) \cdot \boldsymbol{\omega}_{P}=\dot{d}_{\imath}
$$

Assim, obtém-se a relação entre as variáveis que descrevem a velocidade linear e a angular da plataforma móvel e as velocidades dos elos da plataforma plana (Equação 3.1.8). Com esta relação, monta-se a matriz Jacobiana inversa (por se tratar da cinemática inversa) deste manipulador (Equação 3.1.9). 


$$
\begin{aligned}
& \dot{\boldsymbol{q}}=\left[\begin{array}{l}
v_{1} \\
v_{2} \\
v_{3}
\end{array}\right]=J^{-1} \dot{\boldsymbol{x}}=\left[\begin{array}{lll}
\frac{\partial d_{1}}{\partial X} & \frac{\partial d_{1}}{\partial Y} & \frac{\partial d_{1}}{\partial \theta} \\
\frac{\partial d_{2}}{\partial X} & \frac{\partial d_{2}}{\partial Y} & \frac{\partial d_{2}}{\partial \theta} \\
\frac{\partial d_{3}}{\partial X} & \frac{\partial d_{3}}{\partial Y} & \frac{\partial d_{3}}{\partial \theta}
\end{array}\right] \dot{\boldsymbol{x}} \\
& J^{-1}=\left[\begin{array}{ll}
\boldsymbol{s}_{1}^{T} & \left(\boldsymbol{b}_{1} \times \boldsymbol{s}_{1}\right)^{T} \\
\boldsymbol{s}_{2}^{T} & \left(\boldsymbol{b}_{2} \times \boldsymbol{s}_{2}\right)^{T} \\
\boldsymbol{s}_{3}^{T} & \left(\boldsymbol{b}_{3} \times \boldsymbol{s}_{3}\right)^{T}
\end{array}\right]
\end{aligned}
$$

As Equações 3.1.10 a 3.1.12 apresentam o desmembramento dos termos $\mathbf{s}_{i}^{T}$

$$
\begin{aligned}
& \boldsymbol{s}_{1}^{T}=\frac{{\overline{A_{1} B_{1}}}^{T}}{d_{1}}=\left[\begin{array}{ll}
\frac{d_{1} \cos \theta_{1}}{d_{1}} & \frac{d_{1} \operatorname{sen} \theta_{1}}{d_{1}}
\end{array}\right]=\left[\begin{array}{ll}
\cos \theta_{1} & \operatorname{sen} \theta_{1}
\end{array}\right] \\
& \boldsymbol{s}_{2}^{T}=\frac{{\overline{A_{2} B_{2}}}^{T}}{d_{2}}=\left[\begin{array}{ll}
\frac{d_{2} \cos \theta_{2}}{d_{2}} & \frac{d_{2} \operatorname{sen} \theta_{2}}{d_{2}}
\end{array}\right]=\left[\begin{array}{ll}
\cos \theta_{2} & \operatorname{sen} \theta_{2}
\end{array}\right] \\
& \boldsymbol{s}_{3}^{T}=\frac{{\overline{A_{3} B_{3}}}^{T}}{d_{3}}=\left[\begin{array}{ll}
\frac{d_{3} \cos \theta_{3}}{d_{3}} & \frac{d_{3} \operatorname{sen} \theta_{3}}{d_{3}}
\end{array}\right]=\left[\begin{array}{ll}
\cos \theta_{3} & \operatorname{sen} \theta_{3}
\end{array}\right]
\end{aligned}
$$

O produto vetorial $\boldsymbol{b}_{i} \times \boldsymbol{s}_{i}$ é obtido transformando o primeiro vetor em uma matriz antissimétrica $3 \times 3$ denominada matriz til. A Equação 3.1.13 apresenta o desdobramento deste produto vetorial e, na Equação 3.1.14, é reescrita a Equação 3.1.8 com os termos da matriz Jacobiana inversa explicitados.

$$
\begin{gathered}
\boldsymbol{b}_{i} \times \boldsymbol{s}_{i}=\widetilde{\boldsymbol{b}}_{i} \boldsymbol{s}_{i}=\left[\begin{array}{ccc}
0 & 0 & b_{i Y} \\
0 & 0 & -b_{i X} \\
-b_{i Y} & b_{i X} & 0
\end{array}\right]\left[\begin{array}{c}
\cos \theta_{i} \\
\operatorname{sen} \theta_{i} \\
0
\end{array}\right]=\left[\begin{array}{c}
0 \\
0 \\
-b_{i Y} \cos \theta_{i}+b_{i X} \operatorname{sen} \theta_{i}
\end{array}\right] \\
{\left[\begin{array}{c}
\dot{d}_{1} \\
\dot{d}_{2} \\
\dot{d}_{3}
\end{array}\right]=\left[\begin{array}{lll}
\cos \theta_{1} & \operatorname{sen} \theta_{1} & -b_{1 Y} \cos \theta_{1}+b_{1 X} \operatorname{sen} \theta_{1} \\
\cos \theta_{2} & \operatorname{sen} \theta_{2} & -b_{2 Y} \cos \theta_{2}+b_{2 X} \operatorname{sen} \theta_{2} \\
\cos \theta_{3} & \operatorname{sen} \theta_{3} & -b_{3 Y} \cos \theta_{3}+b_{3 X} \operatorname{sen} \theta_{3}
\end{array}\right]\left[\begin{array}{c}
\dot{X} \\
\dot{Y} \\
\dot{\theta}
\end{array}\right]}
\end{gathered}
$$

, nas quais $\theta_{1}, \theta_{2}$ e $\theta_{3}$ são dados pelas Equações 3.1.15 a 3.1.17. 


$$
\begin{aligned}
& \theta_{1}=\operatorname{tg}^{-1}\left[\frac{b_{1 Y}-a_{1 Y}}{b_{1 X}-a_{1 X}}\right]=\operatorname{tg}^{-1}\left[\frac{Y+b_{1 x} \operatorname{sen} \theta+b_{1 y} \cos \theta-a_{1 Y}}{X+b_{1 x} \cos \theta-b_{1 y} \operatorname{sen} \theta-a_{1 X}}\right] \\
& \theta_{2}=\operatorname{tg}^{-1}\left[\frac{b_{2 Y}-a_{2 Y}}{b_{2 X}-a_{2 X}}\right]=\operatorname{tg}^{-1}\left[\frac{Y+b_{2 x} \operatorname{sen} \theta+b_{2 y} \cos \theta-a_{2 Y}}{X+b_{2 x} \cos \theta-b_{2 y} \operatorname{sen} \theta-a_{2 X}}\right] \\
& \theta_{3}=\operatorname{tg}^{-1}\left[\frac{b_{3 Y}-a_{3 Y}}{b_{3 X}-a_{3 X}}\right]=\operatorname{tg}^{-1}\left[\frac{Y+b_{3 x} \operatorname{sen} \theta+b_{3 y} \cos \theta-a_{3 Y}}{X+b_{3 x} \cos \theta-b_{3 y} \operatorname{sen} \theta-a_{3 X}}\right]
\end{aligned}
$$

Reescrevendo em função de $\operatorname{tg}\left(\theta_{i}\right)$ e derivando ambos os lados das Equações 3.1.15 a 3.1.17, obtém-se a Equação 3.1.18, para $i=1,2,3$.

$$
\frac{d\left(\operatorname{tg}\left(\theta_{i}\right)\right)}{d t}=\frac{d}{d t}\left(\frac{Y+b_{i x} \operatorname{sen} \theta+b_{i y} \cos \theta-a_{i Y}}{X+b_{i x} \cos \theta-b_{i y} \operatorname{sen} \theta-a_{i X}}\right)
$$

Resolvendo a derivada em ambos os lados da Equação 3.1.18 e manipulando os termos de modo a colocar em evidência as velocidades lineares absolutas e a velocidade angular da plataforma, obtém-se a Jacobiana inversa que relaciona estas velocidades à velocidade angular de cada um dos membros. Esta relação é apresentada na Equação 3.1.19 e o detalhamento dos termos da matriz é mostrado na Equação 3.1.20.

$$
\begin{aligned}
& \dot{\theta}_{i}=\left[\begin{array}{l}
\dot{\theta_{1}} \\
\dot{\theta_{2}} \\
\dot{\theta_{3}}
\end{array}\right]=\left[\begin{array}{l}
\omega_{1} \\
\omega_{2} \\
\omega_{3}
\end{array}\right]=J_{\theta_{i}}^{-1}\left[\begin{array}{l}
v_{X} \\
v_{Y} \\
\omega_{Z}
\end{array}\right] \\
& J_{\theta_{i}}^{-1}=\left[\begin{array}{lll}
\frac{\left(a_{1 Y}-b_{1 Y}\right) \cos ^{2}\left(\theta_{1}\right)}{\left(b_{1 X}-a_{1 X}\right)^{2}} & \frac{\cos ^{2}\left(\theta_{1}\right)}{\left(b_{1 X}-a_{1 X}\right)} & \frac{\cos ^{2}\left(\theta_{1}\right)}{\left(b_{1 X}-a_{1 X}\right)^{2}} j_{\theta 1} \\
\frac{\left(a_{2 Y}-b_{2 Y}\right) \cos ^{2}\left(\theta_{2}\right)}{\left(b_{2 X}-a_{2 X}\right)^{2}} & \frac{\cos ^{2}\left(\theta_{2}\right)}{\left(b_{2 X}-a_{2 X}\right)} & \frac{\cos ^{2}\left(\theta_{2}\right)}{\left(b_{2 X}-a_{2 X}\right)^{2}} j_{\theta 2} \\
\frac{\left(a_{3 Y}-b_{3 Y}\right) \cos ^{2}\left(\theta_{3}\right)}{\left(b_{3 X}-a_{3 X}\right)^{2}} & \frac{\cos ^{2}\left(\theta_{3}\right)}{\left(b_{3 X}-a_{3 X}\right)} & \frac{\cos ^{2}\left(\theta_{3}\right)}{\left(b_{3 X}-a_{3 X}\right)^{2}} j_{\theta 3}
\end{array}\right]
\end{aligned}
$$

Sendo $c \theta=\cos (\theta), s \theta=\operatorname{sen}(\theta)$ e $j_{\theta i}$ dado pela Equação 3.1.21, para $i=1,2$ e 3 . 


$$
j_{\theta i}=\left(b_{i x} c \theta-b_{i y} s \theta\right)\left(b_{i X}-a_{i X}\right)+\left(b_{i x} s \theta+b_{i y} c \theta\right)\left(b_{i Y}-a_{i Y}\right)
$$

Para obter a relação entre as velocidades e acelerações, lineares e angulares, da plataforma móvel e as acelerações lineares dos atuadores do mecanismo, é calculado o derivativo da Jacobiana inversa, como mostra a equação 3.1.22 (Craig, J. J., 1989). A Equação 3.1.25 apresenta os termos desta matriz.

$$
\ddot{\boldsymbol{q}}=\left[\begin{array}{c}
\dot{v_{1}} \\
\dot{v_{2}} \\
\dot{v}_{3}
\end{array}\right]=\left[\begin{array}{l}
a_{1} \\
a_{2} \\
a_{3}
\end{array}\right]=J^{\dot{-1}} \dot{\boldsymbol{x}}+J^{-1} \ddot{\boldsymbol{x}}=J^{-1}\left[\begin{array}{c}
v_{X} \\
v_{Y} \\
\omega_{Z}
\end{array}\right]+J^{-1}\left[\begin{array}{l}
a_{X} \\
a_{Y} \\
\alpha_{Z}
\end{array}\right]
$$

Sendo

$$
J^{-1}=\frac{\partial J^{-1}}{\partial \mathbf{x}} \dot{\mathbf{x}}
$$

, tem-se que

$$
\begin{gathered}
\ddot{\mathbf{q}}=\frac{\partial J^{-1}}{\partial \mathbf{x}} \dot{\mathbf{x}} \cdot \dot{\mathbf{x}}+J^{-1} \ddot{\mathbf{x}} \\
J^{-1}=\left[\begin{array}{lll}
-s \theta_{1} \omega_{1} & c \theta_{1} \omega_{1} & \dot{b_{1 X}} s \theta_{1}-\dot{b_{1 Y}} c \theta_{1}+b_{1 X} c \theta_{1} \omega_{1}+b_{1 Y} s \theta_{1} \omega_{1} \\
-s \theta_{2} \omega_{2} & c \theta_{2} \omega_{2} & \dot{b_{2 X}} s \theta_{2}-\dot{b_{2 Y}} c \theta_{2}+b_{2 X} c \theta_{2} \omega_{2}+b_{2 Y} s \theta_{2} \omega_{2} \\
-s \theta_{3} \omega_{3} & c \theta_{3} \omega_{3} & \dot{b_{3 X}} s \theta_{3}-\dot{b_{3 Y}} c \theta_{3}+b_{3 X} c \theta_{3} \omega_{3}+b_{3 Y} s \theta_{3} \omega_{3}
\end{array}\right]
\end{gathered}
$$

$\dot{b_{l X}}$ e $\dot{b_{l Y}}$ são dados pelas Equações 3.1 .26 e 3.1.27, respectivamente, para $i=1,2$ e 3 .

$$
\begin{aligned}
& \dot{b_{i X}}=v_{X}-\omega_{Z}\left(b_{i x} s \theta+b_{i y} c \theta\right) \\
& \dot{b_{l Y}}=v_{Y}+\omega_{Z}\left(b_{i x} c \theta-b_{i y} s \theta\right)
\end{aligned}
$$


O mesmo método é aplicado na relação entre as velocidades e acelerações da plataforma móvel e as acelerações angulares dos atuadores (3.1.28). A matriz dos derivativos de $J_{\theta}{ }^{-1}$ é dada pela Equação 3.1.29.

$$
\begin{aligned}
& \ddot{\boldsymbol{\theta}}=\left[\begin{array}{c}
\dot{\omega}_{1} \\
\dot{\omega}_{2} \\
\dot{\omega}_{3}
\end{array}\right]=\left[\begin{array}{l}
\alpha_{1} \\
\alpha_{2} \\
\alpha_{3}
\end{array}\right]=\boldsymbol{J}_{\boldsymbol{\theta}}^{\dot{-1}} \dot{\boldsymbol{x}}+\boldsymbol{J}_{\boldsymbol{\theta}}^{-\mathbf{1}} \ddot{\boldsymbol{x}}=\boldsymbol{J}_{\boldsymbol{\theta}}^{\dot{\boldsymbol{1}}}\left[\begin{array}{c}
v_{X} \\
v_{Y} \\
\omega_{Z}
\end{array}\right]+\boldsymbol{J}_{\boldsymbol{\theta}}^{-\mathbf{1}}\left[\begin{array}{c}
a_{X} \\
a_{Y} \\
\alpha_{Z}
\end{array}\right] \\
& J_{\theta}^{\dot{-1}}=\left[\begin{array}{ccc}
J_{\theta 11}^{\dot{-1}} & J_{\theta 12}^{\dot{-1}} & J_{\theta 13}^{\dot{-1}} \\
J_{\theta 21}^{\dot{-1}} & J_{\theta 22}^{\dot{-1}} & J_{\theta 23}^{\dot{-1}} \\
J_{\theta 31}^{\dot{-1}} & J_{\theta 32}^{\dot{-1}} & J_{\theta 33}^{\dot{-1}}
\end{array}\right]
\end{aligned}
$$

$J_{\theta \imath 1}^{\dot{-1}}, J_{\theta \imath 2}^{\dot{-1}}$ e $J_{\theta \imath 3}^{\dot{-1}}$ são dados pelas Equações 3.1 .30 a 3.1.32, respectivamente, para $i=1,2$ e 3 .

$$
\begin{aligned}
J_{\theta l 1}^{-1} & =\frac{\left[2 c \theta_{i} s \theta_{i} \omega_{i}\left(b_{i Y}-a_{i Y}\right)-b_{l Y} c^{2} \theta_{i}\right]\left(b_{i X}-a_{i X}\right)-2 b_{i X}\left(a_{i Y}-b_{i Y}\right) c^{2} \theta_{i}}{\left(b_{i X}-a_{i X}\right)^{3}} \\
J_{\theta l 2}^{-1} & =\frac{2 c \theta_{i} s \theta_{i} \omega_{i}\left(a_{i X}-b_{i X}\right)-b_{l X} c^{2} \theta_{i}}{\left(b_{i X}-a_{i X}\right)^{2}} \\
J_{\theta l 3}^{-1} & =\frac{\left[-2 c \theta_{i} s \theta_{i} \omega_{i} j_{\theta i}+j \dot{\theta}_{l} c^{2} \theta_{i}\right]\left(b_{i X}-a_{i X}\right)-2 b_{i X} j_{\theta i} c^{2} \theta_{i}}{\left(b_{i X}-a_{i X}\right)^{3}}
\end{aligned}
$$

$\dot{J}_{\dot{\theta}}$ é dado pela Equação 3.1.33, para $i=1,2$ e 3.

$$
\begin{aligned}
& \dot{j}_{\dot{\theta}}=\left(-b_{i y} c\right.\left.\theta-b_{i x} s \theta\right)\left(b_{i X}-a_{i X}\right) \omega_{Z}+\left(b_{i x} c \theta-b_{i y} s \theta\right) \dot{b_{i X}} \\
&+\left(b_{i x} c \theta-b_{i y} s \theta\right)\left(b_{i Y}-a_{i Y}\right) \omega_{Z}+\left(b_{i x} s \theta+b_{i y} c \theta\right) \dot{b_{i Y}}
\end{aligned}
$$

\subsubsection{Cinemática inversa via fluxo de potência}

Como na técnica dos Grafos de Ligação as restrições de velocidade podem ser aplicadas diretamente, pode-se construir o grafo de ligação para a análise do sistema cinemático antes de montar o grafo para análise dinâmica. Em um grafo que descreve corretamente a cinemática (junções 1 e 0 , transformadores e 
giradores), a dinâmica (capacitores, inércias e resistências) pode ser imposta sem o risco de criar modelos onde as principais restrições dos sistemas mecânicos, laços geométricos ou cinemáticos são violados (Speranza Neto et al., 2005).

Neste modelo as condições de velocidade em $v_{X}, v_{Y}$ e $\omega_{Z}$ são impostas por fontes de fluxo ideais. Além destas velocidades, as outras junções 1 (de velocidade comum) indicam as velocidades lineares $\left(v_{1}, v_{2}\right.$ e $\left.v_{3}\right)$ e angulares $\left(\omega_{1}\right.$, $\omega_{2}$ e $\left.\omega_{3}\right)$ dos atuadores. Assim, a cinemática inversa da plataforma plana via grafos de ligação é apresentada na Figura 3.1.2, onde os elementos de duas portas tipo transformadores modulados indicados por $J_{i j}^{-1}$ e $J_{\theta_{i j}}^{-1}$ representam os termos das linhas $i$ e das colunas $j$ das matrizes $J^{-1}$ (Equação 4.1.14) e $J_{\theta}^{-1}$ (Equação 3.1.20). Nesta representação existem 45 ligações, que representam 90 variáveis. A Figura 3.1.3 apresenta o mesmo modelo usando grafos multi-ligação.

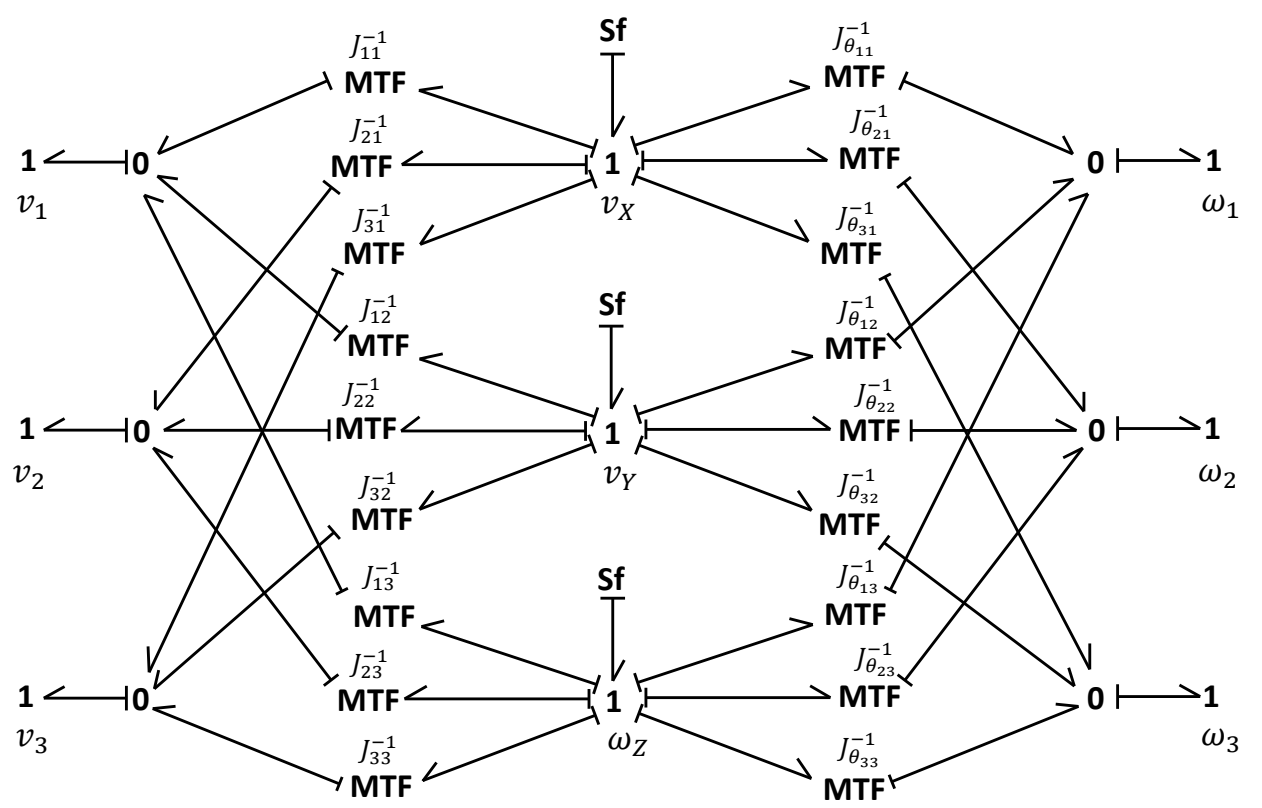

Figura 3.1.2: Cinemática inversa da plataforma plana via grafos de ligação.

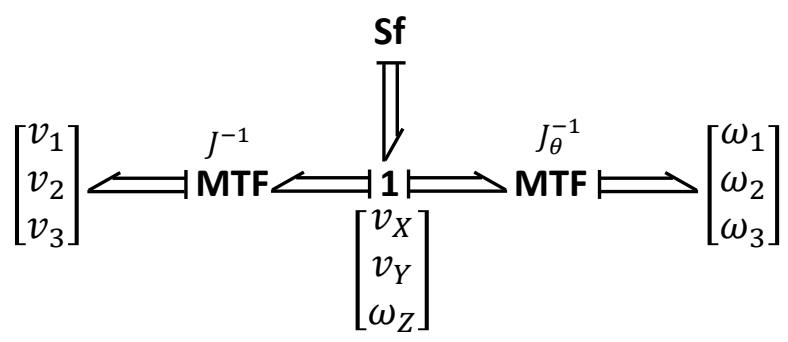

Figura 3.1.3: Cinemática inversa da plataforma plana via grafos multi-ligação. 


\subsection{Dinâmica do mecanismo paralelo plano via fluxo de potência}

Nesta Seção será apresentado o modelo dinâmico da plataforma plana a partir do modelo cinemático via fluxo de potência. Em um primeiro momento, apenas um corpo será considerado no modelo dinâmico do manipulador, a plataforma móvel (com massa $m_{P}$ e momento de inércia $J_{P z z}$ ).

\subsubsection{Relações de causa e efeito}

Segundo Speranza Neto, M. (1999), quando se consegue, tanto compatibilizar completamente as variáveis de potência na entrada e na saída dos subsistemas (mesmos tipo e sentido do fluxo de potência), quanto uma relação de causa e efeito (causalidade) consistente (quais variáveis entram e quais saem dos modelos a serem acoplados), o modelo resultante é totalmente equivalente àquele que seria obtido analiticamente, o que permite a sua simulação a partir da simples conexão dos módulos. Considerando isto, monta-se o esquema da Figura 3.2.1 que ilustra as relações de causa e efeito da plataforma plana com três graus de liberdade.

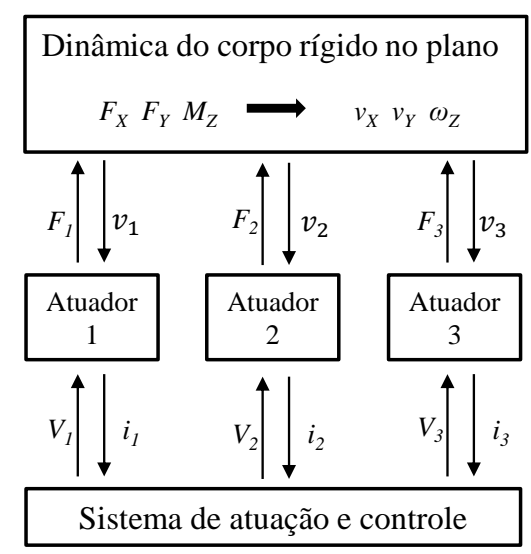

Figura 3.2.1: Relações de causa e efeito da plataforma plana.

Com as relações cinemáticas deste mecanismo paralelo chega-se à relação de consequência da conservação de potência no acoplamento dos atuadores com o corpo rígido baseada na matriz Jacobiana inversa apresentada na Equação 3.1.14. As Equações 3.2.1 a 3.2.3 apresentam o desenvolvimento desta relação. Usando a mesma metodologia, a relação de consequência da conservação de potência no 
acoplamento dos atuadores com o corpo rígido baseada na matriz $\mathbf{J}_{\theta}^{-1}$ (Equação 3.1.20) é apresentada na Equação 3.2.4.

$$
\underset{\text { rígido }}{P_{\text {Corpo }}}=P \underset{\text { de atuação }}{\text { Sistema }} \Rightarrow\left[\begin{array}{lll}
F_{X} & F_{Y} & M_{Z}
\end{array}\right]_{A} \cdot\left[\begin{array}{c}
v_{X} \\
v_{Y} \\
\omega_{Z}
\end{array}\right]=\left[\begin{array}{lll}
F_{1} & F_{2} & F_{3}
\end{array}\right] \cdot\left[\begin{array}{l}
v_{1} \\
v_{2} \\
v_{3}
\end{array}\right]
$$

$$
\begin{aligned}
& {\left[\begin{array}{lll}
F_{X} & F_{Y} & M_{Z}
\end{array}\right]_{A} \cdot\left[\begin{array}{l}
v_{X} \\
v_{Y} \\
\omega_{Z}
\end{array}\right]=\left[\begin{array}{lll}
F_{1} & F_{2} & F_{3}
\end{array}\right] \cdot \boldsymbol{J}^{-1}\left[\begin{array}{c}
v_{X} \\
v_{Y} \\
\omega_{Z}
\end{array}\right]} \\
& {\left[\begin{array}{lll}
F_{X} & F_{Y} & M_{Z}
\end{array}\right]_{A}=\left[\begin{array}{lll}
F_{1} & F_{2} & F_{3}
\end{array}\right] \cdot \boldsymbol{J}^{-1} \Rightarrow\left[\begin{array}{c}
F_{X} \\
F_{Y} \\
M_{Z}
\end{array}\right]_{A}=\left(\boldsymbol{J}^{-1}\right)^{T}\left[\begin{array}{l}
F_{1} \\
F_{2} \\
F_{3}
\end{array}\right]}
\end{aligned}
$$

$$
\left[\begin{array}{lll}
F_{X} & F_{Y} & M_{Z}
\end{array}\right]_{M A}=\left[\begin{array}{lll}
M_{1} & M_{2} & M_{3}
\end{array}\right] \cdot \boldsymbol{J}_{\theta}^{-1} \Rightarrow\left[\begin{array}{c}
F_{X} \\
F_{Y} \\
M_{Z}
\end{array}\right]_{M A}=\left(\boldsymbol{J}_{\theta}^{-1}\right)^{T}\left[\begin{array}{l}
M_{1} \\
M_{2} \\
M_{3}
\end{array}\right]
$$

\subsubsection{Dinâmica direta}

A metodologia dos Grafos de Ligação surgiu no final da década de 50 e foi desenvolvida por Karnopp e Rosenberg (1968) desde a década de 1960. É uma técnica que pode incluir sistemas de naturezas físicas distintas como elétricos, mecânicos, hidráulicos, pneumáticos e térmicos; representar sistemas de parâmetros concentrados, lineares ou não; entre outros. É estabelecida uma representação gráfica para a estrutura do modelo físico do sistema e possui uma formulação para o desenvolvimento do modelo matemático. Esse método possui como características: representação apropriada para as propriedades físicas dos elementos e para suas respectivas relações de causa e efeito.

Nove elementos básicos constituem essa técnica e são estes as fontes de esforço, fontes de fluxo, resistores, inércias, capacitores, transformadores, giradores e as junções " 0 ” e "1". As ligações que conectam os componentes ou subsistemas representam o fluxo de potência entre eles. Nessa técnica são utilizados quatro tipos de variáveis generalizadas: as variáveis de potência - 
esforço $(e)$ e fluxo $(f)$ e as de energia - quantidade de movimento $(p)$ e de deslocamento $(q)$.

Com isso, tem-se a estrutura em grafos de ligação do modelo dinâmico direto aplicado à plataforma plana de três graus de liberdade (Figura 3.2.2). Nesta, foram adicionados os efeitos inerciais dos corpos que compõem os atuadores introduzindo os termos $m_{A i}$ e $J_{A i}$, que correspondem às massas e momentos de inércia dos atuadores, sendo $i=1,2$ e 3 . Os momentos de inércia $J_{A i}$ variam com o comprimento da haste, porém, como esta variação é pequena perto do valor total, como será apresentado em detalhes na Seção 6.1, foi adotado um valor médio constante. Também foi adicionado ao modelo o atrito viscoso das juntas rotativas da base (indicados por $b_{A i}$, com $i=1,2$ e 3). Já o atrito viscoso das juntas da plataforma móvel $\left(B_{i}\right)$ também pode ser adicionado. Neste caso, aparecerá em suas equações constitutivas a diferença de velocidades angulares $\omega_{Z}-\omega_{i}$. A Figura 3.2.3 apresenta o mesmo modelo usando grafos multi-ligação. A Figura 3.2.4 apresenta a alteração no grafo de ligação para este último caso e um esquema mostrando as velocidades envolvidas em detalhe.

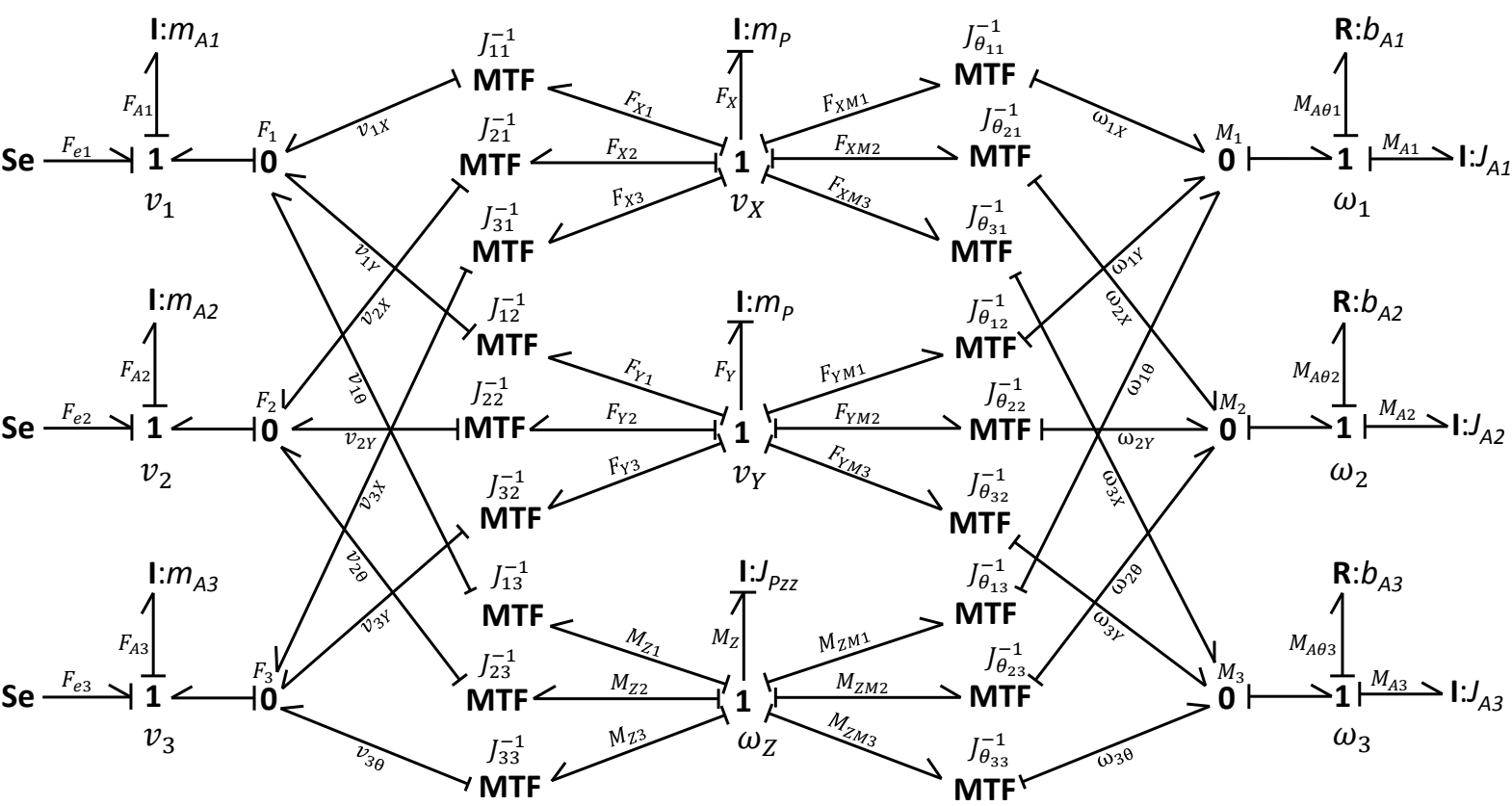

Figura 3.2.2: Dinâmica da plataforma plana via grafos de ligação. 


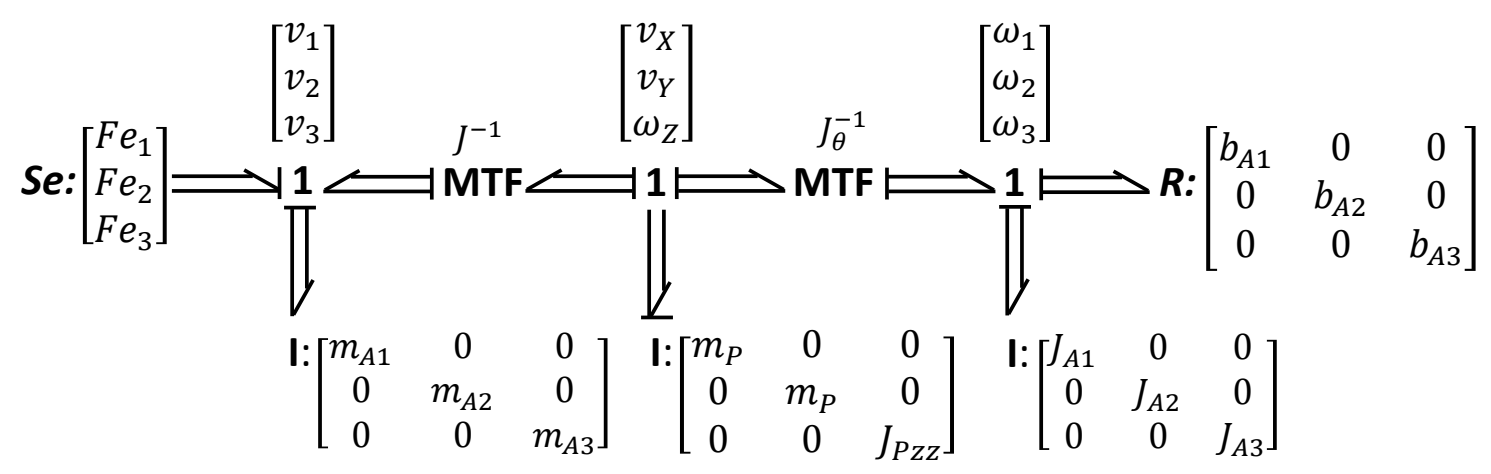

Figura 3.2.3: Dinâmica da plataforma plana via grafos multi-ligação.

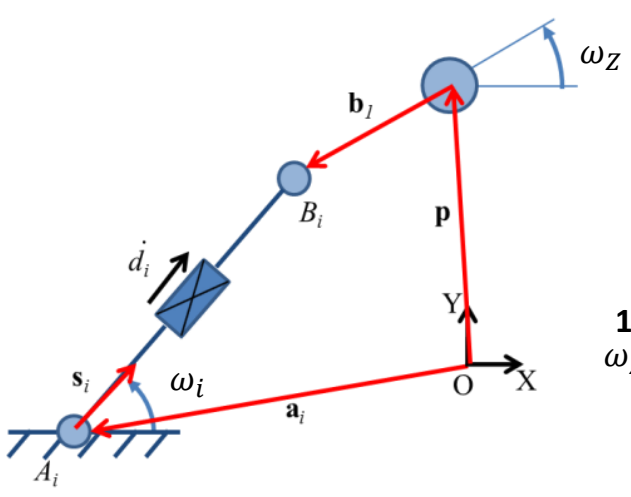

(a)

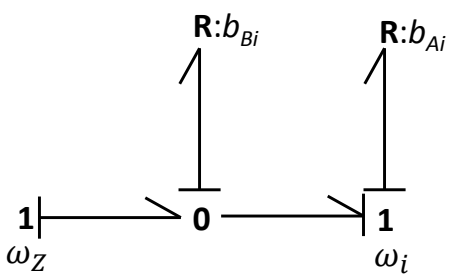

(b)

Figura 3.2.4: Velocidades envolvidas em detalhe (a) e parte do grafo de ligação do modelo que considera o atrito viscoso das juntas rotativas da base $B_{i}$ (b).

As Equações 3.2.5 a 3.2.10 apresentam as equações constitutivas dos elementos de inércia $(I)$ e resistores $(R)$ apresentados no modelo da Figura 3.2.2. As equações refletem a causalidade apresentada no modelo em grafos. Assim, nota-se que as Equações 3.2.5 a 3.2.7 dos elementos de inércia possuem causalidade integral (ou natural) e as Equações 3.2.8 e 3.2.9, com $i=1,2$ e 3, possuem causalidade diferencial (ou forçada), o que levará à existência de uma malha algébrica nas Equações de Estado. Já a Equação 3.2.10, com $i=1,2$ e 3, apresenta a equação constitutiva dos elementos resistores, também respeitando a causalidade apresentada no modelo, que, neste caso, pode ser qualquer uma das duas possíveis, uma vez que suas equações constitutivas são lineares.

$$
v_{X}=\frac{1}{m_{P}} \int F_{X} d t
$$




$$
\begin{aligned}
& v_{Y}=\frac{1}{m_{P}} \int F_{Y} d t \\
& \omega_{Z}=\frac{1}{J_{P Z Z}} \int M_{Z} d t \\
& F_{A i}=m_{A i} \frac{d v_{i}}{d t} \\
& M_{A i}=J_{A i} \frac{d \omega_{i}}{d t} \\
& M_{A \theta i}=b_{A i} \omega_{i}
\end{aligned}
$$

Os conjuntos de Equações 3.2.11, 3.2.12 e 3.2.13 apresentam as equações constitutivas dos elementos transformadores modulados $(M T F)$ associados à $J^{1} \mathrm{e}$ os conjuntos de Equações 3.2.14, 3.2.15 e 3.2.16, apresentam as equações constitutivas dos elementos transformadores modulados $(M T F)$ associados à $J_{\theta}{ }^{-1}$.

$$
\begin{aligned}
& \left\{\begin{array}{l}
F_{X i}=J_{i 1}^{-1} F_{i} \\
v_{i X}=J_{i 1}^{-1} v_{X}
\end{array}\right. \\
& \left\{\begin{array}{l}
F_{Y i}=J_{i 2}^{-1} F_{i} \\
v_{i Y}=J_{i 2}^{-1} v_{Y}
\end{array}\right. \\
& \left\{\begin{array}{l}
M_{Z i}=J_{i 3}^{-1} F_{i} \\
v_{i \theta}=J_{i 3}^{-1} \omega_{Z}
\end{array}\right. \\
& \left\{\begin{array}{c}
F_{X M i}=J_{\theta i 1}^{-1} M_{i} \\
\omega_{i X}=J_{\theta i 1}^{-1} v_{X}
\end{array}\right. \\
& \left\{\begin{array}{l}
F_{Y M i}=J_{\theta i 2}^{-1} M_{i} \\
\omega_{i Y}=J_{\theta i 2}^{-1} v_{Y}
\end{array}\right. \\
& \left\{\begin{array}{l}
M_{Z M i}=J_{\theta i 3}^{-1} M_{i} \\
\omega_{i \theta}=J_{\theta i 3}^{-1} \omega_{Z}
\end{array}\right.
\end{aligned}
$$


As equações das estruturas de junção são apresentadas nos conjuntos de Equações 3.2.17 a 3.2.20. Nas Equações 3.2.17 são apresentadas as equações das junções 0 , com $i=1,2$ e 3 e, de 3.2.18 a 3.2.20, são apresentadas as equações das junções 1 , com $i=1,2$ e 3 .

$$
\begin{aligned}
& \left\{\begin{array}{c}
v_{i}=v_{i X}+v_{i Y}+v_{i \theta} \\
\omega_{i}=\omega_{i X}+\omega_{i Y}+\omega_{i \theta}
\end{array}\right. \\
& \left\{\begin{array}{c}
F_{X}=-\left(F_{X 1}+F_{X 2}+F_{X 3}+F_{X M 1}+F_{X M 2}+F_{X M 3}\right) \\
F_{Y}=-\left(F_{Y 1}+F_{Y 2}+F_{Y 3}+F_{Y M 1}+F_{Y M 2}+F_{Y M 3}\right) \\
M_{Z}=-\left(M_{Z 1}+M_{Z 2}+M_{Z 3}+M_{Z M 1}+M_{Z M 2}+M_{Z M 3}\right)
\end{array}\right. \\
& F_{i}=F_{A i}-F_{e i} \\
& M_{i}=M_{A i}+M_{A \theta i}
\end{aligned}
$$

Para a obtenção das Equações de Estado, as equações das variáveis de energia, ou seja, das variáveis com causalidade integral, são expressas em termos das entradas e das variáveis de co-energia. Assim, as Equações 3.2.5 a 3.2.7 são escritas para $F_{X}, F_{Y}$ e $M_{Z}$, respectivamente, e então, estas são substituídas em 3.2.18. As equações dos transformadores modulados também são substituídas em 3.2.18 e assim são obtidas as Equações 3.2.21 a 3.2.23.

$$
\begin{gathered}
m_{P} \frac{d v_{X}}{d t}=-\left[\begin{array}{lll}
J_{11}^{-1} & J_{21}^{-1} & J_{31}^{-1}
\end{array}\right]\left[\begin{array}{l}
F_{1} \\
F_{2} \\
F_{3}
\end{array}\right]-\left[\begin{array}{lll}
J_{\theta 11}^{-1} & J_{\theta 21}^{-1} & J_{\theta 31}^{-1}
\end{array}\right]\left[\begin{array}{l}
M_{1} \\
M_{2} \\
M_{3}
\end{array}\right] \\
m_{P} \frac{d v_{Y}}{d t}=-\left[\begin{array}{lll}
J_{12}^{-1} & J_{22}^{-1} & J_{32}^{-1}
\end{array}\right]\left[\begin{array}{l}
F_{1} \\
F_{2} \\
F_{3}
\end{array}\right]-\left[\begin{array}{lll}
J_{\theta 12}^{-1} & J_{\theta 22}^{-1} & J_{\theta 32}^{-1}
\end{array}\right]\left[\begin{array}{l}
M_{1} \\
M_{2} \\
M_{3}
\end{array}\right] \\
J_{P Z z} \frac{d \omega_{Z}}{d t}=-\left[\begin{array}{lll}
J_{13}^{-1} & J_{23}^{-1} & J_{33}^{-1}
\end{array}\right]\left[\begin{array}{l}
F_{1} \\
F_{2} \\
F_{3}
\end{array}\right]-\left[\begin{array}{lll}
J_{\theta 13}^{-1} & J_{\theta 23}^{-1} & J_{\theta 33}^{-1}
\end{array}\right]\left[\begin{array}{l}
M_{1} \\
M_{2} \\
M_{3}
\end{array}\right]
\end{gathered}
$$


Substituindo as Equações 3.2.19 e 3.2.20 nas Equações 3.2.21 a 3.2.23, obtém-se a Equação 3.2.24. A Equação 3.2.25 define a matriz dos elementos de inércia da plataforma móvel. Substituindo as equações constitutivas com causalidade diferencial (Equações 3.2 .8 a 3.2.10) na Equação 3.2.24, tem-se a Equação 3.2.26, onde $f_{e}, M_{A}, J_{A}$ e $B_{A}$ são definidos nas Equações 3.2.27 a 3.2.30, respectivamente.

$$
\begin{aligned}
& {\left[\begin{array}{ccc}
m_{P} & 0 & 0 \\
0 & m_{P} & 0 \\
0 & 0 & J_{P Z Z}
\end{array}\right]\left[\begin{array}{l}
a_{X} \\
a_{Y} \\
\alpha_{Z}
\end{array}\right]=J^{-T}\left[\begin{array}{l}
F_{e 1}-F_{A 1} \\
F_{e 2}-F_{A 2} \\
F_{e 3}-F_{A 3}
\end{array}\right]-J_{\theta}^{-T}\left[\begin{array}{l}
M_{A 1}+M_{A \theta 1} \\
M_{A 2}+M_{A \theta 2} \\
M_{A 3}+M_{A \theta 3}
\end{array}\right]} \\
& M_{P} \dot{\boldsymbol{v}}=\left[\begin{array}{ccc}
m_{P} & 0 & 0 \\
0 & m_{P} & 0 \\
0 & 0 & J_{P z Z}
\end{array}\right]\left[\begin{array}{l}
a_{X} \\
a_{Y} \\
\alpha_{Z}
\end{array}\right] \\
& M_{P} \dot{\boldsymbol{v}}=J^{-T} \boldsymbol{f}_{e}-J^{-T} M_{A} \dot{\boldsymbol{v}}_{A}-J_{\theta}^{-T} J_{A} \dot{\boldsymbol{\omega}}_{A}-J_{\theta}^{-T} B_{A} \boldsymbol{\omega}_{A} \\
& \boldsymbol{f}_{e}=\left[\begin{array}{l}
F_{e 1} \\
F_{e 2} \\
F_{e 3}
\end{array}\right] \\
& M_{A} \dot{v}_{A}=\left[\begin{array}{ccc}
m_{A 1} & 0 & 0 \\
0 & m_{A 2} & 0 \\
0 & 0 & m_{A 3}
\end{array}\right]\left[\begin{array}{l}
\dot{v}_{1} \\
\dot{v}_{2} \\
\dot{v}_{3}
\end{array}\right] \\
& J_{A} \dot{\boldsymbol{\omega}}_{A}=\left[\begin{array}{ccc}
J_{A 1} & 0 & 0 \\
0 & J_{A 2} & 0 \\
0 & 0 & J_{A 3}
\end{array}\right]\left[\begin{array}{l}
\dot{\omega}_{1} \\
\dot{\omega}_{2} \\
\dot{\omega}_{3}
\end{array}\right] \\
& B_{A} \boldsymbol{\omega}_{A}=\left[\begin{array}{ccc}
b_{A 1} & 0 & 0 \\
0 & b_{A 2} & 0 \\
0 & 0 & b_{A 3}
\end{array}\right]\left[\begin{array}{l}
\omega_{1} \\
\omega_{2} \\
\omega_{3}
\end{array}\right]
\end{aligned}
$$

Substituindo as equações dos derivativos das matrizes Jacobianas (3.1.28 e 3.1.28) e a Equação 3.1.19 na Equação 3.2.28, são obtidas as Equações de Estado (3.2.31). Nota-se a existência de malhas algébricas associadas à existência de elementos armazenadores. A Equação 3.2.32 apresenta o primeiro passo para a eliminação desta malha. 


$$
\begin{aligned}
& M_{P} \dot{\boldsymbol{v}}= \\
& =J^{-T} \boldsymbol{f}_{e}-J^{-T} M_{A}\left(J^{-1} \boldsymbol{v}+J^{-1} \dot{\boldsymbol{v}}\right)-J_{\theta}^{-T} J_{A}\left(J_{\theta}^{-1} \boldsymbol{v}+J_{\theta}^{-1} \dot{\boldsymbol{v}}\right)-J_{\theta}^{-T} B_{A} J_{\theta}^{-1} \boldsymbol{v} \\
& M_{P} \dot{\boldsymbol{v}}+J^{-T} M_{A} J^{-1} \dot{\boldsymbol{v}}+J_{\theta}^{-T} J_{A} J_{\theta}^{-1} \dot{\boldsymbol{v}}= \\
& =-J^{-T} M_{A} J^{\dot{1}} \boldsymbol{v}-J_{\theta}^{-T} J_{A} J_{\theta}^{-1} \boldsymbol{v}-J_{\theta}^{-T} B_{A} J_{\theta}^{-1} \boldsymbol{v}+J^{-T} \boldsymbol{f}_{e}
\end{aligned}
$$

Considerando

$$
M_{1}=M_{P}+J^{-T} M_{A} J^{-1}+J_{\theta}^{-T} J_{A} J_{\theta}^{-1}
$$

e

$$
M_{2}=-J^{-T} M_{A} J^{\dot{-1}}-J_{\theta}^{-T} J_{A} J_{\theta}^{\dot{-1}}-J_{\theta}^{-T} B_{A} J_{\theta}^{-1}
$$

tem-se

$$
M_{1} \dot{\boldsymbol{v}}=M_{2} \boldsymbol{v}+J^{-T} \boldsymbol{f}_{e}
$$

Assim, chega-se ao Modelo de Estado (Equação 3.2.36), no qual $\boldsymbol{v}$ é o vetor de estado e $\boldsymbol{f}_{e}$, o vetor de entradas. A Equação 3.2.38 apresenta a forma analítica de $M_{1}{ }^{-1}$, onde os termos de $M_{1}$ são representados conforme a Equação 3.2.37 e são calculados de acordo com a Equação 3.2.33. A Equação 3.2.39 apresenta o denominador $M_{1}^{-1}$ den, que, para que exista a matriz inversa de $M_{1}$, ou seja, para que esta seja não singular, deve ser não nulo. Já no caso da cinemática, as configurações do manipulador nas quais a matriz Jacobiana se torna singular são descritas com mais detalhes na Seção 3.3.

$$
\dot{v}=\left(M_{1}^{-1} M_{2}\right) \boldsymbol{v}+\left(M_{1}^{-1} J^{-T}\right) \boldsymbol{f}_{e}
$$




$$
M_{1}=\left[\begin{array}{lll}
M_{1_{11}} & M_{1_{12}} & M_{1_{13}} \\
M_{1_{21}} & M_{1_{22}} & M_{1_{23}} \\
M_{1_{31}} & M_{1_{32}} & M_{1_{33}}
\end{array}\right]
$$

$$
\begin{aligned}
& M_{1}^{-1}= \\
& =\frac{1}{M_{1}^{-1} \operatorname{den}}\left[\begin{array}{ccc}
M_{1_{22}} M_{1_{33}}-M_{1_{23}} M_{1_{32}} & -M_{1_{12}} M_{1_{33}}+M_{1_{13}} M_{1_{32}} & M_{1_{12}} M_{1_{23}}-M_{1_{13}} M_{1_{22}} \\
-M_{1_{21}} M_{1_{33}}+M_{1_{23}} M_{1_{31}} & M_{1_{11}} M_{1_{33}}-M_{1_{13}} M_{1_{31}} & -M_{1_{11}} M_{1_{23}}+M_{1_{13}} M_{1_{21}} \\
M_{1_{21}} M_{1_{32}}-M_{1_{22}} M_{1_{31}} & -M_{1_{11}} M_{1_{32}}+M_{1_{12}} M_{1_{31}} & M_{1_{11}} M_{1_{22}}-M_{1_{12}} M_{1_{21}}
\end{array}\right] \\
& M_{\text {den }}^{-1}=M_{1_{11}} M_{1_{22}} M_{1_{33}}-M_{1_{11}} M_{1_{23}} M_{1_{32}}-M_{1_{12}} M_{1_{21}} M_{1_{33}}+M_{1_{12}} M_{1_{23}} M_{1_{31}} \\
& +M_{1_{13}} M_{1_{21}} M_{1_{32}}-M_{1_{13}} M_{1_{22}} M_{1_{31}}
\end{aligned}
$$

\subsection{Condições de singularidade}

Para realizar diversas tarefas, o movimento de cada junta do manipulador deve ser cuidadosamente coordenado. Existem dois tipos de problemas de coordenação, chamados problemas diretos e inversos de velocidade. No problema direto de velocidade, as variações de entrada das juntas são dadas e o objetivo é encontrar o estado de velocidades da plataforma móvel. No problema inverso, o estado de velocidades é dado e as velocidades de entrada das juntas requeridas para produzir esta velocidade desejada têm que ser encontradas. A matriz Jacobiana é definida como a matriz que transforma as velocidades das juntas no espaço dos atuadores no estado de velocidades no espaço compreendido pela plataforma móvel.

A matriz Jacobiana é útil também em outras aplicações. Em algumas configurações do mecanismo a matriz Jacobiana pode perder seu posto (rank) completo. Estas condições são chamadas de singulares. Numa condição singular um mecanismo paralelo pode ganhar ou perder graus de liberdade. Uma importante limitação deste tipo de mecanismo é que as configurações de singularidade podem existir dentro de seu espaço de trabalho, no qual este ganha um ou mais graus de liberdade, perdendo completamente sua rigidez. Dependendo de qual matriz seja singular (Jacobiana direta ou Jacobiana inversa) o mecanismo 
pode estar em uma configuração singular da cinemática direta, inversa ou até de ambas (Tsai, L. W., 1999).

A análise da Jacobiana de manipuladores paralelos é um problema muito mais difícil do que o de manipuladores seriais porque existem diversos elos que formam certo número de cadeias fechadas.

Sendo as variáveis das juntas denotadas pelo vetor $\mathbf{q}$ e a localização da plataforma móvel descrita pelo vetor $\mathbf{x}$, então as restrições cinemáticas impostas pelos membros podem ser escritas de forma geral como

$$
\mathbf{f}(\mathbf{x}, \mathbf{q})=\mathbf{0}
$$

na qual f é uma função implícita $n$-dimensional de $\mathbf{q}$ e $\mathbf{x}$ e $\mathbf{0}$ é um vetor de zeros $n$ dimensional (Tsai, L. W., 1999).

Derivando a Equação 3.3.1 em relação ao tempo, obtém-se a relação entre as velocidades de entrada das juntas e as velocidades de saída da plataforma móvel como segue

$$
J_{x} \dot{\mathbf{x}}=J_{q} \dot{\mathbf{q}}
$$

na qual

$$
J_{x}=\frac{\partial \mathbf{f}}{\partial \mathbf{x}} \quad \text { e } J_{q}=-\frac{\partial \mathbf{f}}{\partial \mathbf{q}}
$$

A derivação acima leva a duas matrizes Jacobianas separadas. Portanto, a matriz Jacobiana global, $J$, pode ser escrita como

$$
\dot{\mathbf{q}}=J^{-1} \dot{\mathbf{x}}
$$

na qual $J^{-1}=J_{q}^{-1} J_{x}$. Devido à existência de duas matrizes Jacobianas (inversa e direta), um manipulador paralelo é dito em uma configuração singular quando $J$, $J^{-1}$ ou ambos são singulares. Assim podem-se identificar três tipos de singularidade (Tsai, L. W., 1999): 
1. Singularidade da cinemática inversa: Uma singularidade da cinemática inversa ocorre quando o determinante de $J^{1}$ é zero.

$$
\left|J^{-1}\right|=0
$$

Quando $J^{-1}$ é singular e o espaço nulo de $J^{-1}$ não é vazio, existem alguns vetores $\dot{\mathbf{q}}$ não-nulos que resultam em vetores $\dot{\mathbf{x}}$ iguais a zero. Movimentos infinitesimais da plataforma móvel em certas direções não podem ser realizados. Portanto, o mecanismo perde um ou mais graus de liberdade.

2. Singularidade da cinemática direta: Uma singularidade da cinemática direta ocorre quando o determinante de $J$ é zero.

$$
|J|=0
$$

Assumindo a presença de tal condição singular, com o espaço nulo de $J$ não vazio, existem alguns vetores $\dot{\mathbf{x}}$ não nulos que resultam em vetores $\dot{\mathbf{q}}$ iguais a zero. Isto é, a plataforma móvel pode possuir movimento infinitesimal em algumas direções enquanto os atuadores estão completamente bloqueados. Portanto, a plataforma móvel ganha um ou mais graus de liberdade. Em outras palavras, em uma configuração singular da cinemática direta, o manipulador não consegue resistir a forças e momentos em algumas direções. Condições de singularidade da cinemática direta ocorrem normalmente quando diferentes ramos das soluções da cinemática direta se encontram.

3. Singularidades combinadas: Uma singularidade combinada ocorre quando os determinantes de $J$ e $J^{-1}$ são ambos iguais a zero. Geralmente, este tipo de singularidade ocorre apenas em certos manipuladores com uma arquitetura cinemática peculiar. A plataforma móvel pode sofrer movimentos infinitesimais enquanto todos os atuadores estão travados. Por outro lado, também pode se manter estacionária enquanto que os atuadores realizam movimentos infinitesimais.

Uma avaliação de singularidades no manipulador pode ser feita pelo uso do número de condição $\lambda$ dado por 


$$
\lambda\left(J^{-1}\right)=\left\|J^{-1}\right\| \cdot\|J\|
$$

na qual $\|$.$\| é a norma-2 da matriz. Quanto mais próximo \lambda$ for de 1 , melhor condicionada é a matriz. Outro número importante neste tipo de avaliação é o número de condição de reciprocidade ( $r \lambda$; Equação 3.3.8), que é sempre menor ou igual a 1 .

$$
r \lambda\left(J^{-1}\right)=\frac{1}{\operatorname{norma1}\left(J^{-1}\right) \cdot \operatorname{norma1}(J)}
$$

Da mesma forma que $\lambda$, quanto mais próximo de 1 , melhor condicionada é a matriz. Porém, quanto mais próximo este número estiver de zero, mais próximo o mecanismo se encontra de uma condição de singularidade. Este último é um método mais eficiente, porém menos confiável, de estimar a condição de uma matriz. (Stamper, R. E., et al, 1997).

O mesmo tipo de análise poder ser feito para as matrizes dos derivativos das Jacobianas inversa $\left(J^{-1}\right)$ e direta $(\dot{J})$. Esta análise das singularidades dos derivativos da Jacobiana é comumente usada no estudo da rigidez destes mecanismos, como por exemplo, na modificação da rigidez ativa em determinada direção do espaço (Simaan, N., et al, 2003). 


\section{4 \\ Modelo dinâmico do sistema de atuação}

Neste capítulo será apresentado o sistema de atuação e o processo de obtenção de seu modelo dinâmico. Para a caracterização do modelo, seus parâmetros são obtidos através de testes experimentais.

\subsection{Modelo dinâmico de motores elétricos}

Motores elétricos de corrente contínua com campo constante controlados pela armadura (com escovas) podem ser representados pelo esquema da Figura 4.1.1, onde $V$, a tensão elétrica, e $i$, a corrente elétrica, caracterizam a potência de entrada e $T_{m}$, o torque no eixo do motor, e $\omega_{m}$, sua velocidade angular, caracterizam a potência de saída do sistema. Separando as partes elétrica e mecânica do motor, têm-se as representações apresentadas na Figura 4.1.2.a e 4.1.2.b, respectivamente, com seus correspondentes parâmetros (Speranza Neto, M., 2015).

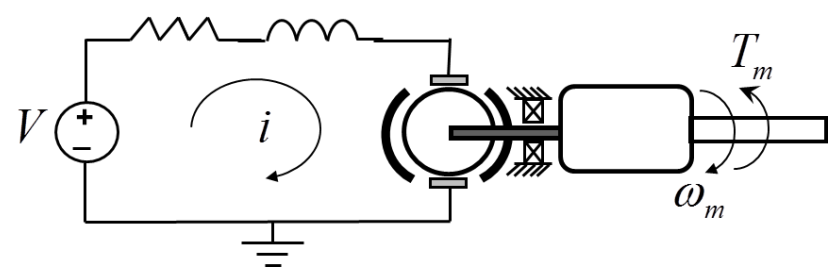

Figura 4.1.1: Variáveis de entrada e de saída do modelo de um motor elétrico CC com escovas.

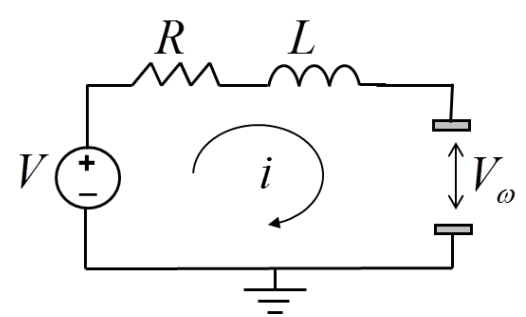

a)

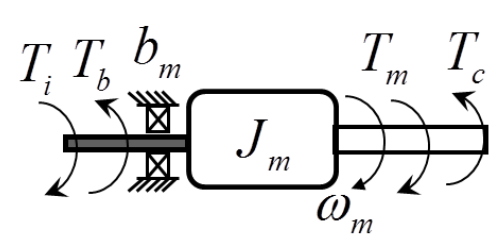

b)

Figura 4.1.2: Esquema da parte elétrica (a) e da parte mecânica (b) do motor CC. 
No modelo da Figura 4.1.2.a, sendo $V_{R}$ e $i_{R}$, a tensão e a corrente no resistor $R, V_{L}$ e $i_{L}$, a tensão e a corrente no indutor $L, V$, a tensão na fonte de alimentação e $V_{\omega}$, a tensão contra eletromotriz, as relações obtidas pela Lei dos Nós e pela Lei das Malhas são dadas pelas Equações 4.1.1 e 4.1.2. Já no modelo da Figura 4.1.2.b, sendo $T_{i}$, o torque eletromagnético, $T_{b}$, o torque dissipado por atrito viscoso nos mancais, $T_{J}$, o torque necessário para mover o rotor e $T_{c} \mathrm{o}$ torque necessário para outras cargas, a relação obtida pela Lei de Euler é dada pela Equação 4.1.3, sendo o torque do motor $\left(T_{m}\right)$ dado pela diferença entre $T_{i}$ e $T_{b}$ (Speranza Neto, M., 2015).

$$
\begin{aligned}
& i_{R}=i_{L}=i \\
& V-V_{R}-V_{L}-V_{\omega}=0 \\
& T_{J}=T_{i}-T_{b}-T_{c}=T_{m}-T_{c}
\end{aligned}
$$

As Equações 4.1.4 a 4.1.7 apresentam as equações constitutivas de $V_{R}, V_{L}$, $T_{J}$ e $T_{b}$, respectivamente, onde $R$ é a resistência elétrica interna do motor, $L$ é a indutância do motor, $J_{m}$, o momento de inércia de massa do rotor e $b_{m}$, o coeficiente de dissipação dos mancais do motor CC. Assim, substituindo estas equações constitutivas nas Equações 4.1.2 e 4.1.3, tem-se as Equações 4.1.8 e 4.1.9 (Speranza Neto, M., 2015).

$$
\begin{aligned}
& V_{R}=R i_{R} \\
& V_{L}=L \frac{d i_{L}}{d t} \\
& T_{J}=J_{m} \frac{d \omega_{m}}{d t} \\
& T_{b}=b_{m} \omega_{m}
\end{aligned}
$$




$$
\begin{aligned}
& L \frac{d i}{d t}=V-R i-V_{\omega} \\
& J_{m} \frac{d \omega_{m}}{d t}=T_{i}-b_{m} \omega_{m}-T_{C}
\end{aligned}
$$

O torque eletromagnético $T_{i}$ se relaciona com a corrente $\mathrm{i}$ do circuito do motor por meio da constante $K_{e}$, a constante eletromagnética do motor, que é proporcional ao campo magnético gerado $(B)$, ao comprimento do rotor $(l)$ e ao raio do rotor (r). A Equação 4.1.10 apresenta esta relação (Speranza Neto, M., 2015). Considerando uma transferência de potência ideal, ou seja, a potência elétrica $\left(P_{e l e}\right)$ igual à potência mecânica $\left(P_{m e c}\right)$, chega-se às relações apresentadas nas Equações 4.1.11 e 4.1.12. Esta última, relaciona a tensão contra eletromotriz à velocidade angular do rotor. As Equações 4.1.10 e 4.1.12 formam o acoplamento eletromecânico do motor (Speranza Neto, M., 2015).

$$
\begin{aligned}
& T_{i}=F_{i} r=i l B r=K_{e} i \\
& P_{m e c}=T_{i} \omega_{m}=K_{e} i \omega_{m}=P_{e l e}=V_{\omega} i \\
& V_{\omega}=K_{e} \omega_{m}
\end{aligned}
$$

Assim, unindo as Equações 4.1.8, 4.19, 4.1.10 e 4.1.12, tem-se o sistema de equações diferenciais ordinárias lineares de primeira ordem apresentado na Equação 4.1.13. A Figura 4.1.14 mostra a forma matricial deste sistema.

$$
\begin{aligned}
& \left\{\begin{array}{c}
\frac{d i}{d t}=\frac{1}{L}\left(V-R i-K_{e} \omega_{m}\right) \\
\frac{d \omega_{m}}{d t}=\frac{1}{J_{m}}\left(K_{e} i-b_{m} \omega_{m}-T_{c}\right)
\end{array}\right. \\
& {\left[\begin{array}{c}
i \\
\dot{\omega_{m}}
\end{array}\right]=\left[\begin{array}{cc}
\frac{-R}{L} & \frac{-K_{e}}{L} \\
\frac{K_{e}}{J_{m}} & \frac{-b_{m}}{J_{m}}
\end{array}\right]\left[\begin{array}{c}
i \\
\omega_{m}
\end{array}\right]+\left[\begin{array}{cc}
\frac{1}{L} & 0 \\
0 & \frac{1}{J_{m}}
\end{array}\right]\left[\begin{array}{c}
V \\
T_{c}
\end{array}\right]}
\end{aligned}
$$

Considerando que a dinâmica elétrica é muito mais rápida do que a dinâmica mecânica pode-se desprezar o valor de $L$, fazendo-o tender a zero. 
Assim, a primeira das Equações 4.1.13 fica como apresentado na Equação 4.1.15 e, substituindo esta na Equação 4.1.10, é obtida a relação da Equação 4.1.16. Substituindo a Equação 4.1.16 na expressão de $T_{m}$, tem-se a Equação 4.1.17.

$$
\begin{aligned}
& V-R i-K_{e} \omega_{m}=0 \Rightarrow i=\frac{1}{R} V-\frac{K_{e}}{R} \omega_{m} \\
& T_{i}=K_{e} i=\frac{K_{e}}{R} V-\frac{K_{e}^{2}}{R} \omega_{m} \\
& T_{m}=\frac{K_{e}}{R} V-\frac{K_{e}^{2}}{R} \omega_{m}-b_{m} \omega_{m}=\frac{K_{e}}{R} V-\frac{K_{e}{ }^{2}+R b_{m}}{R} \omega_{m}
\end{aligned}
$$

Assim, para um motor CC sem redutor e sem carga, desprezando a dinâmica elétrica, a relação do torque do motor com a velocidade angular e a tensão de alimentação é apresentada na Equação 4.1.18, sendo $k_{V}$ dado na Equação 4.1.19 e $k \omega$, na Equação 4.1.20. A Figura 4.1.3 apresenta o gráfico do comportamento descrito pela Equação 4.1.18 para várias tensões de alimentação.

$$
\begin{aligned}
& T_{m}=k_{V} V-k_{\omega} \omega_{m} \\
& k_{V}=\frac{K_{e}}{R} \\
& k_{\omega}=\frac{K_{e}{ }^{2}+R b_{m}}{R}
\end{aligned}
$$

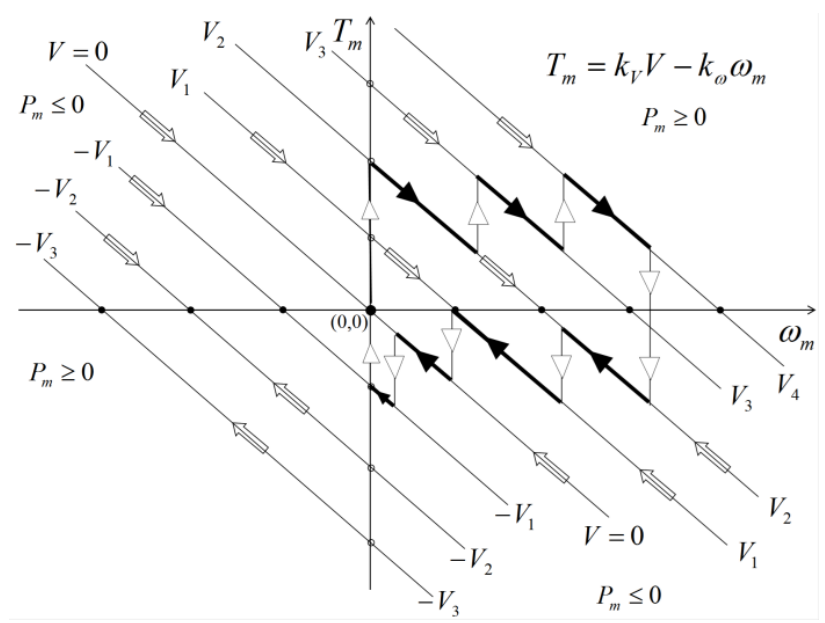

Figura 4.1.3: Curvas de comportamento de um motor CC com escovas. 
Reescrevendo a Equação 4.1.15 em função dos parâmetros $k_{i}$ e $k_{T}$, tem-se a Equação 4.1.21, sendo $k_{i}$ dado pela Equação 4.1.22 e $k_{T}$, pela Equação 4.1.23. A Figura 4.1.4 apresenta outras relações relevantes obtidas das curvas das Equações 4.1.18 e 4.1.21. Rearrumando as Equações 4.1.19, 4.1.20, 4.1.22 e 4.1.23, são obtidos $b_{m}, R$ e $K_{e}$ em função de $k_{V}, k \omega, k_{i}$ e $k_{T}$ (Equações 4.1.24 a 4.1.26).

$$
\begin{aligned}
& i=k_{i} V+k_{T} T_{m} \\
& k_{i}=\frac{b_{m}}{K_{e}{ }^{2}+R b_{m}} \\
& k_{T}=\frac{k_{V}}{k_{\omega}}=\frac{K_{e}}{K_{e}{ }^{2}+R b_{m}}
\end{aligned}
$$

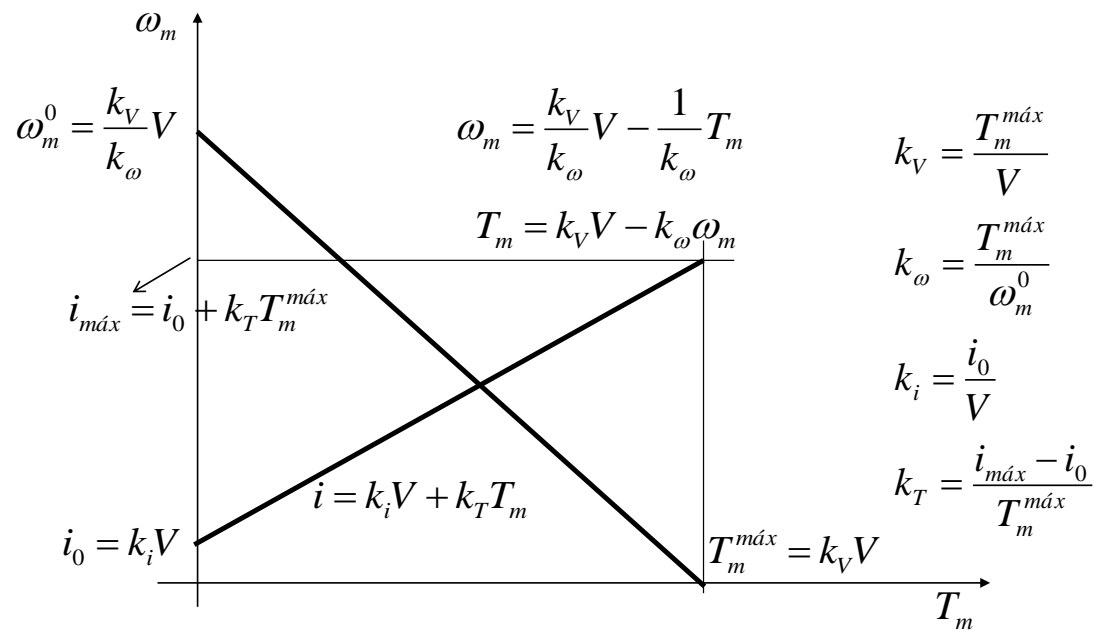

Figura 4.1.4: Relações de parâmetros das curvas de comportamento de um motor CC com escovas.

$$
\begin{aligned}
& b_{m}=\frac{k_{\omega} k_{i}}{k_{V} k_{T}+k_{i}} \\
& R=\frac{k_{T} k_{\omega}}{k_{V}\left(k_{V} k_{T}+k_{i}\right)} \\
& K_{e}=\frac{k_{T} k_{\omega}}{k_{V} k_{T}+k_{i}}
\end{aligned}
$$




\subsection{Descrição do sistema de atuação}

Um atuador linear elétrico é um dispositivo que converte o movimento de rotação de um motor em um movimento linear. São eficientes e têm uma vida útil longa com pouca ou nenhuma manutenção, além de terem uma instalação muito fácil, em comparação, por exemplo, com a de sistemas hidráulicos e ocupa muito menos espaço, uma vez que não necessita de bombas ou mangueiras.

Neste tipo de mecanismo, a velocidade angular do motor elétrico é transmitida por meio de um sistema de engrenagens a um parafuso de avanço, responsável por transformar este movimento rotacional em linear. Neste trabalho será usado o atuador linear elétrico marca LINAK, modelo LA12, curso de 100 $\mathrm{mm}$, alimentado com 24 VDC e passo do parafuso de avanço de $6 \mathrm{~mm}$ (Figura 4.2.1).

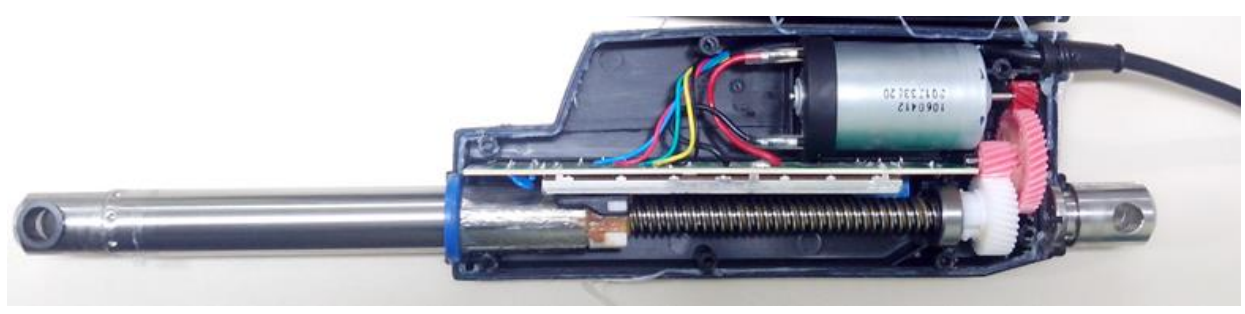

Figura 4.2.1: Atuador linear elétrico LINAK LA12.

Na Figura 4.2.2 um modelo esquemático com todos os componentes do atuador é apresentado. O motor elétrico transmite um torque $T_{m}$ que é convertido na velocidade angular $\omega_{m}$. A velocidade de rotação é transmitida às engrenagens e, posteriormente, ao parafuso de avanço. Observa-se que a velocidade angular $\omega_{A}$ na engrenagem $\mathrm{A}, \operatorname{com} z_{A}$ dentes, é a mesma velocidade do eixo do motor $\omega_{m}$. A transmissão da engrenagem A para engrenagem B1, com $z_{B 1}$ dentes, é $n_{A-B 1}=$ $z_{A} / Z_{B 1}$. A engrenagem $B 2$, com $Z_{B 2}$ dentes, possui a mesma velocidade angular de $\mathrm{B} 1$. A razão de transmissão das engrenagens $\mathrm{B} 2$ para $\mathrm{C}$, sendo este último com $z_{C}$ dentes, é $n_{B 2-C}={ }_{B 2} / z_{C}$. O parafuso de avanço $d$ possui uma velocidade angular $\omega_{C}$. Acoplada a haste do atuador, o movimento da rosca de transporte torna-se linear com velocidade $\dot{d}$. Esta possui a relação $n_{p}=\frac{1}{2 \pi} p N e$, onde $p$ é o passo do 
parafuso e $N e$, o número de entradas da rosca. A razão total de transmissão do sistema é dado por $\dot{d}=n_{p} n_{A-B 1} n_{B 2-C} \omega_{m}$.

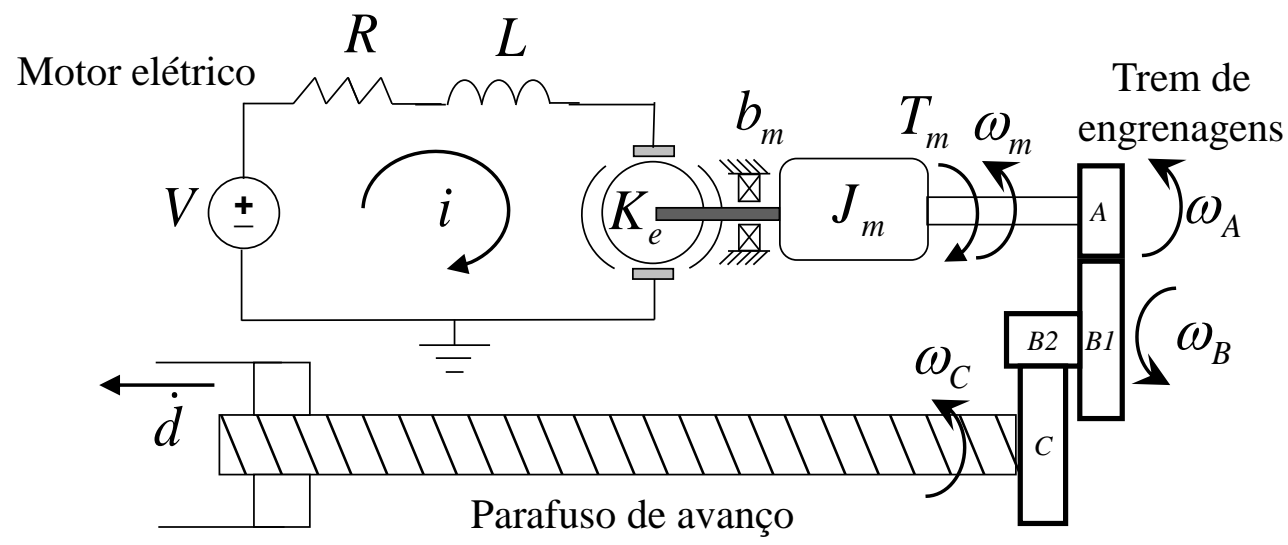

Figura 4.2.2: Esquema do atuador elétrico.

As Figuras 4.2.3 e 4.2.4 apresentam as curvas de desempenho do atuador velocidade (mm/s) x força (N) e corrente elétrica (A) $x$ força (N), respectivamente. A velocidade máxima do atuador é de $40 \mathrm{~mm} / \mathrm{s}$, em situação sem carga e havendo carga de 200 N, máxima força aplicável, sua velocidade é de 27 $\mathrm{mm} / \mathrm{s}$. Nesta situação, de acordo com o fabricante, a corrente elétrica chega a 1 A.

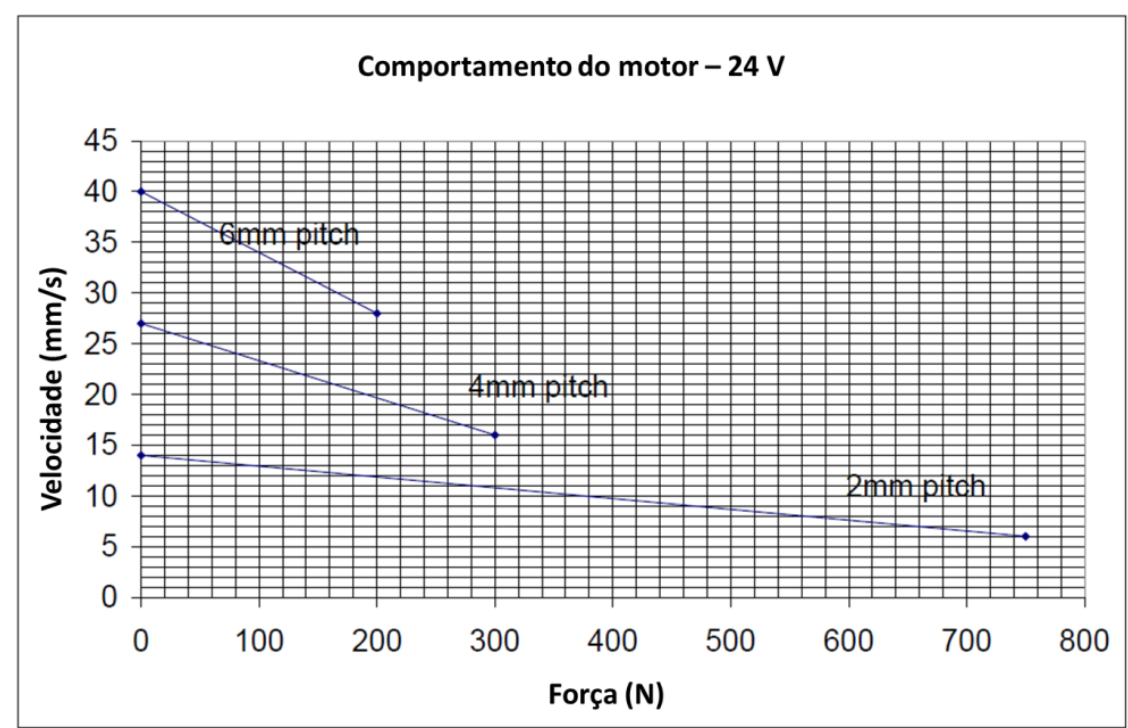

Figura 4.2.3: Curva velocidade $(\mathrm{mm} / \mathrm{s}) x$ força $(\mathrm{N})$ do atuador LINAK LA12. 


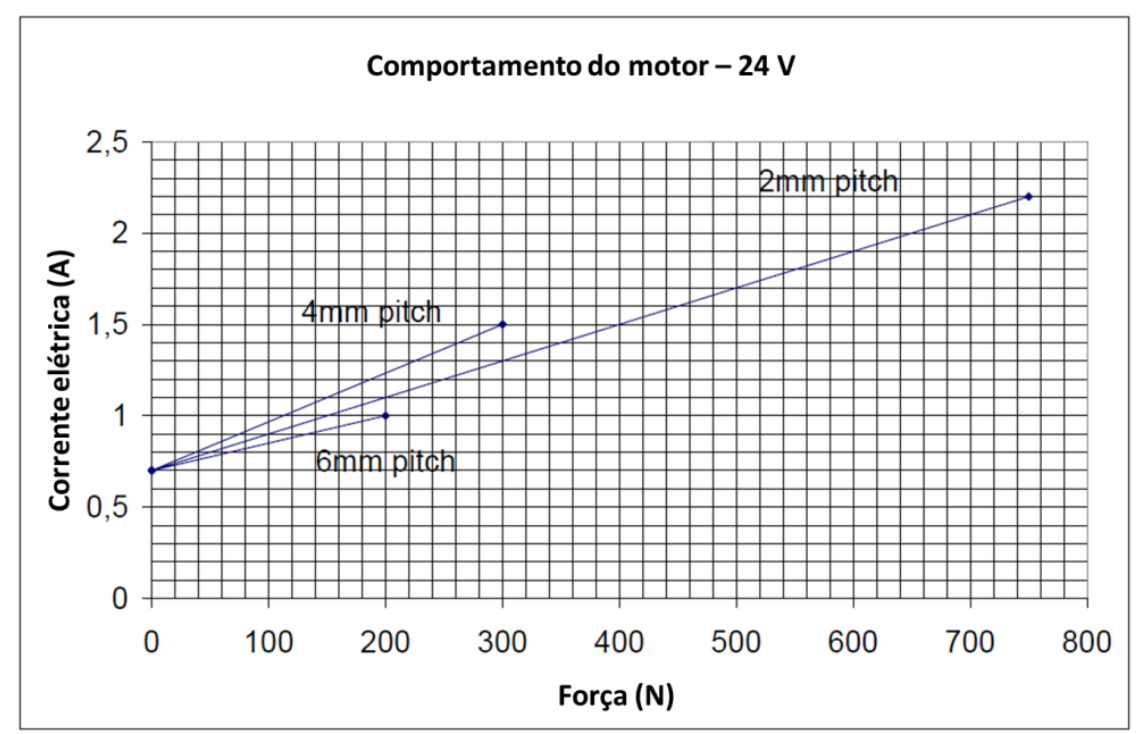

Figura 4.2.4: Curva corrente elétrica $(\mathrm{A}) x$ força $(\mathrm{N})$ do atuador LINAK LA12.

\subsection{Modelo dinâmico do sistema de atuação}

A entrada de tensão elétrica no motor elétrico é considerada como uma fonte esforço $(\mathrm{Se})$. O sistema de atuação apresenta os elementos resistivos $R_{i}, b_{m i}$, $b_{c i}$ e $b_{v i}$ devido à resistividade elétrica do motor e ao atrito viscoso e os elementos de inércia $L_{i}, J_{m i}, J_{c i}$ e $m_{A i}$ devido à indutância do motor elétrico, aos momentos de inércia de massa do eixo do motor e dos elementos do sistema de transmissão e à massa da haste do atuador. A representação gráfica permite a visualização das ligações entre os vários elementos do sistema. Todas as variáveis de esforço e de fluxo estão apresentadas no modelo em grafos de ligação da Figura 4.3.1 ( $i=1,2$, 3). São ao todo 16 ligações e, portanto, 32 variáveis no modelo de cada atuador.

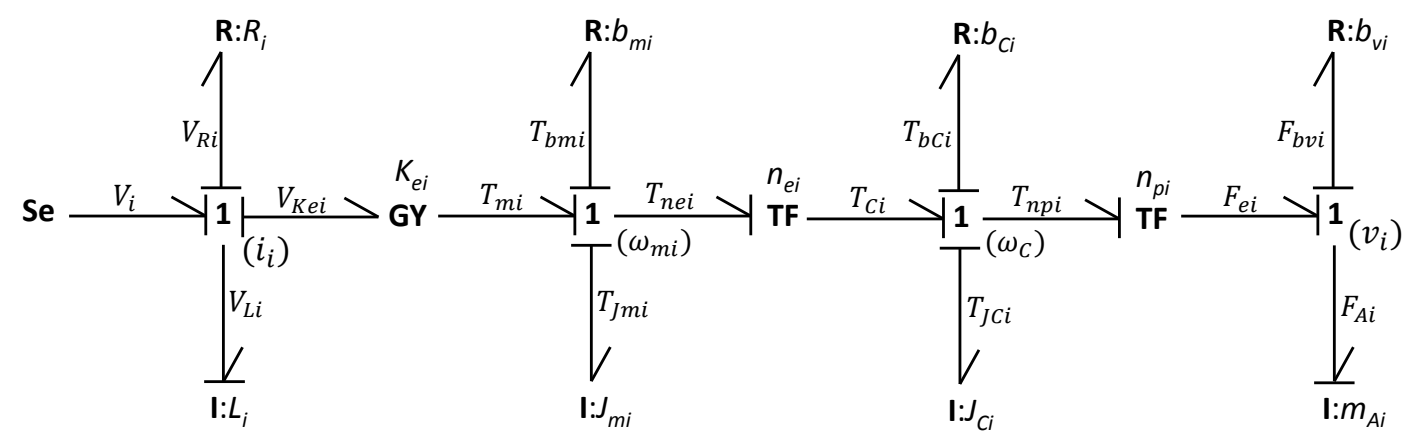

Figura 4.3.1: Grafos de ligação do modelo dinâmico do atuador linear elétrico. 
As Equações 4.3.1 e 4.3.2 apresentam as equações constitutivas dos elementos de inércia com causalidade integral (natural) e as Equações 4.3.3 e 4.3.4 apresentam as equações constitutivas dos elementos de inércia com causalidade diferencial (forçada). Já as Equações 4.3.5 a 4.3.8 apresentam as equações constitutivas dos elementos resistores.

$$
\begin{aligned}
& i_{i}=\frac{1}{L_{i}} \int V_{L i} d t \\
& v_{i}=\frac{1}{m_{A i}} \int F_{A i} d t \\
& T_{J m i}=J_{m i} \frac{d \omega_{m i}}{d t} \\
& T_{J C i}=J_{C i} \frac{d \omega_{C i}}{d t} \\
& V_{R i}=R_{i} i_{i} \\
& T_{b m i}=b_{m i} \omega_{m i} \\
& T_{b C i}=b_{C i} \omega_{C i} \\
& F_{b v i}=b_{v i} v_{i}
\end{aligned}
$$

Os conjuntos de Equações 4.3.9 a 4.3.11 apresentam as equações constitutivas dos elementos giradores e transformadores (GY e TF, respectivamente). Já as Equações 4.3.12 a 4.3.15 apresentam as equações das estruturas de junção (no caso, apenas junções 1).

$$
\begin{gathered}
\left\{\begin{array}{c}
V_{K e i}=K_{e i} \omega_{m i} \\
T_{m i}=K_{e i} i_{i}
\end{array}\right. \\
\left\{\begin{array}{l}
T_{C i}=T_{n e i} / n_{e i} \\
\omega_{m i}=\omega_{C i} / n_{e i}
\end{array}\right.
\end{gathered}
$$




$$
\begin{aligned}
& \left\{\begin{array}{c}
F_{e i}=T_{n p i} / n_{p i} \\
\omega_{C i}=v_{i} / n_{p i}
\end{array}\right. \\
& V_{L i}=V_{i}-V_{R i}-V_{K e i} \\
& T_{n e i}=T_{m i}-T_{b m i}-T_{J m i} \\
& T_{n p i}=T_{C i}-T_{b C i}-T_{J C i} \\
& F_{A i}=F_{e i}-F_{b v i}
\end{aligned}
$$

Substituindo as Equações 4.3.5 e 4.3.9 na Equação 4.3.12 e substituindo esta na Equação 4.3.1, é obtida a Equação 4.3.16. Já escrevendo a Equação 4.3.2 e substituindo nesta as devidas equações de estrutura de junção e equações constitutivas, é obtida a Equação 4.3.17. Eliminando os denominadores, esta Equação de Estado fica como apresentado na Equação 4.3 .18 e, eliminando a malha algébrica, fica como na Equação 4.3.19.

$$
\begin{aligned}
& L_{i} \frac{d i_{i}}{d t}=V_{i}-R_{i} i_{i}-K_{e i} \omega_{m i} \\
& m_{A i} \frac{d v_{i}}{d t}= \\
& =\frac{K_{e i} i_{i}}{n_{p i} n_{e i}}-\frac{b_{m i} v_{i}}{n_{p i}{ }^{2} n_{e i}{ }^{2}}-\frac{J_{m i}}{n_{p i}{ }^{2} n_{e i}{ }^{2}} \frac{d v_{i}}{d t}-\frac{b_{C i} v_{i}}{n_{p i}{ }^{2}}-\frac{J_{C i}}{n_{p i}{ }^{2}} \frac{d v_{i}}{d t}-b_{v i} v_{i} \\
& m_{A i}\left(n_{p i}{ }^{2} n_{e i}{ }^{2}\right) \frac{d v_{i}}{d t}= \\
& =-\left(J_{C i} n_{e i}{ }^{2}+J_{m i}\right) \frac{d v_{i}}{d t}-\left(b_{C i} n_{e i}{ }^{2}+b_{m i}+b_{v i} n_{p i}{ }^{2} n_{e i}{ }^{2}\right) v_{i}+K_{e i} n_{p i} n_{e i} i_{i}
\end{aligned}
$$

$$
\begin{aligned}
& \left(m_{A i} n_{p i}{ }^{2} n_{e i}{ }^{2}+J_{m i}+J_{C i} n_{e i}{ }^{2}\right) \frac{d v_{i}}{d t}= \\
& =K_{e i} n_{p i} n_{e i} i_{i}-\left(b_{C i} n_{e i}{ }^{2}+b_{m i}+b_{v i} n_{p i}{ }^{2} n_{e i}{ }^{2}\right) v_{i}
\end{aligned}
$$


A eliminação da dinâmica elétrica, que possui constantes de tempo ordens de grandeza menores que os da dinâmica mecânica, é feita considerando os valores de $L_{i}$ aproximadamente iguais a zero (para $i=1,2$ e 3 ). Com isso, a Equação 4.3.16 fica como apresentado na Equação 4.3.20 e, substituindo esta na Equação 4.3.19, é obtida a Equação de Estado 4.3.21.

$$
\begin{aligned}
& i_{i}=\frac{V_{i}}{R_{i}}-\frac{K_{e i} \omega_{m i}}{R_{i}}=\frac{V_{i}}{R_{i}}-\frac{K_{e i} v_{i}}{R_{i} n_{p i} n_{e i}} \\
& \left(m_{A i} n_{p i}{ }^{2} n_{e i}{ }^{2}+J_{m i}+J_{C i} n_{e i}{ }^{2}\right) \frac{d v_{i}}{d t}= \\
& =\frac{K_{e i} n_{p i} n_{e i} V_{i}}{R_{i}}-\left(b_{C i} n_{e i}{ }^{2}+b_{m i}+b_{v i} n_{p i}{ }^{2} n_{e i}{ }^{2}+\frac{K_{e i}{ }^{2}}{R_{i}}\right) v_{i}
\end{aligned}
$$

\subsubsection{Modelo dinâmico acoplado}

A Figura 4.3.2 mostra o modelo dinâmico acoplado representado usando a técnica de grafos de ligação e a Figura 4.3.3 apresenta este mesmo modelo usando grafos multi-ligação. O modelo dos atuadores é acoplado ao modelo de plataforma plana através das junções 1 que representam as velocidades de saída do atuador, $v_{i}$, com i = 1, 2 e 3 . A dinâmica dos atuadores será discutida com mais detalhes no Capítulo 4.

Como há uma inversão de causalidade no elemento de inércia $m_{A}$ (de causalidade forçada passa a causalidade natural), a Equação 4.3.2 tem que ser escrita conforme a Equação 4.3.22. A Equação de junção 14.3 .15 fica como apresentado na Equação 4.3.23.

$$
\begin{aligned}
& F_{A i}=m_{A i} \frac{d v_{i}}{d t} \\
& F_{i}=F_{b v i}+F_{A i}-F_{e i}=b_{v i} v_{i}+m_{A i} \frac{d v_{i}}{d t}-T_{n p i} / n_{p i}
\end{aligned}
$$




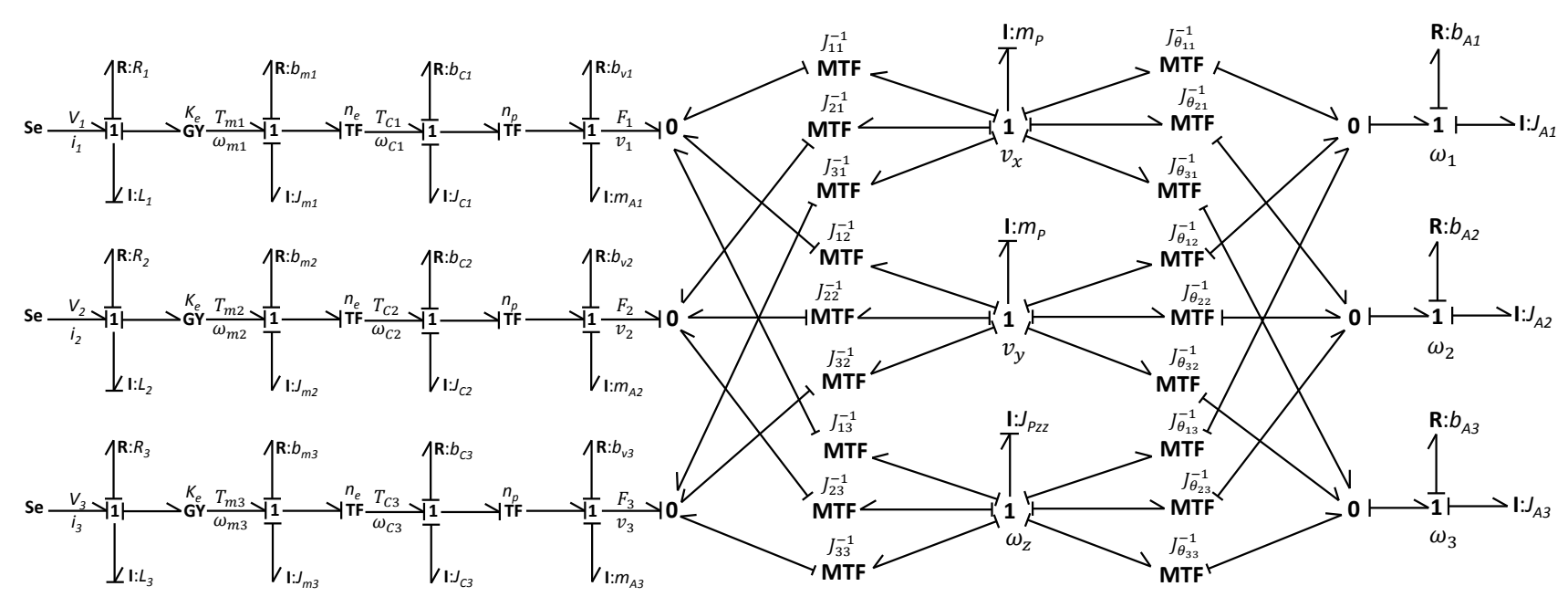

Figura 4.3.2: Representação completa do mecanismo paralelo 3-RPR em grafos de ligação.

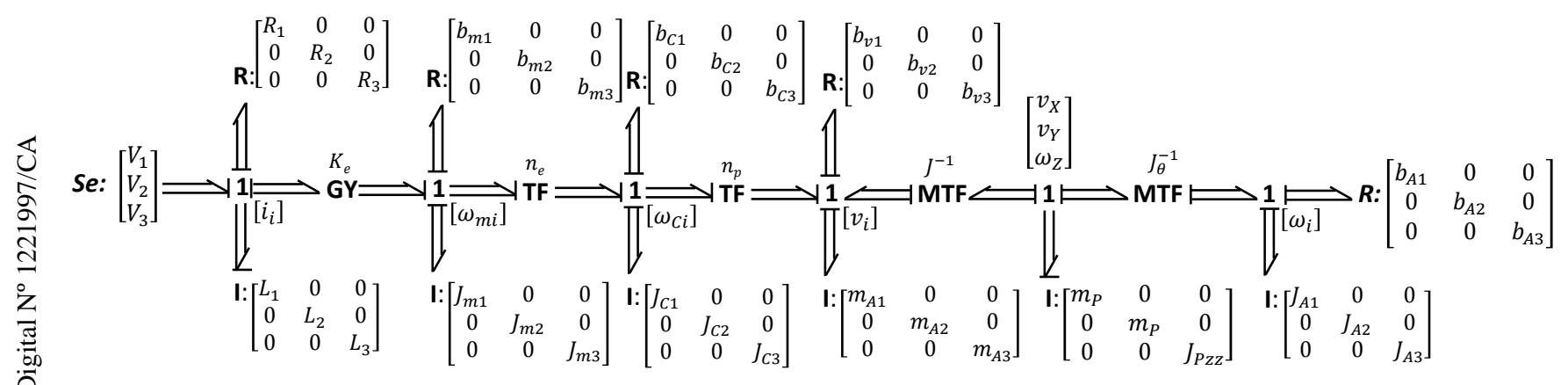

Figura 4.3.3: Representação completa do mecanismo paralelo 3-Rㅛ em grafos multi-ligação.

Substituinado na Equação 4.3.23 as Equações 4.3.14, 4.3.10 e 4.3.13, nesta ordem, é obtida a Equação 4.3.24. Substituindo nesta última as Equações 4.3.9, 4.3.6 e 4.3.3, chega-se à Equação 4.3.25. Considerando que a dinâmica elétrica é muito mais rápida do que a dinâmica mecânica pode-se desprezar o valor de $L$, fazendo-o tender a zero. Assim, usando a Equação 4.1.15 na Equação 4.3.25 é obtida a Equação 4.3.26 e, deixando as variáveis de entrada e saída em evidência, chega-se à Equação 4.3.27.

$$
\begin{aligned}
& F_{i}=b_{v i} v_{i}+m_{A i} \frac{d v_{i}}{d t}-\frac{\left(T_{m i}-T_{b m i}-T_{J m i}\right)}{n_{e i} n_{p i}}+\frac{b_{C i} v_{i}}{n_{p i}{ }^{2}}+\frac{J_{C i}}{n_{p i}{ }^{2}} \frac{d v_{i}}{d t} \\
& F_{i}=\left(b_{v i}+\frac{b_{C i}}{n_{p i}{ }^{2}}\right) v_{i}+\left(m_{A i}+\frac{J_{C i}}{n_{p i}{ }^{2}}\right) \frac{d v_{i}}{d t}-\frac{K_{e i} i_{i}}{n_{e i} n_{p i}}+\frac{b_{m i} \omega_{m i}}{n_{e i} n_{p i}}+\frac{J_{m i}}{n_{e i} n_{p i}} \frac{d \omega_{m i}}{d t}
\end{aligned}
$$




$$
\begin{aligned}
& F_{i}=\left(b_{v i}+\frac{b_{C i}}{n_{p i}{ }^{2}}\right) v_{i}+\left(m_{A i}+\frac{J_{C i}}{n_{p i}{ }^{2}}\right) \frac{d v_{i}}{d t}-\frac{K_{e i} V_{i}}{n_{e i} n_{p i} R_{i}}+\frac{K_{e i}{ }^{2} v_{i}}{n_{e i}{ }^{2} n_{p i}{ }^{2} R_{i}}+\frac{b_{m i} v_{i}}{n_{e i}{ }^{2} n_{p i}{ }^{2}}+ \\
& \frac{J_{m i}}{n_{e i}{ }^{2} n_{p i}{ }^{2}} \frac{d v_{i}}{d t} \\
& F_{i}=\left(b_{v i}+\frac{b_{C i}}{n_{p i}{ }^{2}}+\frac{K_{e i}{ }^{2}}{n_{e i}{ }^{2} n_{p i}{ }^{2} R_{i}}+\frac{b_{m i}}{n_{e i}{ }^{2} n_{p i}{ }^{2}}\right) v_{i}+\left(m_{A i}+\frac{J_{C i}}{n_{p i}{ }^{2}}+\frac{J_{m i}}{n_{e i}{ }^{2} n_{p i}{ }^{2}}\right) \frac{d v_{i}}{d t}- \\
& \frac{K_{e i} V_{i}}{n_{e i} n_{p i} R_{i}}
\end{aligned}
$$

Renomeando os termos da Equação 4.3.27, tem-se a Equação 4.3.28, onde $B_{A v i}, M_{A a i}$ e $K_{V i}$ são definidos pelas Equações 4.3.29 a 4.3.31, respectivamente.

$$
\begin{aligned}
& F_{i}=B_{A v i} v_{i}+M_{A a i} \dot{v}_{l}-K_{V i} V_{i} \\
& B_{A v i}=b_{v i}+\frac{b_{C i}}{n_{p i}{ }^{2}}+\frac{K_{e i}{ }^{2}}{n_{e i}{ }^{2} n_{p i}{ }^{2} R_{i}}+\frac{b_{m i}}{n_{e i}{ }^{2} n_{p i}{ }^{2}} \\
& M_{A a i}=m_{A i}+\frac{J_{C i}}{n_{p i}{ }^{2}}+\frac{J_{m i}}{n_{e i}{ }^{2} n_{p i}{ }^{2}} \\
& K_{V i}=\frac{K_{e i}}{n_{e i} n_{p i} R_{i}}
\end{aligned}
$$

Substituindo as Equações 4.3.23 e 3.2.20 nas Equações 3.2.21 a 3.2.23, obtém-se a Equação 4.3.32. A matriz dos elementos de inércia da plataforma móvel é definida pela Equação 3.2.25. Substituindo as equações constitutivas com causalidade diferencial na Equação 4.3.32, tem-se a Equação 4.3.33, onde $J_{A}$ e $B_{A}$ são definidos nas Equações 3.2.29 e 3.2.30, respectivamente. Já $S_{e}, K_{V}, B_{A v}$ e $M_{A a}$ são definidos pelas Equações 3.2.34 a 3.2.37, respectivamente.

$$
\left[\begin{array}{ccc}
m_{P} & 0 & 0 \\
0 & m_{P} & 0 \\
0 & 0 & J_{P Z Z}
\end{array}\right]\left[\begin{array}{l}
a_{X} \\
a_{Y} \\
\alpha_{Z}
\end{array}\right]=-J^{-T}\left[\begin{array}{l}
B_{A v 1} v_{1}+M_{A a 1} \dot{v}_{1}-K_{V 1} V_{1} \\
B_{A v 2} v_{2}+M_{A a 2} \dot{v}_{2}-K_{V 2} V_{2} \\
B_{A v 3} v_{3}+M_{A a 3} v_{3}-K_{V 3} V_{3}
\end{array}\right]-J_{\theta}^{-T}\left[\begin{array}{l}
M_{A 1}+M_{A \theta 1} \\
M_{A 2}+M_{A \theta 2} \\
M_{A 3}+M_{A \theta 3}
\end{array}\right]
$$




$$
\begin{aligned}
M_{P} \dot{\boldsymbol{v}} & =J^{-T} K_{V} \boldsymbol{S}_{e}-J^{-T} B_{A v} \boldsymbol{v}_{A}-J^{-T} M_{A a} \dot{\boldsymbol{v}}_{A}-J_{\theta}^{-T} J_{A} \dot{\boldsymbol{\omega}}_{A}-J_{\theta}^{-T} B_{A} \boldsymbol{\omega}_{A} \\
\boldsymbol{S}_{e} & =\left[\begin{array}{l}
V_{1} \\
V_{2} \\
V_{3}
\end{array}\right] \\
K_{V} & =\left[\begin{array}{ccc}
K_{V 1} & 0 & 0 \\
0 & K_{V 2} & 0 \\
0 & 0 & K_{V 3}
\end{array}\right] \\
B_{A v} & =\left[\begin{array}{ccc}
B_{A v 1} & 0 & 0 \\
0 & B_{A v 2} & 0 \\
0 & 0 & B_{A v 3}
\end{array}\right] \\
M_{A a} & =\left[\begin{array}{ccc}
M_{A a 1} & 0 & 0 \\
0 & M_{A a 2} & 0 \\
0 & 0 & M_{A a 3}
\end{array}\right]
\end{aligned}
$$

Substituindo as equações dos derivativos das matrizes Jacobianas (3.1.22 e 3.1.28) na Equação 4.3.33 são obtidas as Equações de Estado (4.3.38). Nota-se a existência de malhas algébricas associadas à existência de elementos armazenadores. A Equação 4.3.39 apresenta o primeiro passo para a eliminação desta malha.

$$
\begin{aligned}
& M_{P} \dot{\boldsymbol{v}}=J^{-T} \boldsymbol{S}_{e}-J^{-T} B_{A v} J^{-1} \boldsymbol{v}-J^{-T} M_{A a}\left(J^{-1} \boldsymbol{v}+J^{-1} \dot{\boldsymbol{v}}\right)--J_{\theta}^{-T} J_{A}\left(J_{\theta}^{-1} \boldsymbol{v}+\right. \\
& \left.J_{\theta}^{-1} \dot{\boldsymbol{v}}\right)-J_{\theta}^{-T} B_{A} J_{\theta}^{-1} \boldsymbol{v} \\
& M_{P} \dot{\boldsymbol{v}}+J^{-T} M_{A a} J^{-1} \dot{\boldsymbol{v}}+J_{\theta}^{-T} J_{A} J_{\theta}^{-1} \dot{\boldsymbol{v}}= \\
& =-J^{-T} B_{A v} J^{-1} \boldsymbol{v}-J^{-T} M_{A a} J^{\dot{-1}} \boldsymbol{v}-J_{\theta}^{-T} J_{A} J_{\theta}^{\dot{1}} \boldsymbol{v}-J_{\theta}^{-T} B_{A} J_{\theta}^{-1} \boldsymbol{v}+J^{-T} \boldsymbol{S}_{e}
\end{aligned}
$$

Considerando

$$
M_{3}=M_{P}+J^{-T} M_{A a} J^{-1}+J_{\theta}^{-T} J_{A} J_{\theta}^{-1}
$$


$\mathrm{e}$

$$
M_{4}=-J^{-T} B_{A v} J^{-1}-J^{-T} M_{A a} J^{\dot{-1}}-J_{\theta}^{-T} J_{A} J_{\theta}^{\dot{-1}}-J_{\theta}^{-T} B_{A} J_{\theta}^{-1}
$$

tem-se

$$
M_{3} \dot{v}=M_{4} v+J^{-T} S_{e}
$$

Assim, chega-se ao Modelo de Estado, no qual $\boldsymbol{v}$ é o vetor de estado e $\boldsymbol{S}_{e}$, o vetor de entradas (Equação 4.3.43). O procedimento para inversão da matriz $M_{3}$ é o mesmo descrito no Item 3.2.2 para a matriz $M_{1}$ (Equações 3.2.38 e 3.2.39).

$$
\dot{v}=\left(M_{3}{ }^{-1} M_{4}\right) v+\left(M_{3}{ }^{-1} J^{-T}\right) \boldsymbol{S}_{e}
$$

\subsection{Curvas de desempenho do motor elétrico}

Para analisar o comportamento do motor, foi utilizado um dinamômetro construído especialmente para análise de pequenos motores de corrente contínua do Laboratório de Desenvolvimento de Sistemas Mecatrônicos (Figura 4.4.1).

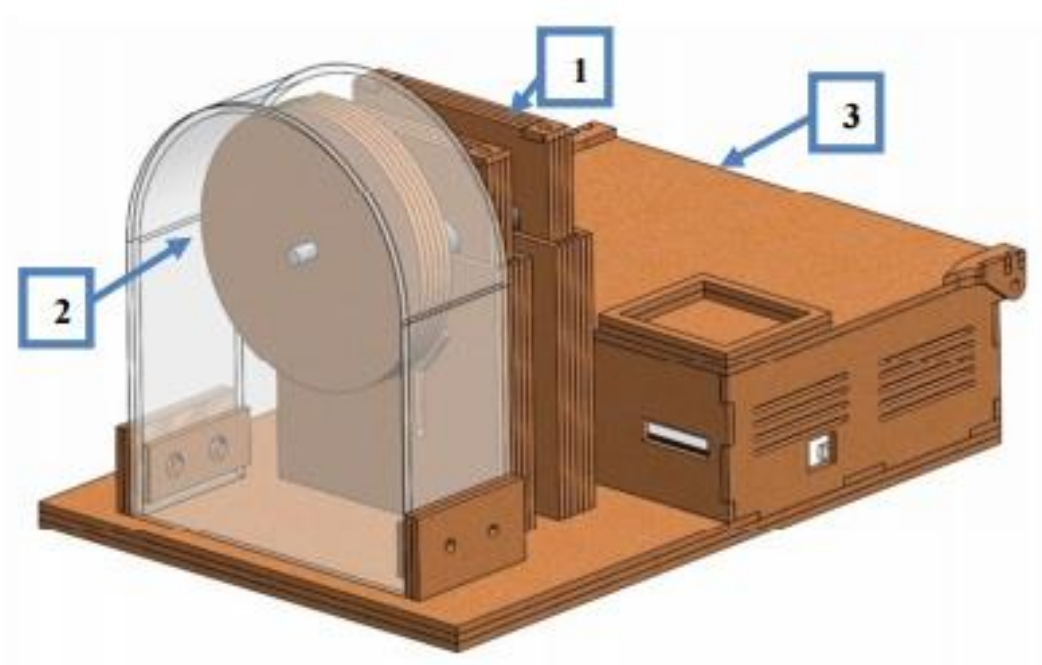

Figura 4.4.1: Dinamômetro de motores de corrente contínua. 
O motor é fixado no dinamômetro (1) e tem seu eixo acoplado a um disco de inércia, protegido por uma capa de acrílico (2). Neste disco encontra-se o ímã do sensor de efeito Hall, responsável pela medição de velocidade angular. A alimentação do motor pode ser feita por uma bateria ou por uma fonte regulável e um sensor de corrente é acoplado ao circuito de alimentação e comando (3). $\mathrm{Na}$ unidade de controle do dinamômetro, se encontra um micro controlador, que processa os sinais dos sensores. $\mathrm{O}$ microcontrolador recebe os sinais de comando por meio de um programa de computador (LabView) e os envia devidamente processados ao circuito elétrico de acionamento. Com o dinamômetro em operação (eixo do motor adquire torque e velocidade angular, ou seja, potência) os sinais dos sensores (velocidade angular, tensão e corrente elétrica) são enviados ao microcontrolador que, por sua vez, os reenvia processados ao programa MatLab, que mostra na tela as curvas de comportamento do motor testado.

Primeiramente foram feitos testes para entradas no motor em tensão constante dada diretamente por uma fonte chaveada. Para cada tensão de teste $(6$, 12, 18 e 24 VDC), foi medida uma curva característica do motor (Figuras 4.4 .2 a 4.4.5, respectivamente), onde são apresentadas as grandezas potência (em W), corrente (em A), velocidade angular (em rad/s) e eficiência do motor (em \%) em função do torque (em N.m). Com estas curvas, foi elaborada a curva torque $\mathrm{x}$ velocidade angular para estes quatro diferentes níveis de tensão (Figura 4.4.6).

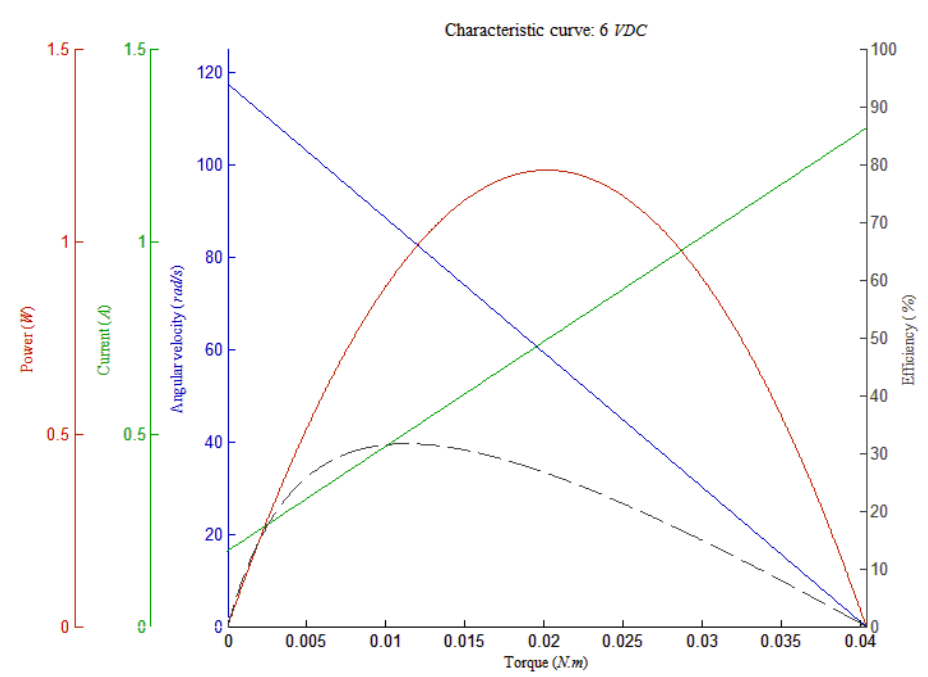

Figura 4.4.2: Curvas características do motor elétrico para 6 VDC. 


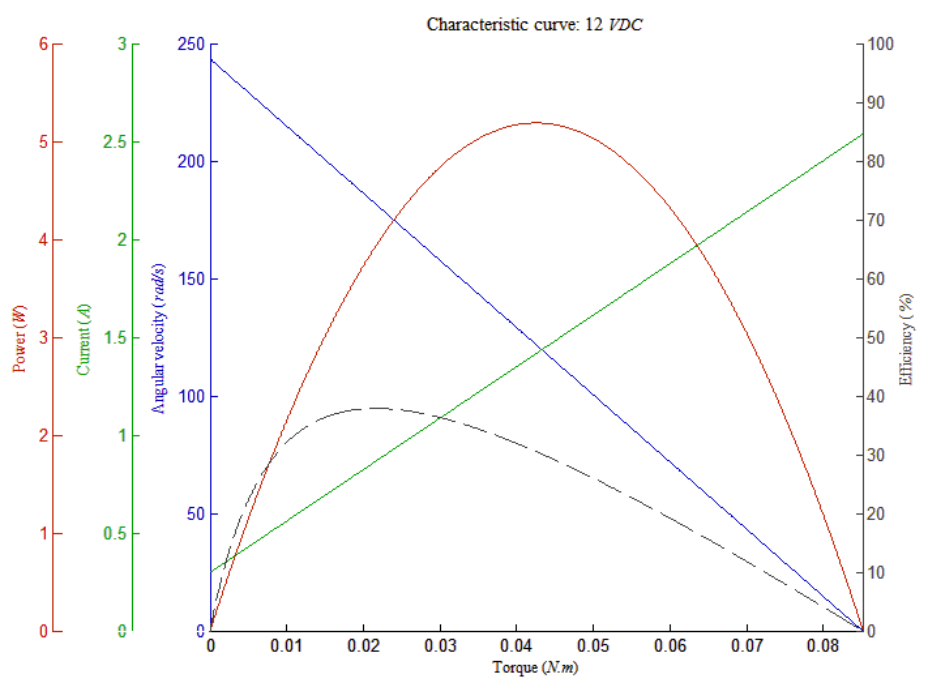

Figura 4.4.3: Curvas características do motor elétrico para 12 VDC.

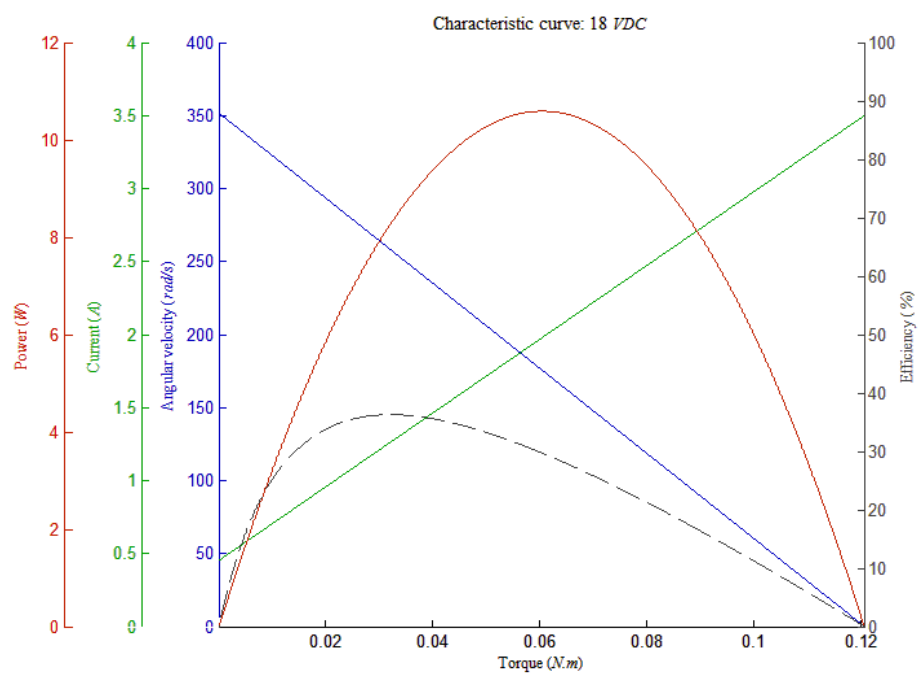

Figura 4.4.4: Curvas características do motor elétrico para 18 VDC.

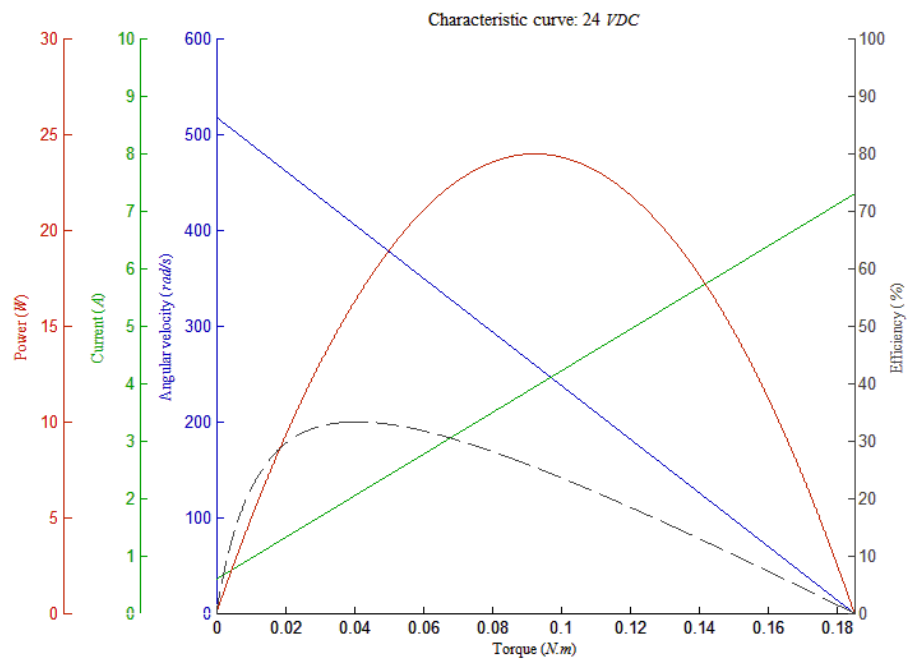

Figura 4.4.5: Curvas características do motor elétrico para 24 VDC. 


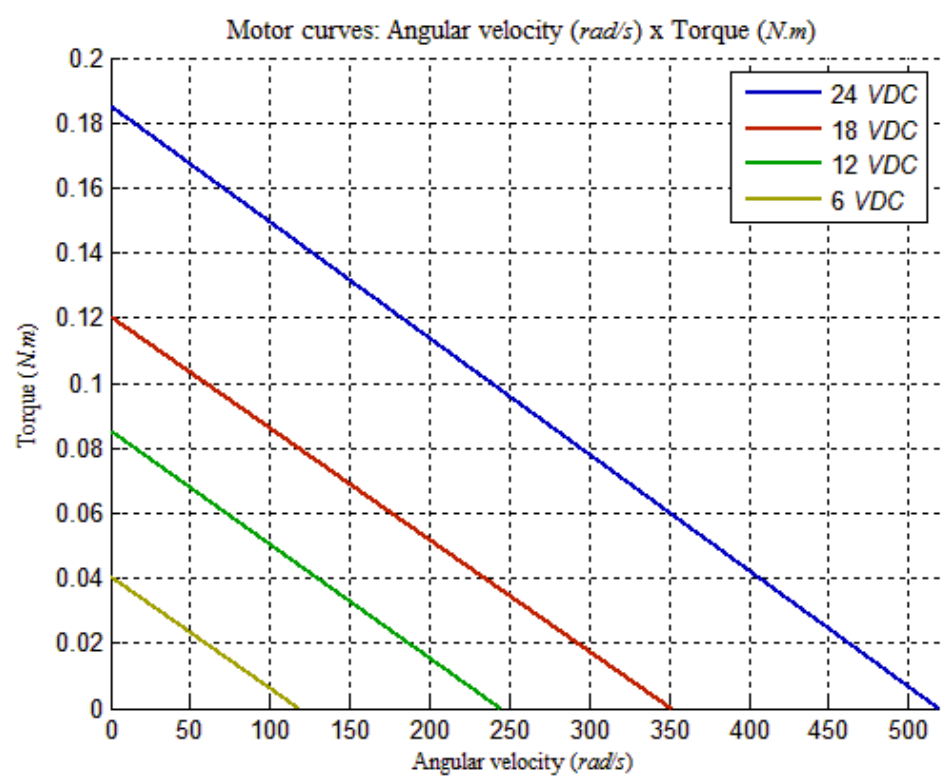

Figura 4.4.6: Curvas torque x velocidade angular para o controle do motor elétrico usando uma fonte CC.

$\mathrm{O}$ conjunto de Equações 4.4.1 apresenta as equações das curvas torque $\mathrm{x}$ velocidade angular para obtenção dos valores de $k_{V(D C)}$ e $k_{\omega(D C)}$. As Equações 4.4.2 e 4.4.3 apresentam os valores médios de $k_{V(D C)}$ e $k_{\omega(D C)}$, respectivamente, com suas devidas incertezas. Já o conjunto de Equações 4.4.4 apresenta as equações das curvas corrente x torque, para obtenção dos valores de $k_{i(D C)}$ e $k_{T(D C)}$. As Equações 4.4.5 e 4.4.6 apresentam os valores médios de $k_{i(D C)}$ e $k_{T(D C)}$, respectivamente.

$$
\begin{aligned}
& \left\{\begin{array}{c}
\tau_{6 V}=-3,437 \cdot 10^{-4} \omega_{6 V}+0,0404 \\
\tau_{12 V}=-3,498 \cdot 10^{-4} \omega_{12 V}+0,0852 \\
\tau_{18 V}=-3,431 \cdot 10^{-4} \omega_{18 V}+0,1205 \\
\tau_{24 V}=-3,571 \cdot 10^{-4} \omega_{24 V}+0,1850
\end{array}\right. \\
& k_{V(D C)}=7,057 \cdot 10^{-3} \pm 9,427 \cdot 10^{-4} \text { N.m/V } \\
& k_{\omega(D C)}=3,484 \cdot 10^{-4} \pm 1,305 \cdot 10^{-5} \text { N.m.s } / \mathrm{rad}
\end{aligned}
$$




$$
\begin{aligned}
& \left\{\begin{array}{c}
i_{6 V}=19,570 \tau_{6 V}+0,1961 \\
i_{12 V}=20,300 \tau_{12 V}+0,2966 \\
i_{18 V}=19,510 \tau_{18 V}+0,4559 \\
i_{24 V}=21,590 \tau_{24 V}+0,5844
\end{array}\right. \\
& k_{i(D C)}=2,677.10^{-2} \pm 7,926 \cdot 10^{-3} \mathrm{~A} / \mathrm{V} \\
& k_{T(D C)}=\frac{k_{V}}{k_{\omega}}=20,241 \pm 1,930 \mathrm{~A} / \mathrm{N} . \mathrm{m}
\end{aligned}
$$

Para controlar o motor elétrico do atuador linear será usado um controlador de velocidade marca Pololu, modelo MC33926 (Figura 4.4.7). Assim, o acionamento do motor será feito a partir de uma onda quadrada com frequência constante de $500 \mathrm{~Hz}$, amplitude de 24 VDC (sinal de 5 VDC amplificado) e seleção do nível de tensão equivalente no motor via modulação da largura de pulso (PWM - Pulse-Width Modulation) do sinal. A Figura 4.4.8 apresenta o painel de controle virtual usado no programa LabView para a execução destes testes.
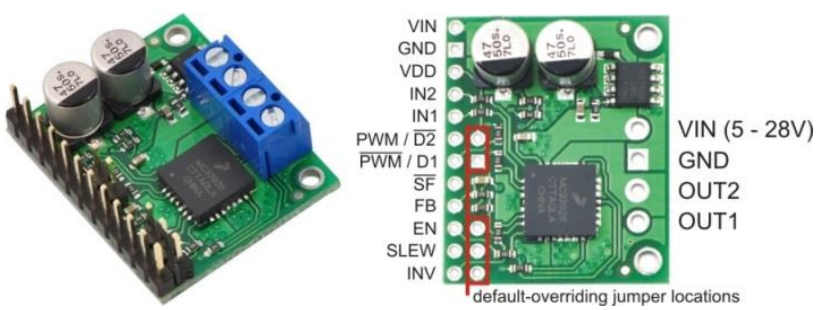

Figura 4.4.7: Controlador MC33926, da Pololu.

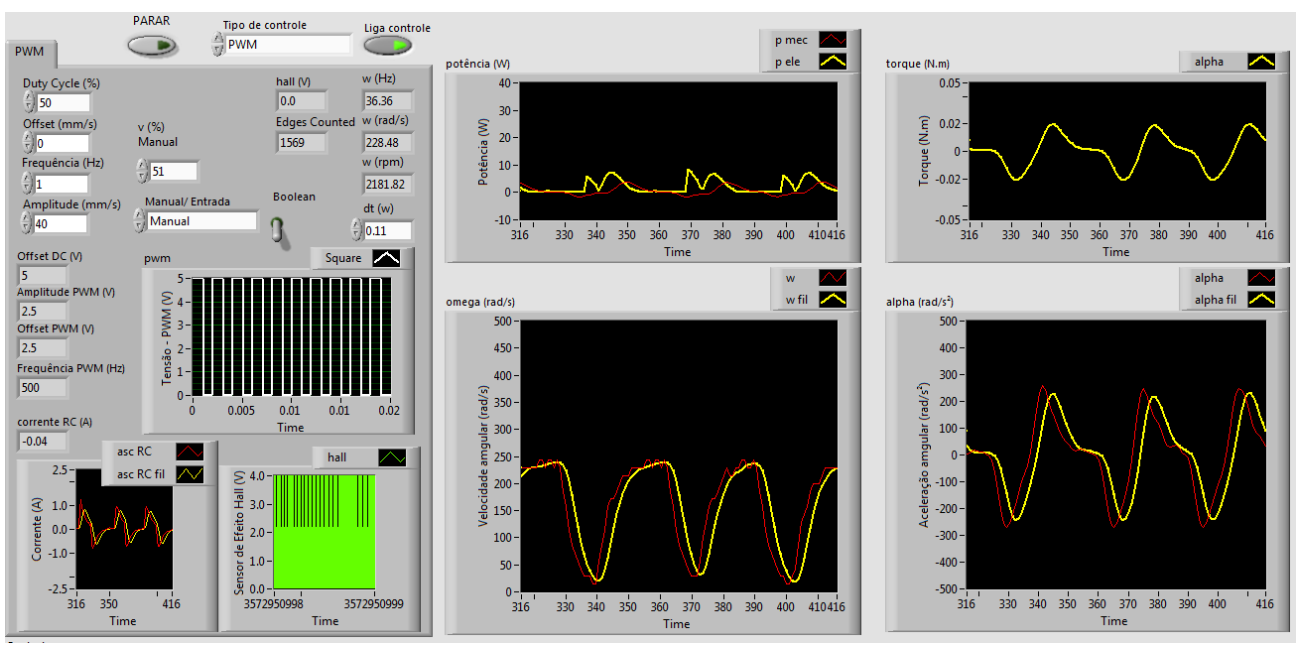

Figura 4.4.8: Painel de controle usado nos testes. 
A medição de corrente foi feita usando um sensor marca Allegro, modelo ACS714 (Figura 4.4.9). A Figura 4.4.10 apresenta sua curva de calibração. Já a medição da velocidade angular foi calibrada usando um tacômetro digital marca Minipa, modelo MDT-2238A. A Tabela 4.4.1 apresenta os dados desta calibração.
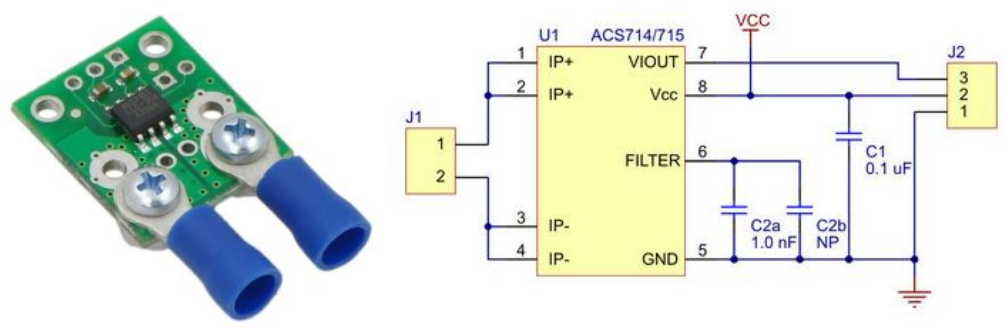

Figura 4.4.9: Sensor de corrente ACS714, da Allegro.

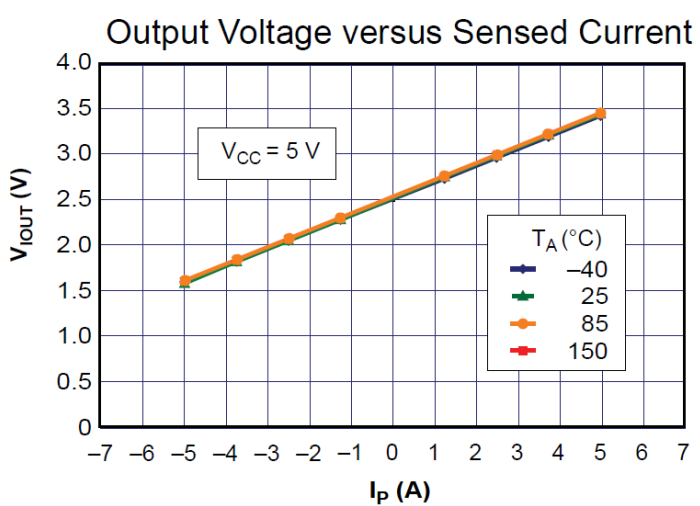

Figura 4.4.10: Curva de calibração do sensor ACS714.

Tabela 4.4.1: Dados da calibração da medição de velocidade angular.

\begin{tabular}{|c|c|c|c|c|c|c|c|c|c|c|c|c|c|c|c|}
\hline \multicolumn{2}{|c|}{$\begin{array}{c}\text { Nivel de } \\
\text { acionamento }\end{array}$} & \multicolumn{3}{|c|}{ Série de leitura 1} & \multicolumn{3}{|c|}{ Série de leitura 2} & \multicolumn{3}{|c|}{ Série de leitura 3} & \multicolumn{2}{|c|}{ Média } & \multirow{2}{*}{\begin{tabular}{|c|}
$\begin{array}{c}\text { Erro de } \\
\text { indicação }\end{array}$ \\
$E I$ \\
$(\%)$
\end{tabular}} & \multirow{2}{*}{ 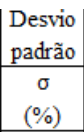 } & \multirow{2}{*}{$\begin{array}{c}\text { Incerteza } \\
\text { expandida }\end{array}$} \\
\hline $\begin{array}{l}D_{p w m} \\
(\%)\end{array}$ & $\begin{array}{l}\mathrm{V}_{\mathrm{eq}} \\
(\mathrm{V})\end{array}$ & $\begin{array}{c}\omega_{\text {tacômetro }} \\
(\mathrm{rpm})\end{array}$ & $\begin{array}{l}\omega_{\text {referenncia }} \\
(\mathrm{rpm})\end{array}$ & $\begin{array}{c}\omega_{\text {dinamômerro }} \\
(\mathrm{rpm})\end{array}$ & $\begin{array}{c}\omega_{\text {tacômetro }} \\
(\mathrm{rpm})\end{array}$ & $\begin{array}{c}\omega_{\text {referenncia }} \\
(\mathrm{rpm})\end{array}$ & $\begin{array}{c}\omega_{\text {dinamômetro }} \\
(\mathrm{rpm})\end{array}$ & $\begin{array}{c}\omega_{\text {tacômetro }} \\
(\mathrm{rpm})\end{array}$ & $\begin{array}{c}\omega_{\text {refirencia }} \\
(\mathrm{rpm})\end{array}$ & $\begin{array}{c}\omega_{\text {dinamômetro }} \\
(\mathrm{rpm})\end{array}$ & $\begin{array}{c}\omega_{\text {referenncia }} \\
(\mathrm{rpm})\end{array}$ & $\begin{array}{c}\omega_{\text {dinamômetro }} \\
(\mathrm{rpm})\end{array}$ & & & \\
\hline 10 & 2,4 & 1060 & 345 & 410 & 1017 & 331 & 273 & 990 & 322 & 273 & 332 & 318 & 4,15 & 24,9 & 25,2 \\
\hline 20 & 4,8 & 2460 & 800 & 819 & 2410 & 783 & 682 & 2350 & 764 & 682 & 782 & 727 & 6,99 & 10,9 & 12,9 \\
\hline 30 & 7,2 & 3800 & 1235 & 1227 & 3770 & 1225 & 1091 & 3730 & 1212 & 1091 & 1224 & 1136 & 7,17 & 6,9 & 10,0 \\
\hline 40 & 9,6 & 5140 & 1671 & 1636 & 5150 & 1674 & 1636 & 5100 & 1658 & 1636 & 1667 & 1636 & 1,85 & 0,0 & 1,9 \\
\hline 50 & 12,0 & 6545 & 2127 & 2182 & 6470 & 2103 & 2045 & 6540 & 2126 & 2045 & 2118 & 2091 & 1,30 & 3,8 & 4,0 \\
\hline 60 & 14,4 & 7950 & 2584 & 2591 & 7900 & 2568 & 2546 & 7940 & 2581 & 2455 & 2577 & 2530 & 1,82 & 2,7 & 3,3 \\
\hline 70 & 16,8 & 9250 & 3006 & 3000 & 9230 & 3000 & 3000 & 9320 & 3029 & 2864 & 3012 & 2955 & 1,90 & 2,7 & 3,3 \\
\hline 80 & 19,2 & 10620 & 3452 & 3409 & 10580 & 3439 & 3409 & 10610 & 3448 & 3409 & 3446 & 3409 & 1,07 & 0,0 & 1,1 \\
\hline 90 & 21,6 & 11780 & 3829 & 3818 & 11250 & 3656 & 3818 & 11790 & 3832 & 3682 & 3772 & 3773 & 0,01 & 2,1 & 2,1 \\
\hline 100 & 24,0 & 13200 & 4290 & 4364 & 12900 & 4193 & 4227 & 13000 & 4225 & 4091 & 4236 & 4227 & 0,20 & 3,2 & 3,2 \\
\hline
\end{tabular}

A Figura 4.4.11 apresenta uma resposta no tempo com todas as variáveis medidas e calculadas ao longo de um dos ensaios para cada um dos níveis de tensão equivalente. Os valores de ciclo de trabalho, $D$, (duty cycle) usados nos 
testes foram 0,25 (equivalente a 6VDC), 0,50 (equivalente a 12VDC), 0,75 (equivalente a 18VDC) e 1,00 (equivalente a 24VDC). Já as Figuras 4.4 .12 a 4.4.15 apresentam as curvas características do motor para cada tensão de alimentação equivalente e a Figura 4.4.16 apresenta as curvas torque x velocidade angular para cada um dos quatro diferentes níveis de tensão equivalente.
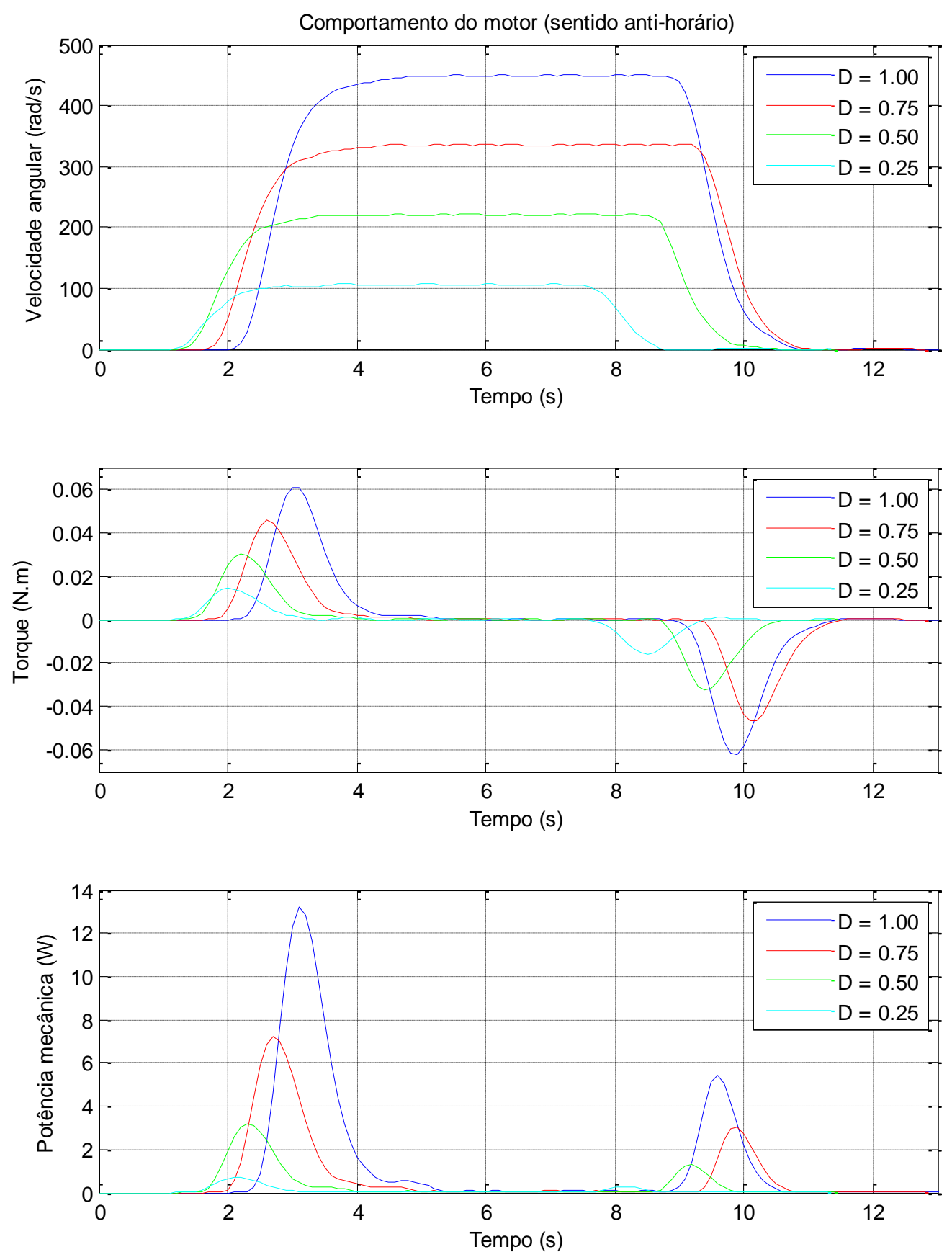

Figura 4.4.11: Respostas no tempo obtidas nos testes do motor elétrico. 


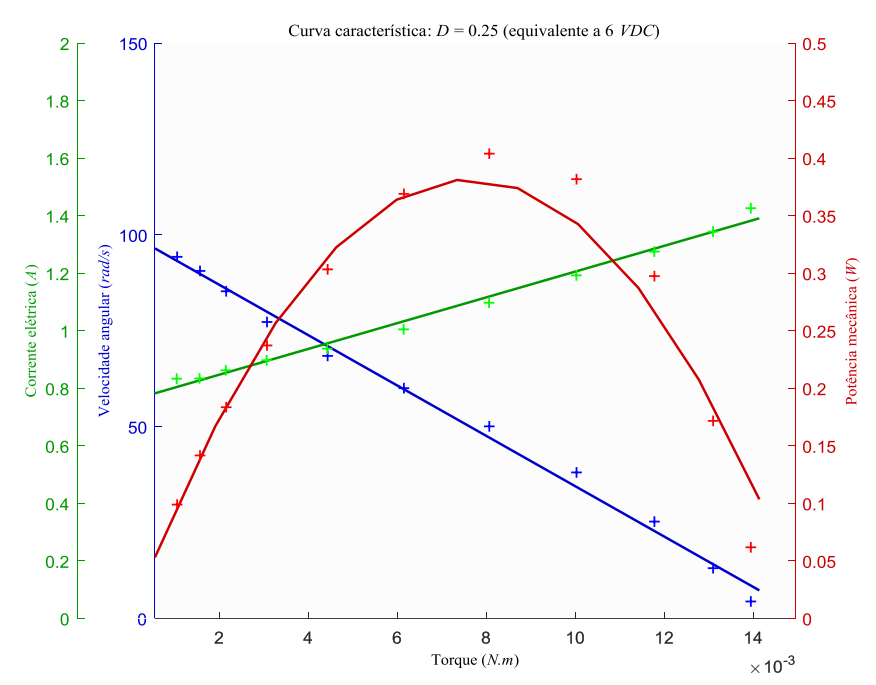

Figura 4.4.12: Curvas características do motor elétrico para $\mathrm{D}=0,25$ (6 VDC).

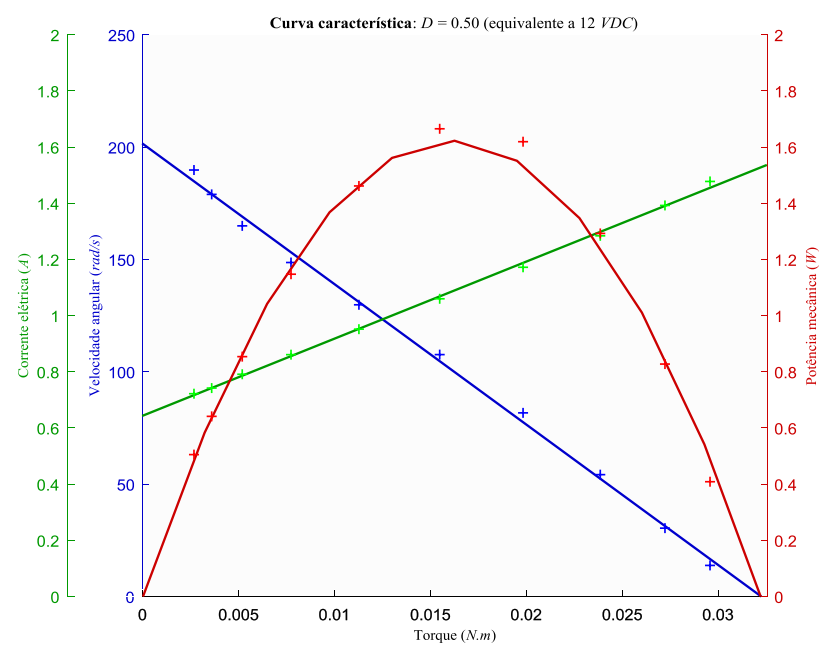

Figura 4.4.13: Curvas características do motor elétrico para D = 0,50 (12 VDC).

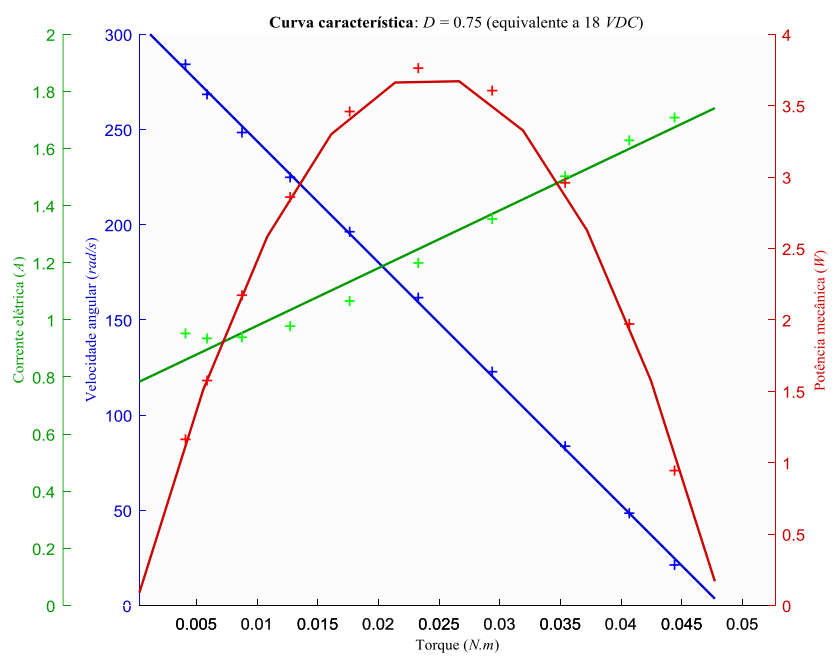

Figura 4.4.14: Curvas características do motor elétrico para D = 0,75 (18 VDC). 


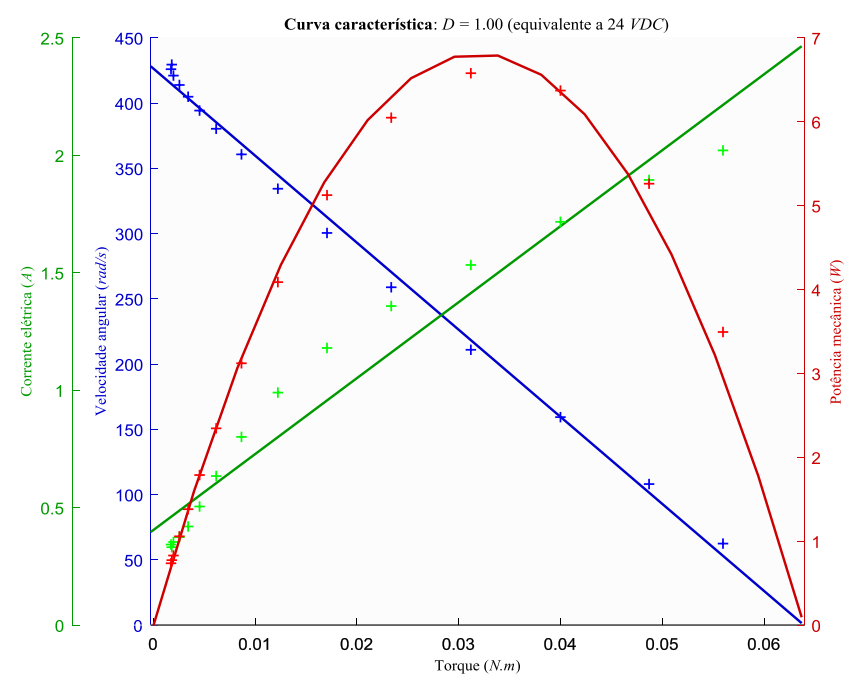

Figura 4.4.15: Curvas características do motor elétrico para D = 1,00 (24 VDC).

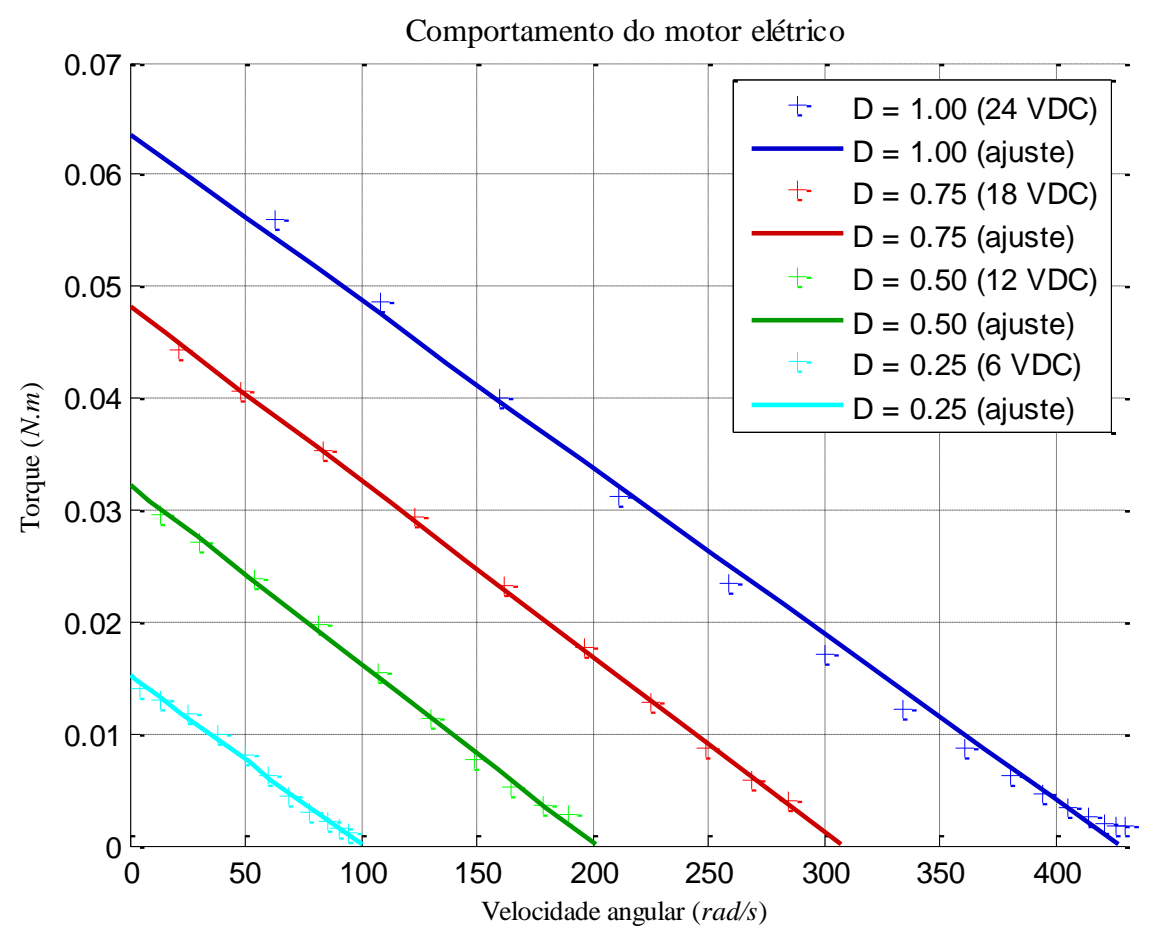

Figura 4.4.16: Curvas torque x velocidade angular para o controle do motor elétrico usando o controlador de velocidade.

$\mathrm{O}$ conjunto de Equações 4.4.11 apresenta as equações das curvas torque $\mathrm{x}$ velocidade angular para obtenção dos valores de $k_{V}$ e $k_{\omega}$. As Equações $4.4 .12 \mathrm{e}$ 4.4.13 apresentam os valores médios de $k_{V}$ e $k_{\omega}$, respectivamente, com suas devidas incertezas e a Figura 4.4.17 apresenta as curvas torque $\mathrm{x}$ velocidade 
angular comparando os dados obtidos usando uma fonte $\mathrm{CC}$ e o controlador de velocidade MC33926. Já o conjunto de Equações 4.4.14 apresenta as equações das curvas corrente $\mathrm{x}$ torque, para obtenção dos valores de $k_{i}$ e $k_{T}$. As Equações 4.4.15 e 4.4.16 apresentam os valores médios de $k_{i}$ e $k_{T}$, respectivamente.

$$
\begin{aligned}
& \left\{\begin{array}{l}
\tau_{0.25}=-1,515 \cdot 10^{-4} \omega_{0.25}+0,01520 \\
\tau_{0.50}=-1,598 \cdot 10^{-4} \omega_{0.50}+0,03218 \\
\tau_{0.75}=-1,568 \cdot 10^{-4} \omega_{0.75}+0,04825 \\
\tau_{1.00}=-1,490 \cdot 10^{-4} \omega_{1.00}+0,06362
\end{array}\right. \\
& k_{V}=2,637 \cdot 10^{-3} \pm 1,406 \cdot 10^{-4} \text { N.m } / \mathrm{V} \\
& k_{\omega}=1,542 \cdot 10^{-4} \pm 9,682 \cdot 10^{-6} \text { N.m.s } / \mathrm{rad}
\end{aligned}
$$

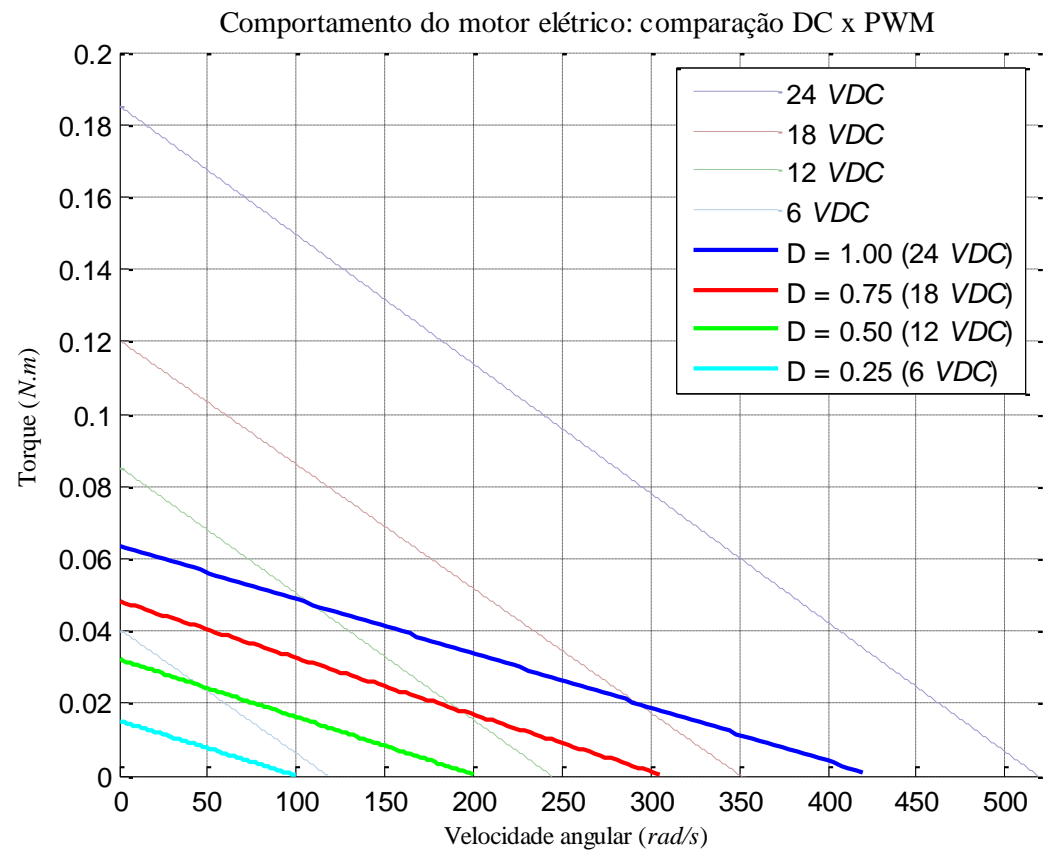

Figura 4.4.17: Comparação das curvas torque x velocidade angular para o controle do motor elétrico usando fonte $\mathrm{CC}$ e controlador de velocidade.

$$
\begin{aligned}
& \left\{\begin{array}{l}
i_{0.25}=16,727 \tau_{0.25}+0,7575 \\
i_{0.50}=16,804 \tau_{0.50}+0,6439 \\
i_{0.75}=17,091 \tau_{0.75}+0,7776 \\
i_{1.00}=17,788 \tau_{1.00}+0,4046
\end{array}\right. \\
& k_{i}=5,999 \cdot 10^{-2} \pm 9,361 \cdot 10^{-3} \mathrm{~A} / \mathrm{V}
\end{aligned}
$$




$$
k_{T}=\frac{k_{V}}{k_{\omega}}=17,103 \pm 9,662 \cdot 10^{-1} A / N \cdot m
$$

\subsection{Caracterização do atuador linear elétrico}

Nesta Seção serão descritos os procedimentos para caracterização do atuador linear elétrico usado no mecanismo paralelo objeto deste trabalho, desde a calibração de seu transdutor potenciométrico de deslocamento linear até a análise das respostas no tempo em diversos testes dinâmicos.

\subsubsection{Calibração do transdutor de deslocamento linear}

Na calibração, o transdutor de deslocamento foi alimentado com tensão constante de $5 \mathrm{~V}$ usando uma fonte de alimentação e um regulador de tensão modelo L7800. Para medição da tensão de saída do transdutor potenciométrico foi usado um multímetro marca Hikari, modelo HM-2090, com resolução de $1 \mathrm{mV}$, além de um paquímetro analógico marca Mitutoyo, modelo 530312B10, com resolução de 0,02 mm e incerteza padrão Tipo B igual a 0,026 mm com nível de confiabilidade de 95,4\% $(k=2)$. A cada $10 \mathrm{~mm}$ de deslocamento da haste do atuador foram registrados os valores do sinal de tensão na saída do transdutor. Foram realizadas três séries de leitura, tanto para a extensão quanto para a retração da haste. Os dados obtidos nestas séries de leitura são apresentados na Tabela 4.5.1. Com estes dados foi obtida a curva de calibração do atuador linear elétrico (Figura 4.5.1).

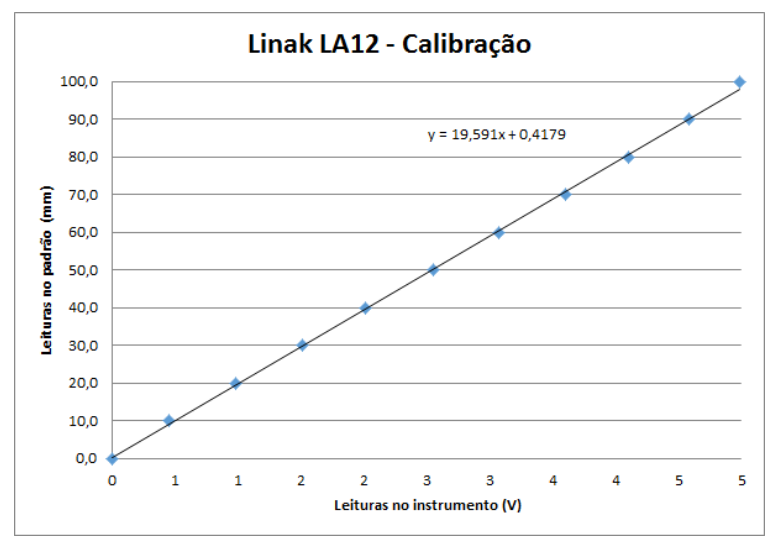

Figura 4.5.1: Curva de calibração do atuador linear elétrico. 
A equação da reta ajustada é $y=19,591 x+0,4179$, com coeficiente de determinação $R^{2}=0,9993$, sendo $y$ o deslocamento $(\mathrm{mm})$ e $x$ a tensão elétrica (V). Levando em consideração apenas o desvio padrão para cálculo de incerteza expandida, e sendo $\mathrm{k}=2$ para um intervalo de confiança de $96 \%$, foi encontrada a faixa de incertezas do deslocamento com a curva de calibração encontrada (Tabela 4.5.2).

Tabela 4.5.1: Séries de leitura para curva de calibração.

\begin{tabular}{ccccccccc}
$\begin{array}{c}\text { Leituras } \\
\text { no padrão } \\
(\mathrm{mm})\end{array}$ & $\begin{array}{c}\text { Série 1 } \\
\text { Extensão } \\
(\mathrm{V})\end{array}$ & $\begin{array}{c}\text { Retração } \\
(\mathrm{V})\end{array}$ & $\begin{array}{c}\text { Extensão } \\
(\mathrm{V})\end{array}$ & $\begin{array}{c}\text { Retração } \\
(\mathrm{V})\end{array}$ & $\begin{array}{c}\text { Extensão } \\
(\mathrm{V})\end{array}$ & $\begin{array}{c}\text { Retração } \\
(\mathrm{V})\end{array}$ & $\begin{array}{c}\text { Média das } \\
\text { leituras }\end{array}$ & $\begin{array}{c}\text { Desvio } \\
\text { Padrão }\end{array}$ \\
\hline 0,0 & 0,00 & 0,00 & 0,00 & 0,00 & 0,00 & 0,00 & 0,00 & 0,000 \\
10,0 & 0,47 & 0,45 & 0,45 & 0,43 & 0,43 & 0,45 & 0,45 & 0,013 \\
20,0 & 0,99 & 1,01 & 0,96 & 0,95 & 0,99 & 0,97 & 0,98 & 0,021 \\
30,0 & 1,48 & 1,54 & 1,53 & 1,49 & 1,50 & 1,50 & 1,51 & 0,022 \\
40,0 & 1,99 & 2,04 & 2,00 & 2,02 & 1,99 & 2,02 & 2,01 & 0,021 \\
50,0 & 2,55 & 2,57 & 2,56 & 2,52 & 2,54 & 2,56 & 2,55 & 0,018 \\
60,0 & 3,06 & 3,10 & 3,08 & 3,09 & 3,04 & 3,09 & 3,08 & 0,021 \\
70,0 & 3,58 & 3,63 & 3,60 & 3,61 & 3,60 & 3,62 & 3,61 & 0,018 \\
80,0 & 4,12 & 4,13 & 4,09 & 4,11 & 4,06 & 4,12 & 4,11 & 0,026 \\
90,0 & 4,55 & 4,62 & 4,57 & 4,58 & 4,58 & 4,59 & 4,58 & 0,023 \\
100,0 & 4,98 & 4,98 & 4,98 & 4,99 & 4,99 & 4,98 & 4,98 & 0,005
\end{tabular}

Tabela 4.5.2: Faixas de incerteza nos pontos da curva de calibração.

\begin{tabular}{cccc}
$\begin{array}{c}\text { Média } \\
\text { das } \\
\text { leituras } \\
(\mathrm{mm})\end{array}$ & $\begin{array}{c}\text { Incerteza do } \\
\text { desvio padrão }\end{array}$ & \multicolumn{2}{c}{ Incerteza expandida } \\
\hline 9,15 & 0,027 & $\pm(\%)$ & $\pm(\mathrm{mm})$ \\
\hline 19,56 & 0,042 & 4,23 & 0,89 \\
29,92 & 0,044 & 2,85 & 0,85 \\
39,76 & 0,042 & 2,06 & 0,82 \\
50,37 & 0,035 & 1,38 & 0,70 \\
60,68 & 0,043 & 1,37 & 0,83 \\
71,05 & 0,035 & 0,97 & 0,69 \\
80,84 & 0,052 & 1,25 & 1,01 \\
90,18 & 0,046 & 1,01 & 0,91 \\
98,05 & 0,010 & 0,21 & 0,20
\end{tabular}




\subsubsection{Ensaios com tensão de alimentação constante}

Com o objetivo de obter os parâmetros do modelo dinâmico do atuador, foram realizados testes para verificar as velocidades de extensão e retração do parafuso de avanço, com carga e sem carga, na horizontal e vertical. Para realizar tais testes, o atuador foi fixado em uma bancada como mostrado na Figura 4.5.2. Nos testes, o transdutor foi alimentado por uma tensão constante de $5 \mathrm{~V}$, enquanto a tensão no motor elétrico foi regulada em $6 \mathrm{~V}, 12 \mathrm{~V}, 18 \mathrm{~V}$ e $24 \mathrm{~V}$ usando uma fonte chaveada Hikari HF-3003S. A Figura 4.5.3 apresenta o esquema com as ligações para alimentação do motor, do transdutor e envio de dados do transdutor para o módulo de aquisição de dados.

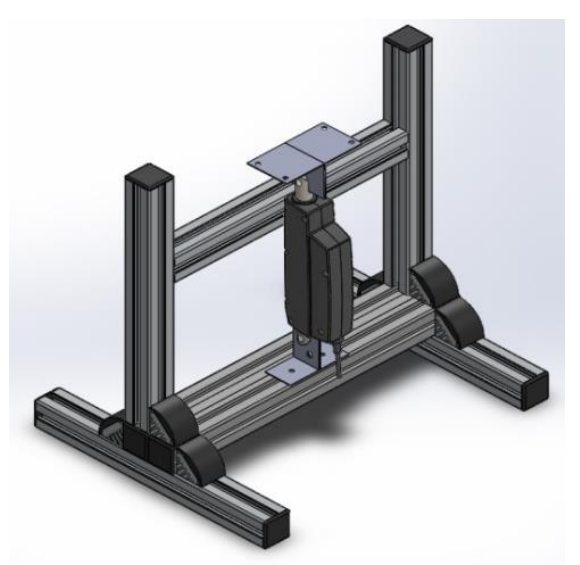

Figura 4.5.2: Bancada para testes experimentais.

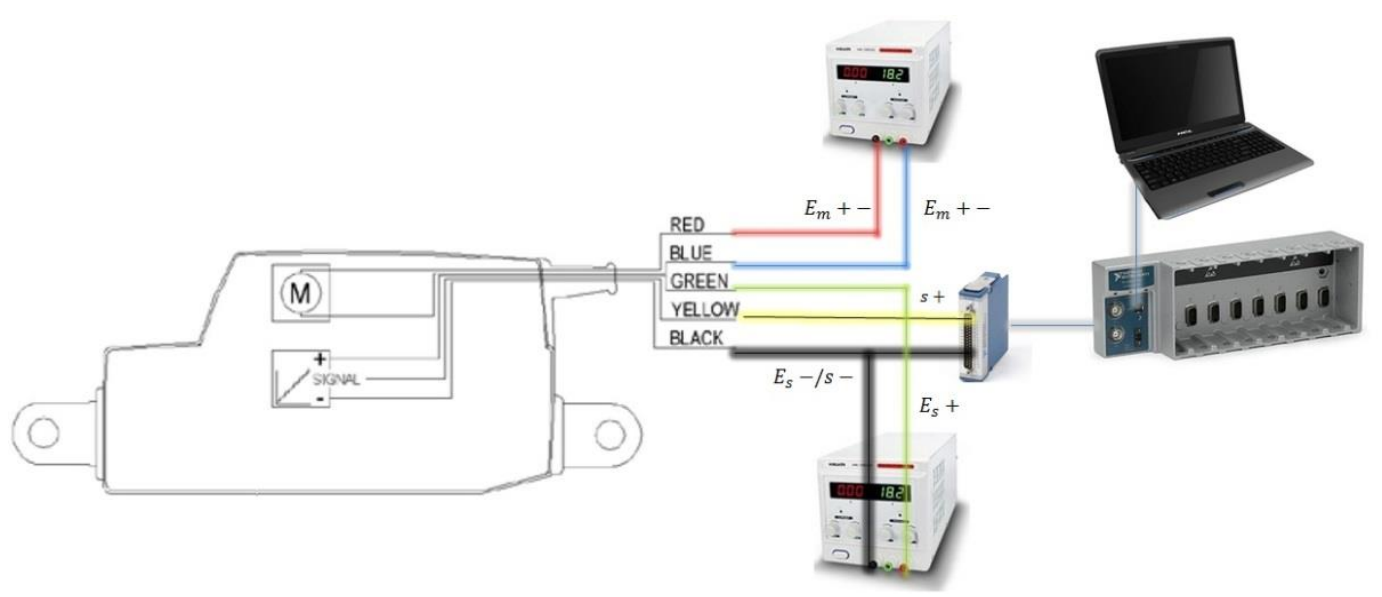

Figura 4.5.3: Esquema de ligação do atuador, transdutor e módulo de aquisição de dados. 
Para leitura do sinal em tempo real é usado um módulo de aquisição NI 9205, da National Instruments, de entradas analógicas. A rotina em LabView (VI virtual instrument) criada é apresentada no Anexo A - Virtual Instruments. Esta possui interface com o MatLab para o tratamento de dados e para gerar os gráficos para análise. Esta rotina permite a aquisição do sinal de tensão elétrica do transdutor, que é transformada no deslocamento da haste usando a curva de calibração.

Com a derivação destes sinais a velocidade instantânea é obtida. Como estas leituras possuem muito ruído, foi usado o filtro Savitzky-Golay para a atenuação. Descrito pela primeira vez em 1964 por Abraham Savitzky e Marcel J. E. Golay, o filtro funciona por uma convolução, processo matemático que consiste em produzir uma função a partir de duas outras, utiliza dois pontos adjacentes com um polinômio de grau baixo e, pelo método de mínimos quadrados, são alocados novos pontos. Quando os pontos estão equidistantes, uma solução analítica é encontrada e aplicada em todos os dados recebidos para suavizar o sinal. A principal vantagem desta aproximação é que tende a preservar características da distribuição inicial tais como os máximos e mínimos relativos. Na Figura 4.5.4 são apresentados os resultados de testes realizados para escolha do tipo de filtro. A saídas filtradas com o filtro Savitzy-Golay são comparadas com o filtro de média movente.
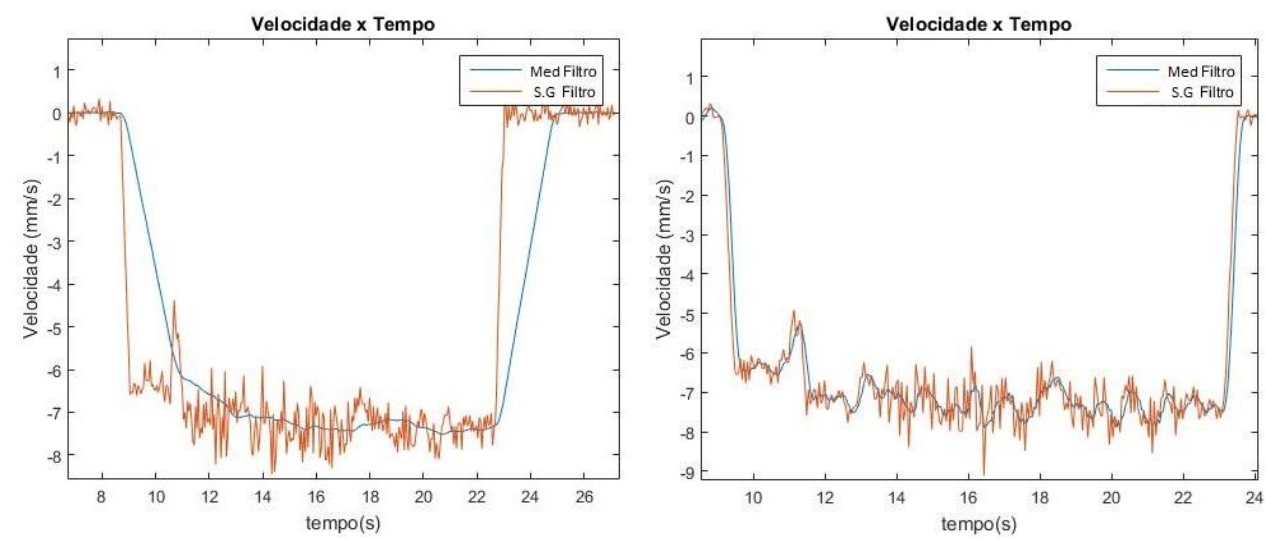

Figura 4.5.4: Testes para escolha do tipo de filtro. 
Com o atuador fixado na bancada, foram realizados os testes vertical e horizontal (Figura 4.5.5). No teste vertical os pesos foram fixados na ponta do parafuso de avanço e nos testes horizontais os pesos foram alinhados com o furo da haste e novamente fixados na cantoneira. Em ambos os testes de carga foram utilizados pequenos pesos de $942,5 \mathrm{~g}$.
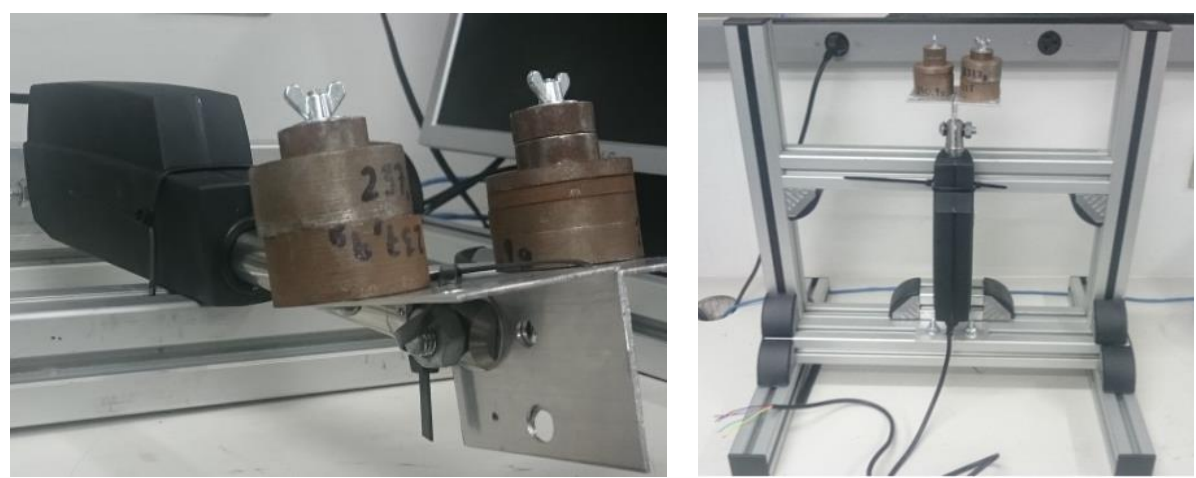

Figura 4.5.5: Testes horizontal e vertical com carga.

As Figuras 4.5.6 a 4.5.9 apresentam a velocidade da haste do atuador em cada um dos testes, horizontais e verticais, com e sem carga, em extensão (tensão de alimentação positiva) e retração (tensão negativa). A Tabela 4.5.3 apresenta os dados dos testes com carga e a Tabela 4.5.4, dos testes sem carga. Os dados mostram que esta carga é muito pequena para afetar significativamente a dinâmica do sistema e que o módulo das velocidades máximas medidas (aproximadamente $45 \mathrm{~mm} / \mathrm{s})$ é um pouco superior à informada pelo fabricante $(40 \mathrm{~mm} / \mathrm{s})$.

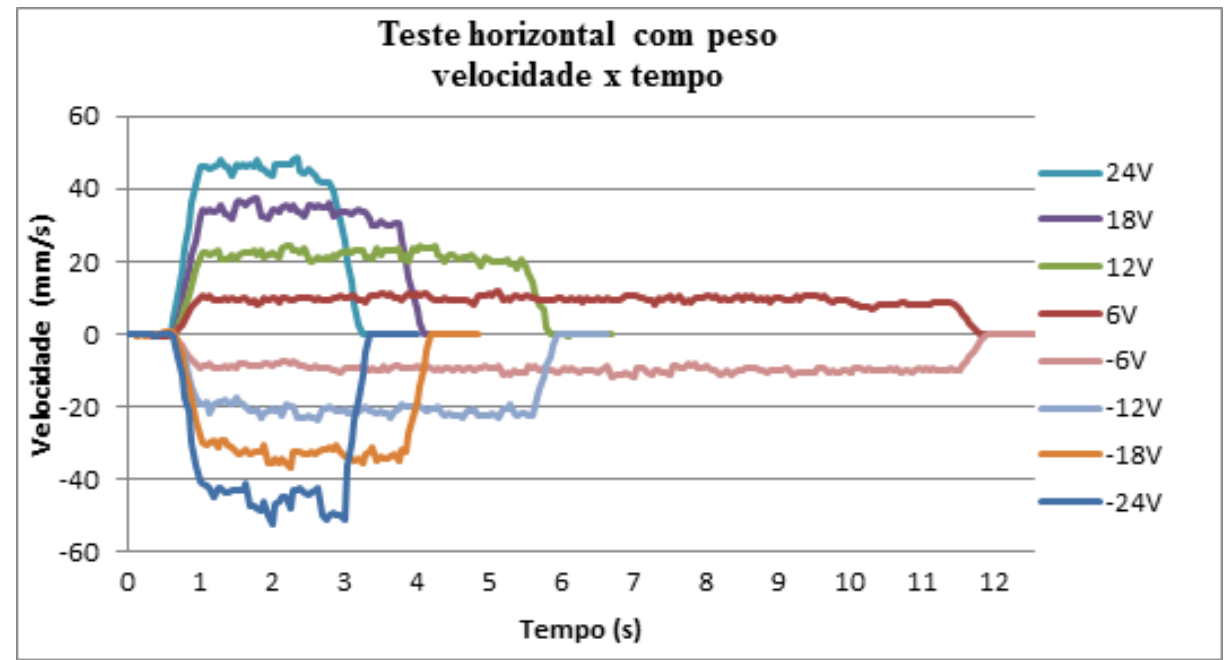

Figura 4.5.6: Teste horizontal com carga. 


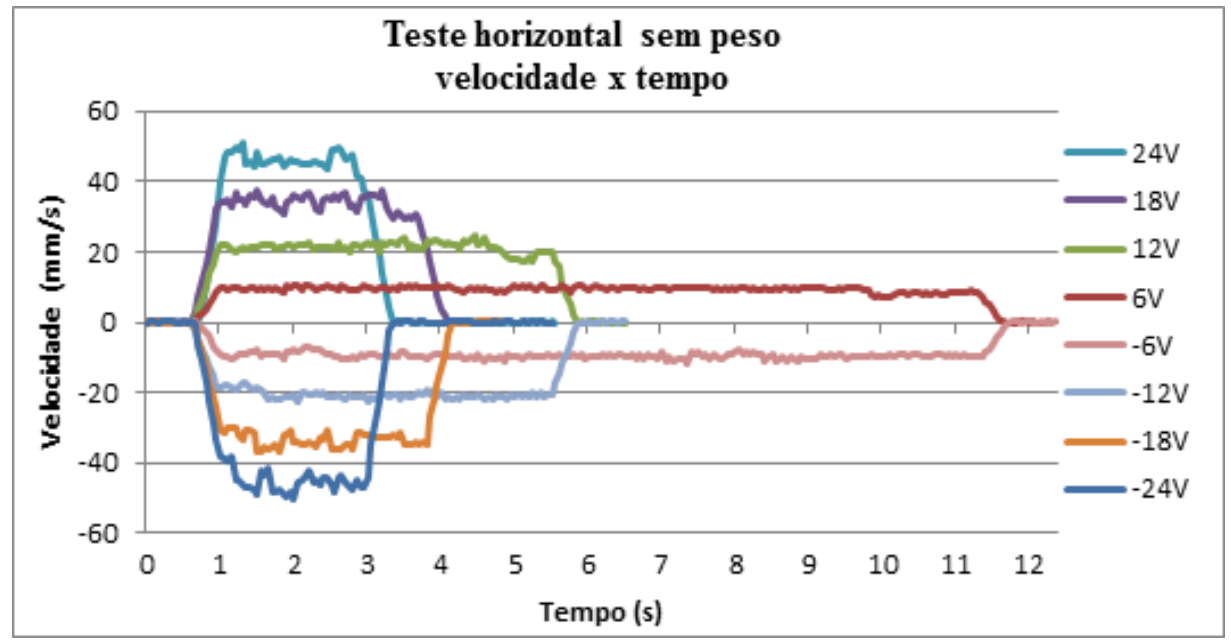

Figura 4.5.7: Teste horizontal sem carga.

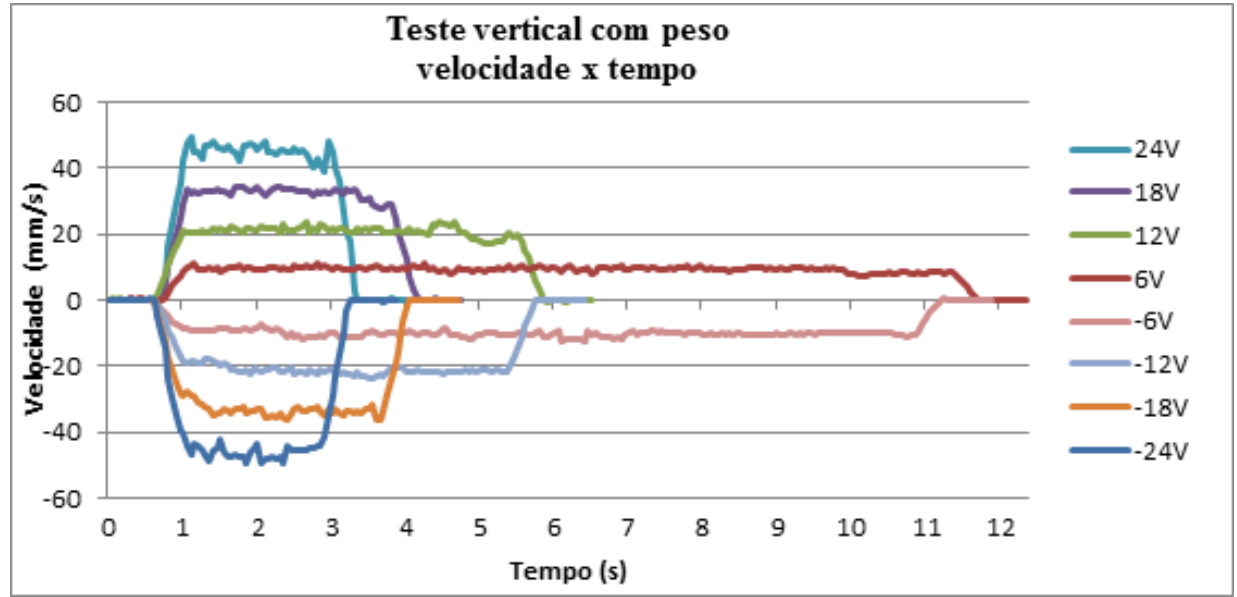

Figura 4.5.8: Teste vertical com carga.

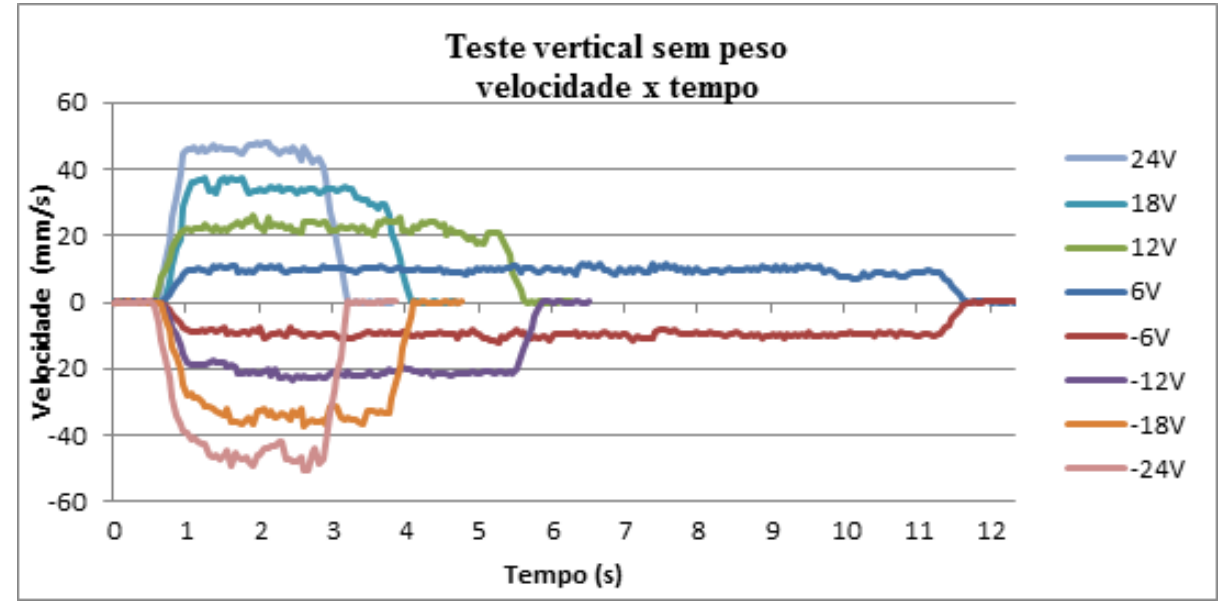

Figura 4.5.9: Teste vertical sem carga. 
Tabela 4.5.3: Resultados dos testes com carga.

\begin{tabular}{|c|c|c|c|c|c|c|c|c|}
\hline \multirow{3}{*}{$\begin{array}{c}\text { Testes } \\
\text { com carga } \\
\text { Tensão no } \\
\text { atuador } \\
\text { (V) }\end{array}$} & \multicolumn{4}{|c|}{ Horizontal } & \multicolumn{4}{|c|}{ Vertical } \\
\hline & \multicolumn{2}{|c|}{ Extensão } & \multicolumn{2}{|c|}{ Retração } & \multicolumn{2}{|c|}{ Extensão } & \multicolumn{2}{|c|}{ Retração } \\
\hline & $\begin{array}{l}\text { Média } \\
(\mathrm{mm} / \mathrm{s})\end{array}$ & $\begin{array}{l}\text { Desvio } \\
\text { Padrão } \\
(\mathrm{mm} / \mathrm{s})\end{array}$ & $\begin{array}{l}\text { Média } \\
(\mathrm{mm} / \mathrm{s})\end{array}$ & $\begin{array}{l}\text { Desvio } \\
\text { Padrão } \\
(\mathrm{mm} / \mathrm{s})\end{array}$ & $\begin{array}{l}\text { Média } \\
(\mathrm{mm} / \mathrm{s})\end{array}$ & $\begin{array}{l}\text { Desvio } \\
\text { Padrão } \\
(\mathrm{mm} / \mathrm{s})\end{array}$ & $\begin{array}{l}\text { Média } \\
(\mathrm{mm} / \mathrm{s})\end{array}$ & $\begin{array}{l}\text { Desvio } \\
\text { Padrão } \\
(\mathrm{mm} / \mathrm{s})\end{array}$ \\
\hline 6 & 9,66 & 0,86 & $-9,56$ & 0,79 & 9,41 & 0,72 & $-10,1$ & 0,84 \\
\hline 12 & 21,78 & 1,36 & -21 & 1,34 & 20,94 & 1,43 & $-21,25$ & 1,22 \\
\hline 18 & 33,67 & 1,91 & $-32,62$ & 1,8 & 32,58 & 1,6 & $-33,36$ & 1,78 \\
\hline 24 & 45,57 & 1,78 & $-45,76$ & 3,18 & 45,23 & 2,17 & $-46,16$ & 1,83 \\
\hline
\end{tabular}

Tabela 4.5.4: Resultados dos testes sem carga.

\begin{tabular}{|c|c|c|c|c|c|c|c|c|}
\hline \multirow{3}{*}{$\begin{array}{c}\text { Testes } \\
\text { sem carga } \\
\text { Tensão no } \\
\text { atuador } \\
\text { (V) }\end{array}$} & \multicolumn{4}{|c|}{ Horizontal } & \multicolumn{4}{|c|}{ Vertical } \\
\hline & \multicolumn{2}{|c|}{ Extensão } & \multicolumn{2}{|c|}{ Retração } & \multicolumn{2}{|c|}{ Extensão } & \multicolumn{2}{|c|}{ Retração } \\
\hline & $\begin{array}{l}\text { Média } \\
(\mathrm{mm} / \mathrm{s})\end{array}$ & $\begin{array}{l}\text { Desvio } \\
\text { Padrão } \\
(\mathrm{mm} / \mathrm{s})\end{array}$ & $\begin{array}{l}\text { Média } \\
(\mathrm{mm} / \mathrm{s})\end{array}$ & $\begin{array}{l}\text { Desvio } \\
\text { Padrão } \\
(\mathrm{mm} / \mathrm{s})\end{array}$ & $\begin{array}{l}\text { Média } \\
(\mathrm{mm} / \mathrm{s})\end{array}$ & $\begin{array}{l}\text { Desvio } \\
\text { Padrão } \\
(\mathrm{mm} / \mathrm{s})\end{array}$ & $\begin{array}{l}\text { Média } \\
(\mathrm{mm} / \mathrm{s})\end{array}$ & $\begin{array}{l}\text { Desvio } \\
\text { Padrão } \\
(\mathrm{mm} / \mathrm{s})\end{array}$ \\
\hline 6 & 9,43 & 0,68 & $-9,55$ & 0,77 & 9,7 & 0,85 & $-9,68$ & 0,72 \\
\hline 12 & 21,35 & 1,51 & $-20,75$ & 1,05 & 22,35 & 1,74 & $-21,05$ & 1,3 \\
\hline 18 & 34,02 & 2,24 & $-33,50$ & 1,99 & 33,79 & 2,22 & $-33,64$ & 2,25 \\
\hline 24 & 46,58 & 1,85 & $-46,05$ & 2,14 & 45,7 & 1,58 & $-45,73$ & 2,67 \\
\hline
\end{tabular}

\subsubsection{Ensaios usando o controlador de velocidade}

Usando o controlador de velocidade Pololu MC33926 descrito na Seção 4.4 foram feitos diversos testes horizontais com e sem carga na ponta da haste do atuador para quatro diferentes ciclos de trabalho: 0,25 (equivalente a 6VDC), 0,50 (equivalente a 12VDC), 0,75 (equivalente a 18VDC) e 1,00 (equivalente a 24VDC).

As Figuras 4.5.10 e 4.5.11 apresentam as respostas no tempo obtidas para a extensão e retração, respectivamente, do atuador nos testes sem carga. Já as Figuras 4.5.12 e 4.5.13 apresentam as respostas no tempo para a extensão e retração, respectivamente, do atuador nos testes com carga de 759,8 g e a Figura 4.5.14 apresenta as respostas no tempo para a extensão e retração do atuador com carga de $5327,8 \mathrm{~g}$. 

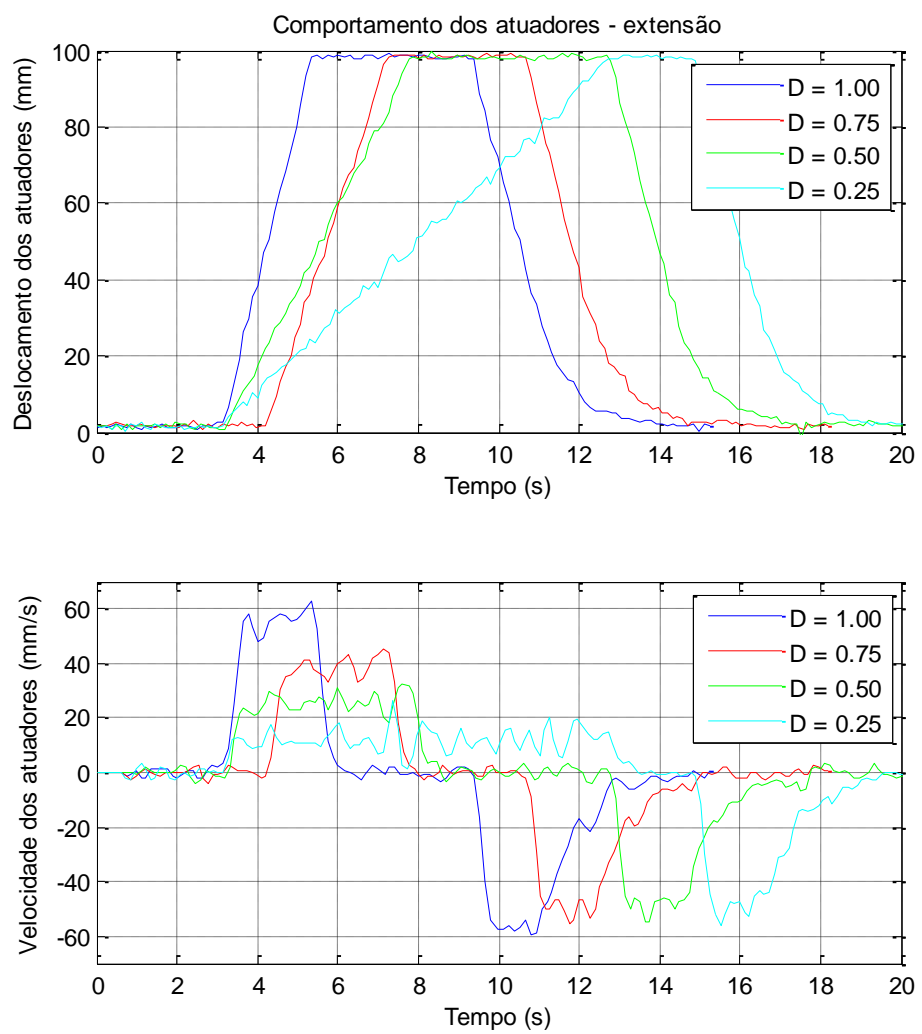

Figura 4.5.10: Extensão do atuador sem carga.
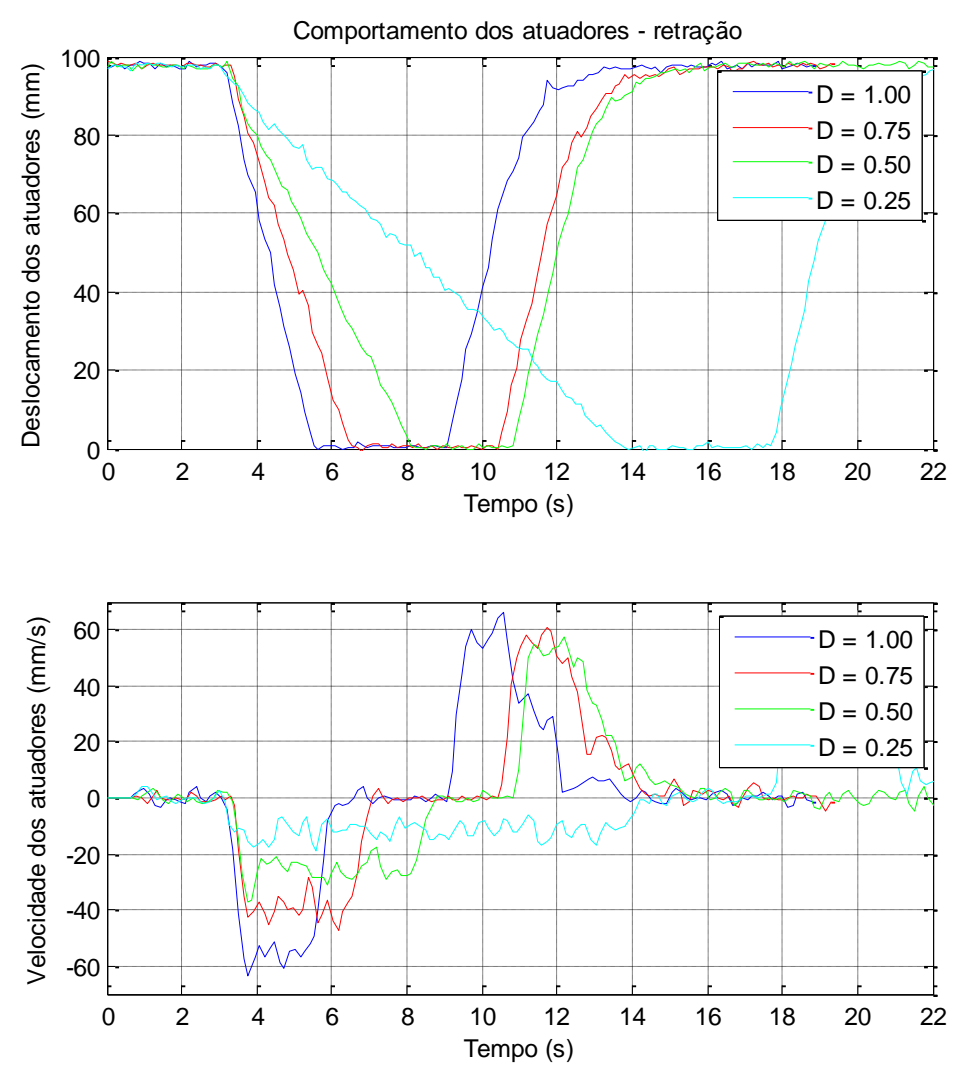

Figura 4.5.11: Retração do atuador sem carga. 

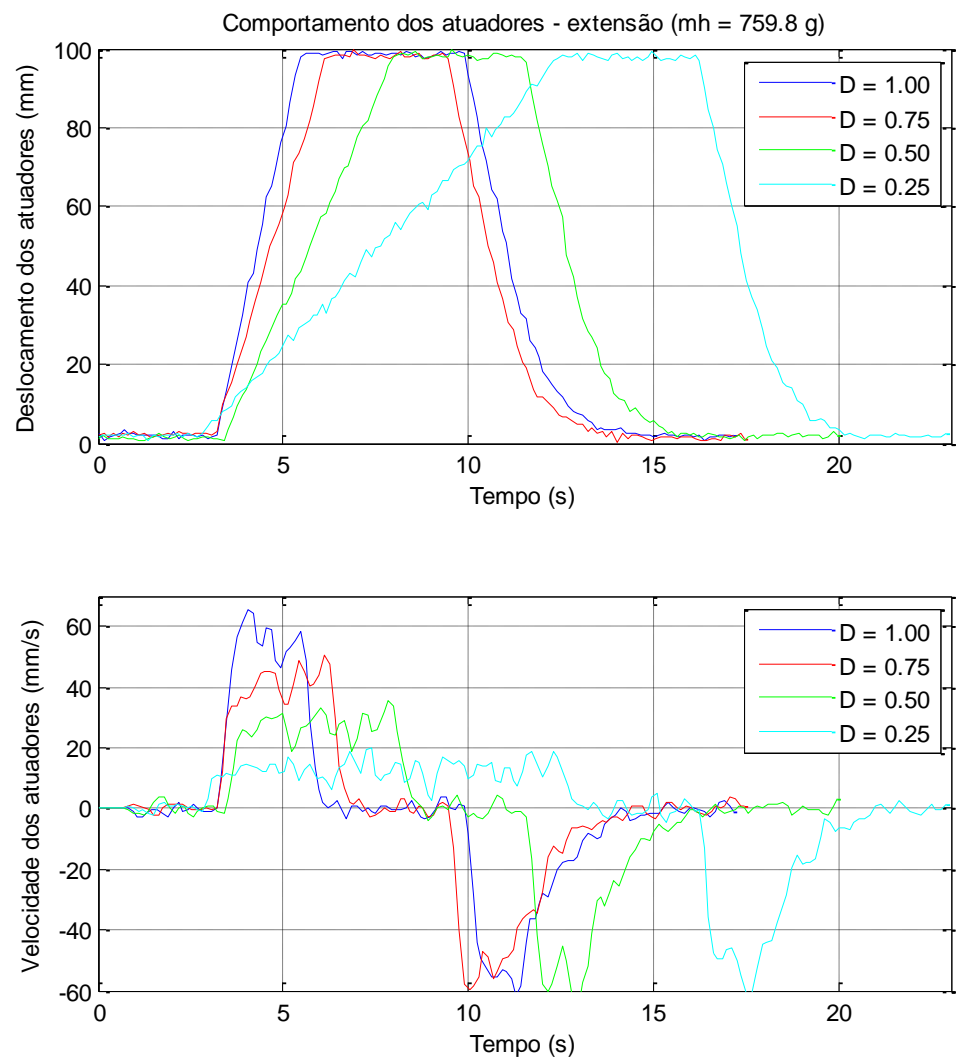

Figura 4.5.13: Extensão do atuador para $m_{h}=759,8 \mathrm{~g}$.
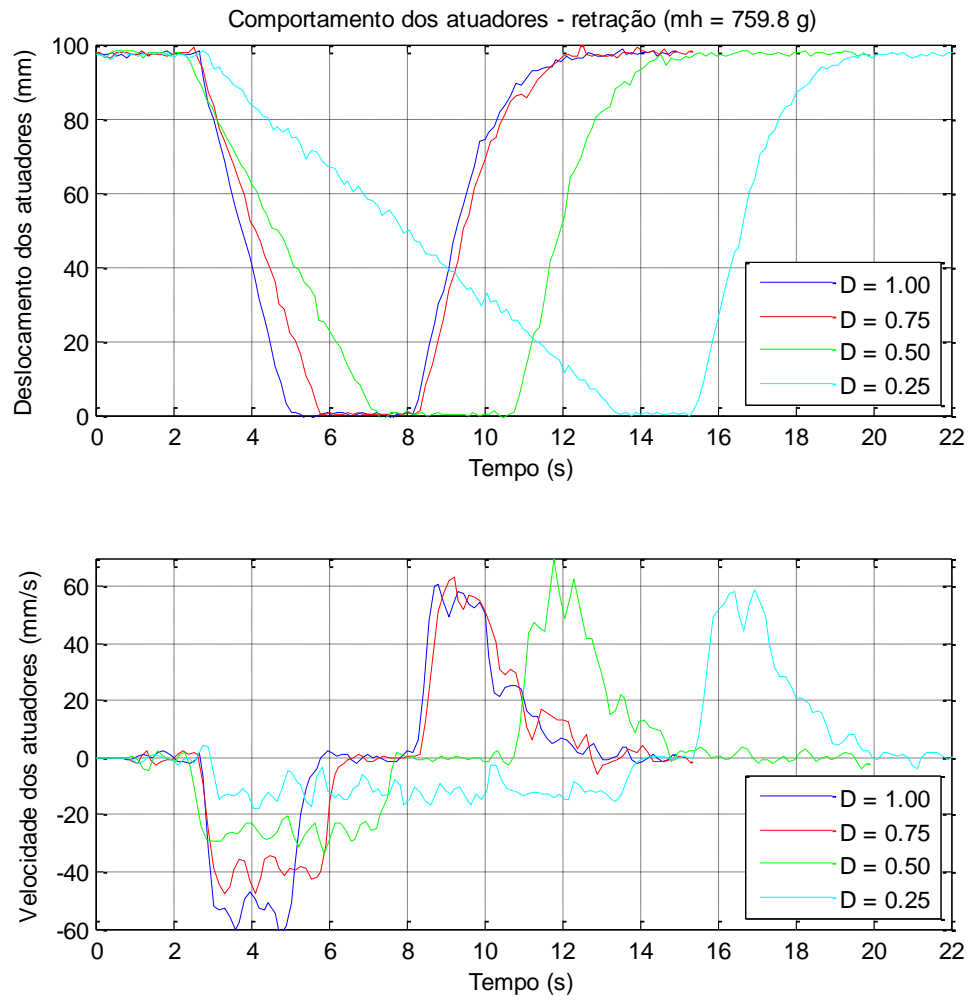

Figura 4.5.14: Retração do atuador para $m_{h}=759,8 \mathrm{~g}$. 

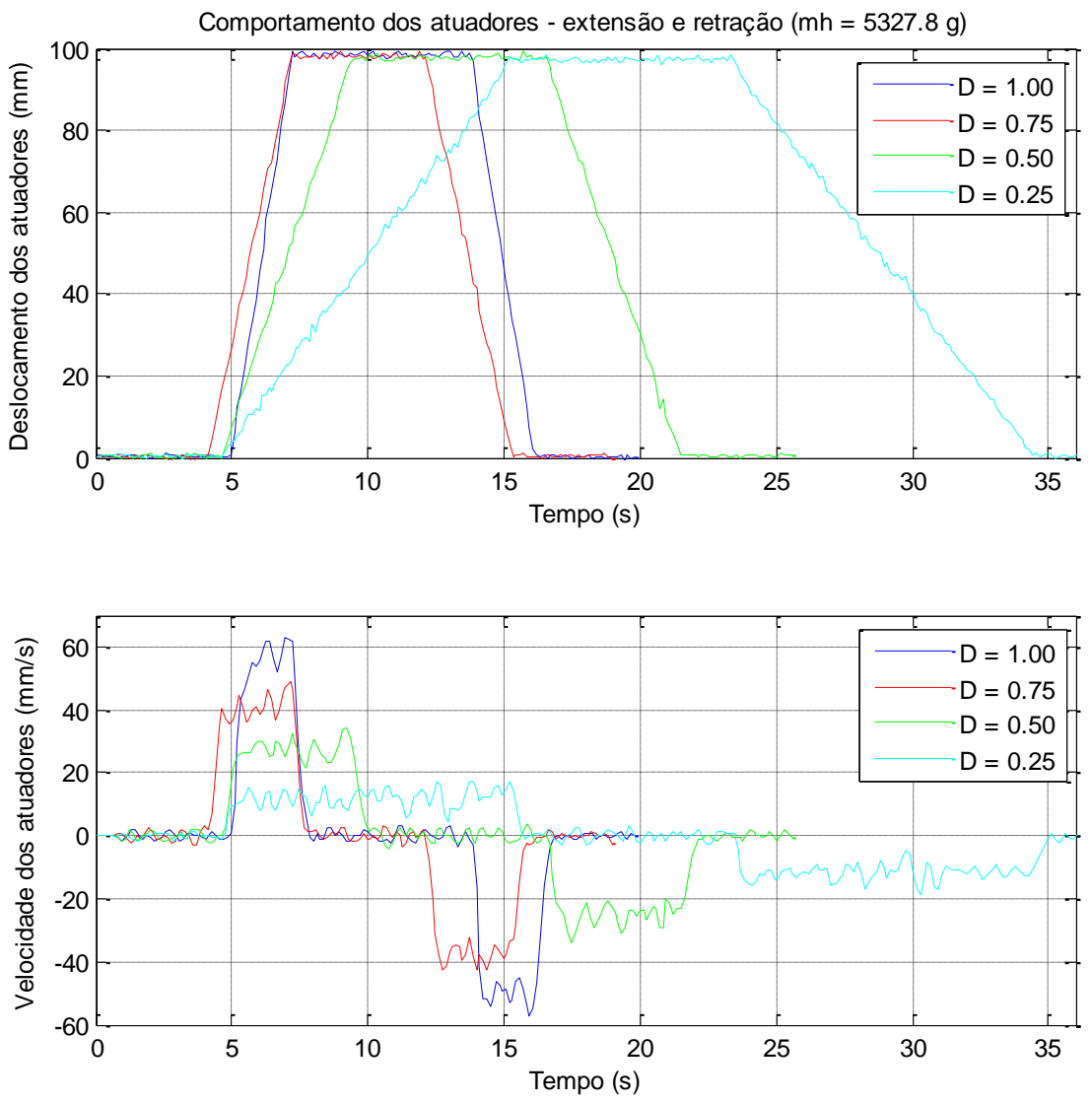

Figura 4.5.14: Extensão e retração do atuador para $m_{h}=5327,8 \mathrm{~g}$.

A Figura 4.5.15 apresenta uma imagem ilustrando o teste com carga $\mathrm{m}_{\mathrm{h}}=$ 759,8 g (a) e $\mathrm{m}_{\mathrm{h}}=5327,8 \mathrm{~g}$ (b). A Tabela 4.5.5 apresenta os resultados das velocidades do atuador para cada nível de acionamento e cada carga. Nesta bateria de testes foi usado um instrumento virtual (vi) cujo painel de controle é apresentado na Figura 4.5.16.

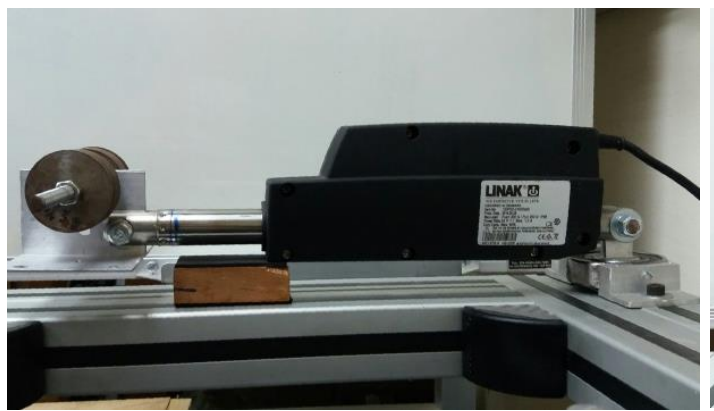

(a)

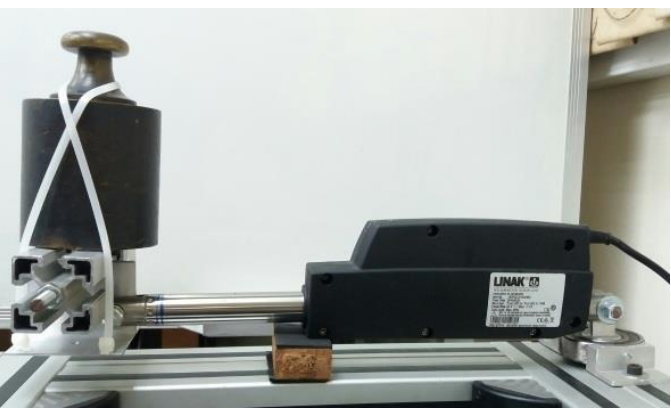

(b)

Figura 4.5.15: Teste horizontal com carga $\mathrm{m}_{\mathrm{h}}=759,8 \mathrm{~g}$ (a) e $\mathrm{m}_{\mathrm{h}}=5327,8 \mathrm{~g}(\mathrm{~b})$. 
Tabela 4.5.5: Resultados dos testes com controlador de velocidade.

\begin{tabular}{c|cc|cc|cc}
\multirow{2}{*}{$\begin{array}{c}\text { Ciclo de } \\
\text { trabalho }\end{array}$} & \multicolumn{2}{|c|}{ sem carga } & \multicolumn{2}{|c|}{$\mathrm{m}_{\mathrm{h}}=759,8 \mathrm{~g}$} & \multicolumn{2}{c}{$\mathrm{m}_{\mathrm{h}}=5327,8 \mathrm{~g}$} \\
& Extensão & Retração & Extensão & Retração & Extensão & Retração \\
\hline \hline$(\mathrm{D})$ & $(\mathrm{mm} / \mathrm{s})$ & $(\mathrm{mm} / \mathrm{s})$ & $(\mathrm{mm} / \mathrm{s})$ & $(\mathrm{mm} / \mathrm{s})$ & $(\mathrm{mm} / \mathrm{s})$ & $(\mathrm{mm} / \mathrm{s})$ \\
\hline $0,25(6 \mathrm{~V})$ & 9,80 & $-8,82$ & 9,79 & $-8,88$ & 9,01 & $-8,60$ \\
$0,50(12 \mathrm{~V})$ & 20,89 & $-19,40$ & 20,98 & $-19,87$ & 20,23 & $-19,55$ \\
$0,75(18 \mathrm{~V})$ & 31,84 & $-30,00$ & 31,52 & $-30,48$ & 31,74 & $-30,47$ \\
$1,00(24 \mathrm{~V})$ & 43,73 & $-40,65$ & 42,29 & $-41,26$ & 43,26 & $-41,04$
\end{tabular}
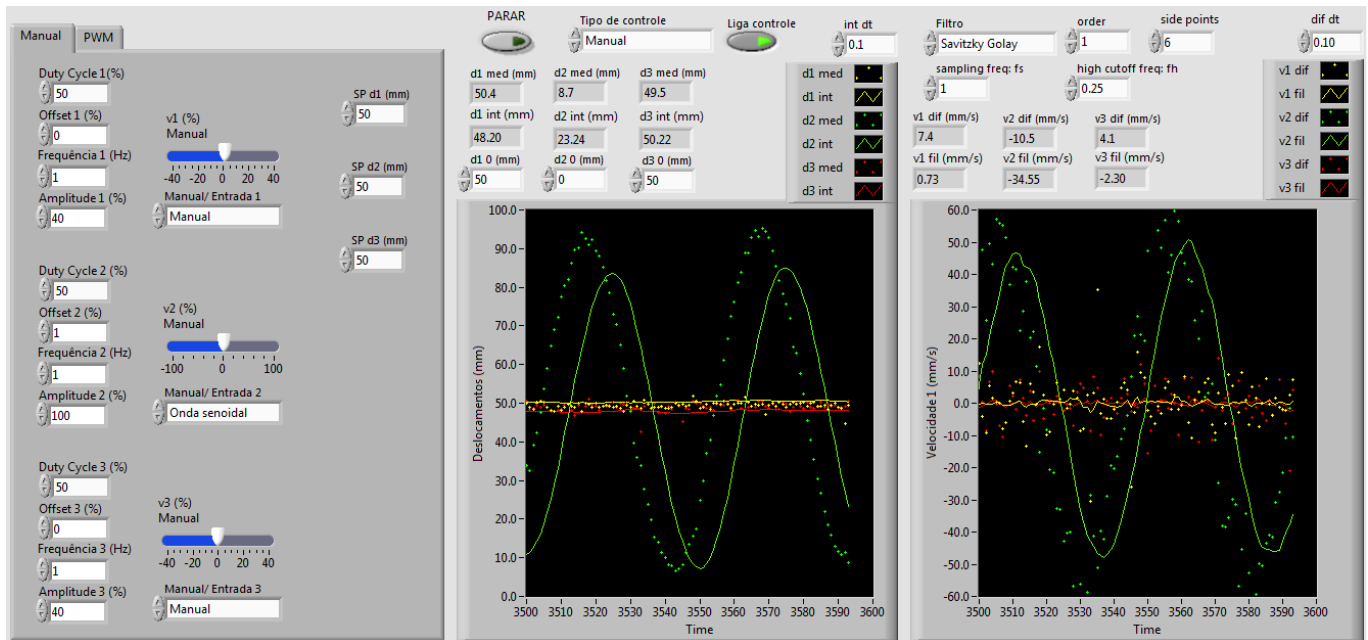

Figura 4.5.16: Painel de controle para os ensaios usando o controlador. 


\section{5 \\ Estratégias de controle}

Neste capítulo será apresentada a estratégia de controle proposta. Primeiramente, será apresentada a estratégia convencional, baseada nos sinais dos transdutores lineares elétricos. Em seguida será apresentada uma estratégia não convencional, baseada no uso de sensores inerciais.

\subsection{Arquitetura de controle via transdutores lineares elétricos}

$\mathrm{O}$ controlador do motor (driver) tem como entradas principais dois parâmetros, a frequência, associada à velocidade em que se abrem e fecham os interruptores de sua ponte $\mathrm{H}$, e o ciclo de trabalho (duty cycle, em inglês), porcentagem de tempo em que estes interruptores permanecem fechados, que determina o nível de tensão equivalente com que o motor é alimentado. Por exemplo, ao reduzir o ciclo de trabalho para metade do período, encontra-se a metade da tensão máxima equivalente. A Equação 5.1.1 apresenta esta relação, sendo $D$, o ciclo de trabalho, $\tau$, o intervalo de tempo no qual a função é não-nula dentro de cada período e $T$, o período da função quadrada.

$$
D=\frac{\tau}{T}
$$

A Figura 5.5.1 apresenta um esquema com da comunicação dos equipamentos para acionamento do motor do atuador linear elétrico e leitura do sinal do transdutor de deslocamento. Para alimentar o controlador Pololu MC33926 é usada uma fonte de alimentação de 24 VDC e para alimentar o circuito do transdutor de deslocamento, uma fonte com um regulador de tensão de $5 \mathrm{~V}$ na saída. A aquisição de dados destes transdutores é feita usando o módulo de aquisição de dados tipo Analog Input (entrada analógica) NI 9205, da National Instruments e a saída de sinais é feita usando um módulo tipo Analog Output NI 9264. Ambas são acopladas em um chassi tipo cDAQ (Compact Data Aquisition 
System), modelo NI 9172. Estes equipamentos formam a controladora do simulador de movimentos, que será o responsável por reunir as informações do sistema de instrumentação e aplicar o resultado do algoritmo de controle nos atuadores elétricos da plataforma.

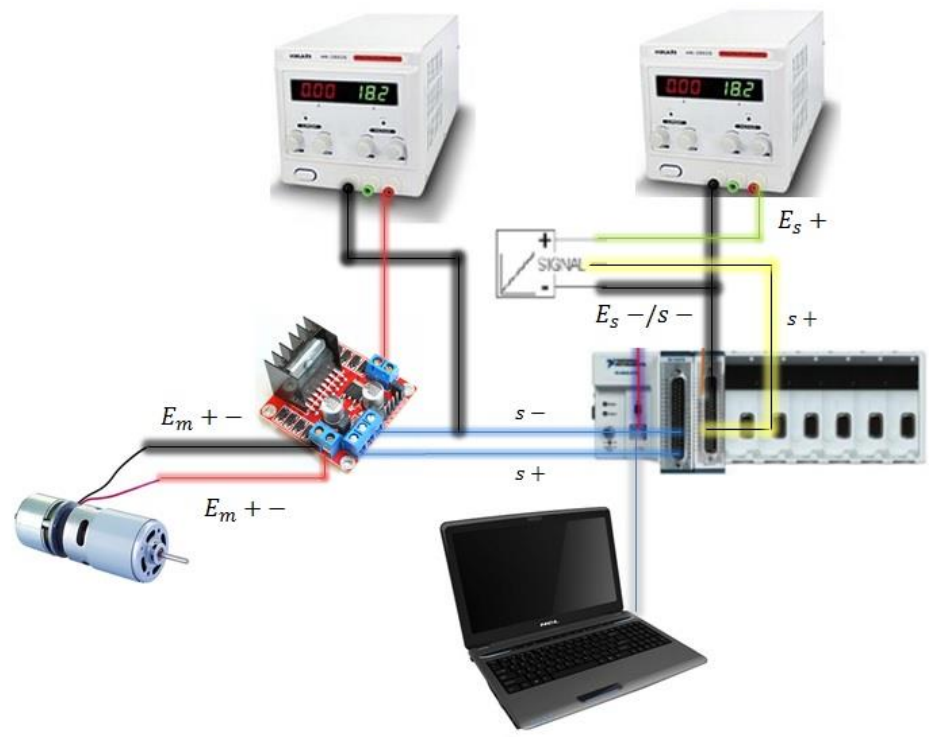

Figura 5.1.1: Esquema do acionamento do motor elétrico.

Para a simulação do sistema em tempo real serão usados os ambientes de programação do MatLab e Simulink, que são bem conhecidos pela sintaxe simples e alta produtividade (Pedersen, M. M., et al., 2012). A estratégia de controle completa envolverá o uso de dois programas simultaneamente, o MatLab e o LabView. Como a simulação do sistema deve ocorrer em tempo real a fim de haver comunicação com o controlador, é essencial limitar o peso computacional a que pode ser alcançado com o equipamento disponível (computador com processador Intel Core i5-2430M CPU @ 2.40GHz, memória RAM de 4,00 GB e sistema operacional de 64 bits). Desta forma, para eliminar este peso, pode-se omitir parte da dinâmica do sistema, o que é aceitável, já que o controlador considera principalmente os valores estacionários da entrada (Pedersen, M. M., et $a l ., 2012$ ). O loop de simulação é executado o mais rápido quanto possível, comumente por volta de $200 \mathrm{~Hz}$, e atualiza todos os parâmetros de simulação e controles da animação (se houver).

Para validação da geometria inversa e controle convencional de posição é usada uma estratégia conforme a apresentada no diagrama da Figura 5.1.2, onde 
$\boldsymbol{x}_{\mathrm{des}}$ é o vetor de entradas do tipo $[X(t) Y(t) \theta(t)]^{\mathrm{T}}, G^{-1}$ corresponde ao modelo da geometria inversa, $\boldsymbol{q}_{\mathrm{des}}$ é o vetor de deslocamentos desejados nos membros do mecanismo, $\left[K_{p}\right]$ é o vetor de ganhos proporcionais, $\boldsymbol{\delta}_{\mathrm{q}}$ é o vetor com as entradas do controlador do motor, $\boldsymbol{v}_{\mathrm{A}}$ é o vetor de velocidades das hastes dos atuadores, $\boldsymbol{q}_{\mathrm{A}}$, o vetor com os deslocamentos reais das hastes, $\boldsymbol{V}_{\text {pot }}$, o sinal dos transdutores de deslocamento acoplados aos atuadores e $\boldsymbol{q}_{\text {med }}$, o vetor com os deslocamentos medidos e $\varepsilon_{\mathrm{q}}$, o sinal de erro de deslocamento. A Equação 5.1.2 apresenta a forma de $\boldsymbol{\delta}_{\mathrm{q}}$, na qual $D_{\mathrm{i}}$ é o ciclo de trabalho do motor $i$ e $s_{\mathrm{i}}$ é a entrada que indica o sentido de rotação ao motor $i, \operatorname{com} i=1,2$ e 3 .

$$
\boldsymbol{\delta}_{\boldsymbol{q}}=\left[\begin{array}{ll}
D_{i} & S_{i}
\end{array}\right]
$$

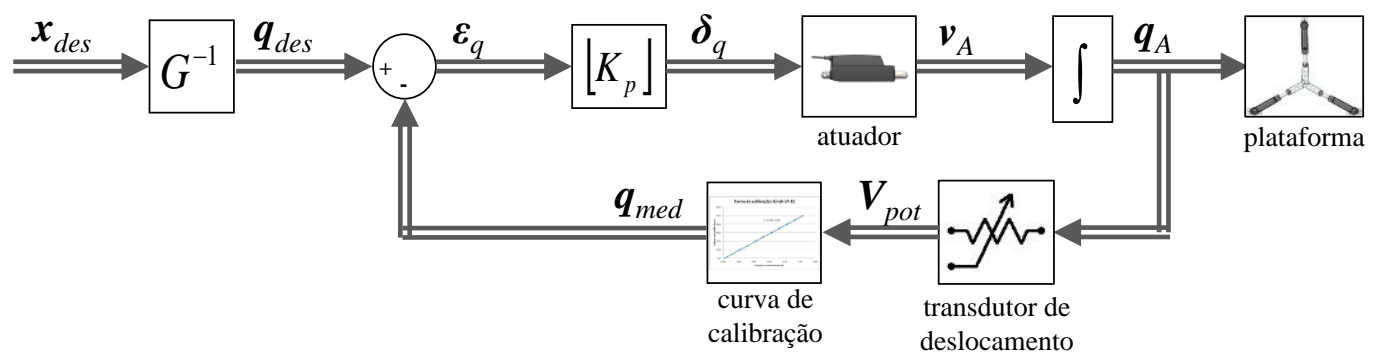

Figura 5.1.2: Estratégia para validação da geometria inversa e controle convencional de posição.

Nesta estratégia as entradas podem ser quaisquer funções no tempo para $X(t), Y(t)$ e $\theta(t)$ e, quanto maiores os ganhos, maiores as intensidades de resposta do atuador aos erros, o que pode diminuir a constante de tempo chegando mais rapidamente em regime permanente, porém, se estes valores forem demasiadamente elevados, podem gerar comportamentos oscilatórios e instabilidades no sistema. Se muito baixos, além de uma resposta mais lenta, podem ficar com erros elevados mesmo em regime permanente. Esta estratégia também pode ser usada como rotina de SetPoint para fazer com que a plataforma vá para a configuração inicial antes de cada teste, por exemplo.

A Figura 5.1.3 apresenta a estratégia para validação da cinemática inversa usando apenas o modelo com a Jacobiana inversa (relações de velocidade), onde $v_{\text {des }}$ é o vetor de entradas do tipo $\left[v_{X}(t) v_{Y}(t) \omega_{Z}(t)\right]^{\mathrm{T}}, J^{-1}$ corresponde ao modelo da cinemática inversa, $\boldsymbol{v}_{\text {Ades }}$ é o vetor de velocidades desejadas, $\boldsymbol{v}_{\text {Aest }}$, o vetor com as 
velocidades estimadas através da derivada no tempo de $\boldsymbol{q}_{\text {med }}$ e $\boldsymbol{\varepsilon}_{\mathrm{v}}$, o sinal de erro de velocidade. Já a Figura 5.1.4 apresenta a estratégia para validação da cinemática inversa usando o modelo com os derivativos da Jacobiana inversa (relações de aceleração), onde $\boldsymbol{a}_{\mathrm{des}}$ é o vetor de entradas do tipo $\left[\begin{array}{lll}a_{X}(t) & a_{Y}(t) & \alpha_{Z}(t)\end{array}\right]^{\mathrm{T}}, \dot{J}^{-1}$ corresponde ao modelo da cinemática inversa usando os derivativos da Jacobiana inversa, $\boldsymbol{a}_{A \text { des }}$ é o vetor de acelerações desejadas, $\boldsymbol{a}_{\text {Aest }}$ o vetor com as acelerações estimadas através da derivada no tempo de $\boldsymbol{v}_{\text {Aest }}$ e $\boldsymbol{\varepsilon}_{\mathrm{a}}$, o sinal de erro de aceleração.

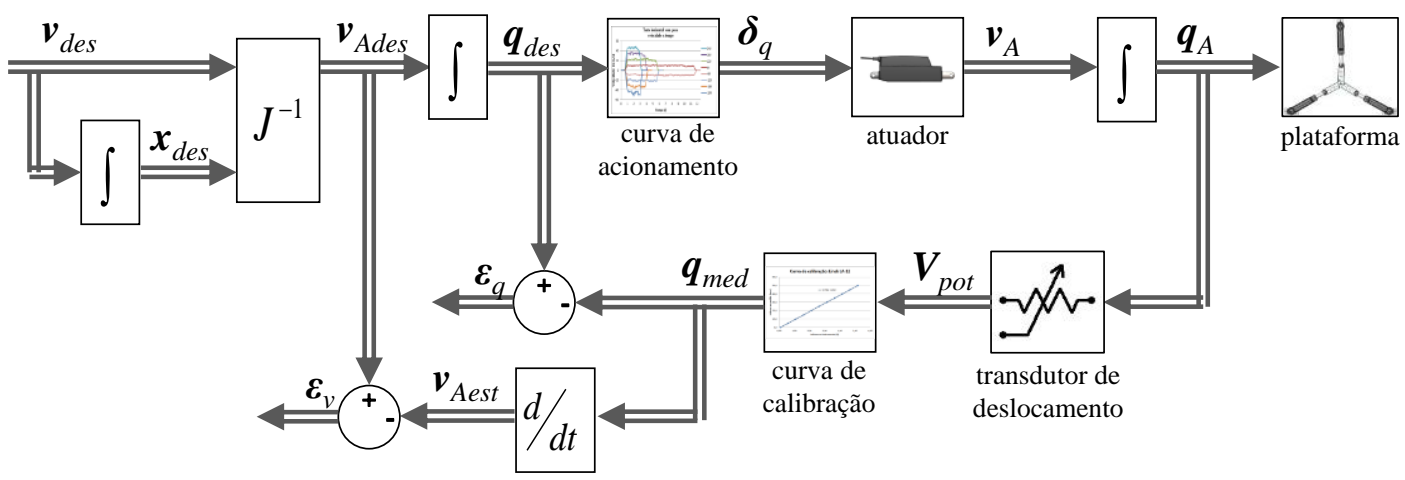

Figura 5.1.3: Estratégia para validação para modelo da Jacobiana inversa.

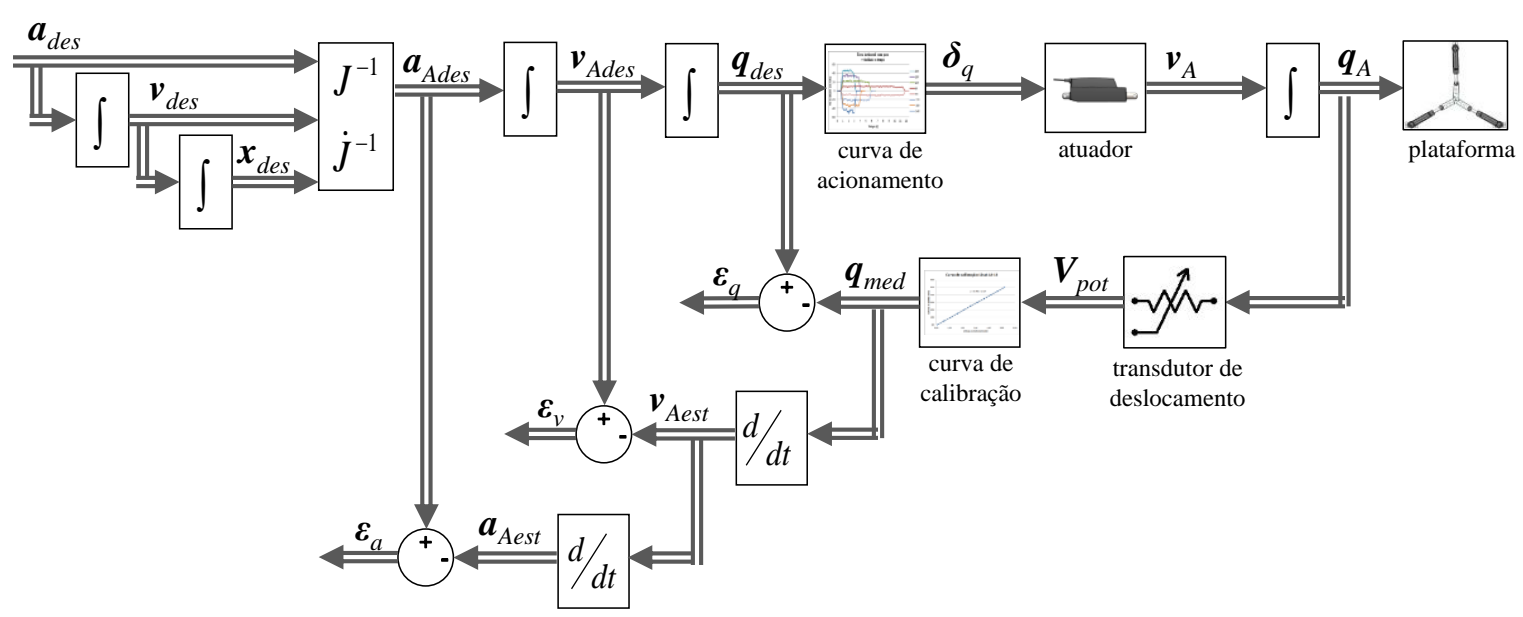

Figura 5.1.4: Estratégia para validação para modelo dos derivativos da Jacobiana inversa.

A partir da estratégia de validação da Figura 5.1.3 foi desenvolvida uma estratégia de controle convencional de velocidade e posição. A Figura 5.1.5 apresenta esta estratégia, que usa apenas o modelo cinemático inverso baseado na matriz Jacobiana inversa. Nesta estratégia é feita uma realimentação comparando 
os sinais de deslocamento desejado $\left(\boldsymbol{q}_{\text {des }}\right)$ e deslocamento medido $\left(\boldsymbol{q}_{\mathrm{med}}\right)$, gerando o sinal de erro de deslocamento $\left(\varepsilon_{\mathrm{q}}\right)$ e, derivando este no tempo, o sinal de erro de velocidade $\left(\boldsymbol{\varepsilon}_{\mathrm{v}}\right)$ para que sejam usados num controlador tipo PD.

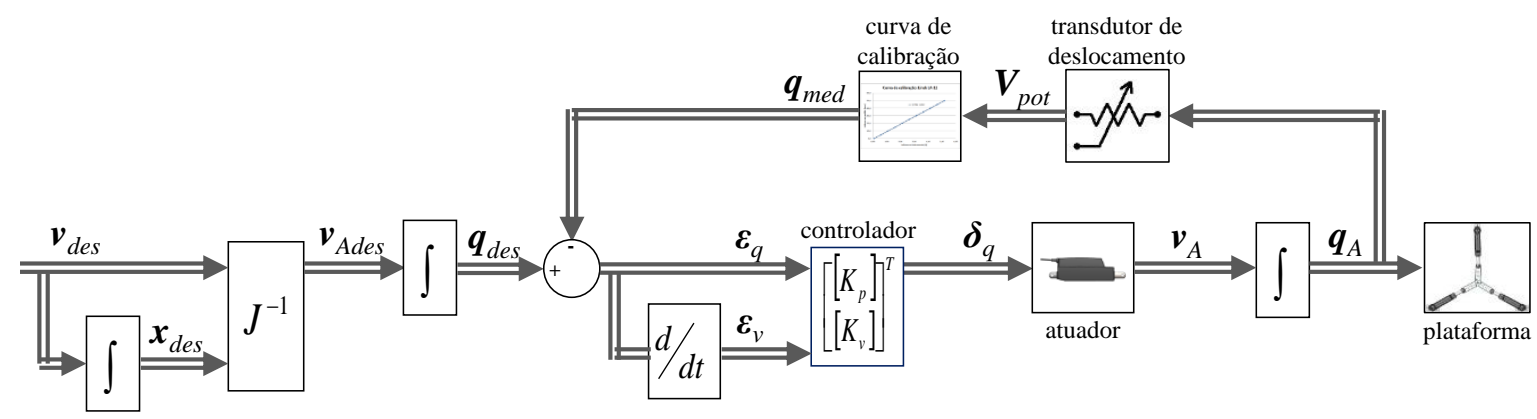

Figura 5.1.5: Estratégia para controle convencional de velocidade e posição.

Já partir da estratégia de validação da Figura 5.1.4 foi desenvolvida uma estratégia de controle convencional de aceleração, velocidade e posição. A Figura 5.1.6 apresenta esta estratégia, que usa o modelo cinemático inverso baseado nos derivativos da matriz Jacobiana inversa. Nesta estratégia é feita uma realimentação comparando os sinais de deslocamento desejado ( $\left.\boldsymbol{q}_{\text {des }}\right)$ e deslocamento medido $\left(\boldsymbol{q}_{\text {med }}\right)$, gerando o sinal de erro de deslocamento $\left(\boldsymbol{\varepsilon}_{\mathrm{q}}\right)$ e, derivando este no tempo uma e duas vezes, os sinais de erro de velocidade $\left(\boldsymbol{\varepsilon}_{\mathrm{v}}\right)$ e de erro de aceleração $\left(\boldsymbol{\varepsilon}_{\mathrm{a}}\right)$ para que sejam usados num controlador tipo PID.

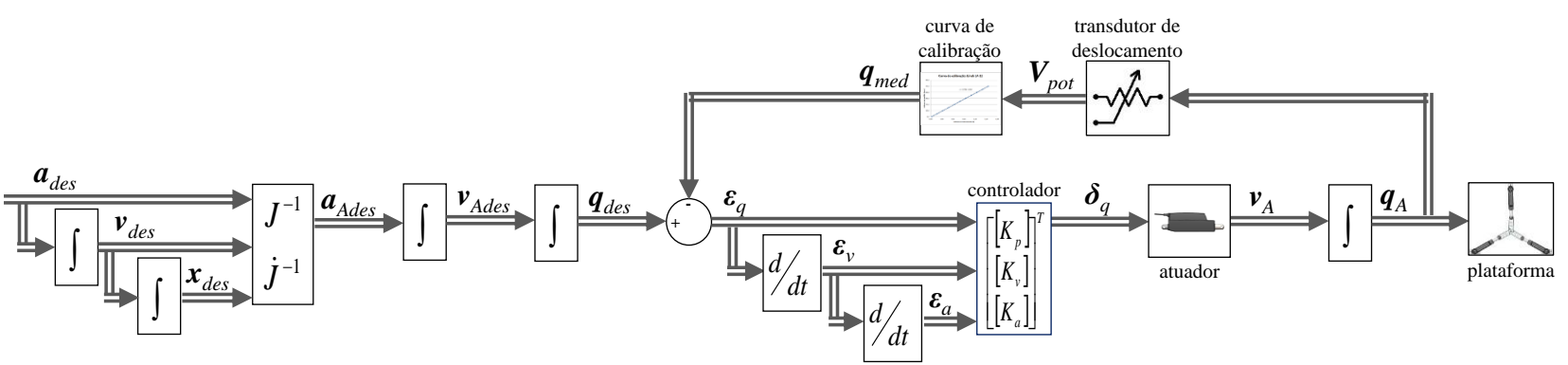

Figura 5.1.6: Estratégia para controle convencional de aceleração, velocidade e posição.

\subsection{Controle via transdutores lineares elétricos e central inercial}

Como outra forma de obtenção do estado cinemático da plataforma móvel do simulador de movimentos será usada a central inercial Pixhawk (Figura 5.2.1), que 
tem embutido os principais sensores necessários para a estratégia de controle proposta: girômetro, acelerômetro e magnetômetro. Além disso, o sistema conta com um sistema de telemetria via rádio que permite analisar e guardar os dados fornecidos para esta central em um computador.
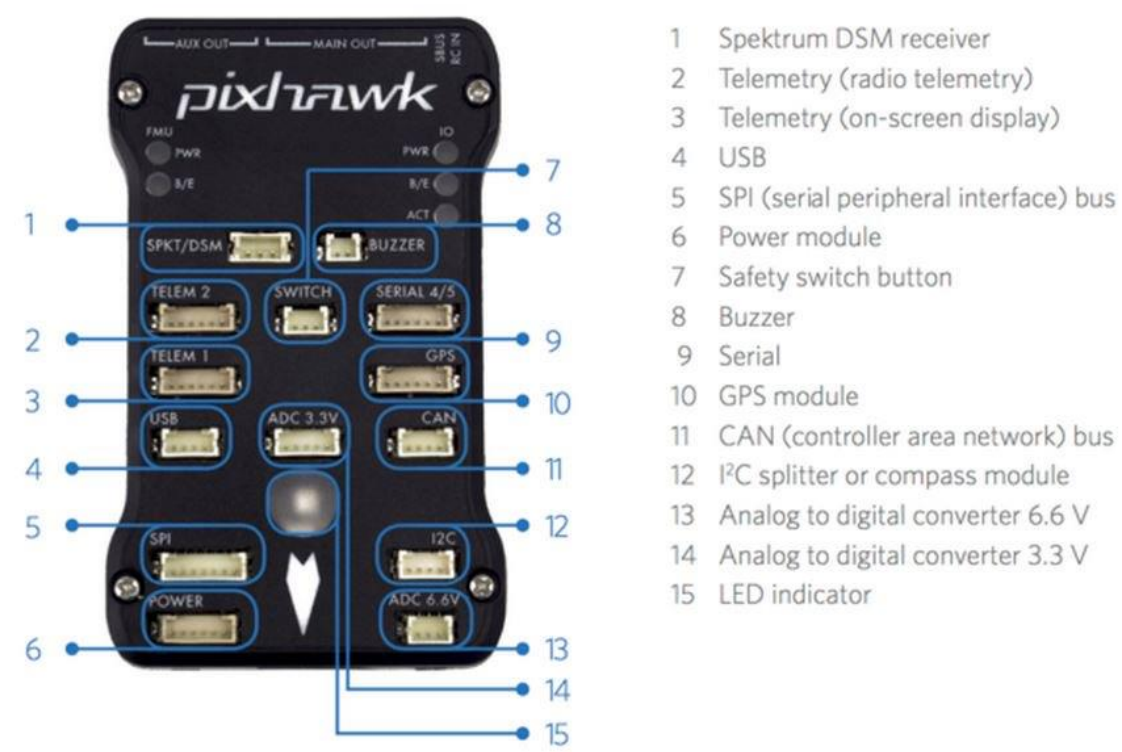

Figura 5.2.1: Central inercial Pixhawk, da 3D Robotics.

O Pixhawk possui cinco módulos de sensores; o primeiro consiste de um girômetro capaz de medir velocidades angulares nos três eixos. Esse equipamento é do tipo MEMS (Micro Electro Mechanical Systems), ou seja, é um dispositivo muito pequeno capaz de medir a vibração de objetos sobre efeito de rotação. Uma pequena massa é presa em um circuito que, ao ser deformado, produz um diferencial de tensão elétrica; quando o sensor rotaciona, a força de Coriolis aplicada na massa produz uma vibração - e, consequentemente, uma deformação - em um plano distinto do de repouso, percebido então pelo circuito do girômetro (Assad, M. M., 2015).

O segundo módulo de sensores envolve um acelerômetro e um magnetômetro, ambos de três eixos. O princípio de funcionamento do acelerômetro é muito parecido com o do girômetro: uma massa sob efeito de aceleração linear irá exercer uma força sobre um circuito sensível à deformação (efeito piezoresistivo). O diferencial de tensão ou corrente gerado irá indicar a relação entre a aceleração sofrida e a gravitacional. O magnetômetro, por sua vez, mede a força e direção de campos magnéticos - no caso, o da Terra - o que permite determinar a orientação absoluta do veículo. Esse equipamento possui pouca precisão para movimentos rápidos, mas tem 
um desvio quase nulo ao longo do tempo. Assim, ele é comumente usado para ajustar os erros acumulados dos dados vindos do acelerômetro e girômetro, que ainda são integrados para determinar a posição da plataforma, agravando esse problema (Assad, M. M., 2015).

O terceiro módulo engloba outro acelerômetro e girômetro de três eixos, ambos do tipo MEMS, resultando em um segundo conjunto para redundância. $\mathrm{O}$ quarto módulo é um barômetro, instrumento capaz de medir as altitudes relativa e absoluta a partir da diferença de pressão atmosférica. Muito usado em voos, esse sensor não será utilizado neste trabalho. Por fim, o último módulo consiste de um GPS com bússola, que também não será usado.

De forma a obter todas as informações de aceleração, velocidade e deslocamento, os módulos apresentados podem ser analisados em conjunto, através de alguma técnica de fusão de sensores, como o filtro de Kalman, por exemplo (Costa, M. S. M., 2014 e Costa, M. S. M., et al. 2015).

Assim, para validar o uso desta central inercial em uma estratégia de controle híbrida, esta central será usada em conjunto com os transdutores de deslocamento, evitando assim o uso da segunda derivada para obtenção de aceleração linear e da primeira para obtenção de velocidade angular.

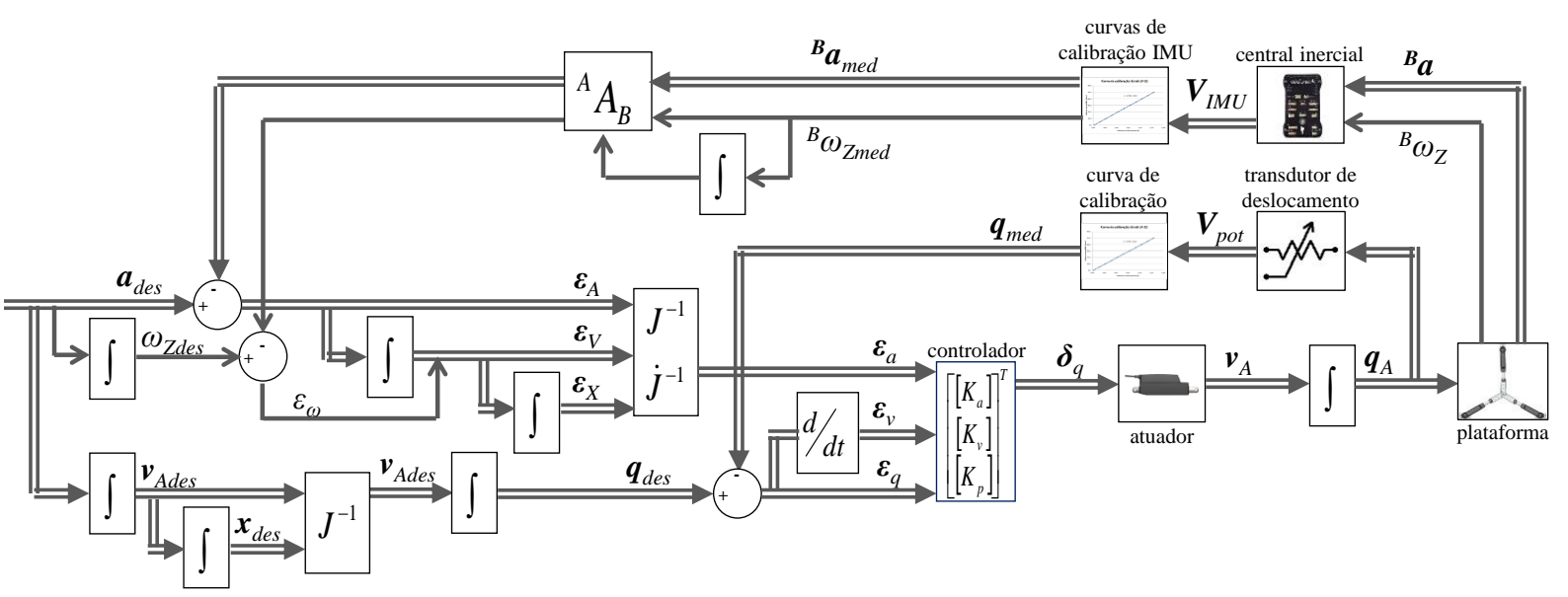

Figura 5.2.2: Estratégia não convencional de aceleração, velocidade e posição.

O sinal de saída do acelerômetro pode ser integrado numericamente para fornecer o sinal de velocidade sem a necessidade de um processamento complexo (Jazar, R. N, 2010). Como os dados obtidos pela central inercial estão no referencial local, B, embarcado na plataforma móvel do mecanismo, estes têm que 
ser transformados para o sistema de coordenadas global, A, fixo no espaço. Dada a posição da origem do sistema móvel em relação à posição da origem do sistema fixo ${ }^{\mathrm{A}} \boldsymbol{\delta}=\left[\begin{array}{ll}X & Y\end{array}\right]^{\mathrm{T}}$ e a matriz de rotação ${ }^{\mathrm{A}} R_{\mathrm{B}}$ (Equação 3.1.1), as coordenadas de um ponto $P$ da plataforma ${ }^{\mathrm{B}} \boldsymbol{r}_{P}$ no sistema local e global são relacionadas pela Equação 5.2.1. Já o vetor velocidade, ${ }^{A} \boldsymbol{v}_{P}$ é descrito pela Equação 5.2.2. Já a aceleração ${ }^{A} \mathbf{a}_{\mathrm{P}}$ é dada pela Equação 5.2.3 (Jazar, R. N, 2010).

$$
\begin{aligned}
& { }^{A} \boldsymbol{r}_{P}={ }^{A} R_{B}{ }^{B} \boldsymbol{r}_{P}+{ }^{A} \boldsymbol{\delta}_{B} \\
& { }^{A} \boldsymbol{v}_{P}={ }^{A} \dot{R}_{B}{ }^{A} R_{B}{ }^{T}\left({ }^{A} \boldsymbol{r}_{P}-{ }^{A} \boldsymbol{\delta}_{B}\right)+{ }^{A} \dot{\boldsymbol{\delta}}_{B}={ }_{A} \widetilde{\omega}_{B}\left({ }^{A} \boldsymbol{r}_{P}-{ }^{A} \boldsymbol{\delta}_{B}\right)+{ }^{A} \dot{\boldsymbol{\delta}}_{B}= \\
& ={ }_{A} \boldsymbol{\omega}_{B} \times\left({ }^{A} \boldsymbol{r}_{P}-{ }^{A} \boldsymbol{\delta}_{B}\right)+{ }^{A} \dot{\boldsymbol{\delta}}_{B}={ }_{A} \boldsymbol{\omega}_{B} \times{ }_{B}^{A} \boldsymbol{r}_{P}+{ }^{A} \dot{\boldsymbol{\delta}}_{B} \\
& { }^{A} \boldsymbol{a}_{P}={ }^{A} \dot{\boldsymbol{v}}_{P}= \\
& ={ }_{A} \boldsymbol{\alpha}_{B} \times\left({ }^{A} \boldsymbol{r}_{P}-{ }^{A} \boldsymbol{\delta}_{B}\right)+{ }_{A} \boldsymbol{\omega}_{B} \times\left({ }_{A} \boldsymbol{\omega}_{B} \times\left({ }^{A} \boldsymbol{r}_{P}-{ }^{A} \boldsymbol{\delta}_{B}\right)\right)+{ }^{A} \ddot{\boldsymbol{\delta}}_{B}
\end{aligned}
$$

\subsection{Controle via central inercial}

De forma geral, a estratégia de controle baseada nas acelerações lineares e velocidades angulares da plataforma móvel em questão é inspirada na estratégia apresentada no diagrama da Figura 5.3.1. As posições, velocidades e acelerações lineares, assim como a orientação, a velocidade e a aceleração angular que formam o conjunto de informações que descrevem a trajetória desejada, passam pelos modelos da cinemática inversa dos mecanismos para a obtenção das velocidades e acelerações desejadas nos atuadores. A comparação com os valores atuais (medidos pela IMU) gera o sinal de erro que é tratado no controlador e passa pelo modelo do sistema de atuação para assim gerar a saída com a trajetória efetiva da plataforma móvel. As acelerações lineares e a velocidade angular efetivas do mecanismo são medidas pela central inercial para então passar pelos modelos da dinâmica direta a fim de obter os valores efetivos das velocidades e acelerações dos atuadores, para que estes possam ser comparados com os valores desejados (Albuquerque, A. N., 2012). 


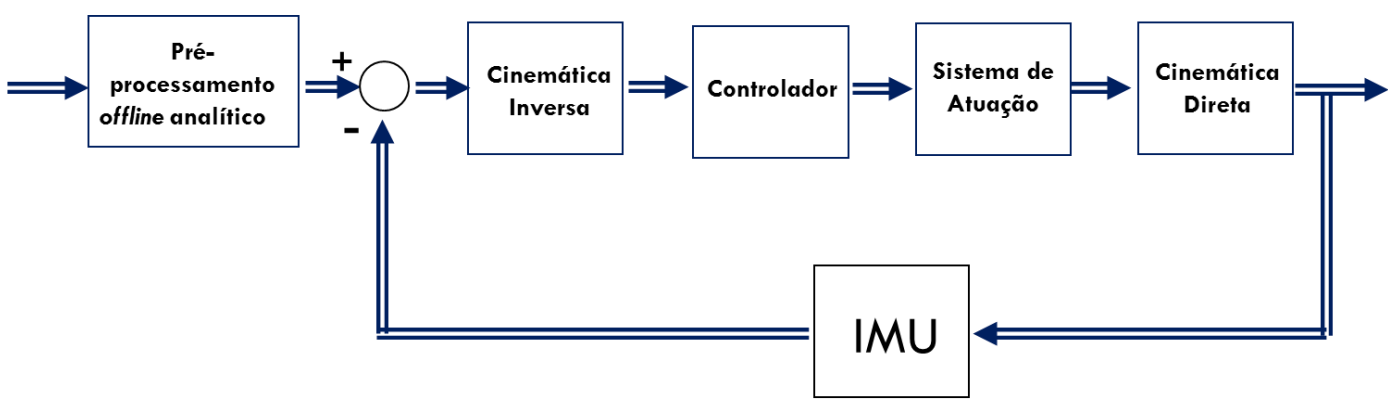

Figura 5.3.1: Sistema em malha fechada.

A Figura 5.3.2 apresenta o diagrama de blocos desta malha de controle com o detalhamento das variáveis e dos modelos cinemáticos e dinâmicos ao longo da malha. A trajetória desejada dada em termos da posição e orientação da plataforma móvel é tratada fora do ambiente de simulação para que as acelerações lineares e velocidades angulares resultantes formem o conjunto de variáveis de entrada do problema.

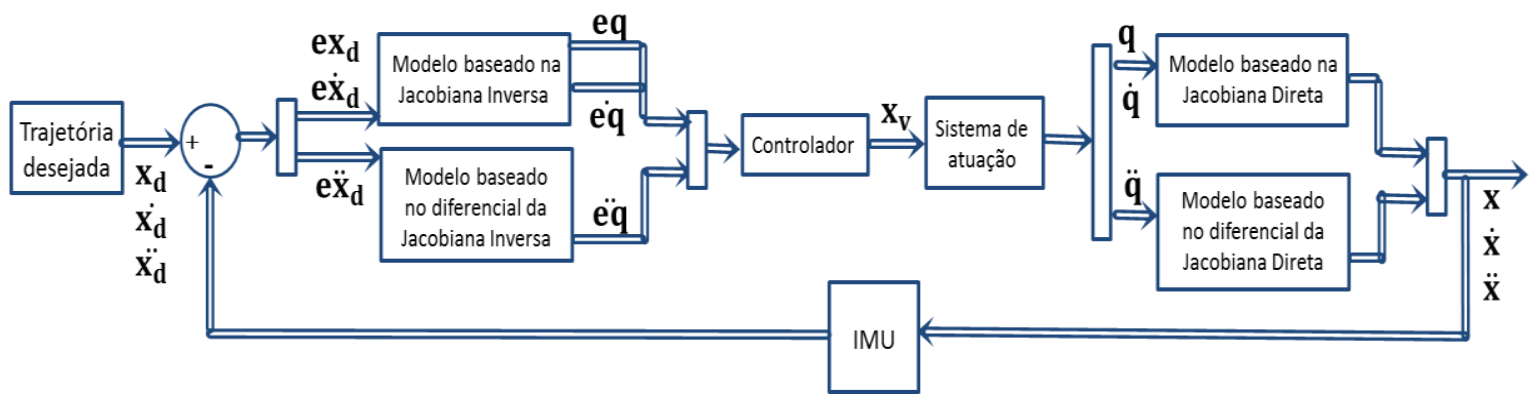

Figura 5.3.2: Esquema dos modelos cinemáticos da malha de controle.

Assim, o sistema de controle para o simulador de movimentos proposto em Albuquerque, A. N. (2012) fica como detalhado na Figura 5.3.3. O controlador assume a forma de uma matriz de ganhos que multiplicam os sinais dos erros em posição, velocidade e aceleração.

Inspirado nesta estratégia foi desenvolvida a estratégia da Figura 5.3.4, na qual uma central inercial é usada para controlar aceleração, velocidade e posição da plataforma plana com três graus de liberdade. A dinâmica do mecanismo real substitui o modelo cinemático direto e assim, após os sinais passarem pela controladora e o sistema de atuação gerar o movimento dos membros do mecanismo, a própria resposta do sistema em $\boldsymbol{a}$ (e consequentemente, em $\boldsymbol{v}$ e $\boldsymbol{x}$ ) 
alimentará a IMU. Lembrando que os dados da IMU são obtidos no referencial local (B) e, para serem comparados com as entradas, que estão no referencial global (A), tem que ser feita uma transformação conforme o modelo apresentado na Seção 5.2.

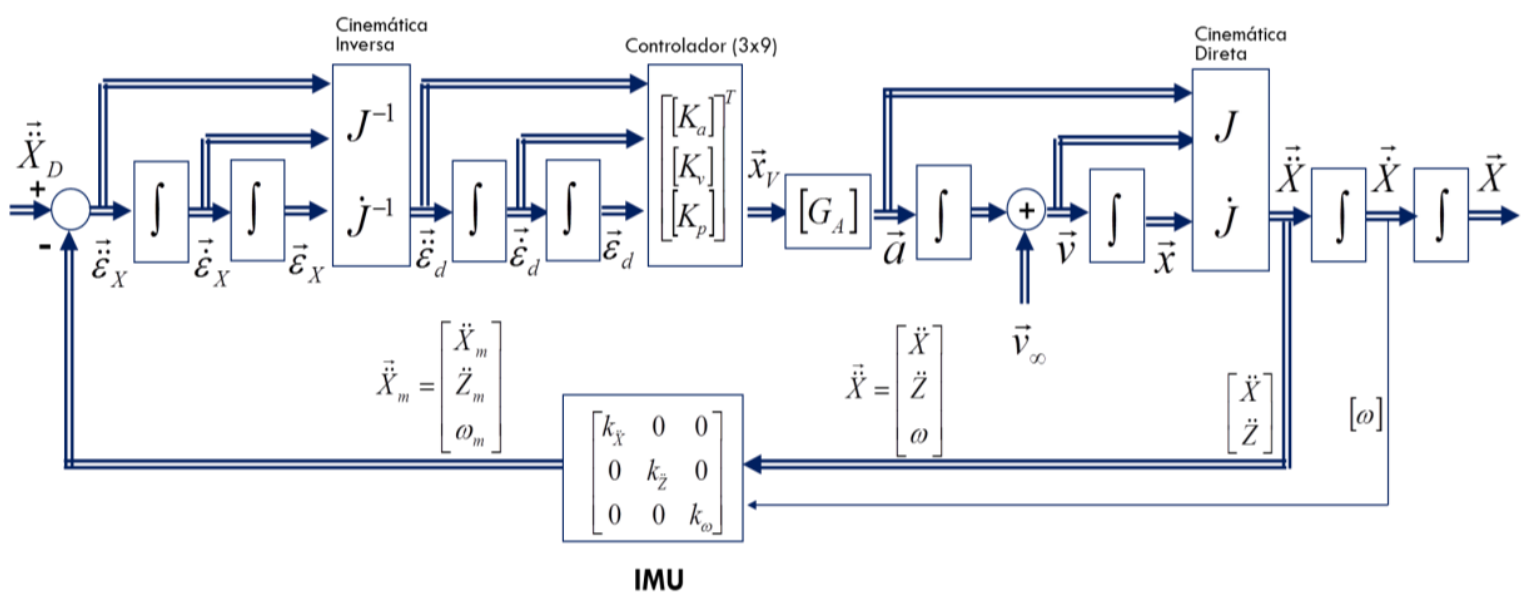

Figura 5.3.3: Diagrama de blocos da malha de controle.

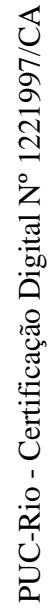

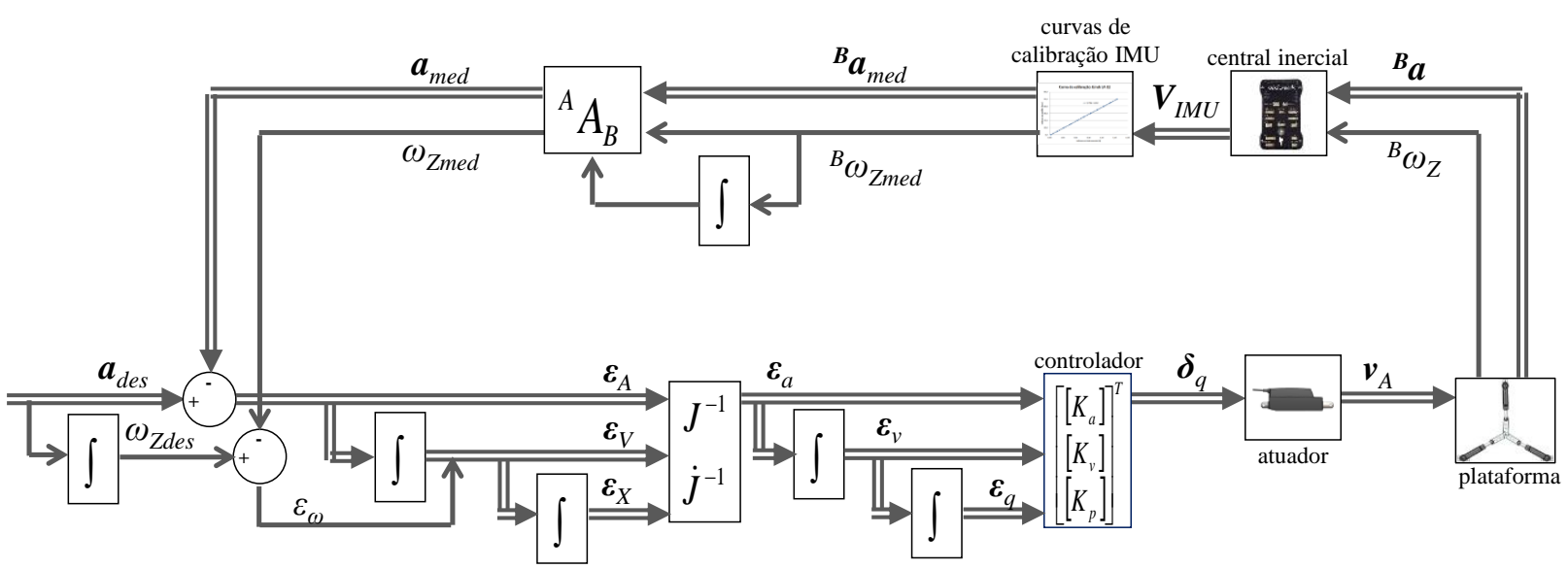

Figura 5.3.4: Estratégia de controle via central inercial. 


\section{Simulações para avaliação dos modelos desenvolvidos}

Neste capítulo são apresentadas as simulações, que são executadas nos programas SolidWorks Motion Analysis e MatLab/Simulink, para validação dos modelos dinâmicos do atuador linear elétrico, do mecanismo paralelo plano e da estratégia de controle proposta.

\subsection{Atuador linear elétrico}

\subsubsection{Simulações em MatLab/Simulink}

Neste Item são apresentadas as simulações feitas usando os modelos obtidos na Seção 4.1. Primeiramente é feita uma simulação com um modelo simplificado. A estrutura em grafos de ligação deste modelo é apresentada na Figura 6.1.1 e seu modelo correspondente é apresentado na Equação 6.1.1. Para obtenção da inércia equivalente é usada a Equação 6.1.2.

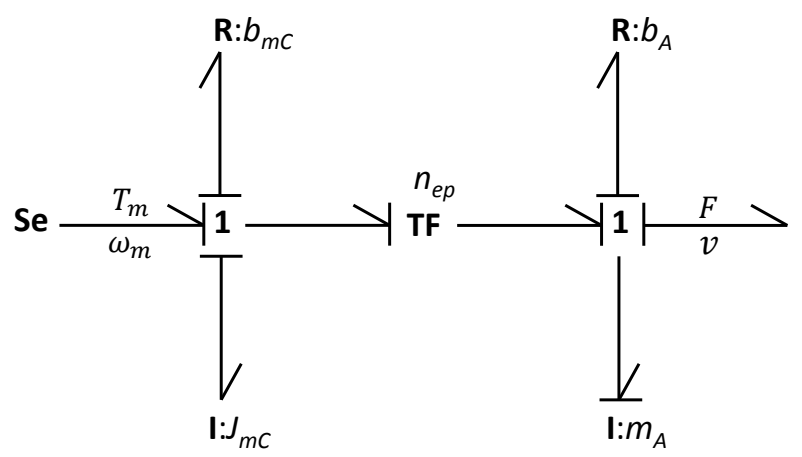

Figura 6.1.1: Modelo do atuador simplificado.

$$
\begin{aligned}
& \dot{v}=\left(\frac{n_{e p}}{J_{m C}+n_{e p^{2} m_{A}}}\right) T_{m}-\left(\frac{b_{m C}+b_{A} n_{e p}^{2}}{J_{m C}+n_{e p}{ }^{2} m_{A}}\right) v \\
& J_{m C}=J_{1}+J_{2}\left(\frac{r_{A}}{r_{B 1}}\right)^{2}+J_{3}\left(\frac{r_{B 2}}{r_{C}}\right)^{2}
\end{aligned}
$$


Para os coeficientes de dissipação $\left(b_{m c}\right.$ e $\left.b_{A}\right)$ é estimada uma resistência equivalente $\left(R_{e q}\right)$. Os elementos da equação $J_{1}, J_{2}$ e $J_{3}$ foram obtidos das propriedades de massa do modelo completo em CAD. O torque aplicado foi extraído dos testes realizados com o motor elétrico (Seção 4.4). A Figura 6.1.2.a apresenta o perfil no tempo deste torque aplicado. A Tabela 6.1.1 apresenta os valores dos parâmetros usados na simulação.

Tabela 6.1.1: Parâmetros usados na simulação do atuador linear elétrico.

\begin{tabular}{|c|c|c|c|}
\hline Identificação & Representação & Valor & Unidade \\
\hline Momento de inércia do motor e trem de engrenagens & $J_{m c}$ & $5,62 \times 10^{-5}$ & $\mathrm{~kg} . \mathrm{m}^{2}$ \\
\hline Massa da haste & $m_{A}$ & 0,1749 & $\mathrm{~kg}$ \\
\hline Razão total de transmissão & $n_{e p}$ & 0,1156 & $\mathrm{~m}$ \\
\hline Coeficiente de dissipação do motor e trem de engrenagens & $b_{m c}$ & 0,003 & $\mathrm{~N} . \mathrm{m} . \mathrm{s} / \mathrm{rad}$ \\
\hline Coeficiente de dissipação da haste do atuador & $b_{A}$ & 0,003 & N.s $/ \mathrm{m}$ \\
\hline
\end{tabular}

Com esses dados de entrada foram obtidas as respostas no tempo para a aceleração, velocidade e deslocamento do atuador (Figuras 6.1.2.b a 6.1.2.d, respectivamente). Na Figura 6.1.2.d, o deslocamento máximo do atuador quando o regime permanente é atingido é próxima de $70 \mathrm{~mm}$, sendo o curso máximo do atuador, $100 \mathrm{~mm}$. Em um sistema sem dissipação, quando o perfil de torque atinge zero, o que acontece em aproximadamente $2 \mathrm{~s}$ de tempo de simulação, a aceleração também vai a zero e a velocidade permanece constante. Porém, devido aos elementos dissipativos, a haste desacelera e a velocidade vai a zero. A Figura 6.1.2.c apresenta a velocidade do atuador ao longo da simulação e a máxima velocidade alcançada é de $37,7 \mathrm{~mm} / \mathrm{s}$. Lembrando que a velocidade máxima de acordo com o fabricante é de $40 \mathrm{~mm} / \mathrm{s}$. Já a Figura 6.1.2.b indica a resposta no tempo da aceleração do atuador. No início do movimento da haste, sua aceleração é máxima. Há um decrescimento da aceleração conforme o torque diminuiu ao longo do tempo e observa-se que no tempo de aproximadamente 1,5 s, a aceleração fica negativa, o que faz a haste frear e atingir seu valor em regime permanente. 


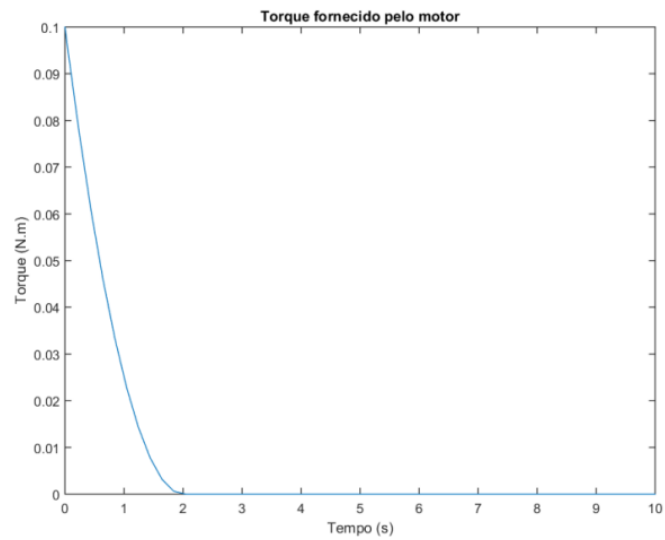

(a)

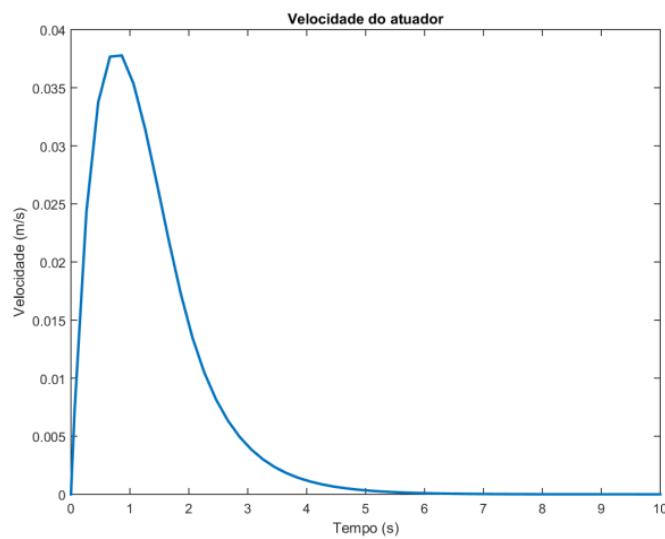

(c)

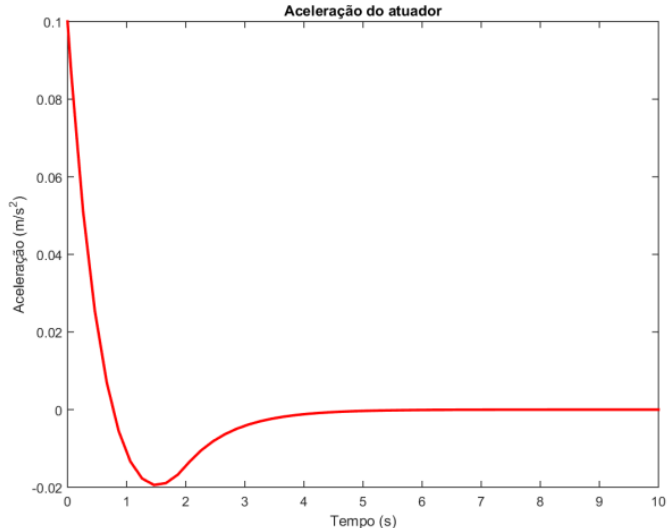

(b)

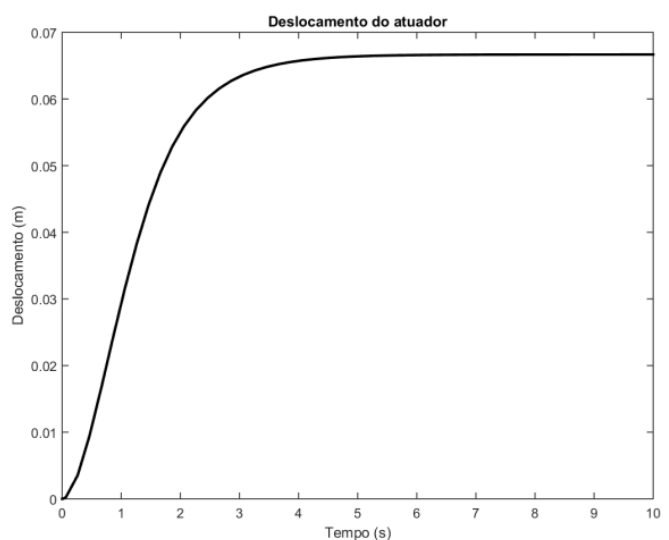

(d)

Figura 6.1.2: Torque fornecido pelo motor (a), aceleração (b), velocidade (c) e deslocamentos do atuador (d).

\subsubsection{Simulações em SolidWorks Motion Analysis}

A Análise de Movimento do SolidWorks (SolidWorks Motion) permite que dois tipos de problemas relacionados com o movimento dos corpos sólidos sejam estudados: a cinemática, estudo do movimento de um corpo rígido sem considerar as forças que resultam neste movimento, e a dinâmica, estudo do movimento de um corpo rígido como um resultado das cargas aplicadas sobre o corpo. Estas cargas podem ser forças e/ou torque externos (fontes de esforços); entradas em velocidade são dadas por motores lineares ou rotativos ideais (fontes de fluxo); e os parâmetros do sistema são dados por molas (elementos capacitores do sistema), amortecedores (elementos resistores do sistema) e as massas e momentos de inércias que são incorporadas do próprio modelo desenvolvido em CAD 
(elementos de inércia do sistema). Assim, a simulação do SolidWorks Motion pode calcular o efeito destes elementos, da ação da gravidade e do contato entre os componentes (via inserção de coeficientes de atrito nas superfícies do modelo; Nizar, M. H. M., 2013).

No ambiente de simulação, um corpo rígido sem restrições no espaço tem seis graus de liberdade: três translacionais e três rotacionais. Este pode mover-se ao longo dos eixos $\mathrm{X}, \mathrm{Y}$, e Z e rotacionar em torno destes eixos. Porém, restrições podem ser impostas para adequar o modelo às restrições do sistema real ou até mesmo para simplificar uma simulação. Um conjunto de equações diferenciais e equações algébricas definem as equações de movimento do SolidWorks Motion. A solução numérica destas equações é obtida pela integração destas equações diferenciais enquanto são satisfeitas as restrições algébricas em cada passo do tempo da simulação. Com esta ferramenta, também podem ser detectadas interferências mecânicas nos modelos simulados durante o movimento analisado.

As entradas do sistema podem ser valores constantes, funções no tempo ou até mesmo dados interpolados de uma curva de desempenho de um atuador, por exemplo. Podem ser escolhidos três métodos de interpolação: interpolação Akima (Akima, H., 1970), cúbica ou linear.

Para o projeto e construção da plataforma plana foi usado um modelo em CAD simplificado do atuador linear elétrico LINAK LA12. Este modelo contém apenas sua estrutura externa e a haste (Figura 6.1.3.a). Já para as simulações usando o Motion Analysis, extensão para simulação dos modelos dinâmicos do programa SolidWorks, usado para o desenvolvimento dos modelos em CAD, foi elaborado um modelo com todas as principais características geométricas (posição e orientação no espaço, diâmetro primitivo das engrenagens e outros dimensionamentos básicos), cinemáticas (relações de transmissão entre engrenagens e entre o parafuso de avanço e a haste, além de outras restrições cinemáticas de movimento) e dinâmicas (massas, momentos de inércia e coeficientes de atrito) das partes móveis (Figura 6.1.3.b). 


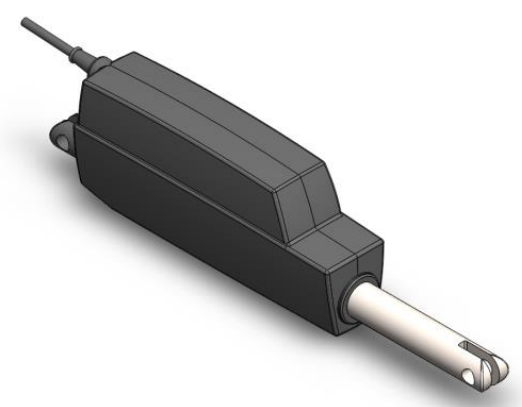

(a)

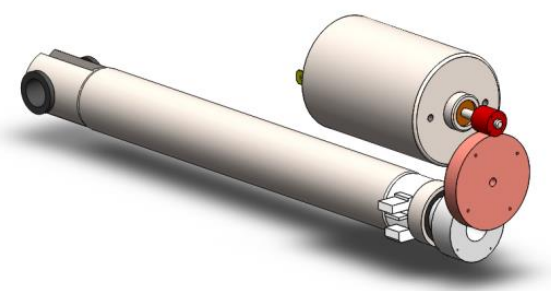

(b)

Figura 6.1.3: Modelo simplificado (a) e detalhado (b) do atuador linear elétrico.

Para estudar o comportamento do modelo detalhado, foi aplicado um torque conforme mostra a Figura 6.1.5.a. Este torque foi aplicado conforme mostra a Figura 6.1.4. A Figura 6.1.5.b apresenta a velocidade da haste do atuador no tempo.

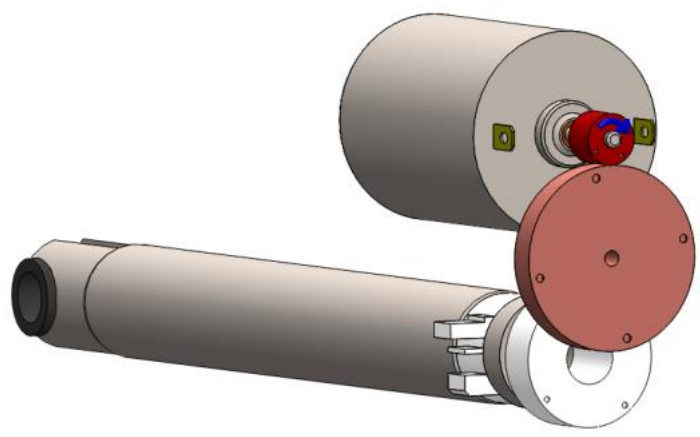

Figura 6.1.4: Torque aplicado no modelo.

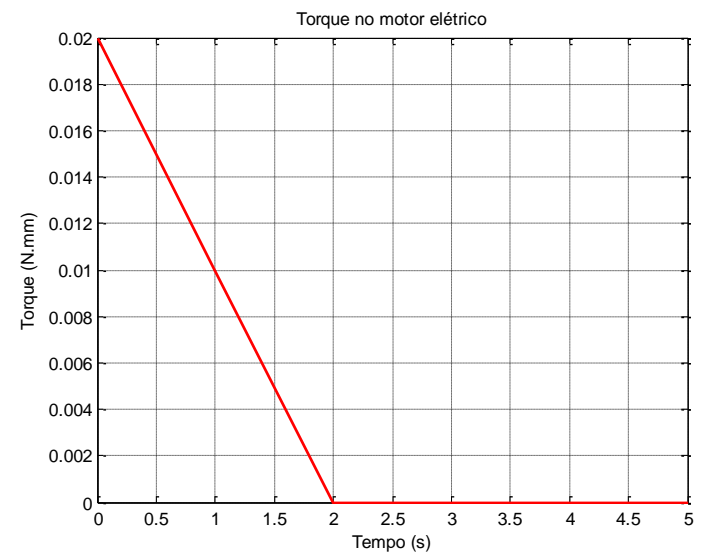

(a)

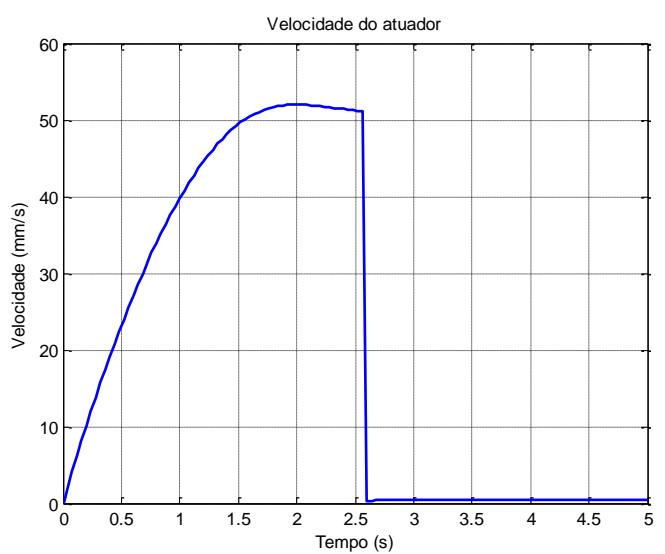

(b)

Figura 6.1.5: Velocidade da haste do atuador no tempo. 


\subsection{Modelo cinemático do mecanismo paralelo plano}

\subsubsection{Simulações em MatLab/Simulink}

Um conjunto de simulações foi feito para verificar e validar os modelos da geometria (pela cadeia vetorial) e da cinemática inversa (usando as matrizes $\mathbf{J}^{-1} \mathrm{e}$ $\mathbf{J}_{\theta}^{-1}$ ). A Tabela 6.2.1 apresenta os parâmetros geométricos e a Figura 6.2.1 apresenta duas configurações do mecanismo plano no ambiente de simulação do MatLab/Simulink: a condição inicial, onde $\left[\begin{array}{lll}X & Y & \theta\end{array}\right]=\left[\begin{array}{llll}0.0 & 0.0 & 0.0\end{array}\right]$ (a) e uma configuração onde $\left[\begin{array}{lll}X & Y\end{array}\right]=\left[\begin{array}{lll}20.0 & 30.0 & 0.262\end{array}\right]$ (b), com $X$ e $Y$ em mm e $\theta$ em rad.

Tabela 6.2.1 - Parâmetros geométricos.

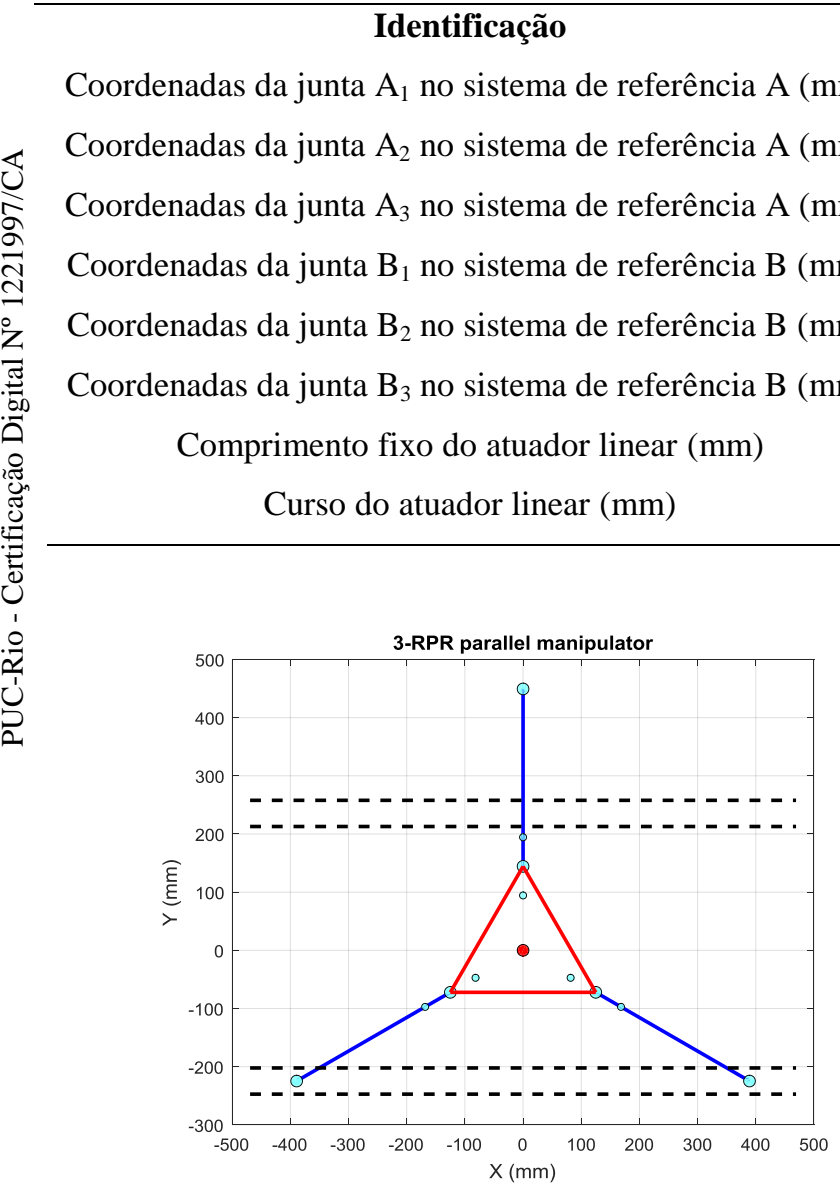

(a)

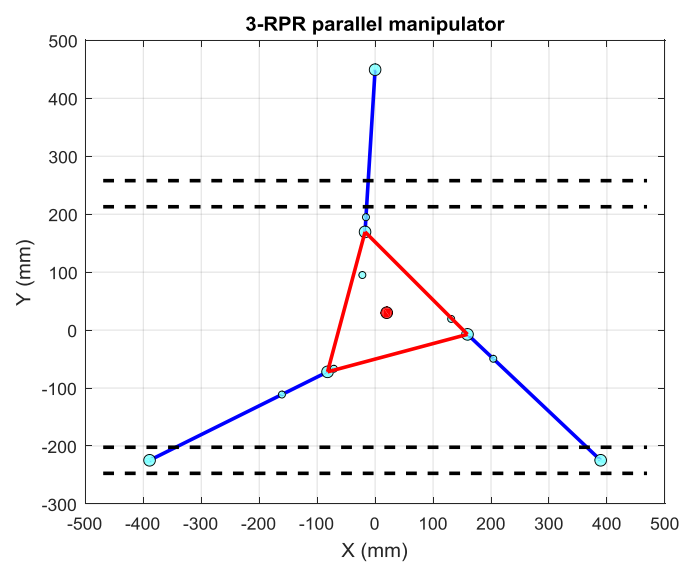

(b)

Figura 6.2.1: Manipulador paralelo 3-RPR: (a) $X=0.0 \mathrm{~mm}, Y=0.0 \mathrm{~mm}$ e $\theta=$ $0.000 \mathrm{rad}$; (b) $X=20.0 \mathrm{~mm}, Y=30.0 \mathrm{~mm}$ e $\theta=0.262 \mathrm{rad}\left(15.0^{\circ}\right)$. 
Usando as matrizes Jacobianas das Equações 3.1.14 e 3.1.20, foram obtidas as repostas no tempo para o conjunto de funções de entrada apresentado na Equação 6.2.1. As Figuras 6.2.2.b e 6.2.2.d apresentam as velocidades lineares e angulares dos atuadores, respectivamente, obtidas diretamente e das matrizes Jacobianas. Já as Figuras 6.2.2.a e 6.2.2.c apresentam os deslocamentos lineares e angulares dos atuadores, respectivamente, pela integração (com as condições de contorno correspondentes) das velocidades dos atuadores.

$$
\left\{\begin{array}{l}
v_{X}=50.00 \sin (\pi t) \mathrm{mm} / \mathrm{s} \\
v_{Y}=50.00 \sin (\pi t) \mathrm{mm} / \mathrm{s} \\
\omega_{Z}=0.785 \sin (\pi t) \mathrm{rad} / \mathrm{s}
\end{array}\right.
$$

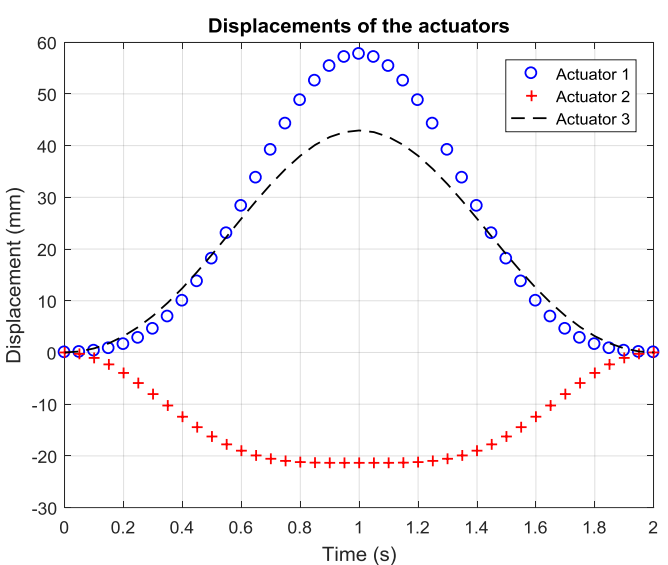

(a)

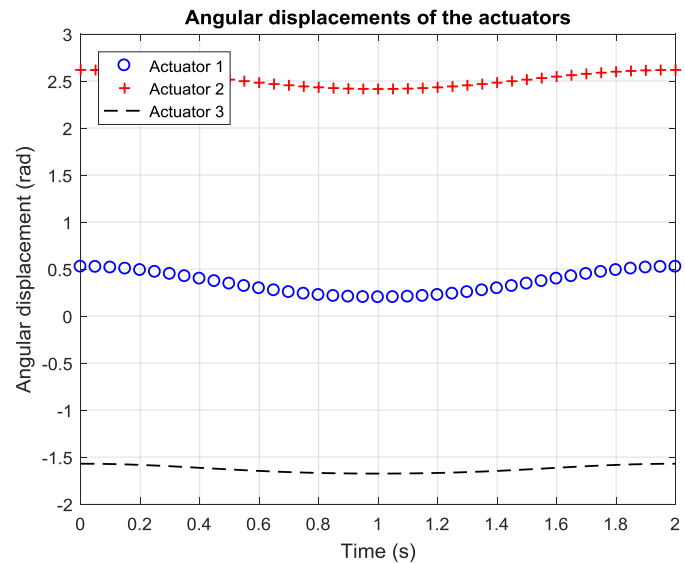

(c)

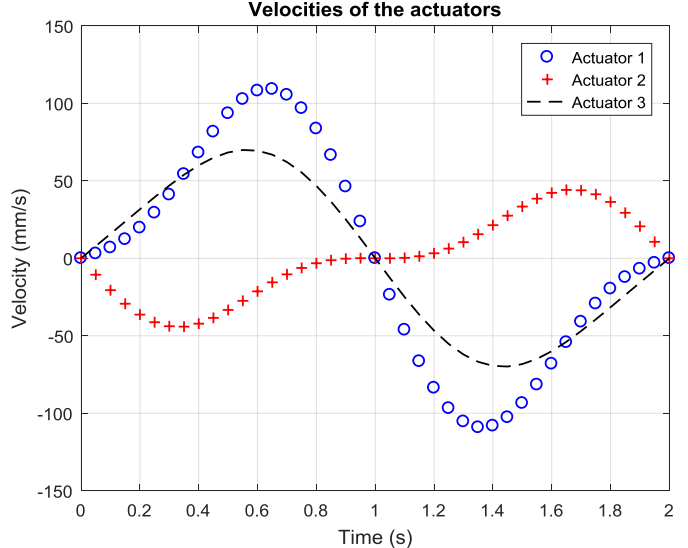

(b)

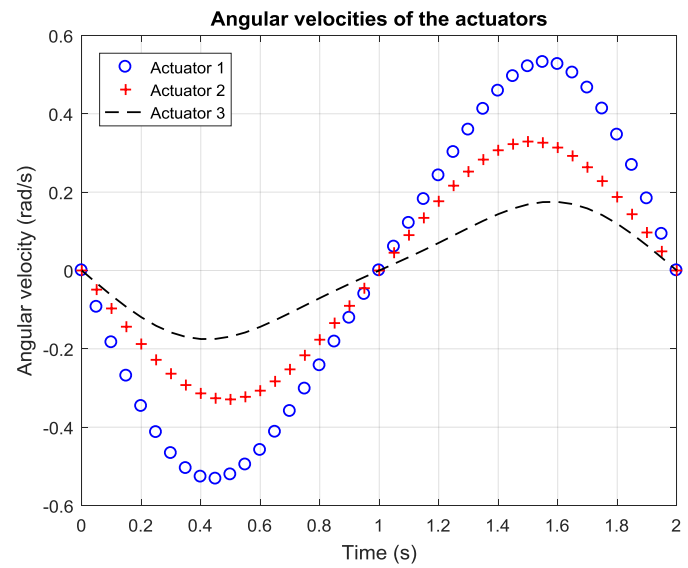

(d)

Figura 6.2.2: Deslocamento e velocidades lineares e angulares dos atuadores.

Usando as matrizes dos derivativos do Jacobiano (Equações 3.1.25 e 3.1.29), a resposta no tempo para o movimento dos atuadores foi obtida para o 
conjunto de funções de entrada apresentado na Equação 6.2.2. As Figuras 6.2.3.b e 6.2.3.d apresentam as acelerações lineares e angulares dos atuadores e as Figuras 6.2.3.a e 6.2.3.c apresentam as velocidades lineares e angulares dos atuadores, respectivamente, pela integração (com as condições de contorno correspondentes) das acelerações dos atuadores.

$$
\left\{\begin{array}{l}
a_{X}=5.00 \sin (\pi t) \mathrm{mm} / \mathrm{s}^{2} \\
a_{Y}=-5.00 \sin (\pi t) \mathrm{mm} / \mathrm{s}^{2} \\
\alpha_{Z}=0.0873 \sin (\pi t) \mathrm{rad} / \mathrm{s}^{2}
\end{array}\right.
$$

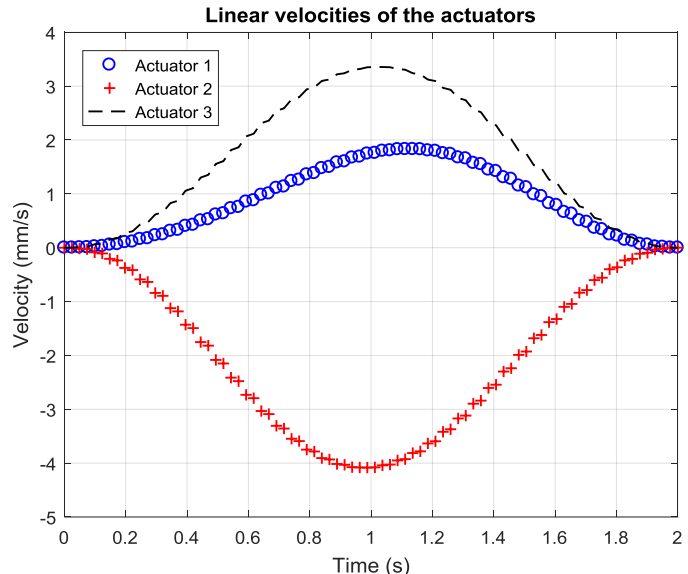

(a)

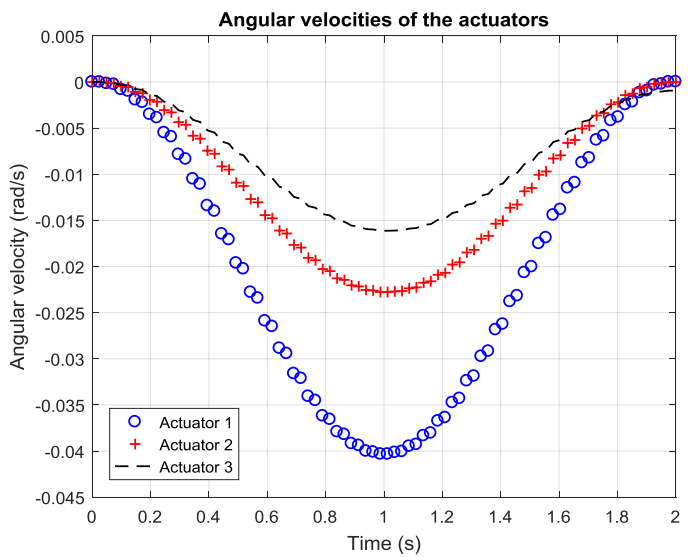

(c)

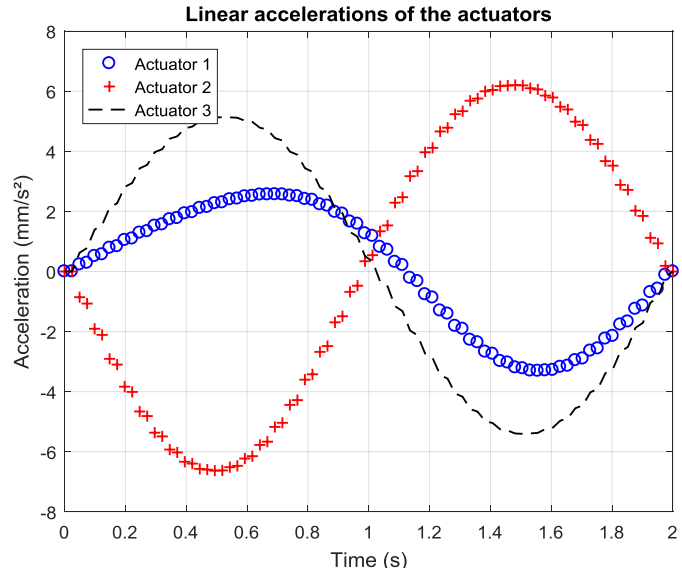

(b)

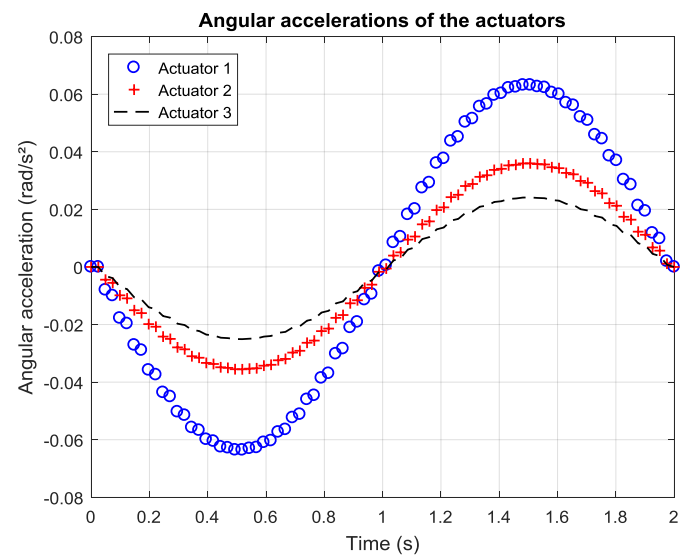

(d)

Figura 6.2.3: Velocidades e acelerações lineares e angulares dos atuadores.

\subsubsection{Simulações em SolidWorks Motion Analysis}

A Figura 6.2.1 apresenta o modelo em CAD usado no ambiente de simulação do SolidWorks Motion Analysis. O desenvolvimento deste modelo em 
CAD é detalhado na Seção 7.1. Nas primeiras simulações foram dadas entradas constantes nas velocidades da plataforma móvel. As Figura 6.2.4.a 6.2.4.b apresentam as respostas no tempo dos atuadores para entradas em $v_{X}=10 \mathrm{~mm} / \mathrm{s}$ e $v_{Y}=10 \mathrm{~mm} / \mathrm{s}$, respectivamente.

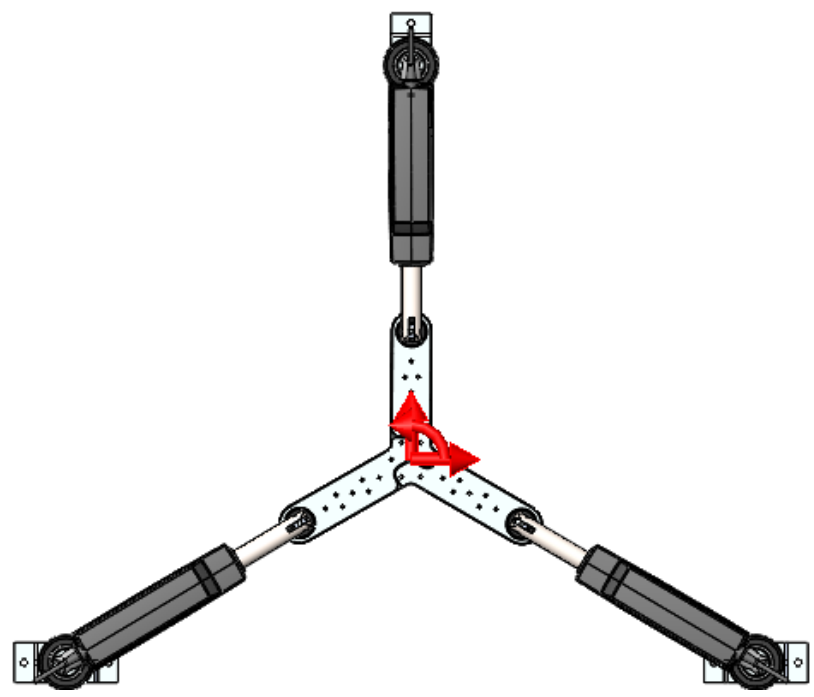

Figura 6.2.1: Modelo em CAD da plataforma paralela plana usada nas simulações.

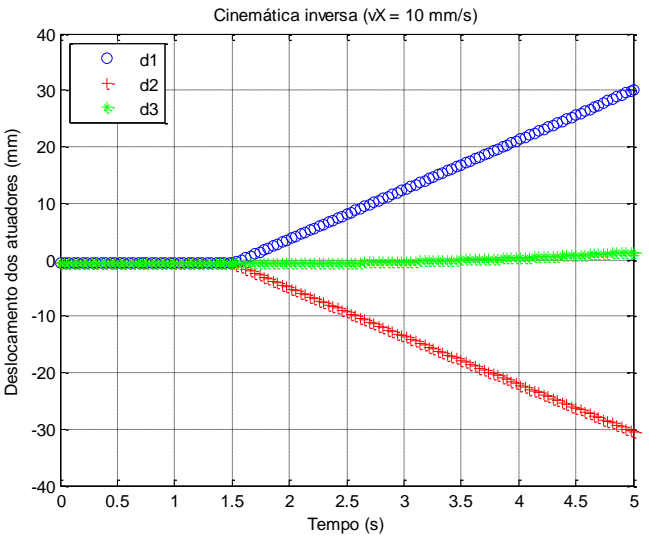

(a)

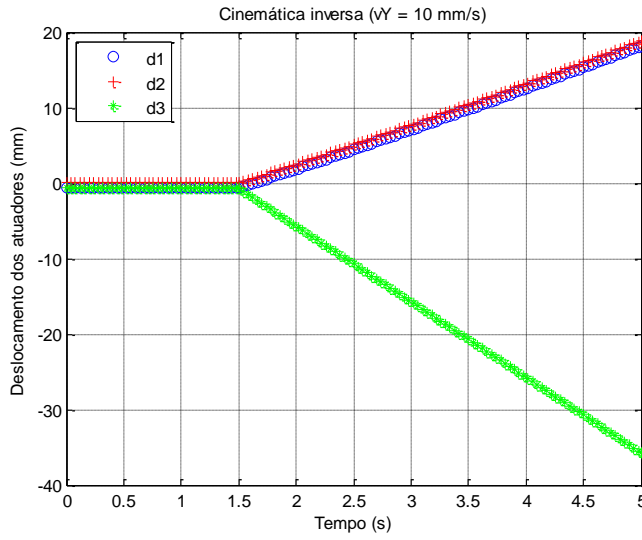

(b)

Figura 6.2.4: Respostas no tempo para as entradas $v_{X}(t)=10 \mathrm{~mm} / \mathrm{s}$ (a) e $v_{Y}(t)=10$ $\mathrm{mm} / \mathrm{s}$.

As Figuras 6.2.5.a e 6.2.5.b apresentam as respostas no tempo dos deslocamentos e velocidades dos atuadores, respectivamente, para as entradas em velocidade descritas na Equação 6.2.1. Já as Figuras 6.2.6.a e 6.2.6.b apresentam as respostas no tempo das velocidades e acelerações dos atuadores, respectivamente, para as entradas em aceleração descritas na Equação 6.2.2. 


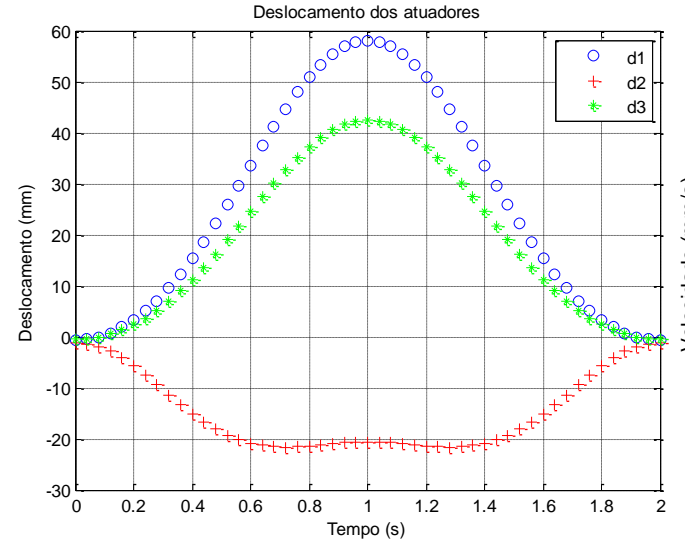

(a)

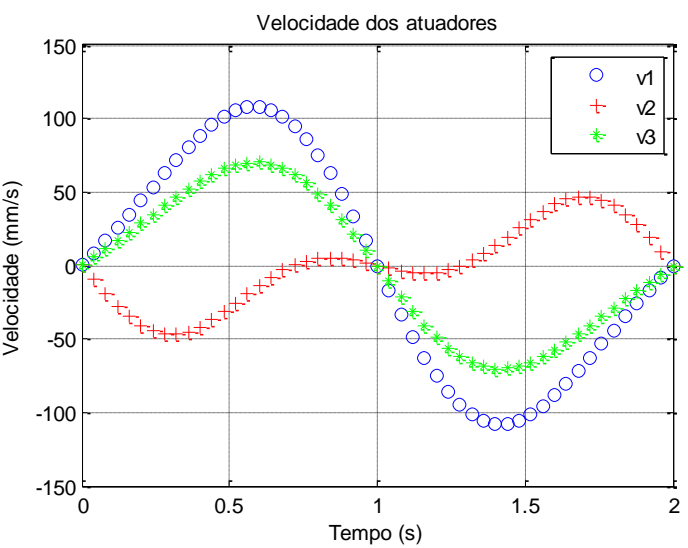

(b)

Figura 6.2.5: Respostas no tempo dos deslocamentos (a) e velocidades (b) para as entradas da Equação 6.2.1.

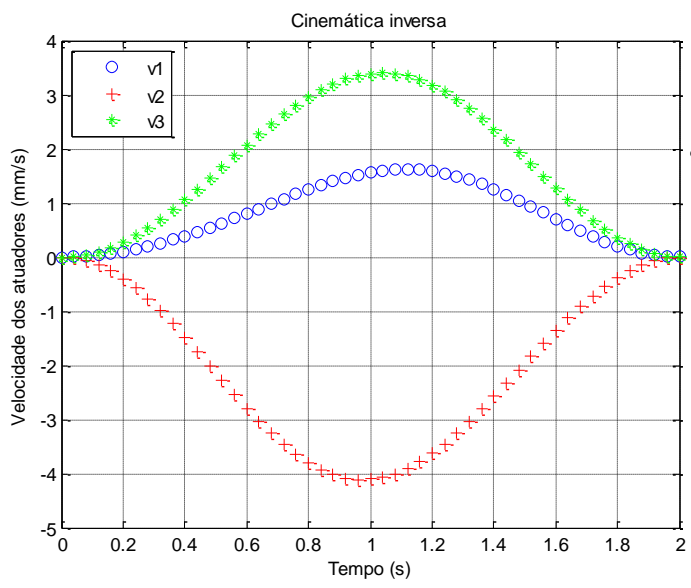

(a)

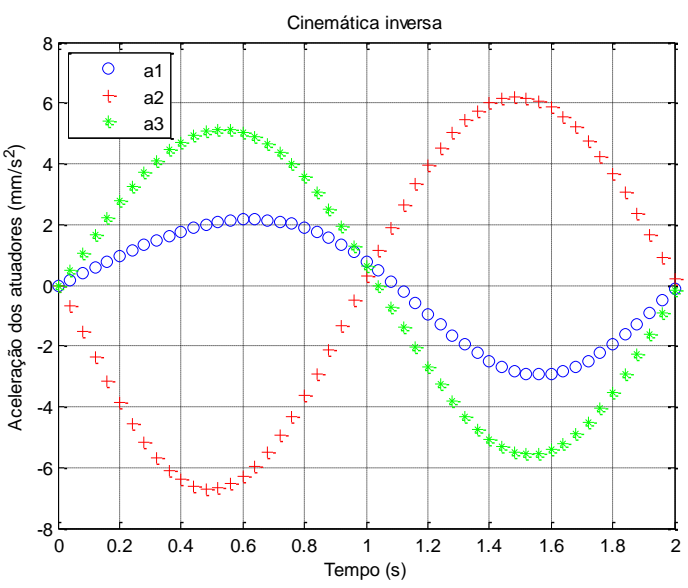

(b)

Figura 6.2.6: Respostas no tempo das velocidades (a) e acelerações (b) para as entradas da Equação 6.2.2.

\subsection{Modelo dinâmico do mecanismo paralelo plano}

\subsubsection{Simulações em MatLab/Simulink}

$\mathrm{Na}$ simulação do modelo dinâmico foram consideradas a massa e o momento de inércia de massa da plataforma móvel, $m_{P}$ e $J_{P z z}$, a massa e o momento de inércia de massa dos atuadores, $m_{A 1}, m_{A 2}, m_{A 3}$ e $J_{A 1}, J_{A 2}, J_{A 3}$, e o coeficiente de atrito viscoso das juntas dos atuadores, $b_{A 1}, b_{A 2}$ e $b_{A 3}$. A Tabela 6.3.1 apresenta os parâmetros usados na simulação. Como o momento de inércia 
da haste em relação ao centro da junta da base para o movimento de rotação no plano da plataforma é de $5,44 \times 10^{-4} \mathrm{~kg} . \mathrm{m}^{2}$, o erro associado ao uso do valor médio do momento de inércia do atuador, desconsiderando a variação gerada pelo deslocmaneto da haste, é de 7,47\%.

A resposta no tempo dos atuadores foi obtida para as entradas apresentadas na Figura 6.3.1. Dois pulsos com amplitudes $5 \mathrm{~N}$ e $-5 \mathrm{~N}$, larguras de $0.1 \mathrm{~s}$ e intervalo de $0.1 \mathrm{~s}$ entre eles foram dados no atuador 1. As Figuras 6.3.2.a e 6.3.2.b apresentam as acelerações lineares e angulares da plataforma móvel, as Figuras 6.3.2.c e 6.3.2.d apresentam as velocidades lineares e angulares da plataforma móvel e as Figuras 6.3.2.e e 6.3.2.f apresentam os deslocamentos lineares e angulares da plataforma móvel.

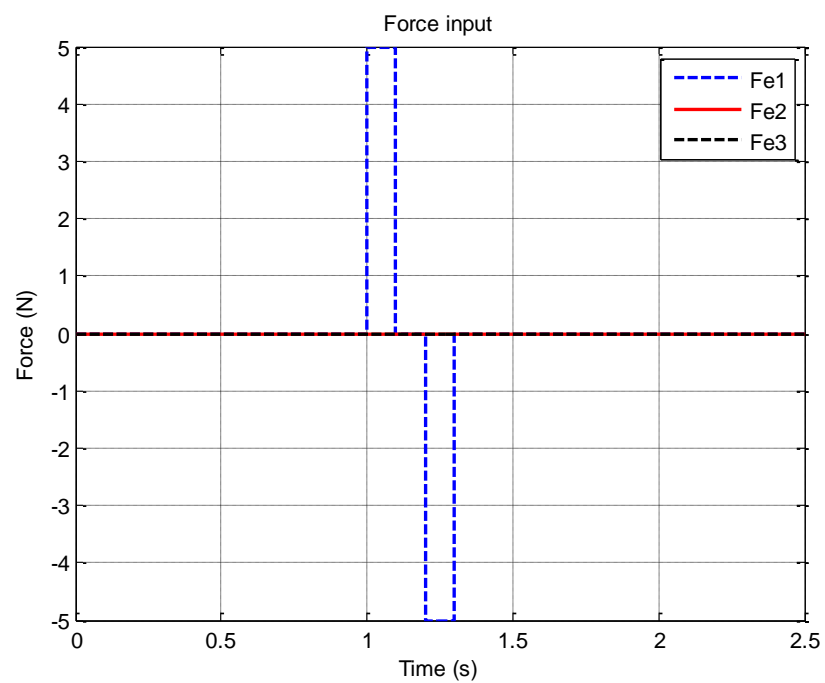

Figura 6.3.1: Forças geradas pelos atuadores.

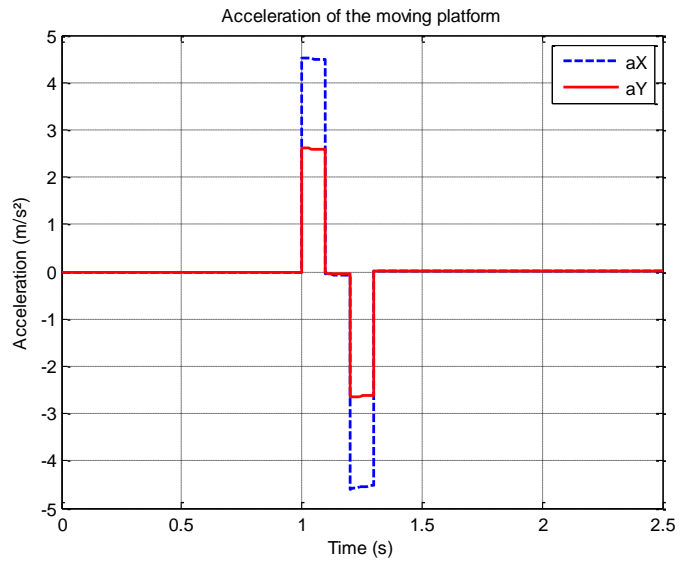

(a)

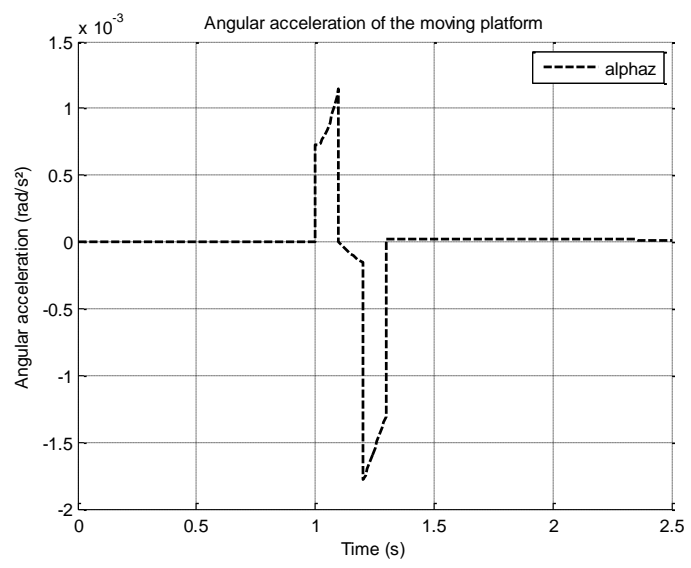

(b) 


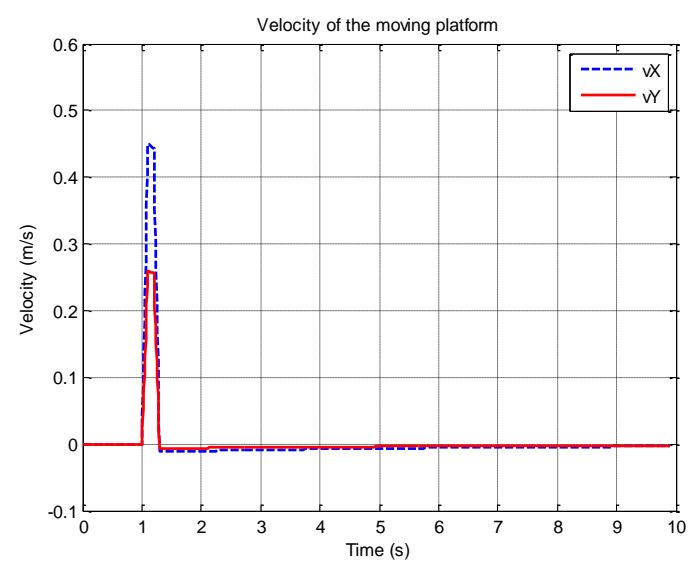

(c)

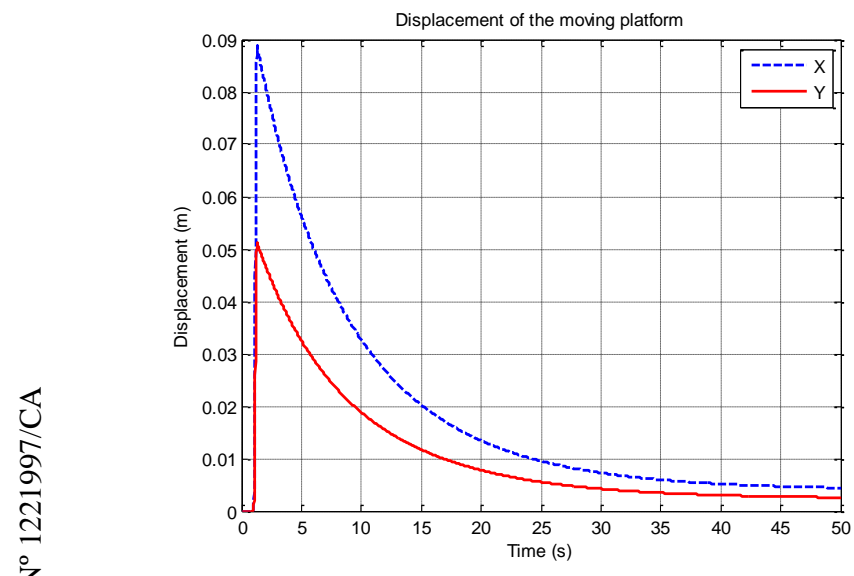

(e)

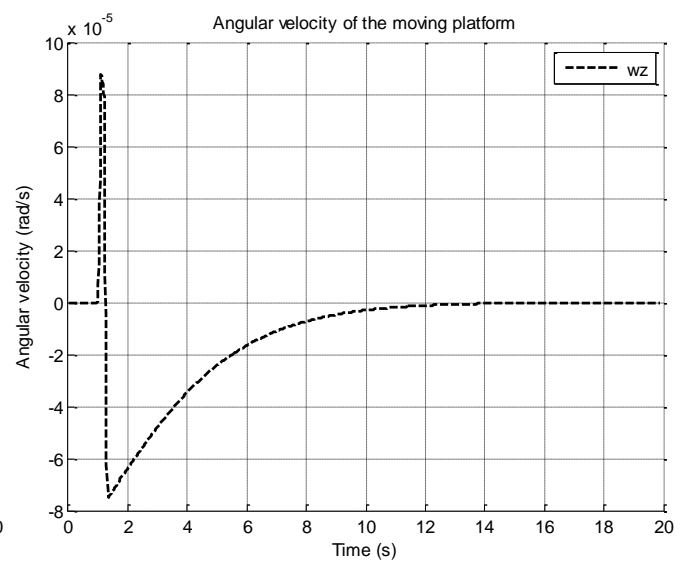

(d)

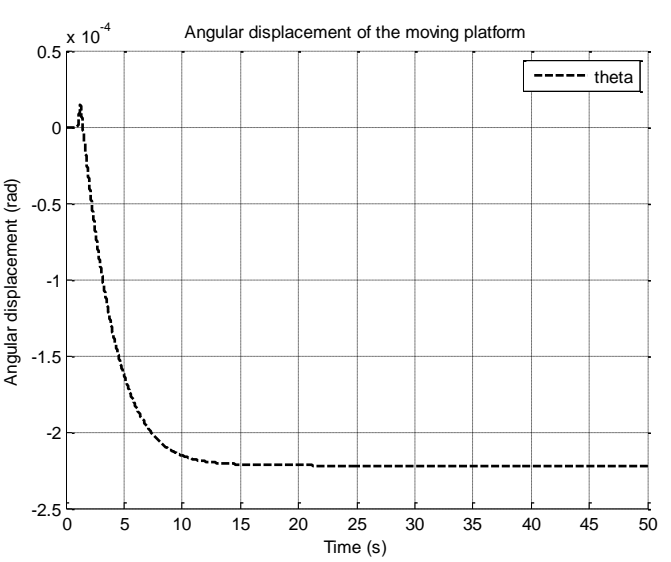

(f)

Figura 6.3.2: Acelerações, velocidades e deslocamentos lineares e angulares da plataforma móvel.

Tabela 6.3.2 - Parâmetros da dinâmica do mecanismo plano.

$\begin{array}{ccc}\text { Identificação } & \text { Símbolo } & \text { Valor } \\ \text { Massa da plataforma móvel }(\mathrm{kg}) & m_{P} & 0.578 \\ \text { inércia de massa da plataforma móvel }\left(\mathrm{kg} . \mathrm{m}^{2}\right) & J_{P_{Z z}} & 4.50 \times 10^{-3} \\ \text { Massa da haste do atuador }(\mathrm{kg}) & m_{A 1}, m_{A 2}, m_{A 3} & 0.175 \\ \text { de inércia de massa médio do atuador }\left(\mathrm{kg} . \mathrm{m}^{2}\right) & J_{A 1}, J_{A 2}, J_{A 3} & 7.28 \times 10^{-3} \\ \text { iente de atrito viscoso das juntas }\left(\mathrm{N} . \mathrm{s} . \mathrm{m}^{-1}\right) & b_{A l}, b_{A 2}, b_{A 3} & 0.006\end{array}$

Usando os mesmos parâmetros apresentados na Tabela 6.3.2 e as curvas de comportamento apresentadas nas Seções 4.4 e 4.5, foram realizadas simulações com o modelo dinâmico do mecanismo acoplado ao sistema de atuação. Foram dadas entradas com valor constante em $a_{X}(t)$. As Figuras 6.3.3.a a 6.3.3.d apresentam os resultados para entradas em $a_{X}(t)$ com valores de $1 \mathrm{~mm} / \mathrm{s}^{2}, 5 \mathrm{~mm} / \mathrm{s}^{2}$, $10 \mathrm{~mm} / \mathrm{s}^{2}$ e $15 \mathrm{~mm} / \mathrm{s}^{2}$, respectivamente. 


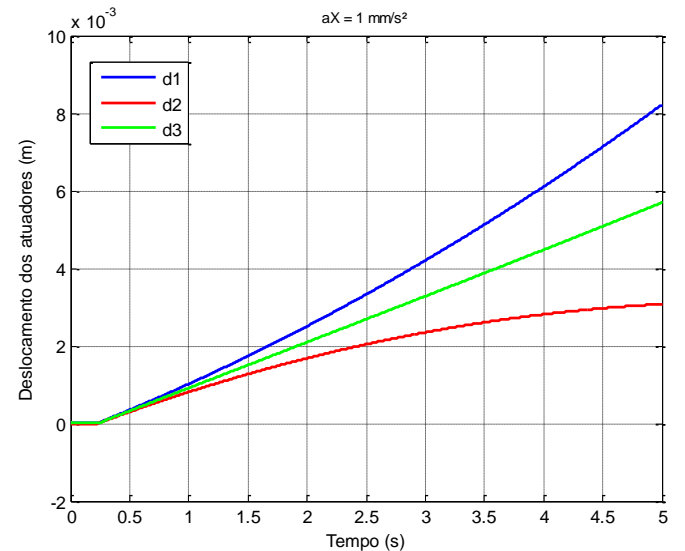

(a)

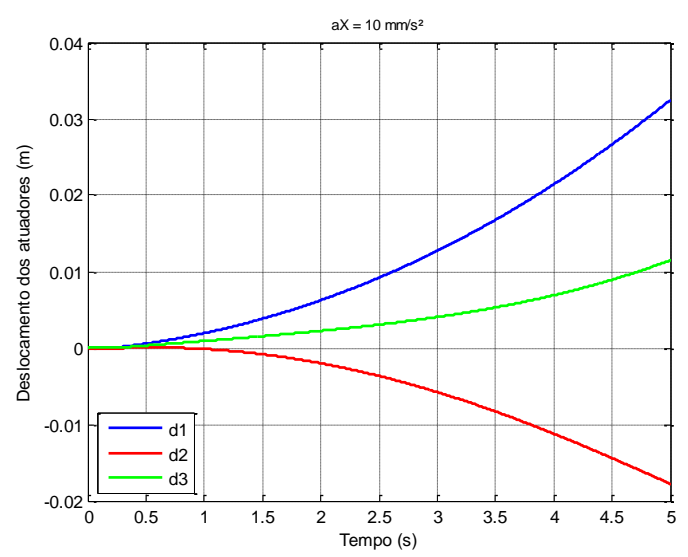

(c)

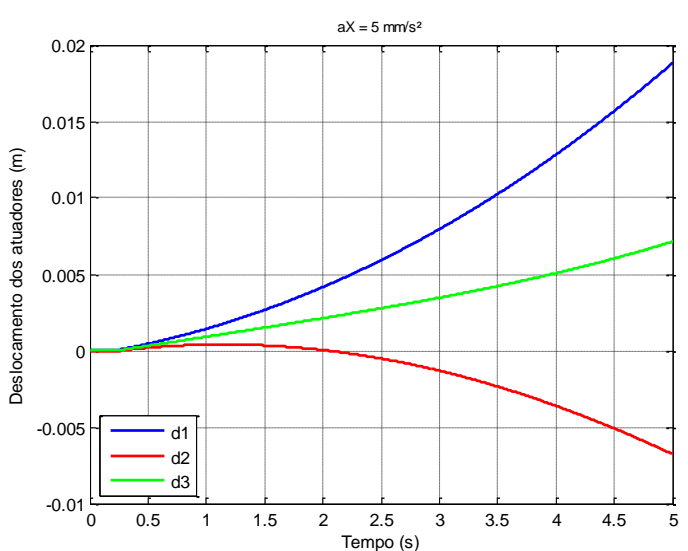

(b)

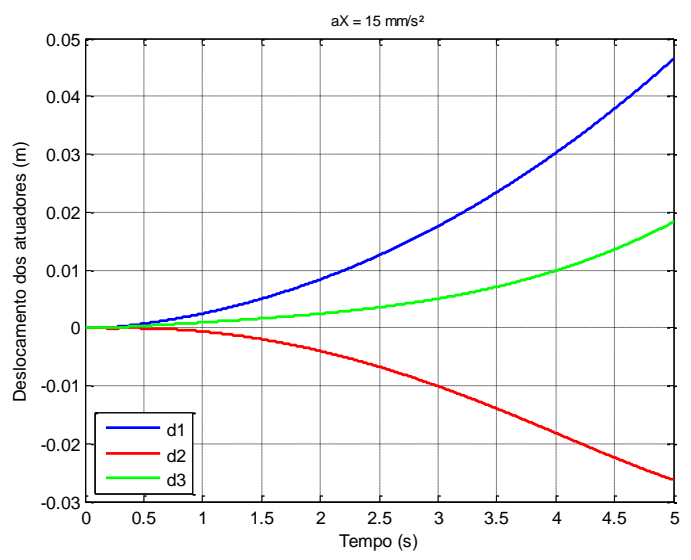

(d)

Figura 6.3.3: Simulação com entradas $a_{X}(t)=1 \mathrm{~mm} / \mathrm{s}^{2}$ (a), $a_{X}(t)=5 \mathrm{~mm} / \mathrm{s}^{2}$ (b), $a_{X}(t)=10 \mathrm{~mm} / \mathrm{s}^{2}(\mathrm{c})$ e $a_{X}(t)=15 \mathrm{~mm} / \mathrm{s}^{2}(\mathrm{~d})$.

\subsubsection{Simulações em SolidWorks Motion Analysis}

As Figuras 6.3.4.a e 6.3.4.b apresentam as respostas no tempo das velocidades e acelerações dos atuadores, respectivamente, para as entradas em força apresentadas na Figura 6.3.1. 


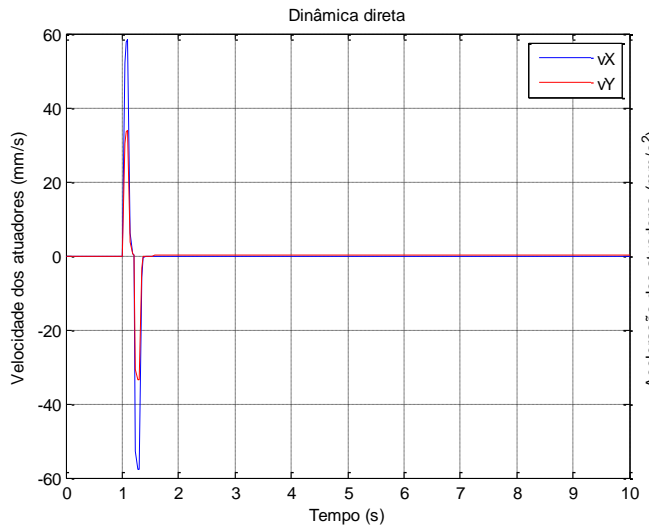

(a)

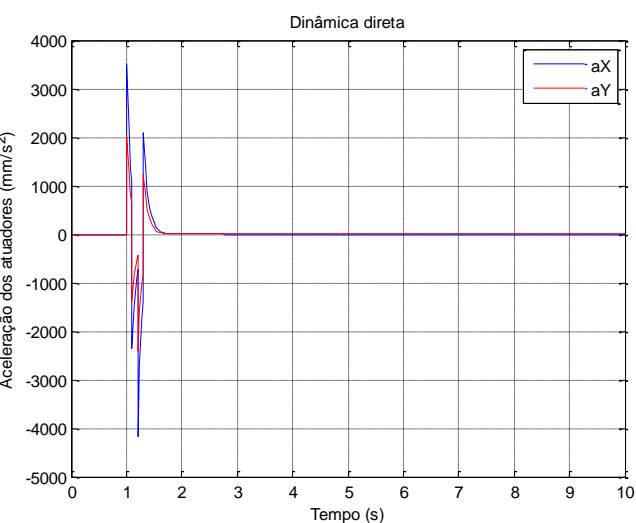

(b)

Figura 6.3.4: Respostas no tempo das velocidades (a) e acelerações (b) para as entradas da Figura 6.3.1.

\subsection{Validação das estratégias de controle}

As primeiras simulações para controle via transdutores de deslocamento foram os testes de controle de posição. Estas foram feitas usando a arquitetura da Figura 5.1.2, na qual são inseridos os valores desejados de posição da plataforma móvel $(X(t), Y(t)$ e $\theta(t))$. As Figuras 6.4.1.a e 6.4.1.b apresentam as respostas no tempo dos atuadores para entrada em $X(t)$ com valor constante de $20 \mathrm{~mm}$ usando um ganho proporcional $k_{p}$ nos valores de 0,5 e 1,0. Já as Figuras 6.4.2.a e 6.4.2.b apresentam as respostas no tempo dos atuadores para entrada em $Y(t)$ com valor constante de $20 \mathrm{~mm}$ um ganho proporcional $k_{p}$ nos valores de 0,5 e 1,0.

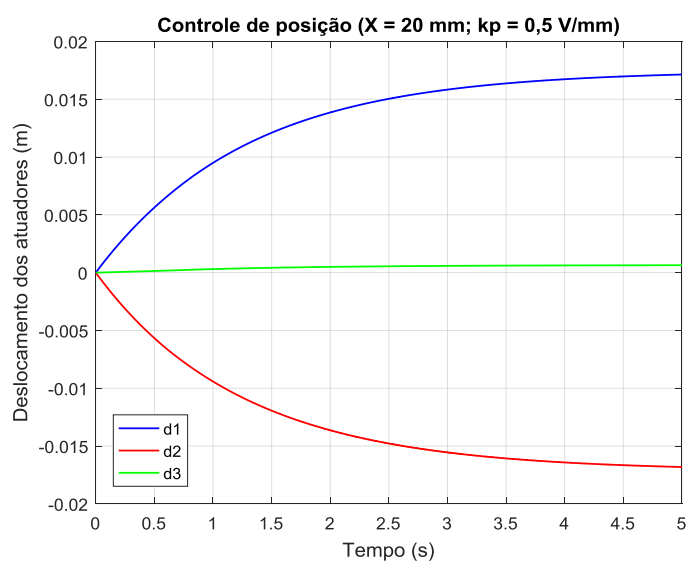

(a)

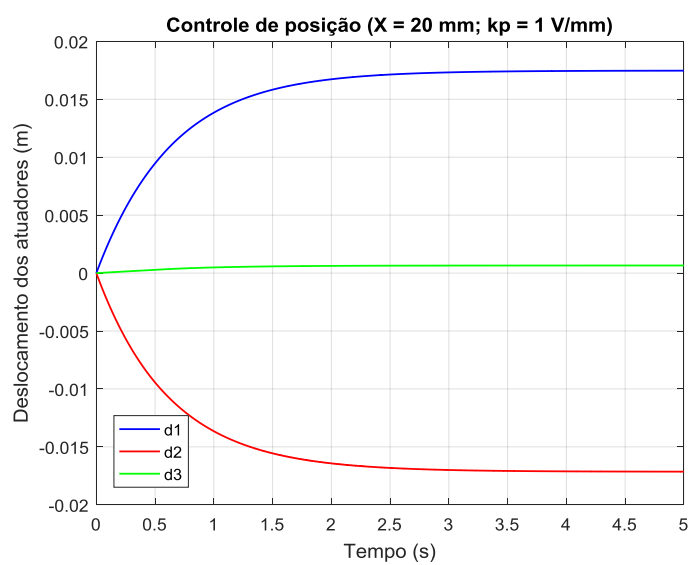

(b)

Figura 6.4.1: Respostas no tempo para a entrada $X(t)=20 \mathrm{~mm}$. (a) $k_{p}=0,5$; (b) $k_{p}$ $=1,0$. 


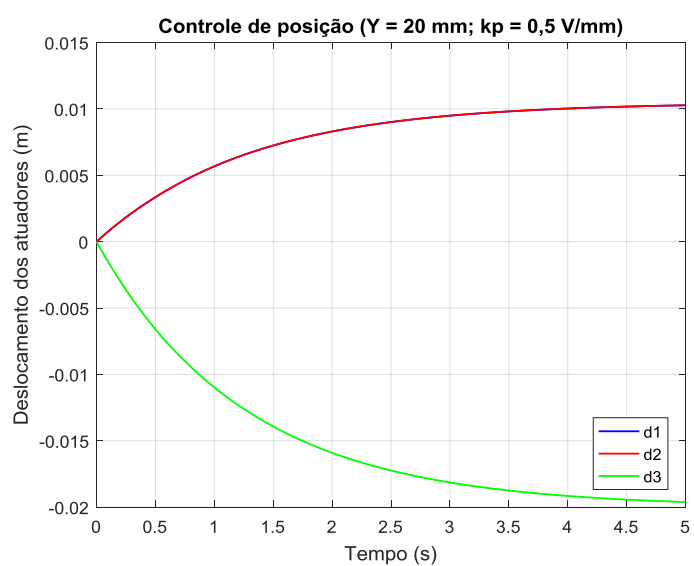

(a)

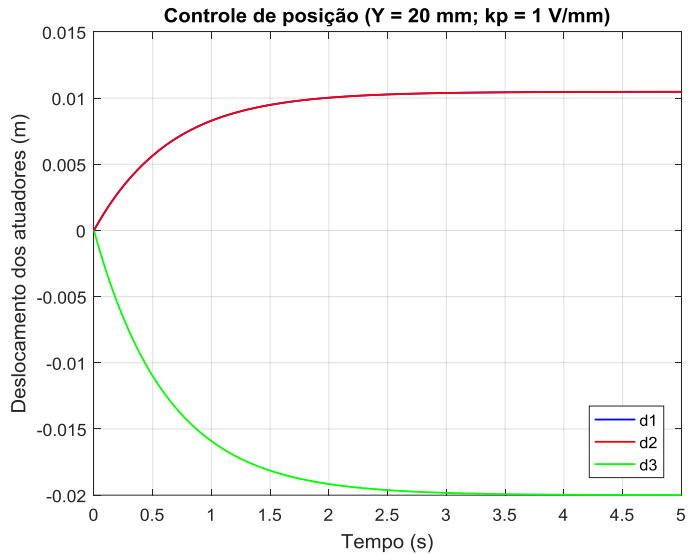

(b)

Figura 6.4.2: Respostas no tempo para a entrada $Y(t)=20 \mathrm{~mm}$. (a) $k_{p}=0,5$; (b) $k_{p}$

$$
=1,0 \text {. }
$$

As simulações dos testes de controle de velocidade foram feitas usando a arquitetura da Figura 5.1.5, na qual são inseridos os valores desejados de velocidade da plataforma móvel $\left(v_{X}(t), v_{Y}(t)\right.$ e $\left.\omega_{Z}(t)\right)$. As Figuras 6.4.3.a e 6.4.2.b apresentam as respostas no tempo dos atuadores para entrada $v_{X}(t)=10 \mathrm{~mm} / \mathrm{s}$ usando valores de ganho proporcional $k_{p}$ iguais a 0,8 e de ganhos derivativos, $k_{v}$, iguais a 0,01 e 0,1 .

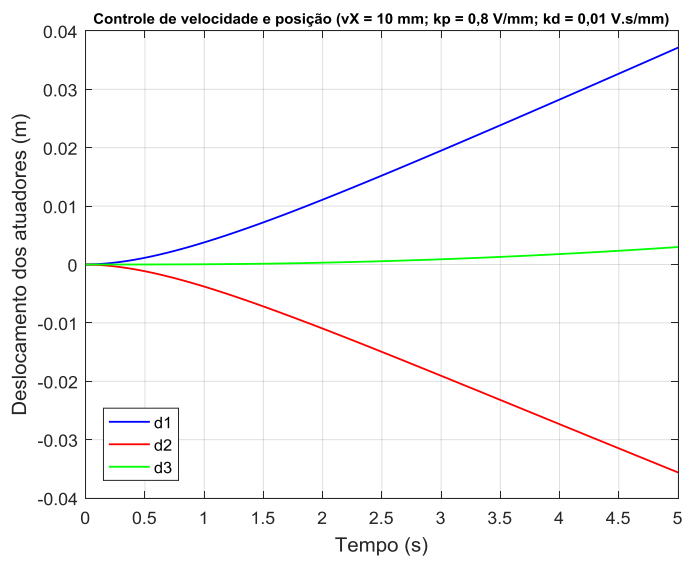

(a)

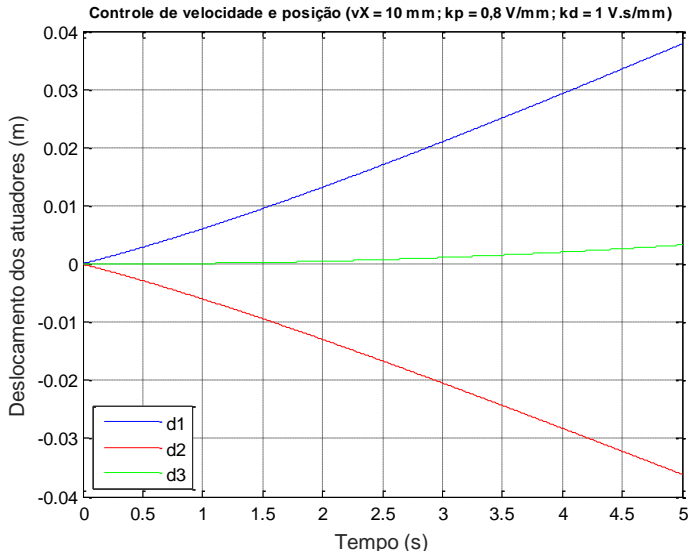

(b)

Figura 6.4.3: Respostas no tempo para a entrada $v_{X}(t)=10 \mathrm{~mm} / \mathrm{s}$. (a) $k_{p}=0,8$ e $k_{v}$

$$
=0,01 ; \text { (b) } k_{p}=0,8 \text { e } k_{v}=1,00 \text {. }
$$

As Figuras 6.4.4.a e 6.4.4.b apresentam as respostas no tempo dos atuadores usando valores de ganho proporcional $k_{p}$ iguais a 0,8 , de ganhos derivativos, $k_{v}$, iguais a 0,1 e entradas $v_{X}(t)=10 \mathrm{~mm} / \mathrm{s}$ e $v_{X}(t)=30 \mathrm{~mm} / \mathrm{s}$, respectivamente. Já as 
Figuras 6.4.4.c e 6.4.4.d apresentam as respostas no tempo dos atuadores usando os mesmos valores de ganho proporcional e derivativo e entradas $v_{Y}(t)=10 \mathrm{~mm} / \mathrm{s}$ e $v_{Y}(t)=20 \mathrm{~mm} / \mathrm{s}$, respectivamente.

As simulações dos testes de controle de aceleração foram feitas usando a arquitetura da Figura 5.1.6, na qual são inseridos os valores desejados de aceleração da plataforma móvel $\left(a_{X}(t), a_{Y}(t)\right.$ e $\left.\alpha_{Z}(t)\right)$. As Figuras 6.4.5.a a 6.4.5.c apresentam as respostas no tempo dos atuadores para entrada $a_{X}(t)=5 \mathrm{~mm} / \mathrm{s}^{2}$ usando valores de ganho proporcional $k_{p}$ iguais a 0,8 , de ganhos derivativos, $k_{v}$, iguais a 0,05 e de ganhos integrais, $k_{i}$, iguais a $10^{-4}, 10^{-5}$ e $10^{-6}$, respectivamente. Estes valores de ganho foram escolhidos por se adequarem às características e limites físicos do equipamento descrito no Capítulo 7.

As simulações dos testes para verificação da estratégia de controle baseada na obtenção de acelerações lineares e velocidade angular da plataforma móvel via IMU usam a arquitetura da Figura 5.3.4, na qual são inseridos os valores desejados de aceleração da plataforma móvel $\left(a_{X}(t), a_{Y}(t)\right.$ e $\left.\alpha_{Z}(t)\right)$. As Figuras 6.4.6 e 6.4.7 apresentam as respostas no tempo dos atuadores para entrada $a_{X}(t)=$ $5 \mathrm{~mm} / \mathrm{s}^{2}$ usando diversos valores de ganhos $k_{p}, k_{v}$ e $k_{i}$.

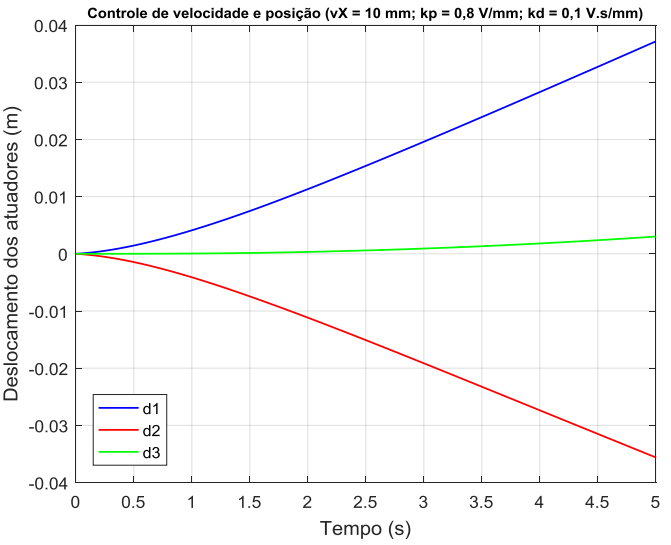

(a)

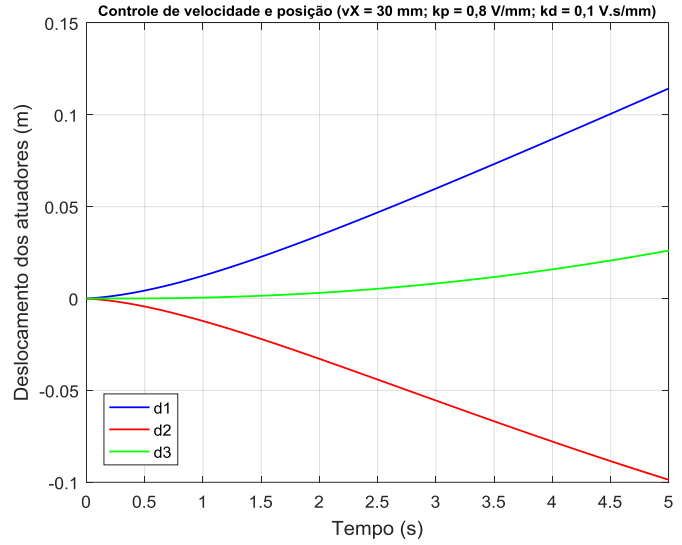

(b) 


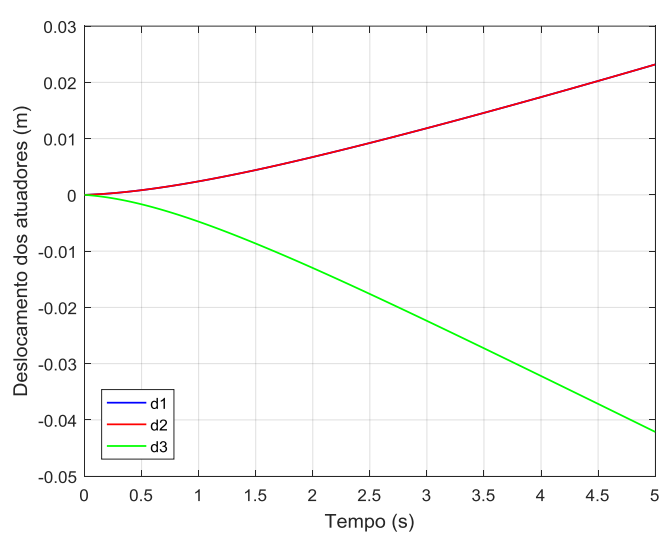

(c)

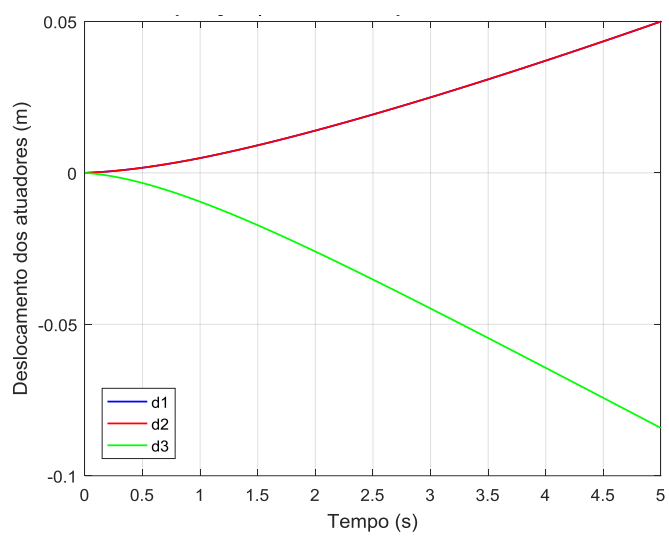

(d)

Figura 6.4.4: Respostas no tempo para ganhos $k_{p}=0,8$ e $k_{v}=0,01$. (a) $v_{X}(t)=10$ $\mathrm{mm} / \mathrm{s}$; (b) $v_{X}(t)=30 \mathrm{~mm} / \mathrm{s}$; (c) $v_{Y}(t)=10 \mathrm{~mm} / \mathrm{s}$; (d) $v_{Y}(t)=20 \mathrm{~mm} / \mathrm{s}$.

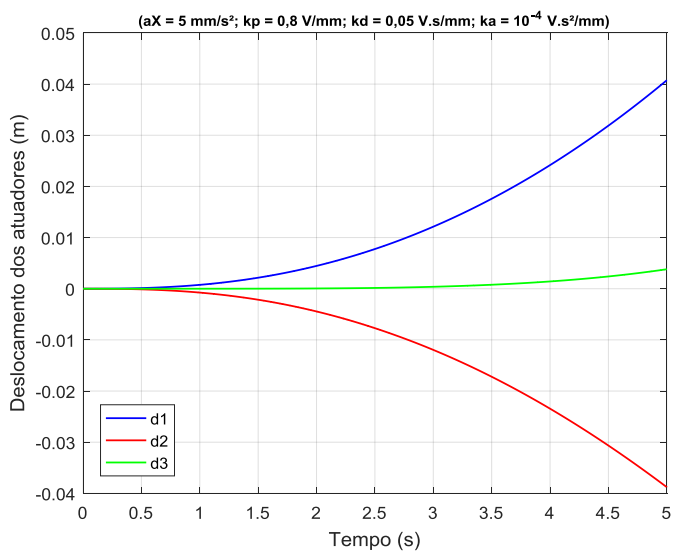

(a)

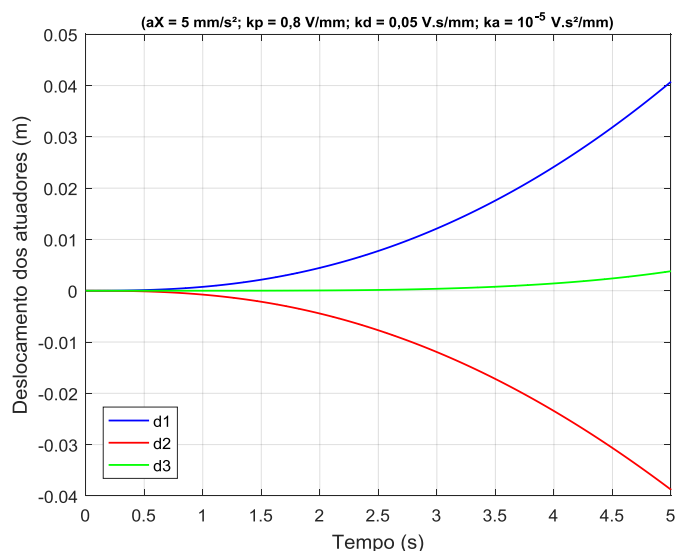

(b)

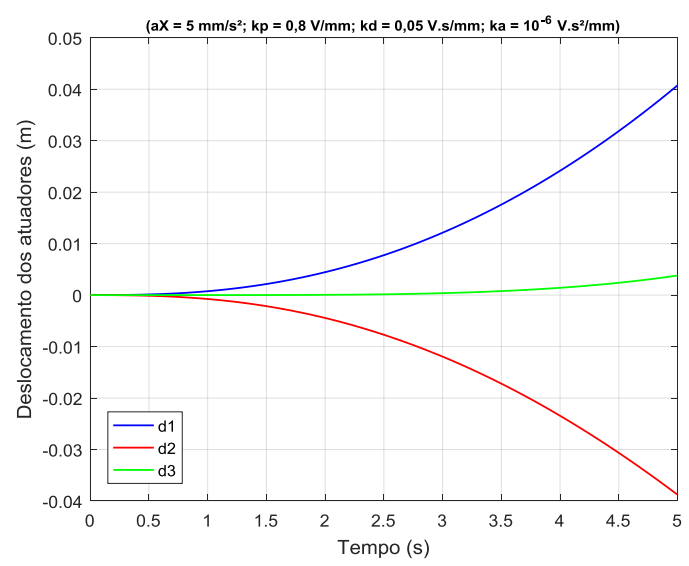

(c)

Figura 6.4.5: Respostas no tempo para a entrada $a_{X}(t)=5 \mathrm{~mm} / \mathrm{s}^{2}, k_{p}=0,8$ e $k_{v}=$ 0,05. (a) $k_{i}=10^{-4}$; (b) $k_{i}=10^{-5}$; (c) $k_{i}=10^{-6}$. 


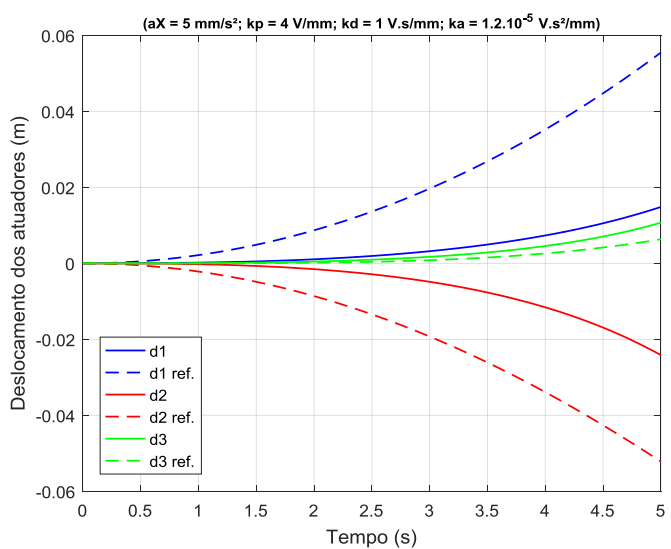

(a)

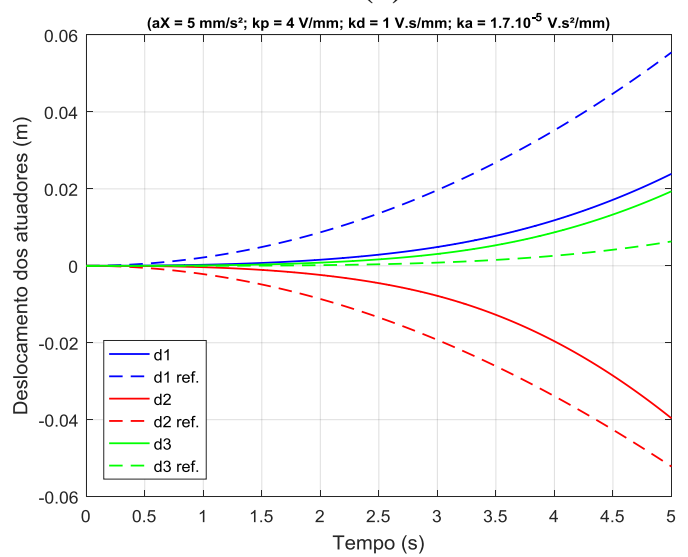

(c)

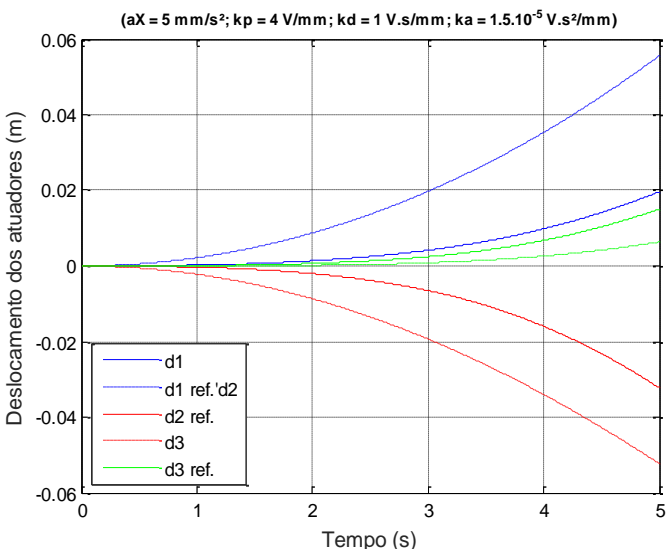

(b)

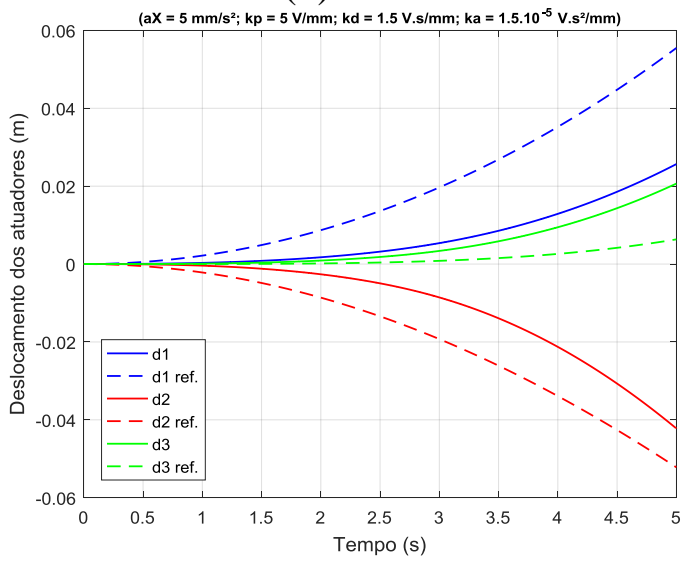

(d)

Figura 6.4.6: Respostas no tempo dos deslocamentos dos atuadores para a entrada $a_{X}(t)=5 \mathrm{~mm} / \mathrm{s}^{2}$. (a) $k_{p}=4, k_{v}=1$ e $k_{i}=1,2.10^{-4}$; (b) $k_{p}=4, k_{v}=1$ e $k_{i}=1,5.10^{-4}$; (c) $k_{p}=4, k_{v}=1$ e $k_{i}=1,7 \cdot 10^{-4}$; (d) $k_{p}=5, k_{v}=1,5$ e $k_{i}=1,5.10^{-4}$.

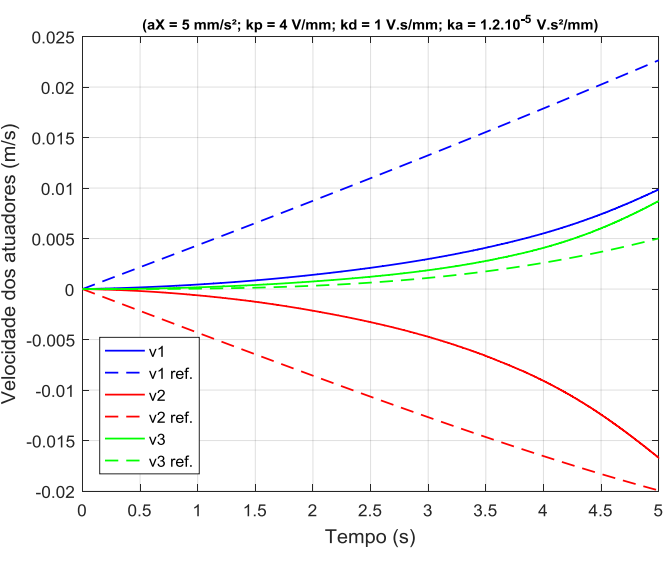

(a)

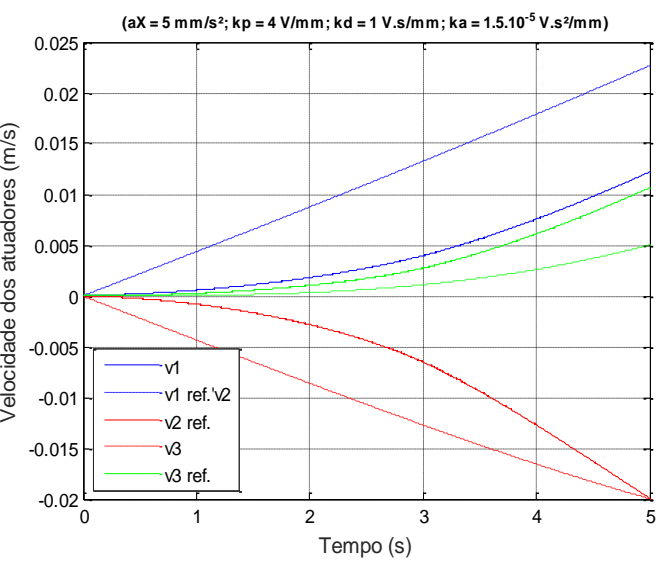

(b) 


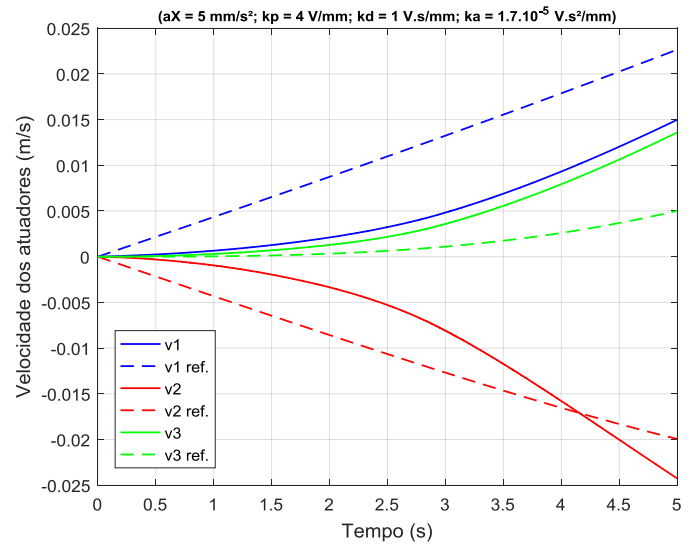

(c)

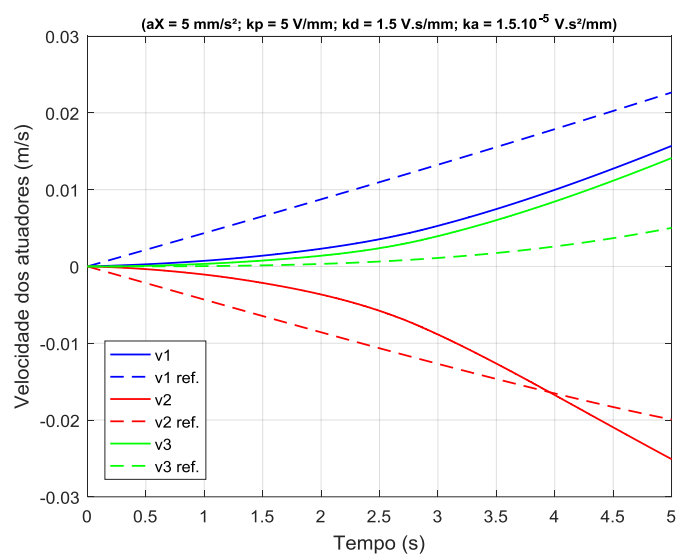

(d)

Figura 6.4.7: Respostas no tempo das velocidades dos atuadores para a entrada $a_{X}(t)=5 \mathrm{~mm} / \mathrm{s}^{2}$. (a) $k_{p}=4, k_{v}=1$ e $k_{i}=1,2.10^{-4}$; (b) $k_{p}=4, k_{v}=1$ e $k_{i}=1,5.10^{-4}$; (c) $k_{p}=4, k_{v}=1$ e $k_{i}=1,7 \cdot 10^{-4}$; (d) $k_{p}=5, k_{v}=1,5$ e $k_{i}=1,5.10^{-4}$.

As respostas no tempo indicam a estratégia de controle via IMU não tem o mesmo desempenho que as estratégias baseadas nos transdutores de deslocamento. Para uma entrada em $a_{X}(t)=5 \mathrm{~mm} / \mathrm{s}^{2}$, por exemplo, o deslocamento do atuador 1 atinge um valor de $40 \mathrm{~mm}$ após $5 \mathrm{~s}$ usando a estratégia convencional de controle de posição contra um valor de referência de $55 \mathrm{~mm}$. Já usando a estratégia via central inercial este valor cai para $25 \mathrm{~mm}$ na melhor combinação de ganhos simulada. Porém, apesar destas diferenças, o comportamento geral usando os dois tipos de estratégias é muito semelhante, o que indica que uma melhor escolha dos parâmetros de controle pode levar a um desempenho tão bom ou melhor do que os das estratégias baseadas em transdutores de deslocamento. 


\section{7 \\ Resultados experimentais}

Neste capítulo é apresentada a bancada experimental, que consiste de um mecanismo paralelo com três graus de liberdade como o descrito na Figura 3.1.1, porém com geometria simétrica. Também são apresentados os resultados de todos os testes experimentais para validação de todos os modelos desenvolvidos e de todas as estratégias de controle propostas.

\subsection{Descrição da bancada experimental}

O modelo em CAD dos atuadores foi apresentado no Capítulo 6, Figura 6.1.1. Com este modelo, foram desenvolvidos os modelos das juntas rotativas que ligam estes na bancada (base fixa) e na plataforma móvel, respectivamente. As juntas rotativas da base são constituídas por um rolamento radial de esferas do tipo 6206. Estes são fixados à base, constituída de perfis de alumínio Bosch modelo $45 \times 45 \mathrm{~mm}$, através de peças de alumínio desenvolvidas na Oficina de Desenvolvimento de Protótipos (ODP) da PUC-Rio. Foi usada uma fresadora CNC marca Roch Tech, modelo VMC 420L para o processo e o programa SprutCAM para gerar o código $\mathrm{G}$ de usinagem. A Figura 7.1.1.a apresenta o modelo em $\mathrm{CAD}$ da peça de acoplamento do rolamento à base.

A peça para o acoplamento do rolamento da base com o atuador foi fabricada usando uma fresadora convencional. Seu desenho técnico de fabricação encontra-se no Anexo B. A Figura 7.1.1.b apresenta o modelo CAD com a montagem desta peça ao rolamento e à peça de acoplamento com a base. Processo semelhante foi usado na fabricação da peça de acoplamento do rolamento da plataforma móvel com a haste do atuador. Seu desenho técnico de fabricação também se encontra no Anexo B. 


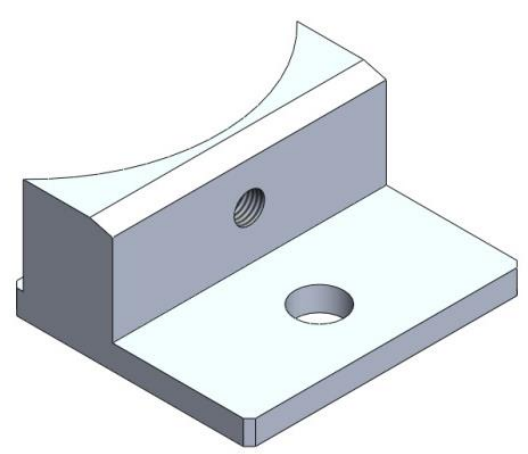

(a)

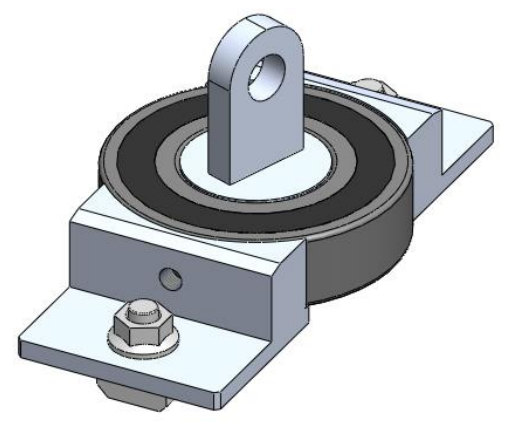

(b)

Figura 7.1.1: Modelo em CAD do acoplamento do rolamento à base fixa (a) e da junta rotativa da base fixa (b).

As peças da plataforma móvel foram fabricadas pelo mesmo processo que as peças de acoplamento do rolamento à base fixa. A Figura 7.1.2.a apresenta o modelo em CAD de uma das seis peças que compõem a plataforma móvel. Já a Figura 7.1.2.b apresenta a plataforma móvel completa.

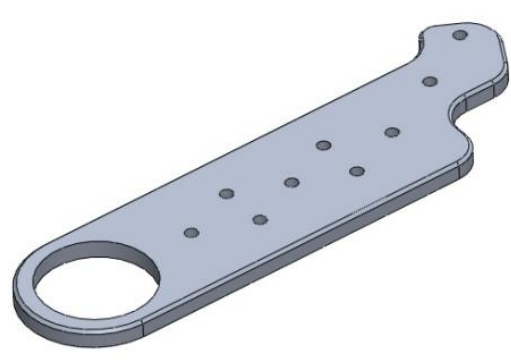

(a)

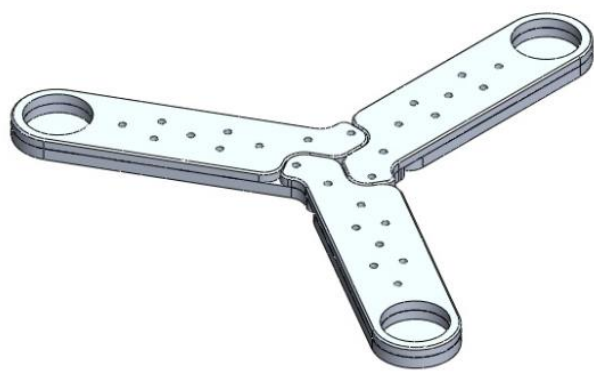

(b)

Figura 7.1.2: Modelo em CAD de uma das peças da plataforma móvel (a) e da plataforma montada (b).

Com todos os componentes projetados, foi desenvolvido o modelo em CAD da plataforma plana para simulação de movimentos (Figura 7.1.3) e, para facilitar o processo de montagem, também foi desenvolvido o modelo em CAD da bancada que servirá como base fixa do aparato (Figura 7.1.4). 


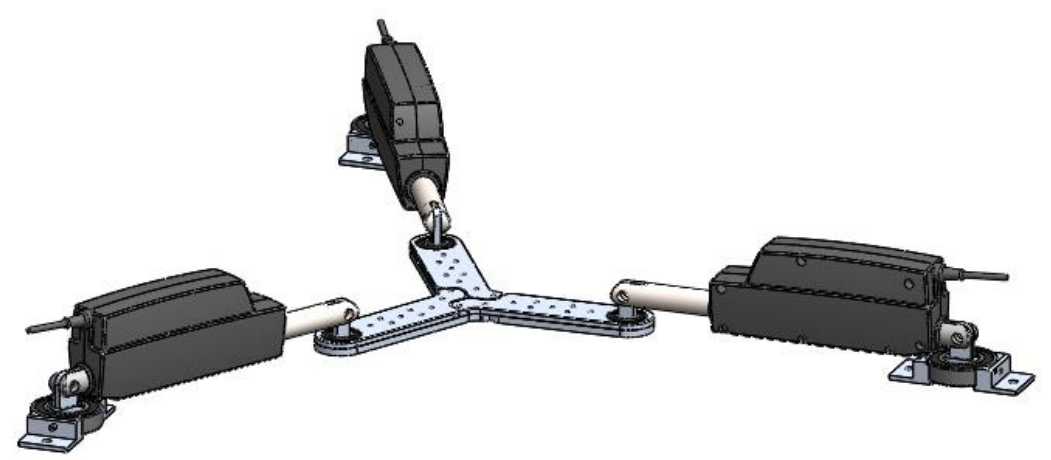

Figura 7.1.3: Modelo em CAD da plataforma plana para simulação de movimentos.

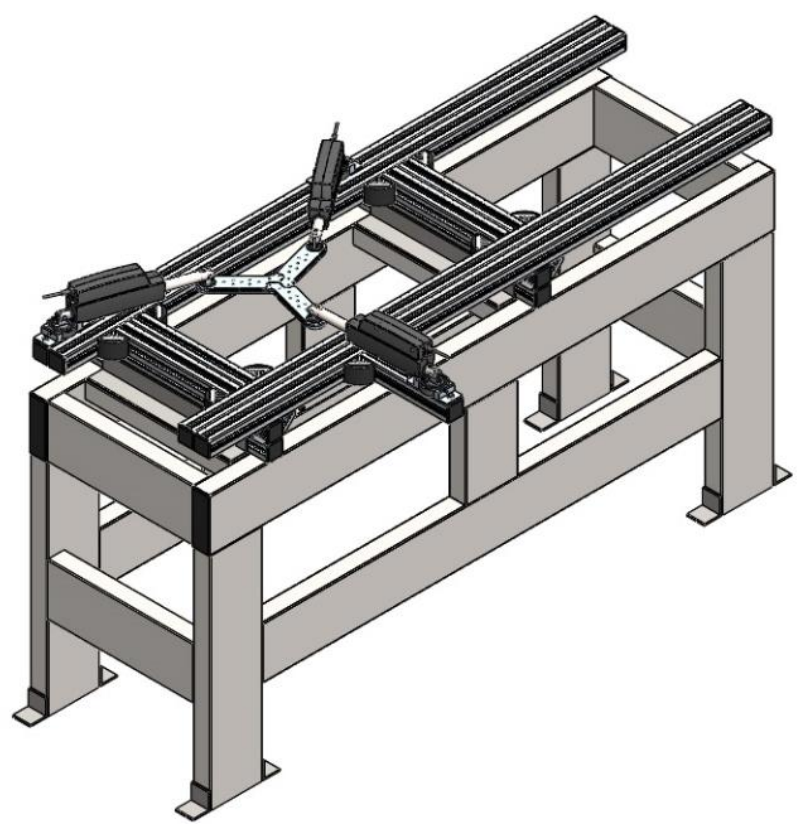

Figura 7.1.4: Modelo em CAD da bancada (base fixa) com a plataforma.

A Figura 7.1.5 apresenta os outros equipamentos do sistema de controle com um número indicando cada um. Estes são: fonte de alimentação chaveada 75W 24VDC 3A (1) para alimentar os três controladores de motor Pololu MC33926 (2), fonte estabilizada de alimentação FB-79 12 VDC com regulador de tensão L7800 na saída (3) para alimentar os transdutores de deslocamento dos atuadores LINAK LA12, interface para conexão dos atuadores (4) e chassi tipo cDAQ (5), modelo NI 9172 com um módulo de aquisição de dados tipo Analog Input (entrada analógica) NI 9205 e um módulo tipo Analog Output NI 9264. Já a Figura 7.1.6 apresenta o mecanismo paralelo desenvolvido, o sistema de controle e a bancada. 


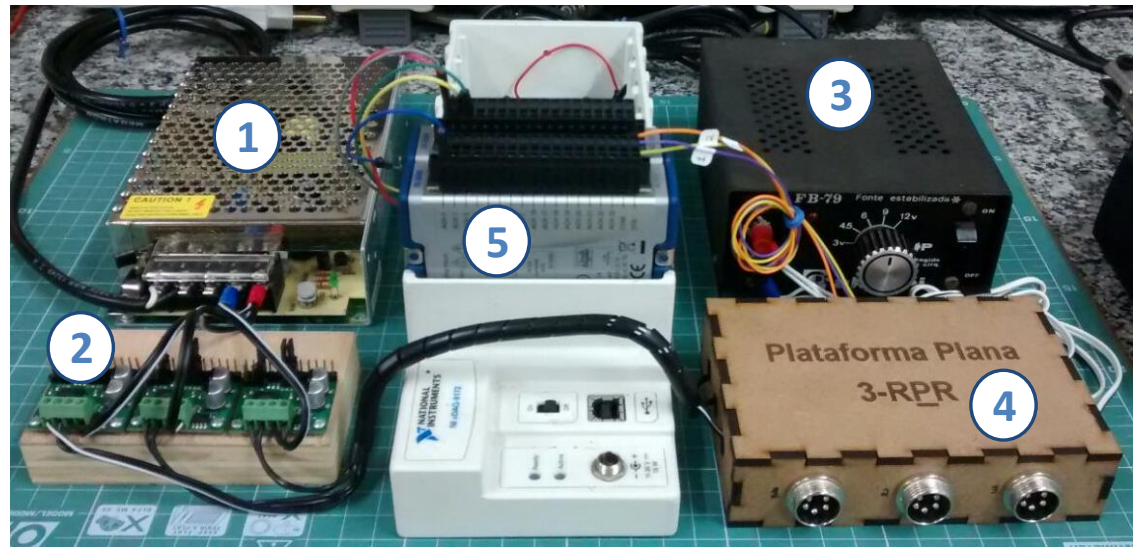

Figura 7.1.5: Eletrônica de controle da plataforma.

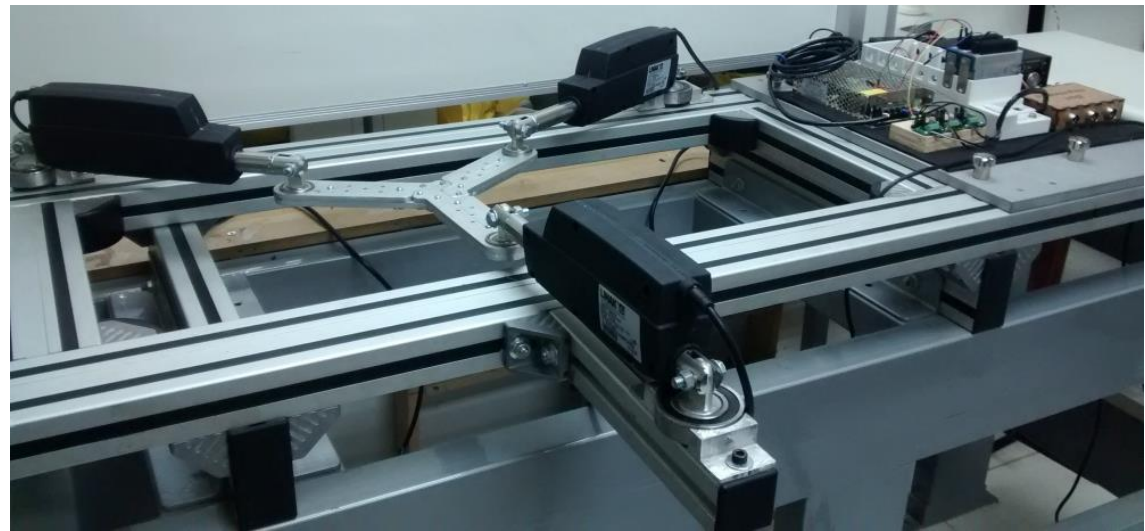

Figura 7.1.6: Bancada experimental.

As Figuras 7.1.7.a e 7.1.7.b apresentam a plataforma móvel em duas distintas configurações. Mais detalhes de como foram feitos estes e outros testes se encontram nas próximas seções.

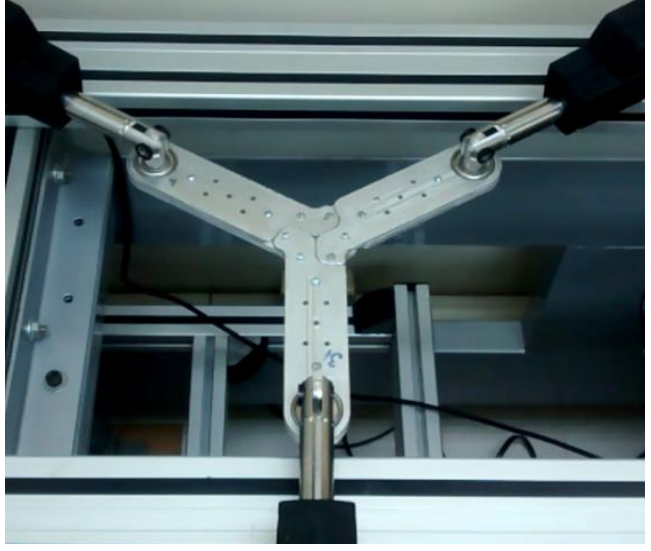

(a)

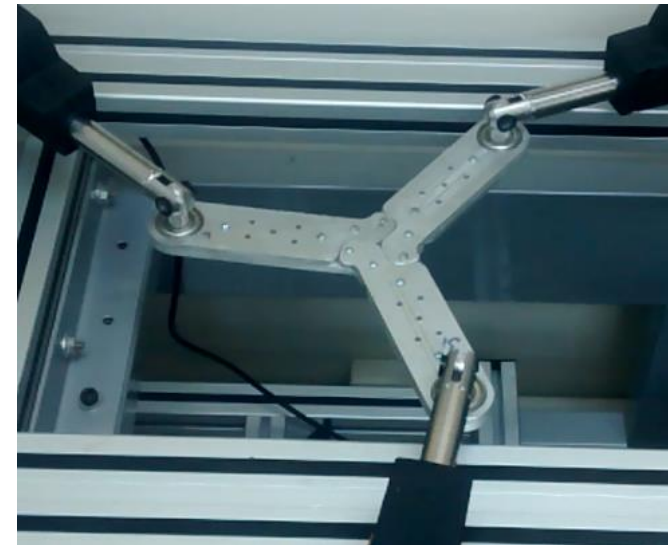

(b)

Figura 7.1.7: Configurações distintas da plataforma móvel. 


\subsection{Validação da Geometria Inversa}

Os testes para validação da geometria inversa foram feitos usando a arquitetura de controle da Figura 5.1.2, na qual são inseridos os valores desejados de posição da plataforma móvel $(X(t), Y(t)$ e $\theta(t))$. A Figura 7.2.1 apresenta o painel de controle usado nesta rotina. Neste painel há uma aba na qual podem ser escolhidos os tipos de entrada, que podem ser entradas com valores constantes ou em ondas do tipo senoidal, quadrada ou triangular. Também existem comandos para escolher o tipo de filtro usado nos dados de velocidade (Savitzky-Golay, Butterworth ou Bessel) e alterar os parâmetros do filtro escolhido. Estes dados filtrados são integrados e comparados com os dados brutos obtidos do transdutor de deslocamento para verificar a eficiência do processo de filtragem.

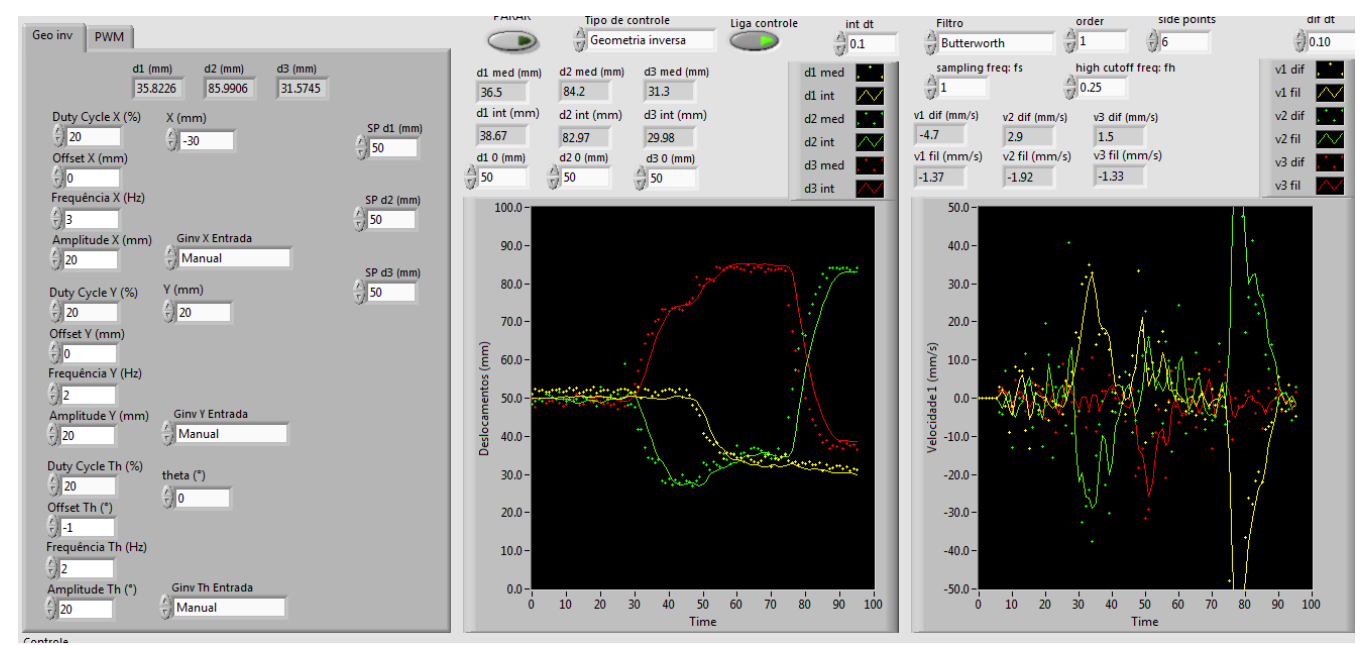

Figura 7.2.1: Painel de controle para os testes de validação da geometria inversa.

O primeiro teste foi feito para entradas constantes em $X(t)$. A Tabela 7.2.1 apresenta os valores destas entradas, os valores dos deslocamentos dos atuadores de acordo com o modelo da geometria inversa e os valores em regime permanente medidos para cada posição. A Figura 7.2.2 apresenta a resposta no tempo dos três atuadores durante o teste. $\mathrm{O}$ segundo teste foi semelhante ao primeiro, mas desta vez foram dadas entradas em $Y(t)$. A Tabela 7.2.2 apresenta os valores destas entradas, os valores dos deslocamentos dos atuadores de acordo com o modelo da geometria inversa e os valores em regime permanente medidos para cada posição. A Figura 7.2.3 apresenta a resposta no tempo dos três atuadores durante este teste. 
Já no terceiro teste foram dadas entradas em $\theta(t)$. A Tabela 7.2.3 apresenta os valores destas entradas, os valores dos deslocamentos dos atuadores de acordo com o modelo da geometria inversa e os valores em regime permanente medidos para cada posição. A Figura 7.2.4 apresenta a resposta no tempo dos três atuadores durante este teste.

Tabela 7.2.3 - Erros de posição para entradas em $X(t)$.

\begin{tabular}{c|ccc|ccc|ccc}
$\begin{array}{c}X(t) \\
(\mathrm{mm})\end{array}$ & $\begin{array}{c}d_{\text {Imodelo }} \\
(\mathrm{mm})\end{array}$ & $\begin{array}{c}d_{\text {Imedido }}(\mathrm{mm}) \\
\text { erro }_{d 1} \\
(\%)\end{array}$ & $\begin{array}{c}d_{2 \text { modelo }} \\
(\mathrm{mm})\end{array}$ & $\begin{array}{c}d_{2 \text { medido }} \\
(\mathrm{mm})\end{array}$ & $\begin{array}{c}\text { erro }_{d 2} \\
(\%)\end{array}$ & $\begin{array}{c}d_{3 \text { modelo }} \\
(\mathrm{mm})\end{array}$ & $\begin{array}{c}d_{3 \text { medido }} \\
(\mathrm{mm})\end{array}$ & $\begin{array}{c}\text { erro }_{d 3} \\
(\%)\end{array}$ \\
\hline \hline 20,0 & 67,478 & 67,7 & 0,33 & 32,855 & 34,1 & 3,79 & 50,655 & 51,6 & 1,87 \\
35,0 & 80,769 & 80,7 & 0,09 & 20,245 & 20,5 & 1,26 & 52,002 & 51,9 & 0,20 \\
$-20,0$ & 32,855 & 34,4 & 4,70 & 67,478 & 66,6 & 1,30 & 50,655 & 50,0 & 1,29 \\
$-35,0$ & 20,250 & 20,0 & 1,23 & 80,769 & 80,5 & 0,33 & 52,001 & 50,8 & 2,31
\end{tabular}

Tabela 7.2.2 - Erros de posição para entradas em $Y(t)$.

\begin{tabular}{|c|c|c|c|c|c|c|c|c|c|}
\hline $\begin{array}{c}Y(t) \\
(\mathrm{mm}) \\
\end{array}$ & $\begin{array}{c}d_{\text {Imodelo }} \\
(\mathrm{mm})\end{array}$ & $\begin{array}{c}d_{\text {Imedido }} \\
(\mathrm{mm})\end{array}$ & $\begin{array}{c}\text { erro }_{d l} \\
(\%)\end{array}$ & $\begin{array}{c}d_{2 \text { modelo }} \\
(\mathrm{mm})\end{array}$ & $\begin{array}{c}d_{2 \text { medido }} \\
(\mathrm{mm})\end{array}$ & $\begin{array}{c}\text { erro }_{d 2} \\
(\%) \\
\end{array}$ & $\begin{array}{c}d_{3 \text { modelo }} \\
(\mathrm{mm})\end{array}$ & $\begin{array}{c}d_{3 m e d i d o} \\
(\mathrm{~mm})\end{array}$ & $\begin{array}{c}\text { erro }_{d 3} \\
(\%) \\
\end{array}$ \\
\hline 20,0 & 60,478 & 60,7 & 0,37 & 60,478 & 59,7 & 1,29 & 30,000 & 29,9 & 0,33 \\
\hline 35,0 & 68,923 & 68,5 & 0,61 & 68,923 & 69,3 & 0,55 & 15,000 & 15,8 & 5,33 \\
\hline$-20,0$ & 40,510 & 40,8 & 0,72 & 40,510 & 40,7 & 0,47 & 70,000 & 70,6 & 0,86 \\
\hline$-35,0$ & 34,096 & 35,1 & 2,94 & 34,096 & 35,2 & 3,24 & 85,000 & 84,8 & 0,24 \\
\hline
\end{tabular}

Tabela 7.2.3 - Erros de posição para entradas em $\theta(t)$.

\begin{tabular}{c|ccc|ccc|ccc}
$\begin{array}{c}\theta(t) \\
\left({ }^{\circ}\right)\end{array}$ & $\begin{array}{c}d_{\text {Imodelo }} \\
(\mathrm{mm})\end{array}$ & $\begin{array}{c}d_{\text {Imedido }} \\
(\mathrm{mm})\end{array}$ & $\begin{array}{c}\text { erro }_{d 1} \\
(\%)\end{array}$ & $\begin{array}{c}d_{2 \text { modelo }} \\
(\mathrm{mm})\end{array}$ & $\begin{array}{c}d_{2 \text { medido }} \\
(\mathrm{mm})\end{array}$ & $\begin{array}{c}\text { erro }_{d 2} \\
(\%)\end{array}$ & $\begin{array}{c}d_{3 \text { modelo }} \\
(\mathrm{mm})\end{array}$ & $\begin{array}{c}d_{3 \text { medido }} \\
(\mathrm{mm})\end{array}$ & $\begin{array}{c}\text { erro }_{d 3} \\
(\%)\end{array}$ \\
\hline \hline 10,0 & 53,216 & 51,1 & 3,98 & 53,215 & 52,8 & 0,78 & 53,213 & 52,8 & 0,78 \\
30,0 & 77,272 & 77,5 & 0,30 & 77,27 & 76,9 & 0,48 & 77,269 & 76,8 & 0,61
\end{tabular}

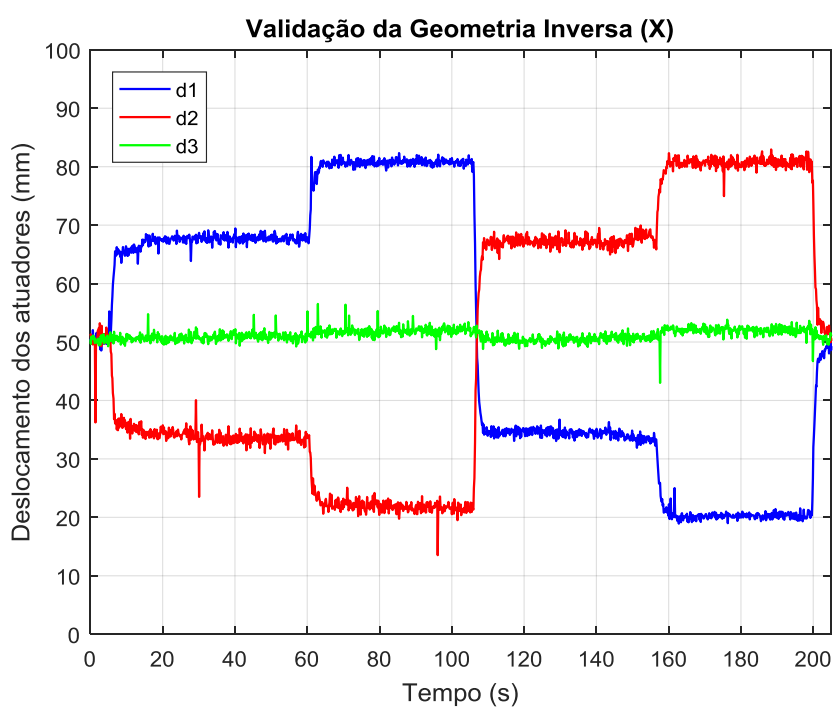

Figura 7.2.2: Respostas no tempo nos testes para validação da geometria inversa com entrada em $X(t)$. 


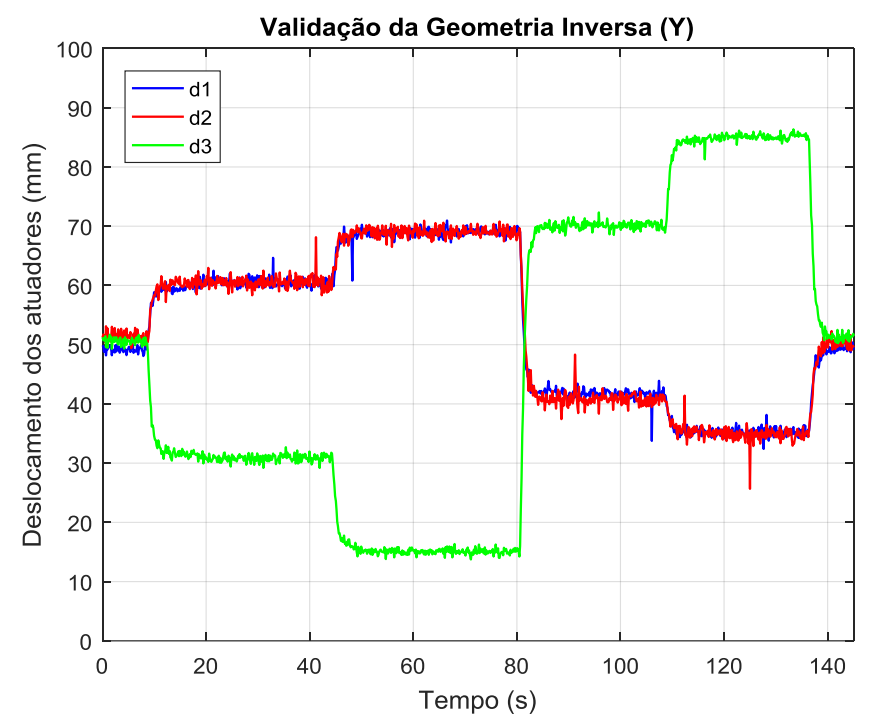

Figura 7.2.3: Respostas no tempo nos testes para validação da geometria inversa com entrada em $Y(t)$.

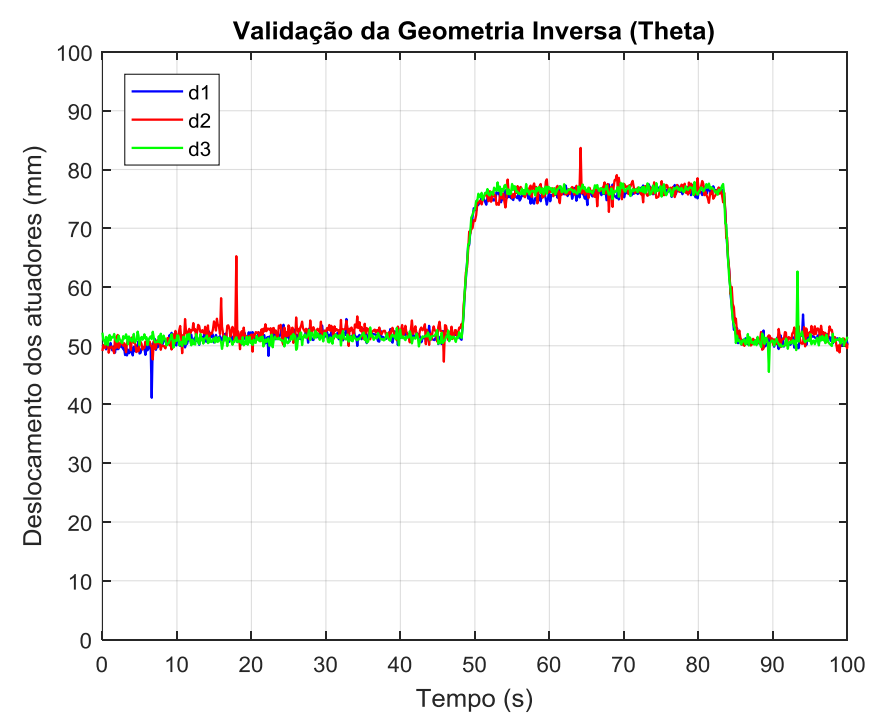

Figura 7.2.4: Respostas no tempo nos testes para validação da geometria inversa com entrada em $\theta(t)$.

Também foram executados testes com entradas em mais de um elemento. No quarto teste foram dadas entradas em $X(t), Y(t)$ e $\theta(t)$. A Tabela 7.2.4 apresenta os valores destas entradas, os valores dos deslocamentos dos atuadores de acordo com o modelo da geometria inversa e os valores em regime permanente medidos para cada posição. As Figuras 7.2.5.a e 7.2.5.b apresentam as respostas no tempo dos três atuadores durante este teste. 
Tabela 7.2.4 - Erros de posição para entradas em $X(t), Y(t)$ e $\theta(t)$.

\begin{tabular}{c|ccc|ccc|ccc}
$\begin{array}{c}{[X(t) \mathrm{Y}(t) \theta(t)]} \\
{\left[(\mathrm{mm})(\mathrm{mm})\left({ }^{\circ}\right)\right]}\end{array}$ & $\begin{array}{c}d_{\text {Imodelo }} \\
(\mathrm{mm})\end{array}$ & $\begin{array}{c}d_{\text {1medido }}(\mathrm{mm}) \\
\text { erro }_{d 1} \\
(\%)\end{array}$ & $\begin{array}{c}d_{2 \text { modelo }} \\
(\mathrm{mm})\end{array}$ & $\begin{array}{c}d_{\text {2medido }} \\
(\mathrm{mm})\end{array}$ & $\begin{array}{c}\text { erro }_{d 2} \\
(\%)\end{array}$ & $\begin{array}{c}d_{3 \text { modelo }} \\
(\mathrm{mm})\end{array}$ & $\begin{array}{c}d_{3 \text { medido }} \\
(\mathrm{mm})\end{array}$ & $\begin{array}{c}\text { erro }_{d 3} \\
(\%)\end{array}$ \\
\hline \hline$[35,035,00,0]$ & 98,045 & 98,0 & 0,05 & 41,077 & 40,9 & 0,43 & 17,259 & 16,3 & 5,56 \\
{$[20,020,010,0]$} & 79,986 & 78,6 & 1,73 & 49,415 & 47,6 & 3,67 & 32,237 & 32,0 & 0,74
\end{tabular}

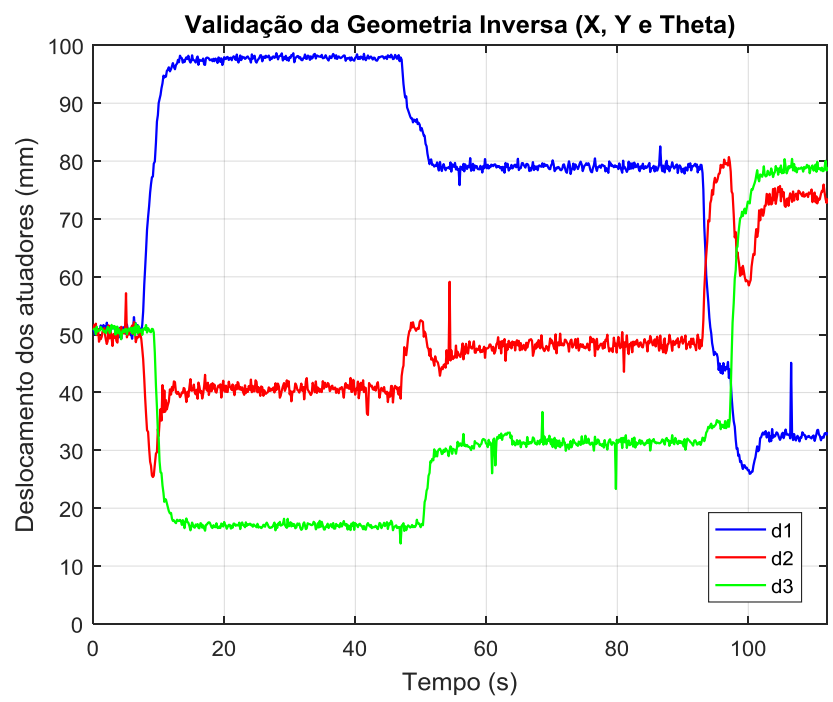

(a)

Figura 7.2.5: Respostas no tempo nos testes para validação da geometria inversa com entradas em $X(t), Y(t)$ e $\theta(t)$.

\subsection{Validação da Cinemática Inversa}

\subsubsection{Modelo da matriz Jacobiana (relação de velocidades)}

Os testes para validação da cinemática inversa com o modelo da matriz Jacobiana foram feitos usando a arquitetura da Figura 5.1.3, na qual são inseridos os valores desejados de velocidade da plataforma móvel $\left(v_{X}(t), v_{Y}(t)\right.$ e $\left.\omega_{Z}(t)\right)$. O painel de controle é semelhante ao usado na Seção 7.2.

$\mathrm{Na}$ primeira bateria de testes foram dadas entradas com valor constante em $v_{X}(t)$ e $v_{Y}(t)$. As Figuras 7.3.1 a 7.3.3 apresentam os resultados para entradas em $v_{X}(t)$ com valores de $10 \mathrm{~mm} / \mathrm{s}, 20 \mathrm{~mm} / \mathrm{s}$ e $30 \mathrm{~mm} / \mathrm{s}$, respectivamente, e as Figuras 7.3.4 a 7.3.6 apresentam os resultados para entradas em $v_{Y}(t)$ com valores de 10 $\mathrm{mm} / \mathrm{s}, 20 \mathrm{~mm} / \mathrm{s}$ e $30 \mathrm{~mm} / \mathrm{s}$, respectivamente. 


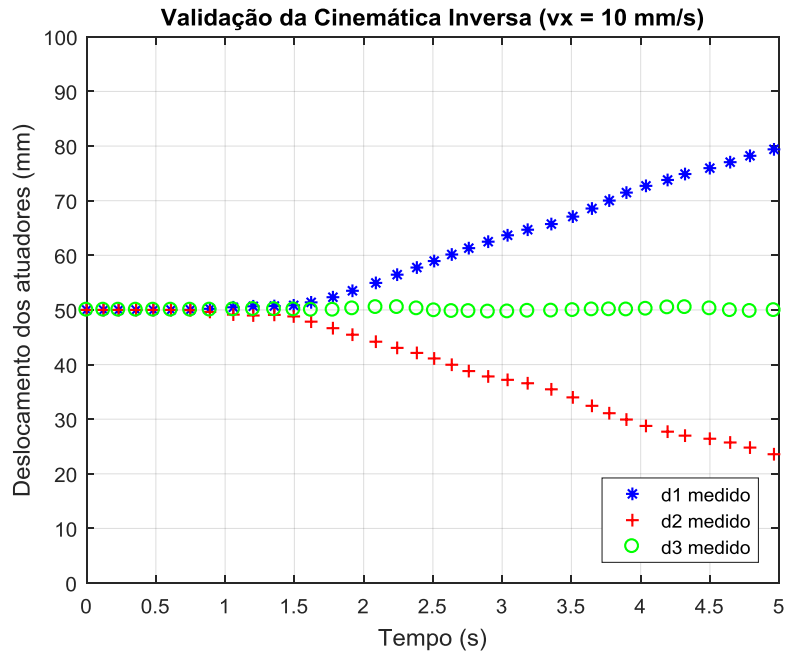

Figura 7.3.1: Teste com entrada $v_{X}(t)=10 \mathrm{~mm} / \mathrm{s}$.

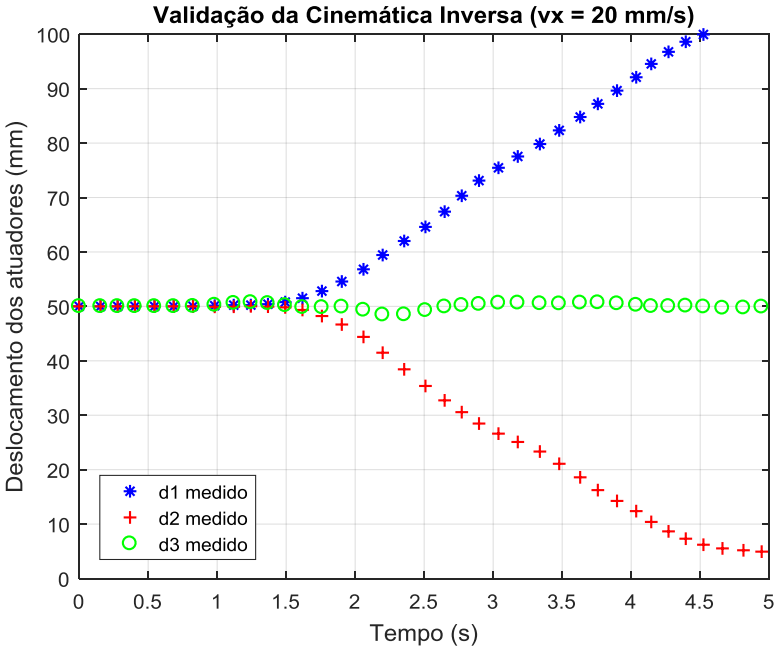

Figura 7.3.2: Teste com entrada $v_{X}(t)=20 \mathrm{~mm} / \mathrm{s}$.

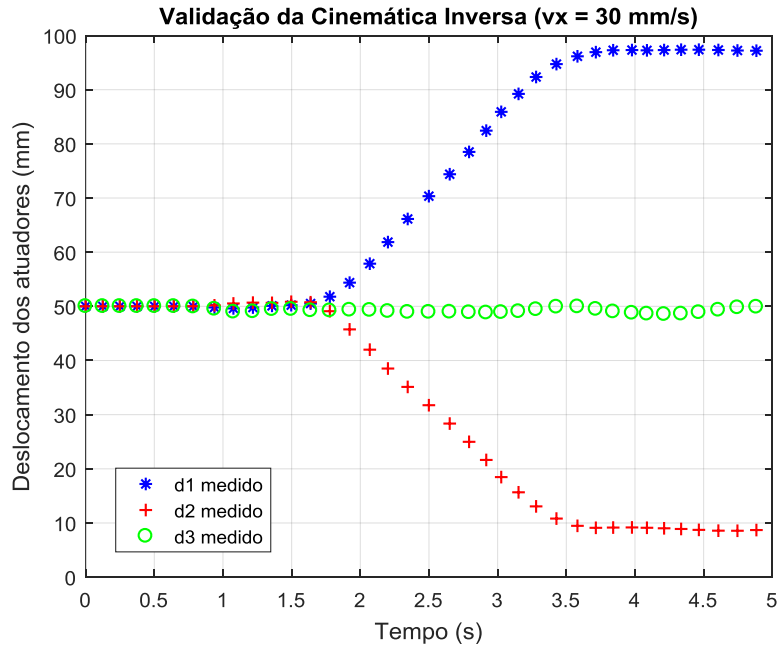

Figura 7.3.3: Teste com entrada $v_{X}(t)=30 \mathrm{~mm} / \mathrm{s}$. 


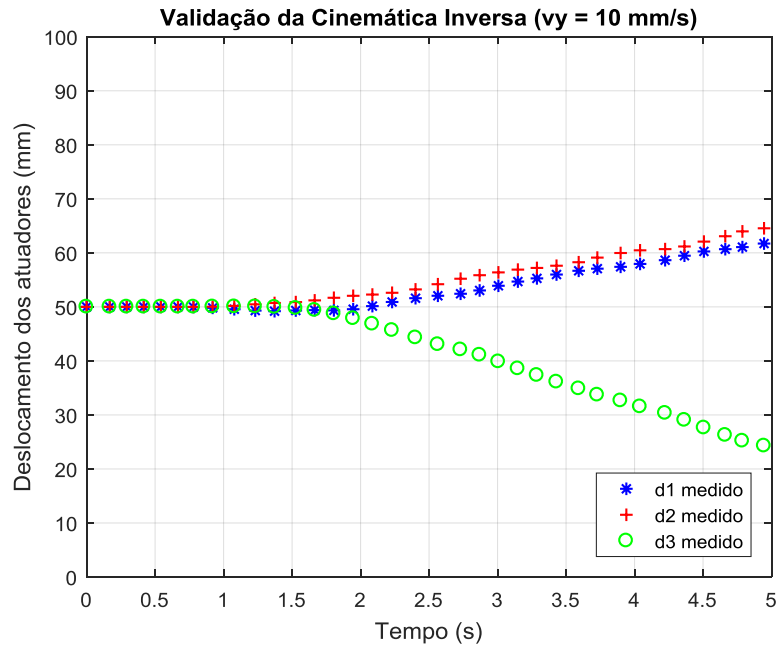

Figura 7.3.4: Teste com entrada $v_{Y}(t)=10 \mathrm{~mm} / \mathrm{s}$.

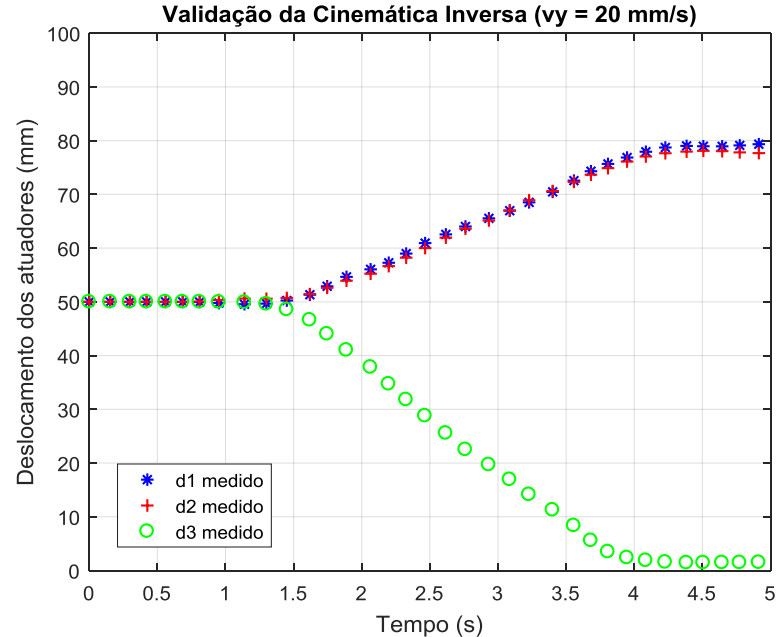

Figura 7.3.5: Teste com entrada $v_{Y}(t)=20 \mathrm{~mm} / \mathrm{s}$.

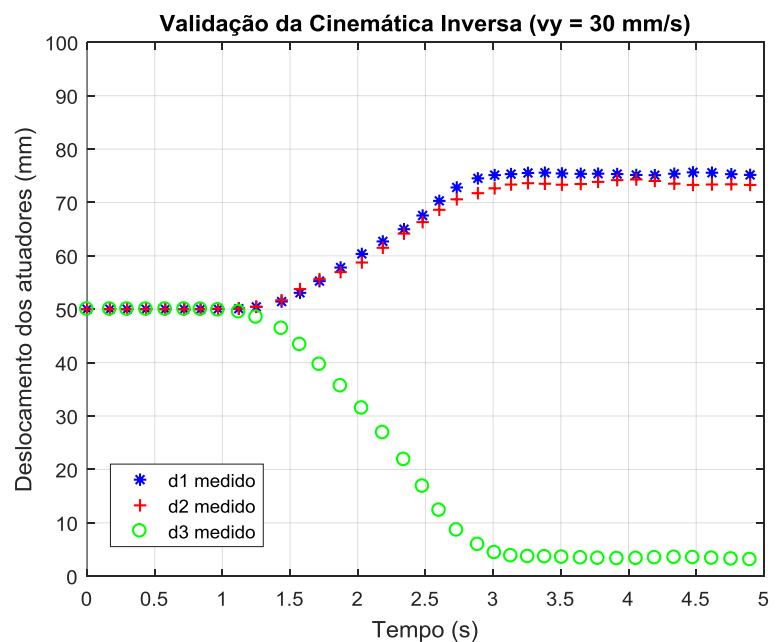

Figura 7.3.6: Teste com entrada $v_{Y}(t)=30 \mathrm{~mm} / \mathrm{s}$. 
No primeiro teste da segunda bateria foi dada uma entrada tipo senóide em $v_{X}(t)$ com amplitude de $20 \mathrm{~mm} / \mathrm{s}$ e frequência de $1 \mathrm{~Hz}$. A Figura 7.3.7 apresenta as respostas no tempo do deslocamento e das velocidades para esta entrada. Já a Figura 7.3.8 apresenta as respostas no tempo do deslocamento e das velocidades para entrada em $v_{X}(t)$ com amplitude de $20 \mathrm{~mm} / \mathrm{s}$ e frequência de $3 \mathrm{~Hz}$.

As Figuras 7.3.9 e 7.3.10 apresentam respostas no tempo para entradas tipo senóide em $v_{Y}(t)$ com amplitudes de $20 \mathrm{~mm} / \mathrm{s}$ e frequências de $1 \mathrm{~Hz}$ e $3 \mathrm{~Hz}$, respectivamente. Em todas as legendas das Figuras 7.3.7 a 7.3.10, o termo "entrada" indica que são os valores calculados usando o modelo da matriz Jacobiana (relação de velocidades) e que, após este processo, são usados como entrada $\left(\boldsymbol{q}_{\text {des }}\right.$ e $\left.\boldsymbol{v}_{\text {Ades }}\right)$ no modelo do sistema de atuação (curva de acionamento).
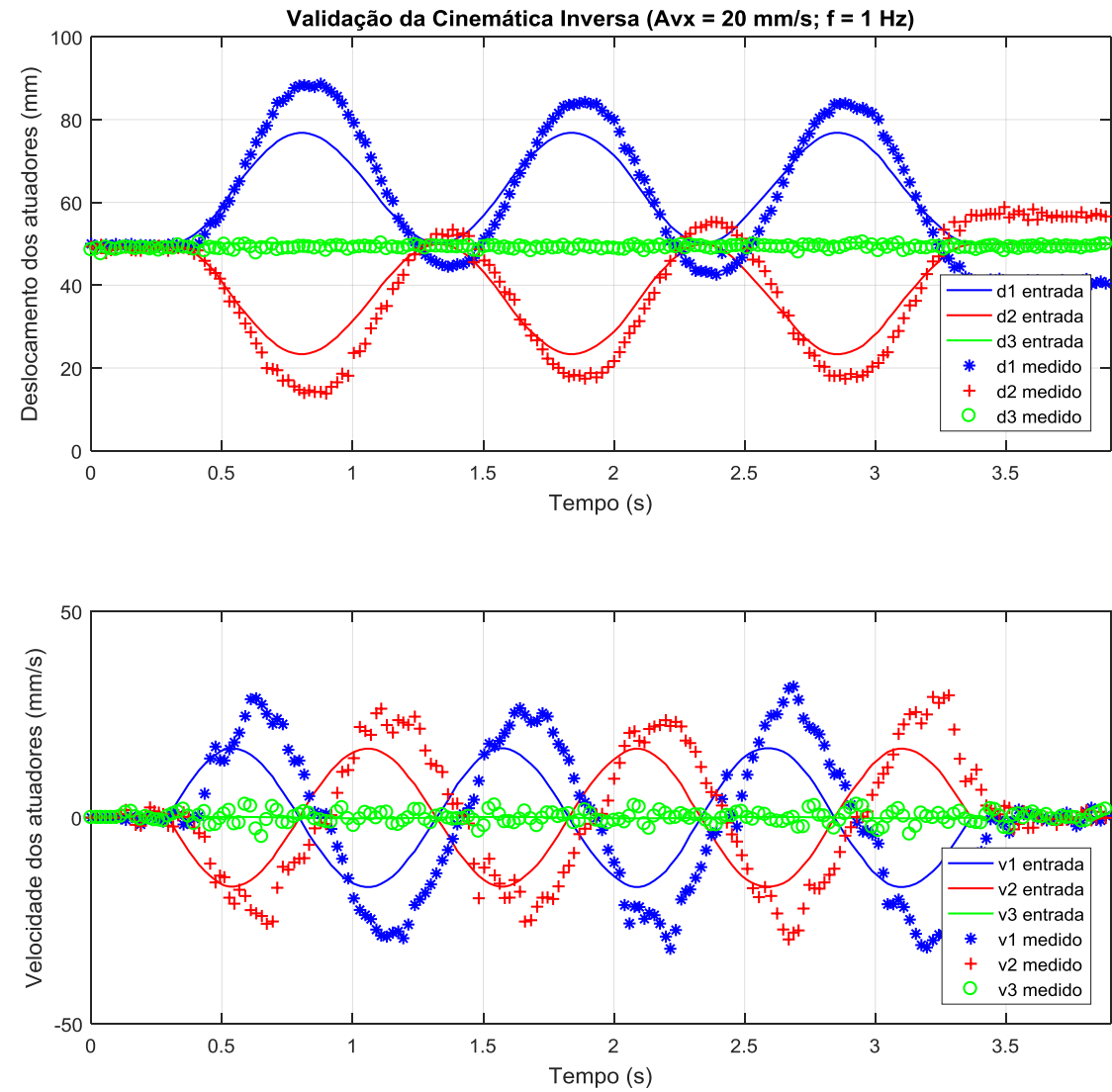

Figura 7.3.7: Teste com entrada $v_{X}(t)=20 . \operatorname{sen}(2 \pi t)[\mathrm{mm} / \mathrm{s}]$. 

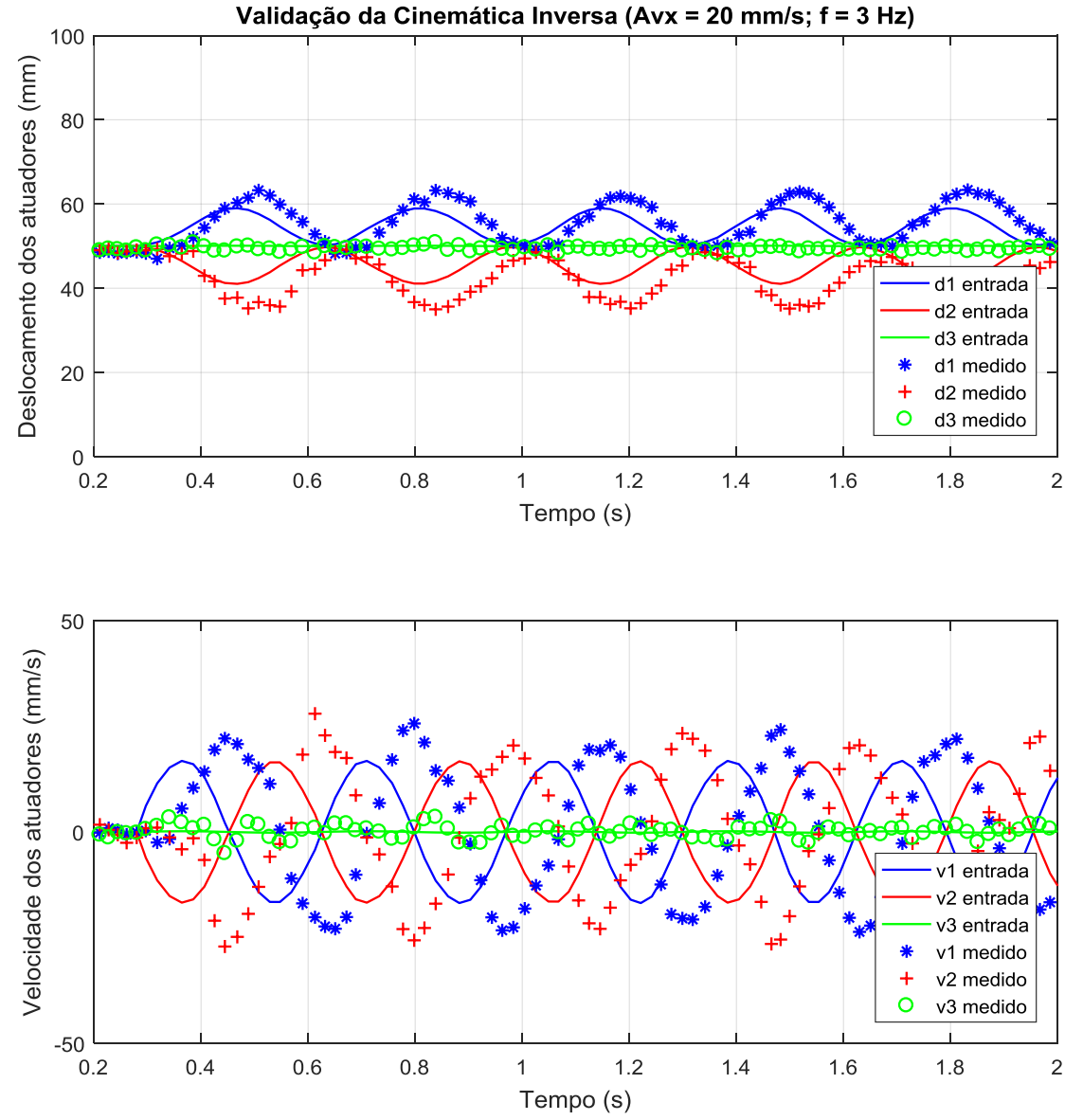

Figura 7.3.8: Teste com entrada $v_{X}(t)=20 \cdot \operatorname{sen}(6 \pi t)[\mathrm{mm} / \mathrm{s}]$.
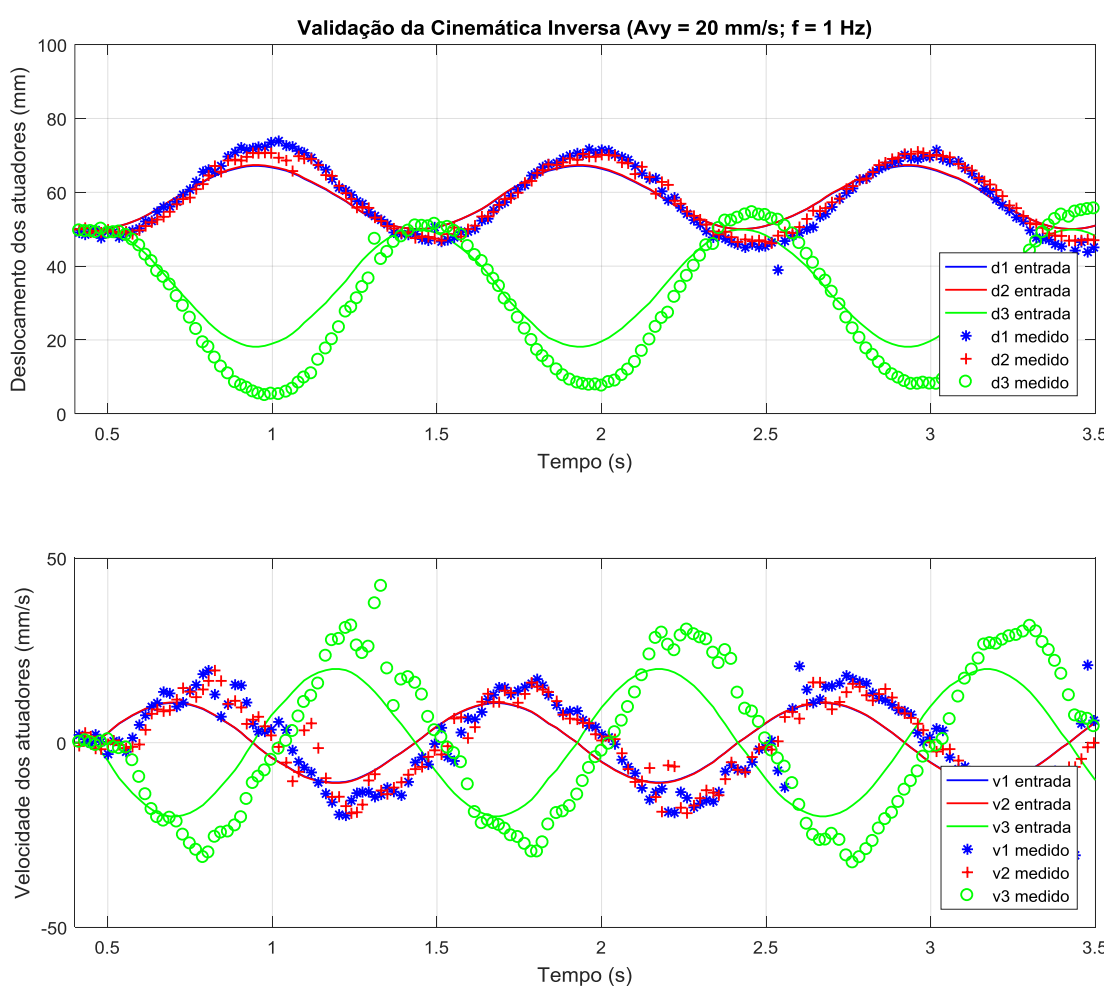

Figura 7.3.9: Teste com entrada $v_{Y}(t)=20 . \operatorname{sen}(2 \pi t)[\mathrm{mm} / \mathrm{s}]$. 

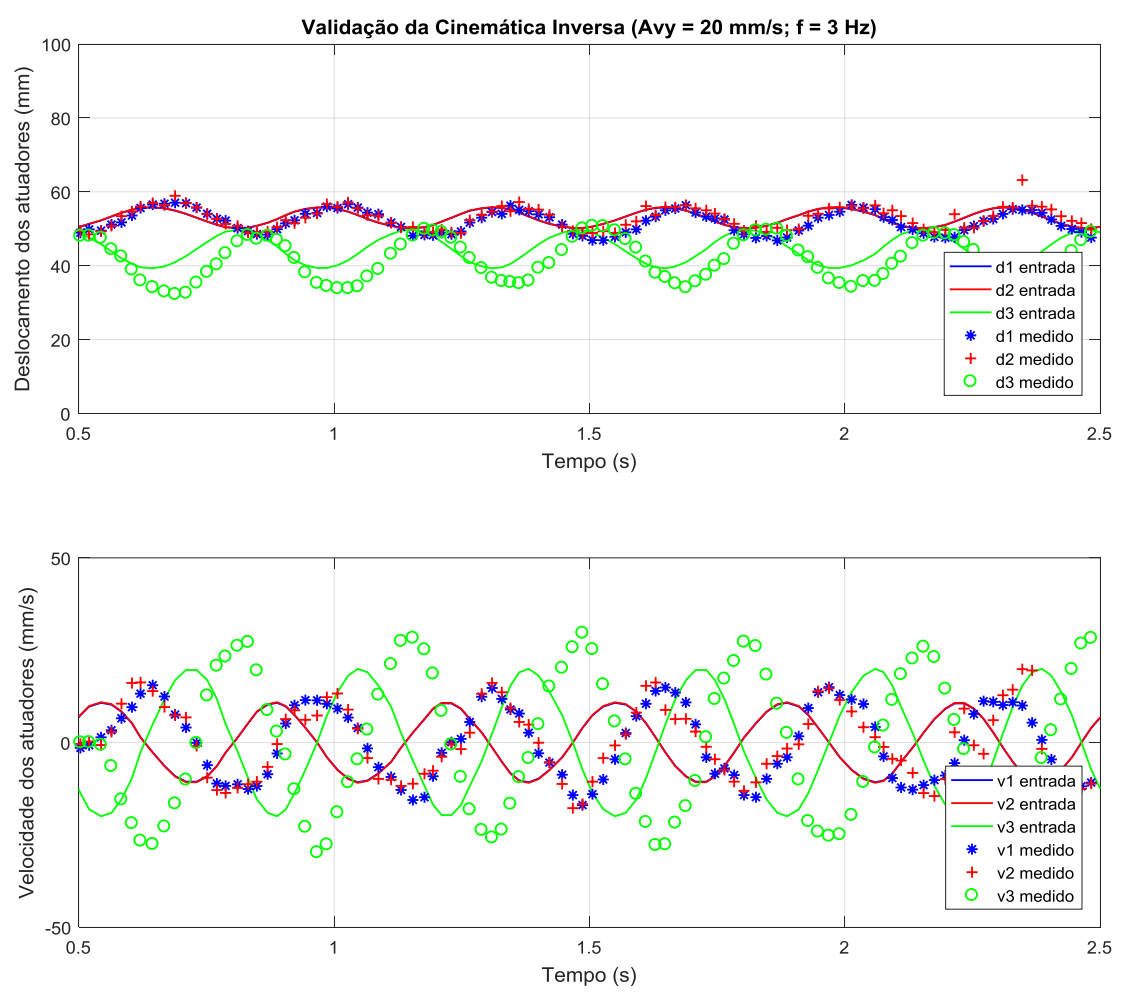

Figura 7.3.10: Teste com entrada $v_{Y}(t)=20 \cdot \operatorname{sen}(6 \pi t)[\mathrm{mm} / \mathrm{s}]$.

Os resultados apresentados nas Figuras 7.3.7 a 7.3.10 indicam, além de pequenos erros de filtragem, um atraso dos valores medidos em relação aos valores obtidos pelos modelos analíticos. Como o modelo em questão é apenas cinemático, este não leva em consideração os efeitos inerciais e de dissipação do sistema. Assim, quanto maiores as velocidades e as variações de velocidades no teste, maiores os erros. Nos testes de velocidade constante, cujos resultados são apresentados nas Figuras 7.3.1 e 7.3.6 as velocidades calculadas a partir da vairação do deslocamento no tempo os erros foram menores. Comandos com baixa velocidade ou baixa variação de velocidade são comumente usados no controle cinemático de manipuladores como o em estudo.

As Figuras 7.3.11 e 7.3.12 apresentam respostas no tempo para entradas tipo senóide em $v_{X}(t)$ e $v_{Y}(t)$. Na resposta no tempo da Figura 7.3.11 as amplitudes nas duas senóides são de $20 \mathrm{~mm} / \mathrm{s}$ e as frequências são de $3 \mathrm{~Hz}$. Já na resposta no tempo da Figura 7.3 .12 as amplitudes são de $30 \mathrm{~mm} / \mathrm{s}$ e as frequências são de 5 $\mathrm{Hz}$. 

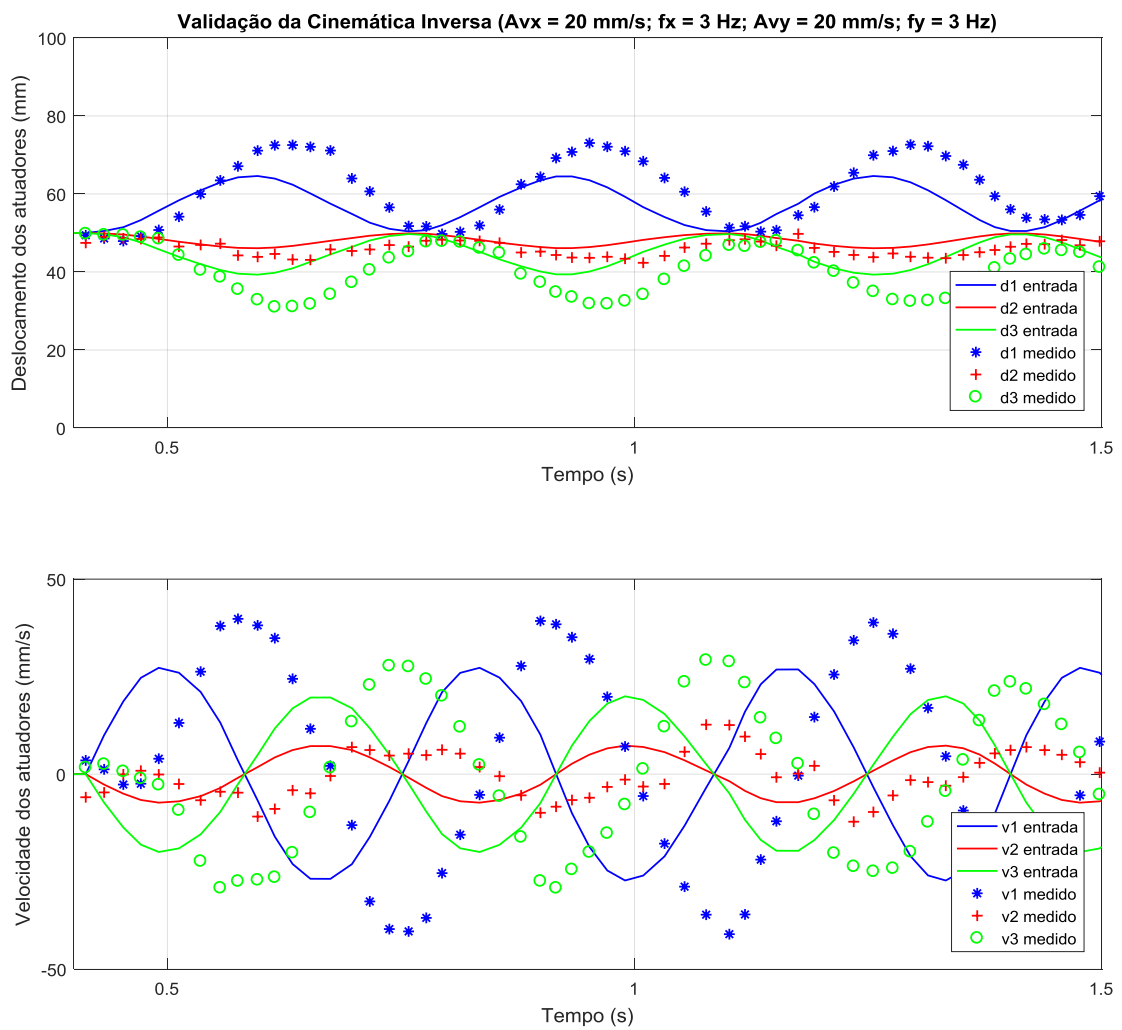

Figura 7.3.11: Teste com entradas $v_{X}(t)=20 \cdot \operatorname{sen}(6 \pi t)$ e $v_{Y}(t)=20 \cdot \operatorname{sen}(6 \pi t)[\mathrm{mm} / \mathrm{s}]$.
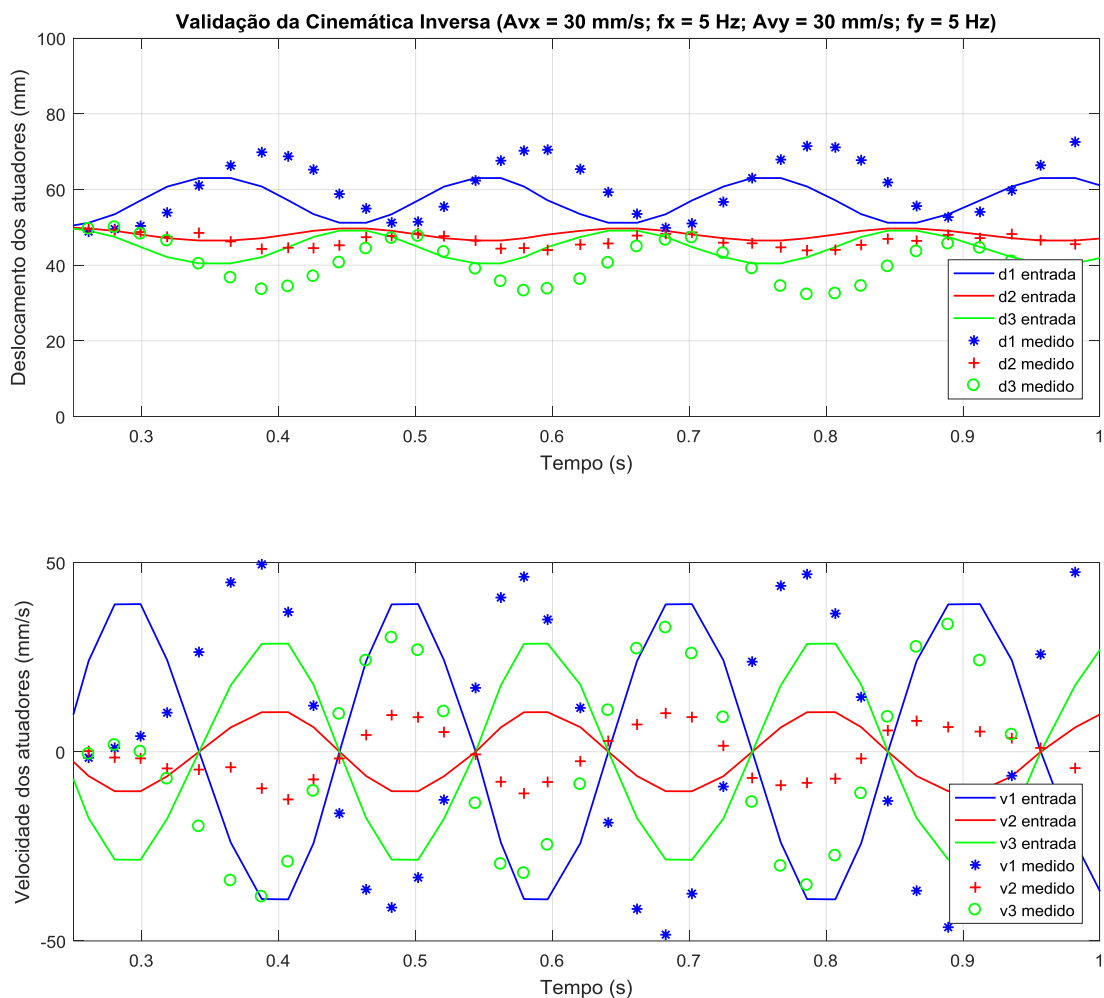

Figura 7.3.12: Teste com entradas $v_{X}(t)=30 \cdot \operatorname{sen}(10 \pi t)$ e $v_{Y}(t)=30 \cdot \operatorname{sen}(10 \pi t)$ $[\mathrm{mm} / \mathrm{s}]$. 
Nas legendas das Figuras 7.3.11 e 7.3.12, o termo "entrada" indica que são os valores calculados usando o modelo da matriz Jacobiana (relação de velocidades) e que, após este processo, são usados como entrada $\left(\boldsymbol{q}_{\text {des }}\right.$ e $\left.\boldsymbol{v}_{\text {Ades }}\right)$ no modelo do sistema de atuação (curva de acionamento). Os resultados apresentados também indicam um atraso dos valores medidos em relação aos valores obtidos pelos modelos analíticos. Como o modelo em questão é apenas cinemático, este não leva em consideração os efeitos inerciais e de dissipação do sistema. Assim, por se tratar de um sistema em malha aberta, quanto maiores as velocidades e as variações de velocidades no teste, maiores os erros.

\subsubsection{Modelo dos derivativos da matriz Jacobiana (relação de acelerações)}

Os testes para validação da cinemática inversa usando o modelo dos derivativos da matriz Jacobiana foram feitos usando a arquitetura da Figura 5.1.4, na qual são inseridos os valores desejados de aceleração da plataforma móvel $\left(a_{X}(t), a_{Y}(t)\right.$ e $\left.\alpha_{Z}(t)\right)$. O painel de controle é semelhante ao usado na Seção 7.2.

$\mathrm{Na}$ primeira bateria de testes foram dadas entradas com valor constante em $a_{X}(t)$ e $a_{Y}(t)$. As Figuras 7.3.13.a a 7.3.13.d apresentam os resultados para entradas em $a_{X}(t)$ com valores de $1 \mathrm{~mm} / \mathrm{s}^{2}, 5 \mathrm{~mm} / \mathrm{s}^{2}, 10 \mathrm{~mm} / \mathrm{s}^{2}$ e $15 \mathrm{~mm} / \mathrm{s}^{2}$, respectivamente, e as Figuras 7.3.14.a a 7.3.14.d apresentam os resultados para entradas em $a_{Y}(t)$ com valores de $1 \mathrm{~mm} / \mathrm{s}^{2}, 5 \mathrm{~mm} / \mathrm{s}^{2}, 10 \mathrm{~mm} / \mathrm{s}^{2}$ e $15 \mathrm{~mm} / \mathrm{s}^{2}$, respectivamente.

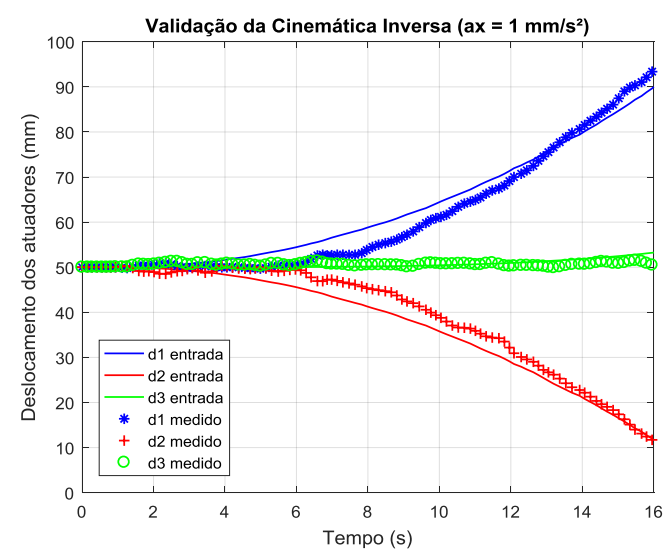

(a)

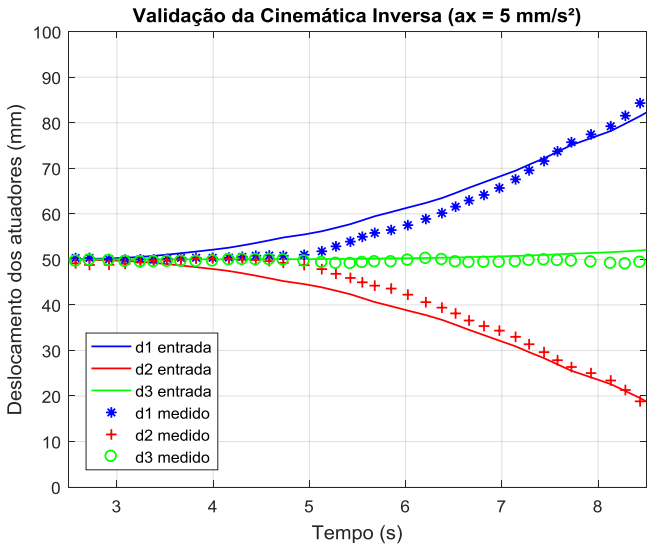

(b) 


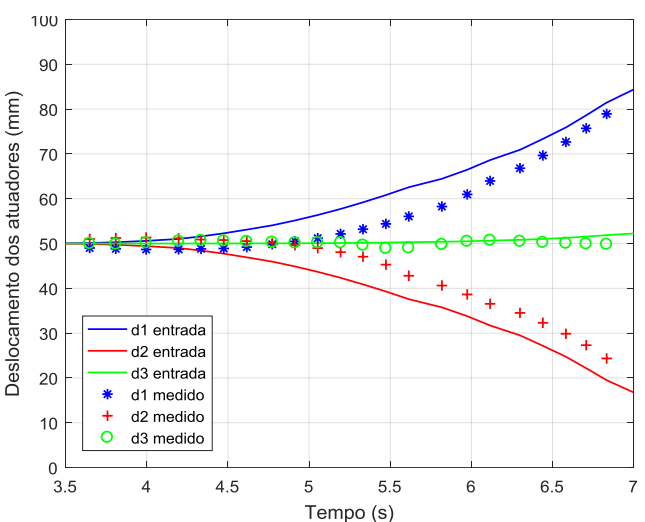

(c)

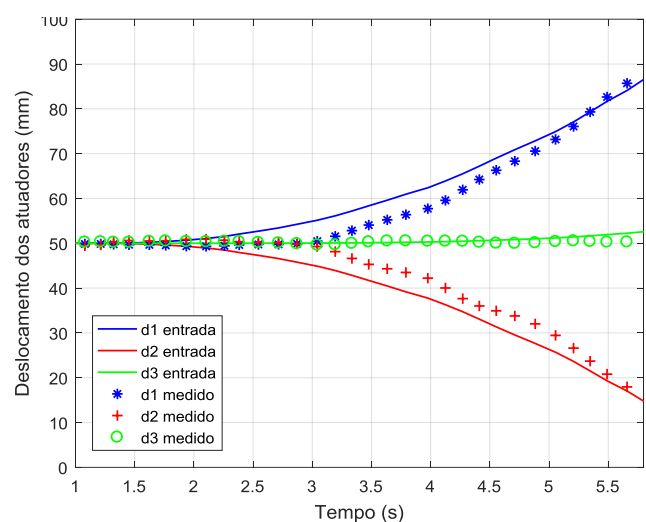

(d)

Figura 7.3.13: Teste com entradas $a_{X}(t)=1 \mathrm{~mm} / \mathrm{s}^{2}(\mathrm{a}), a_{X}(t)=5 \mathrm{~mm} / \mathrm{s}^{2}(\mathrm{~b}), a_{X}(t)=$ $10 \mathrm{~mm} / \mathrm{s}^{2}(\mathrm{c})$ e $a_{X}(t)=15 \mathrm{~mm} / \mathrm{s}^{2}(\mathrm{~d})$.

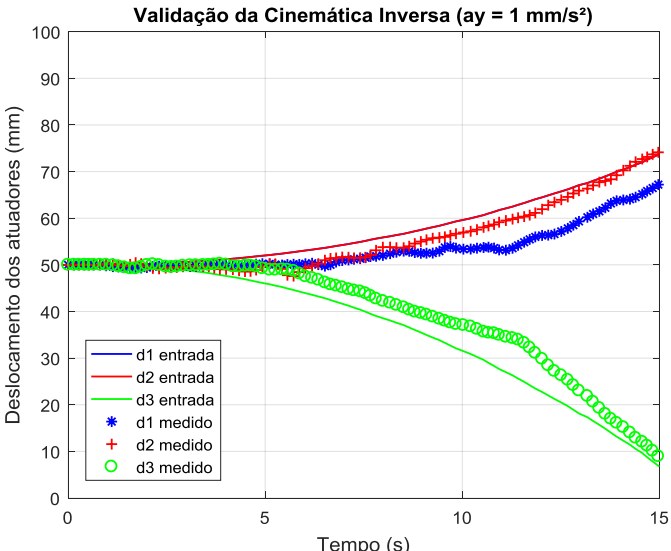

(a)

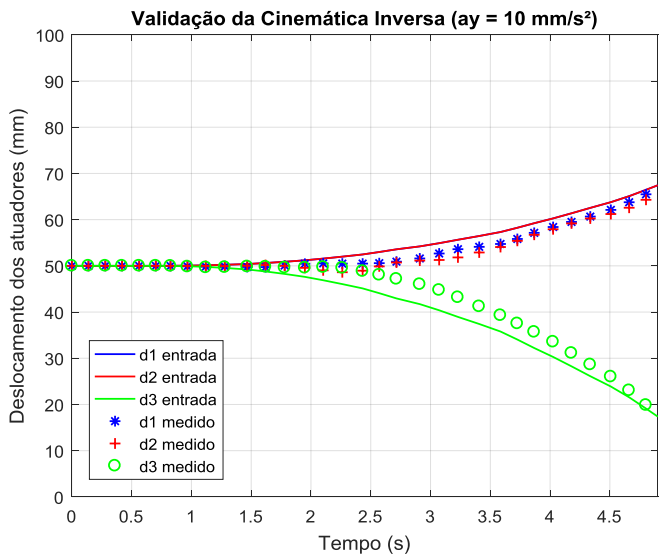

(c)

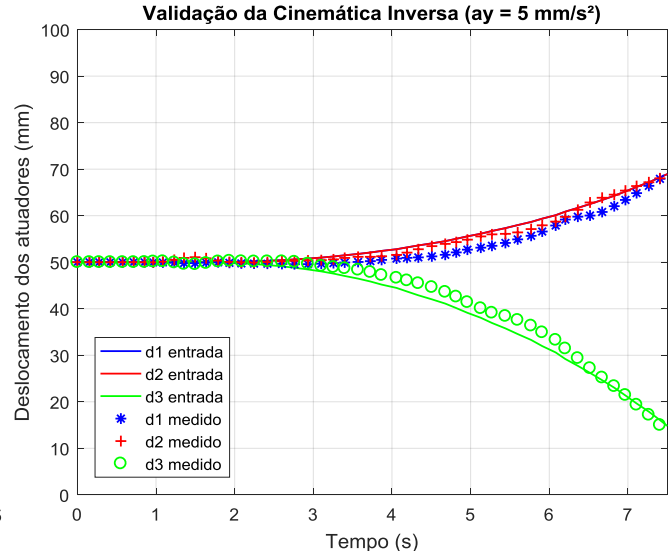

(b)

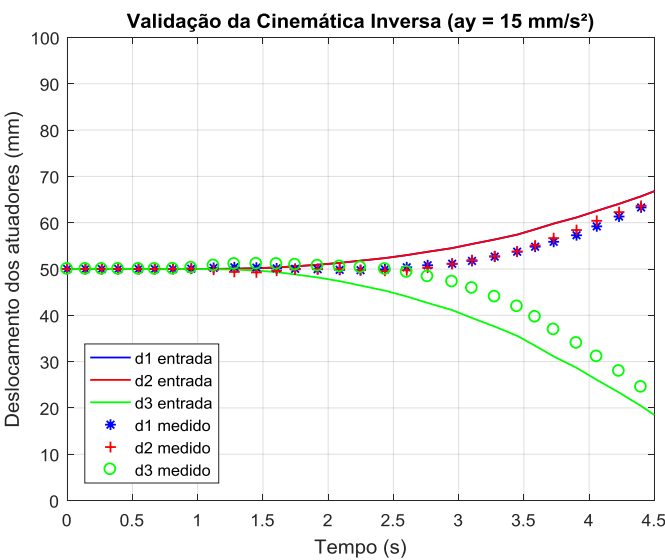

(d)

Figura 7.3.14: Teste com entradas $a_{Y}(t)=1 \mathrm{~mm} / \mathrm{s}^{2}(\mathrm{a}), a_{Y}(t)=5 \mathrm{~mm} / \mathrm{s}^{2}(\mathrm{~b}), a_{Y}(t)=$ $10 \mathrm{~mm} / \mathrm{s}^{2}(\mathrm{c})$ e $a_{Y}(t)=15 \mathrm{~mm} / \mathrm{s}^{2}(\mathrm{~d})$. 
Nas legendas das Figuras 7.3.17 e 7.3.18, o termo "entrada" indica que são os valores calculados usando o modelo dos derivativos da matriz Jacobiana (relação de acelerações) e que, após este processo, são usados como entrada ( $\boldsymbol{q}_{\text {des }} \mathrm{e}$ $\boldsymbol{v}_{\text {Ades}}$ ) no modelo do sistema de atuação (curva de acionamento). Os resultados apresentados indicam um atraso dos valores medidos em relação aos valores obtidos pelos modelos analíticos. Como o modelo em questão é apenas cinemático, este não leva em consideração os efeitos inerciais e de dissipação do sistema. Assim, por se tratar de um sistema em malha aberta, quanto maiores as velocidades e as variações de velocidades no teste, maiores os erros.

\subsection{Estratégias de controle}

\subsubsection{Controle via transdutores de deslocamento}

Os primeiros testes para controle via transdutores de deslocamento foram os testes de controle de posição. Estes foram feitos usando a arquitetura da Figura 5.1.2, na qual são inseridos os valores desejados de posição da plataforma móvel $(X(t), Y(t)$ e $\theta(t))$. O painel de controle é semelhante ao usado na Seção 7.2.

As Figuras 7.4.1.a a 7.4.1.d apresentam as respostas no tempo dos atuadores 1 e 2 para entrada em $X(t)$ com valor constante de $20 \mathrm{~mm}$ usando valores de ganho proporcional $k_{p}$ iguais a 0,5 a 4,0. Já as Figuras 7.4.2.a a 7.4.2.d apresentam as respostas no tempo dos atuadores 1 e 3 para entrada em $Y(t)$ com valor constante de $20 \mathrm{~mm}$ usando valores de ganho proporcional $k_{p}$ iguais a 0,5 a 4,0 .

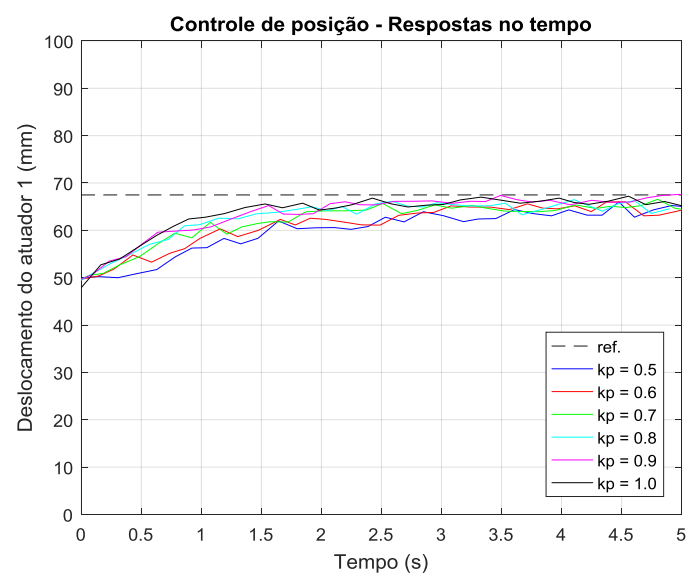

(a)

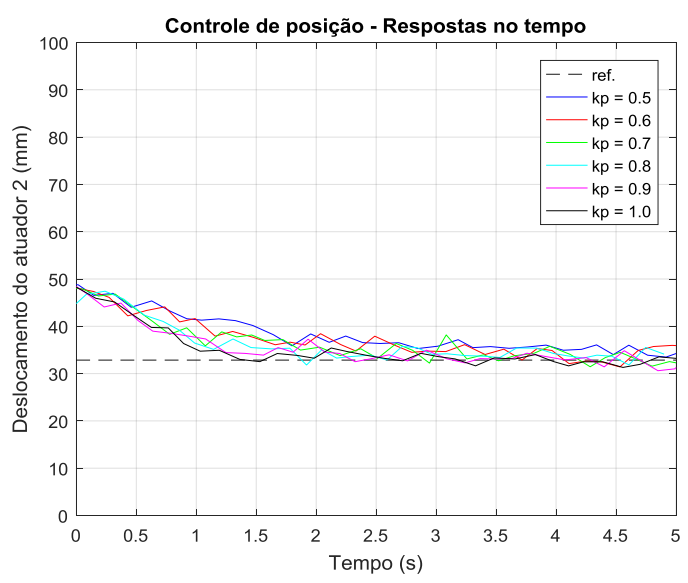

(b) 


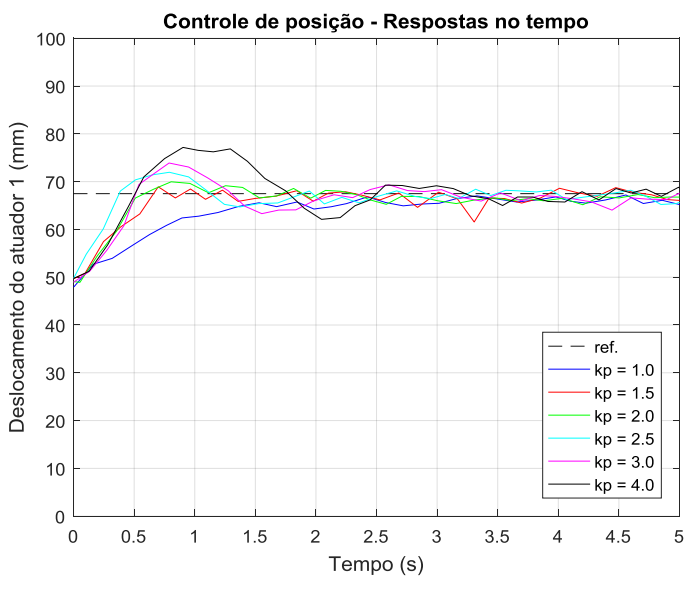

(c)

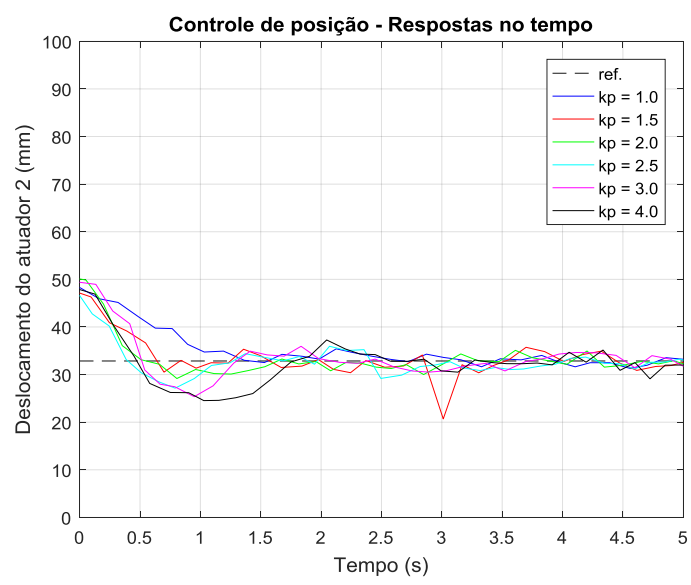

(d)

Figura 7.4.1: Respostas no tempo para entrada $X(t)=20 \mathrm{~mm}$. (a) Atuador 1 e $k_{p}=$ 0,5 a 1,0; (b) atuador 2 e $k_{p}=0,5$ a 1,0; (c) atuador 1 e $k_{p}=1,0$ a 4,0; (d) atuador 2 e $k_{p}=1,0$ a 4,0 .

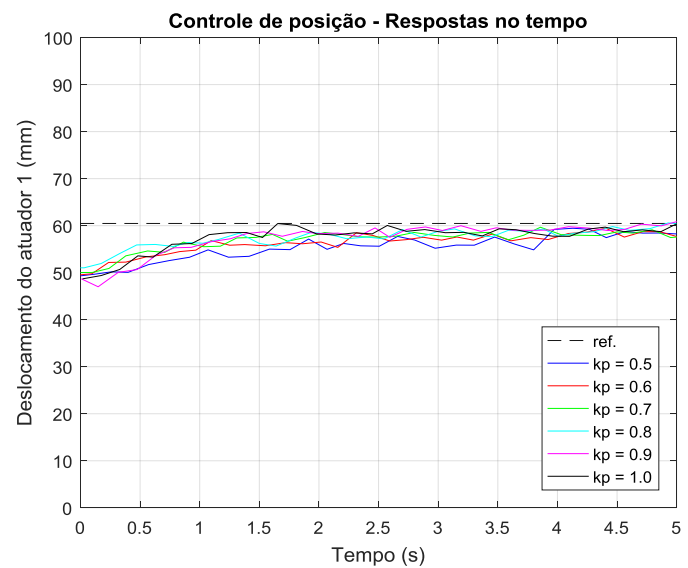

(a)

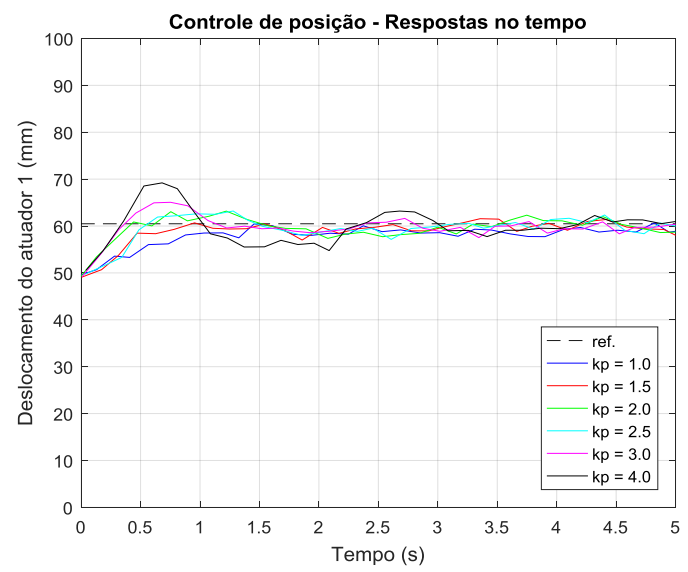

(c)

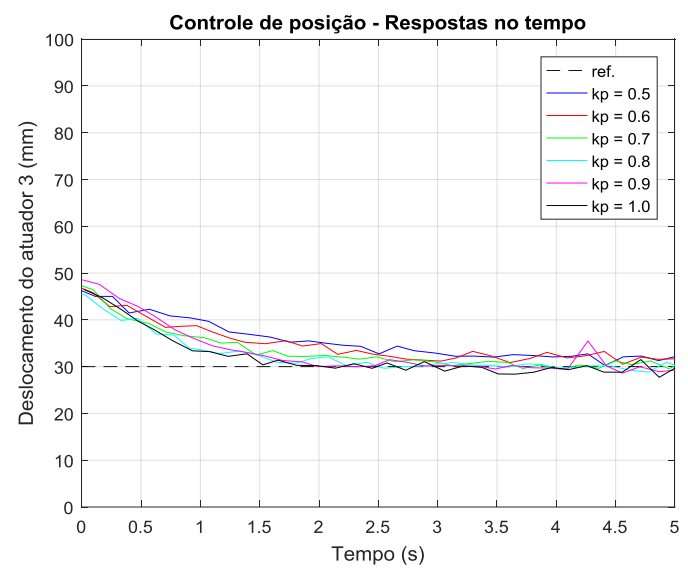

(b)

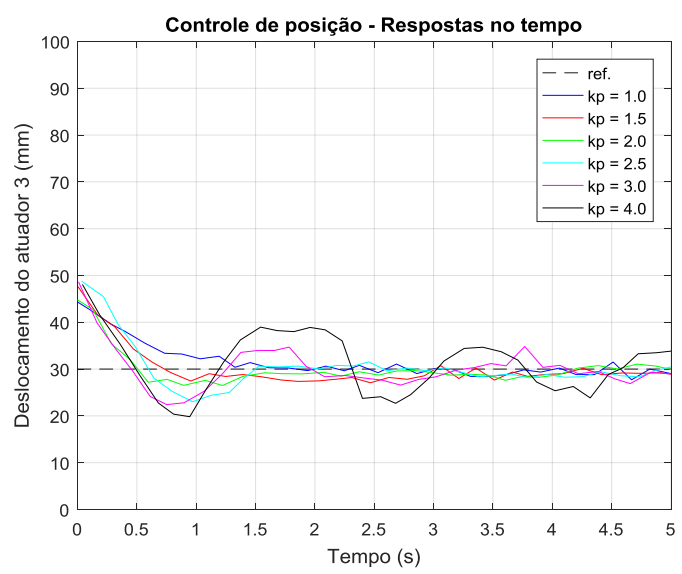

(d)

Figura 7.4.2: Entrada $Y(t)=20 \mathrm{~mm}$. (a) Atuador 1 e $k_{p}=0,5$ a 1,0; (b) atuador $3 \mathrm{e}$ $k_{p}=0,5$ a 1,$0 ;$ (c) atuador 1 e $k_{p}=1,0$ a 4,0; (d) atuador 3 e $k_{p}=1,0$ a 4,0. 
Os testes de controle de velocidade foram feitos usando a arquitetura da Figura 5.1.5, na qual são inseridos os valores desejados de velocidade da plataforma móvel $\left(v_{X}(t), v_{Y}(t)\right.$ e $\left.\omega_{Z}(t)\right)$. O painel de controle é semelhante ao usado na Seção 7.2.

As Figuras 7.4.2.a e 7.4.2.b apresentam as respostas no tempo dos atuadores 1 e 2 para entrada $v_{X}(t)=10 \mathrm{~mm} / \mathrm{s}$ usando ganho proporcional $k_{p}$ nos valores de 0,5 a 4,0 e ganho derivativo $k_{v}=0,1$.

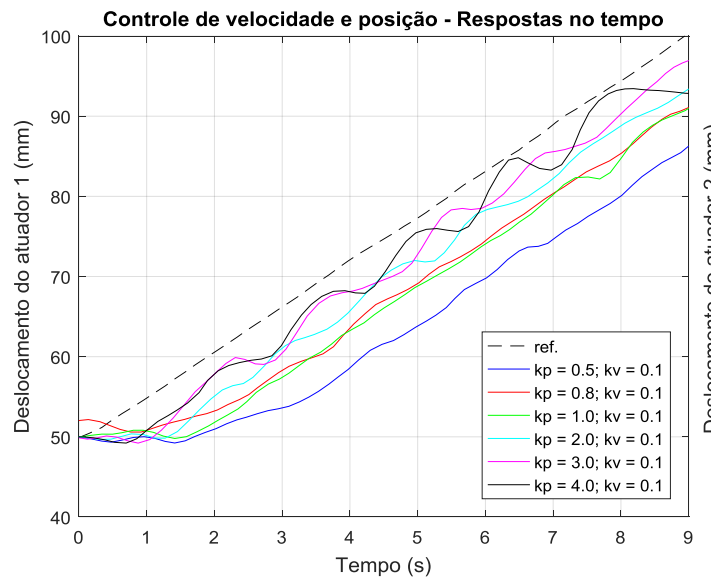

(a)

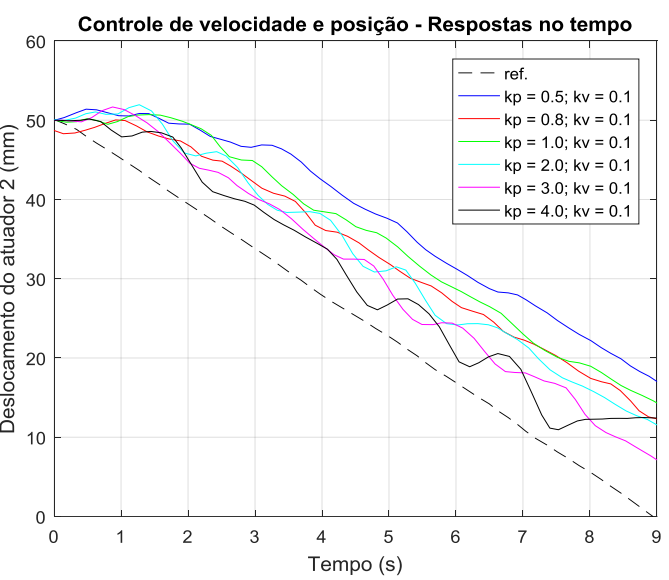

(b)

Figura 7.4.2: Respostas no tempo para entrada $v_{X}(t)=10 \mathrm{~mm} / \mathrm{s}$. (a) Atuador $1, k_{p}$ $=0,5$ a 4,0 e $k_{v}=0,1 ;$ (b) atuador $2, k_{p}=0,5$ a 4,0 e $k_{v}=0,1$.

As Figuras 7.4.3.a a 7.4.3.d apresentam as respostas no tempo dos atuadores 1 e 2 para entrada $v_{X}(t)=10 \mathrm{~mm} / \mathrm{s}$ usando valores de ganho proporcional $k_{p}=0,8$ e ganho derivativo $k_{v}$ de 0,01 a 1,0. As Figuras 7.4.4.a e 7.4.4.b apresentam as respostas no tempo dos atuadores 1 e 2 para entrada $v_{X}(t)=30 \mathrm{~mm} / \mathrm{s}$ usando valores de ganho proporcional $k_{p}=0,8$ e ganho derivativo $k_{v}$ de 0,01 a 1,0. Já as Figuras 7.4.5.a e 7.4.5.b apresentam as respostas no tempo dos atuadores 1 e 3 para entrada $v_{Y}(t)=10 \mathrm{~mm} / \mathrm{s}$ usando valores de ganho proporcional $k_{p}=0,8 \mathrm{e}$ ganho derivativo $k_{v}$ de 0,01 a 1,0 . 


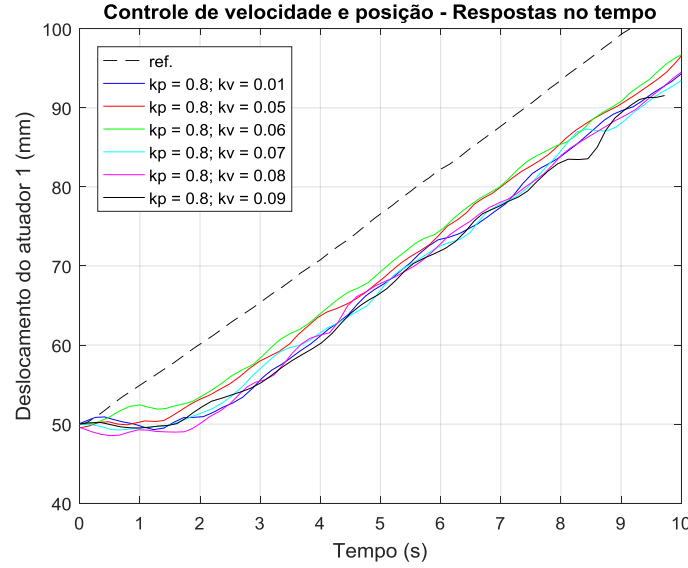

(a)

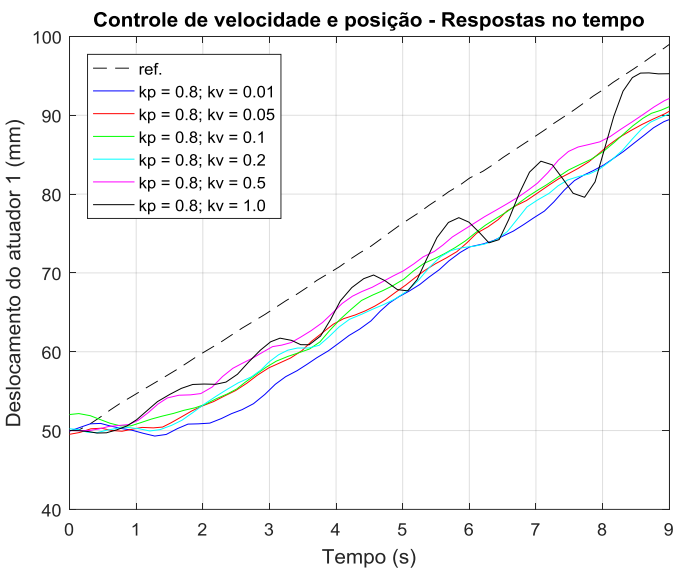

(c)

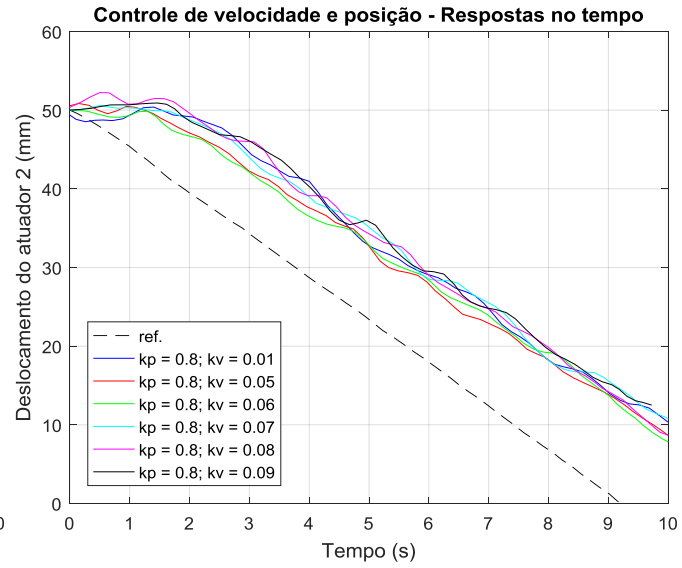

(b)

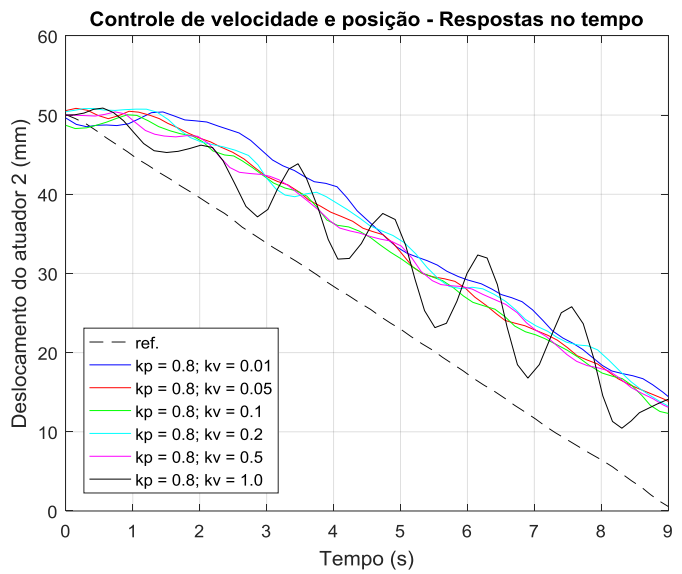

(d)

Figura 7.4.3: Respostas no tempo para entrada $v_{X}(t)=10 \mathrm{~mm} / \mathrm{s}$. (a) Atuador $1, k_{p}$ $=0,8$ e $k_{v}=0,01$ a 0,09; (b) atuador $2, k_{p}=0,8$ e $k_{v}=0,01$ a 0,09 ; (c) atuador $1, k_{p}$ $=0,8$ e $k_{v}=0,01$ a 1,$0 ;$ (d) atuador $2, k_{p}=0,8$ e $k_{v}=0,01$ a 1,0 .

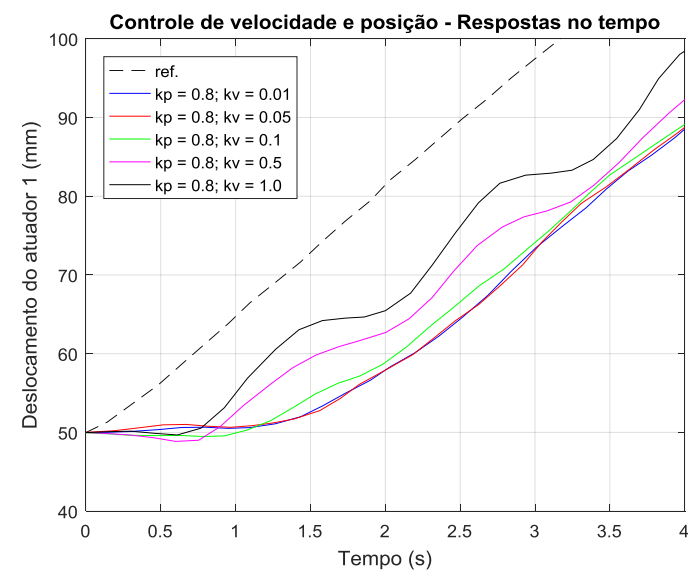

(a)

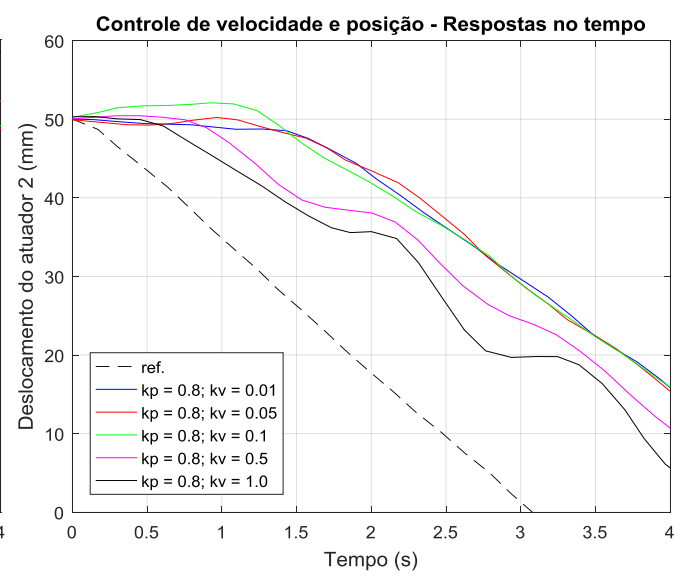

(b)

Figura 7.4.4: Respostas no tempo para entrada $v_{X}(t)=30 \mathrm{~mm} / \mathrm{s}$. (a) Atuador $1, k_{p}$ $=0,8$ e $k_{v}=0,01$ a 1,$0 ;$ (b) atuador $2, k_{p}=0,8$ e $k_{v}=0,01$ a $1,0$. 


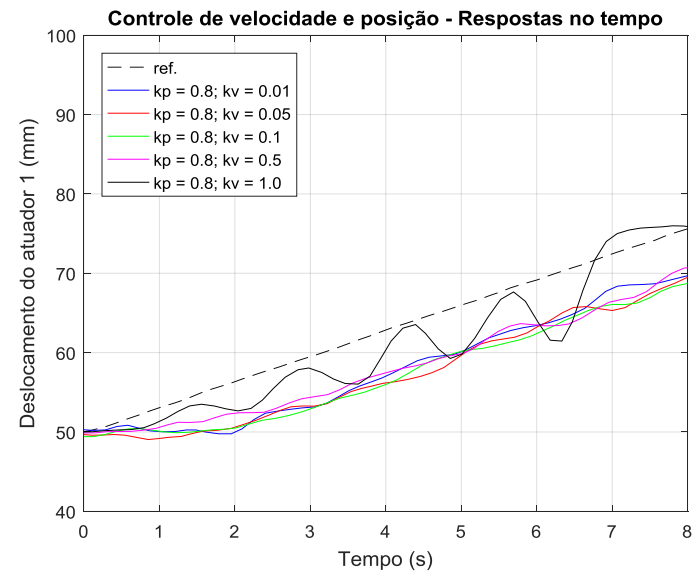

(a)

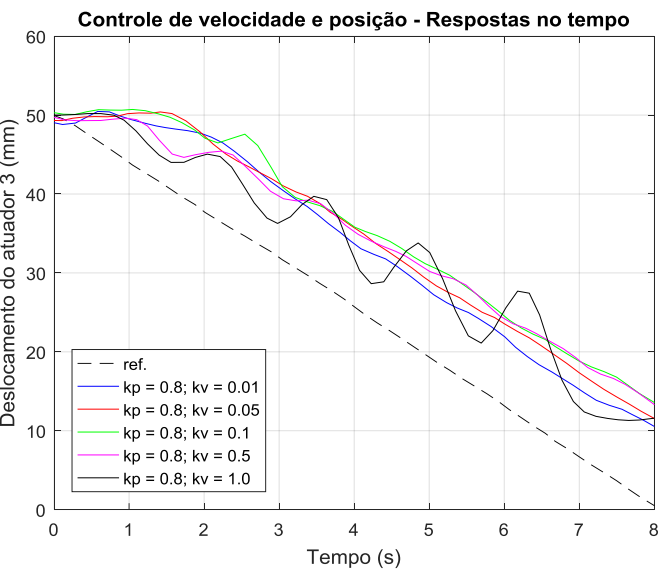

(b)

Figura 7.4.5: Respostas no tempo para entrada $v_{Y}(t)=10 \mathrm{~mm} / \mathrm{s}$. (a) Atuador $1, k_{p}=$ 0,8 e $k_{v}=0,01$ a 1,$0 ;$ (b) atuador $3, k_{p}=0,8$ e $k_{v}=0,01$ a 1,0 .

\subsubsection{Calibração da central inercial}

A Figura 7.4.6 apresenta a central inercial montada na plataforma móvel do mecanismo paralelo plano. O painel de controle para os testes usando a central inercial é apresentado na Figura 7.4.7. Já a Figura 7.4.8 apresenta uma das repsostas no tempo obtidas no processo de calibração, onde é dada uma entrada em forma de onda (senoidal, por exemplo) na posição e orientação da plataforma e estas funções são derivadas analitacamente para comparar os resultados com os obtidos pela IMU. No exemplo da Figura 7.4.8 são apresentados dados de saída em velocidade angular para ondas senoidais com frequência de $1 \mathrm{~Hz}$ e amplitudes de $20^{\circ}$ e $30^{\circ}$.

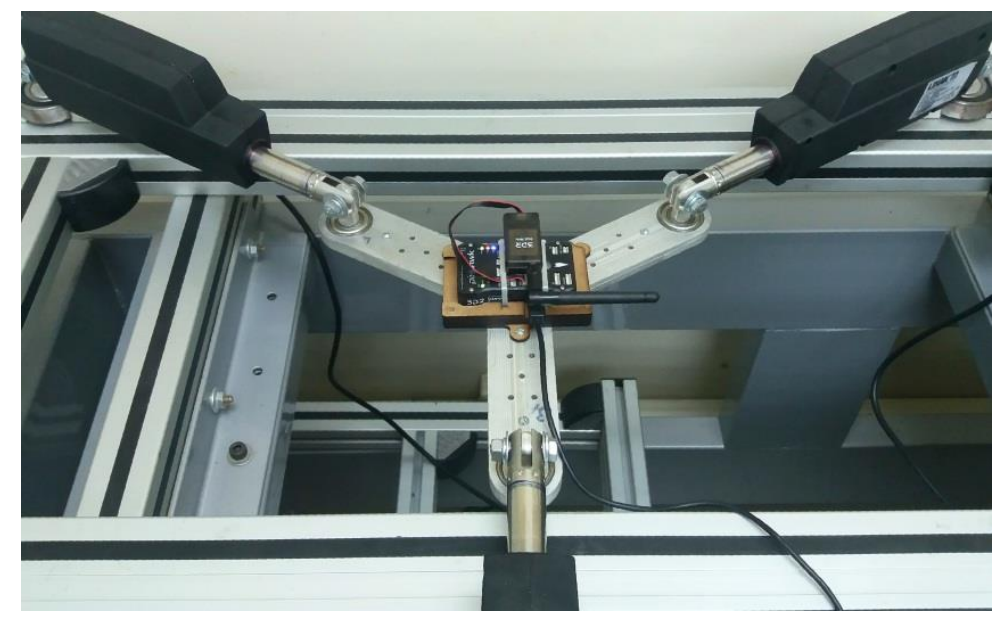

Figura 7.4.6: IMU fixada na plataforma móvel. 


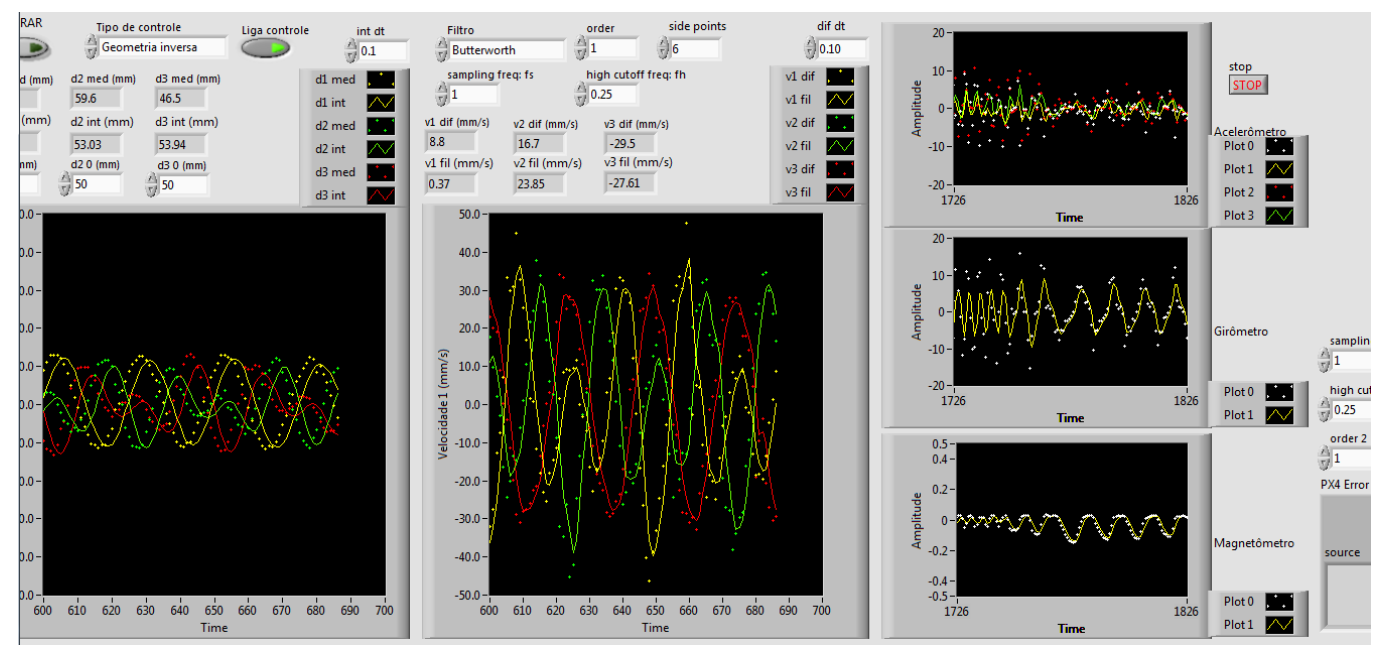

Figura 7.4.7: Painel do controle para os testes com IMU.

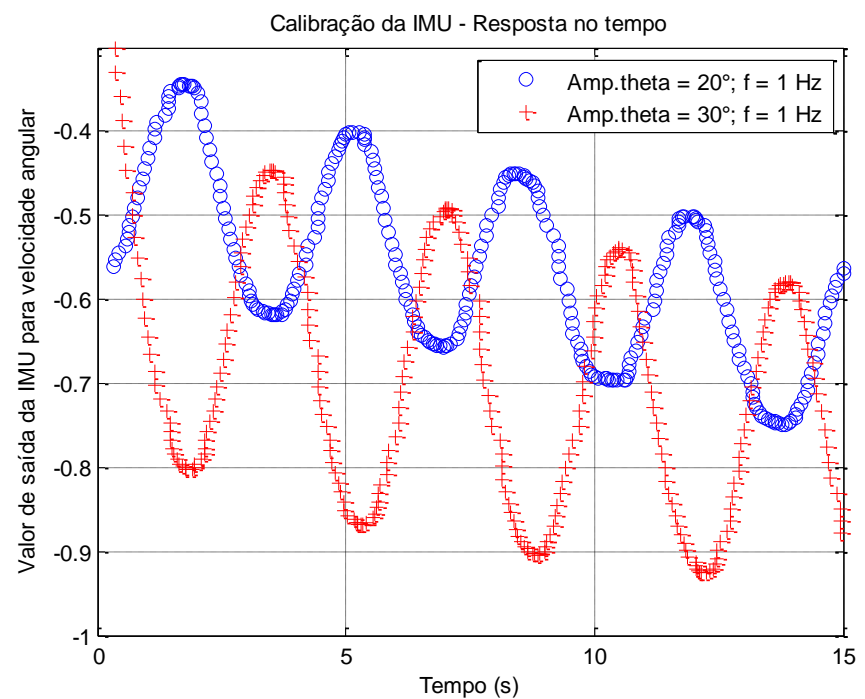

Figura 7.4.8: Exemplo de resposta no tempo obtida durante a calibração da IMU.

\subsubsection{Controle via central inercial}

Após coletados os dados das respostas no tempo no processo de calibração, estes foram correlacionados com as funções de entrada para elaboração das curvas de calibração. Com estas curvas os dados obtidos pela IMU podem ser inseridos na estratégia de controle apresentada da Seção 5.3. A Figura 7.4.9 apresenta um exemplo de resposta no tempo para orientação da plataforma para entradas em degrau de $5^{\circ}$ na orientação da plataforma e diversos valores de ganho proporcional. Já a Figura 7.4.10 apresenta uma resposta no tempo semelhante, esta para entrada em degrau de $30^{\circ}$. 


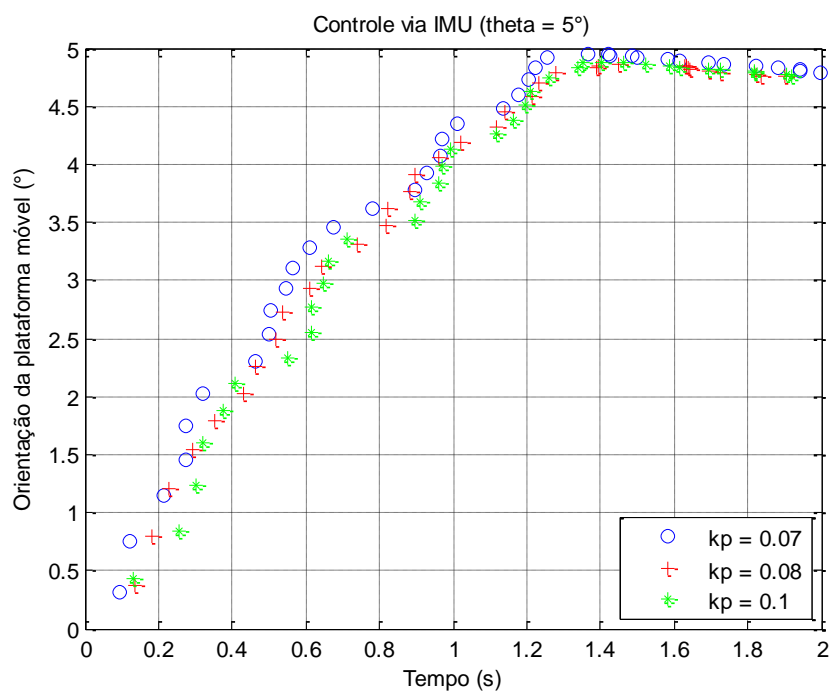

Figura 7.4.9: Respostas no tempo para entrada em degrau de $5^{\circ}$.

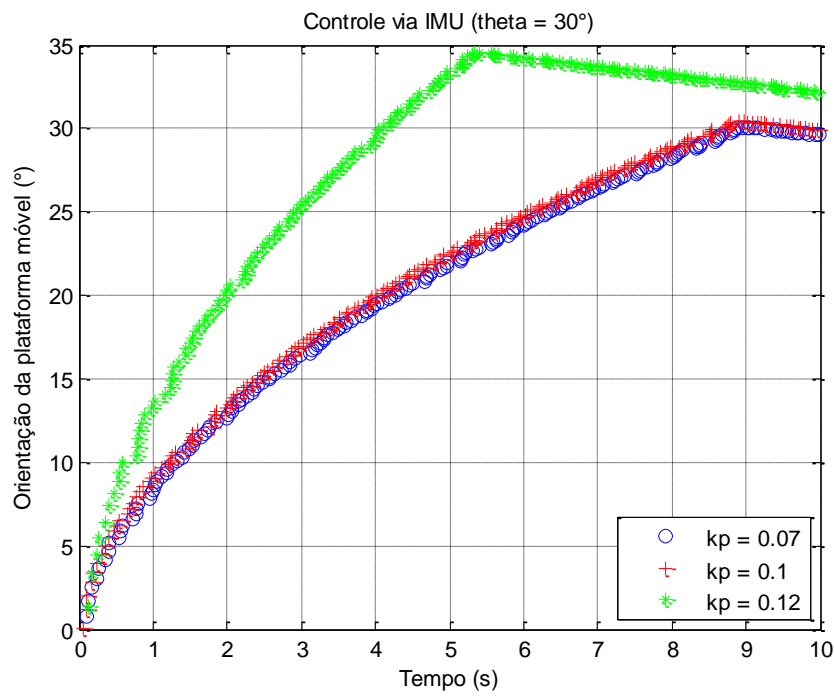

Figura 7.4.10: Respostas no tempo para entrada em degrau de $30^{\circ}$.

Os resultados para orientação da plataforma indicam que o método é válido para atingir valores em regime permanente com erros pequenos, porém, nos testes executados, os valores de constante de tempo foram grandes, como 9 segundos em alguns casos. Um melhor ajuste de parâmetros a escolha de outro tipo de controlador podem ser feitos para tentar alcançar uma resposta mais rápida. Já com relação à posição da plataforma, foi verificado que é necessário um melhor tratamento do processo de filtragem destes tipos de sensores usando técnicas como a de fusão de sensores, por exemplo, para um melhor desempenho na aplicação em estratégias de controle como a proposta. 


\section{8 \\ Conclusões}

\subsection{Conclusões}

Neste trabalho foi apresentado um procedimento para a determinação da solução analítica do modelo dinâmico de um mecanismo paralelo 3-RPR através da caracterização do fluxo de potência entre os seus componentes. A partir das relações geométricas associadas ao deslocamento dos seus graus de liberdade, as relações cinemáticas associadas às suas velocidades foram determinadas. Considerando o fluxo de potência entre os graus de liberdade e entre estes e os elementos de atuação, foram obtidas as relações de equilíbrio das forças e torques. Além disso, foram tomadas em conta a inércia dos componentes do sistema, rigidez e efeitos de amortecimento e as equações de movimento foram analiticamente determinadas. Esta abordagem adota os mesmos fundamentos, conceitos e elementos da técnica dos grafos de ligação.

Um conjunto de simulações foi realizado para validar esta abordagem, usando os dados reais (geometria, inércia, amortecimento, forças de atuadores, etc.) obtidos a partir de um mecanismo paralelo plano projetado e construído especialmente com o propósito de comparar os resultados simulados e experimentais.

Para realizar esta comparação com os dados obtidos no mecanismo projetado, foram adotados diversos procedimentos para caracterização do sistema de atuação, desde a obtenção das curvas de desempenho dos motores elétricos que compõem este sistema até a obtenção das curvas caraterísticas dos atuadores lineares.

Com a implementação dos modelos cinemáticos na plataforma construída, foram verificadas as respostas em ambiente real e estas foram comparadas com as respostas obtidas através de simulações computacionais. Foi verificado que o uso das equações analíticas conduz a um processo de simulação e a um controle em tempo real mais eficiente destes sistemas. 
A estratégia de controle baseada no uso de uma central inercial para a obtenção da configuração espacial das plataformas móveis dos mecanismos analisados através das medidas de aceleração linear e velocidade angular destas plataformas foi implementada e analisada. Os resultados das simulações e dos testes experimentais indicam que é possível controlar tais mecanismos através destes sinais, o que traz benefícios em termos de custo e projeto mecânico de tais mecanismos.

\subsection{Principais contribuições}

A modelagem dinâmica destes tipos de mecanismos é necessária para a solução de diversos problemas na área de robótica e, além disso, estabelecer uma metodologia para a modelagem de tais mecanismos também trará benefícios ao projeto e análise de outros sistemas como os de suspensão veicular. É notório o esforço na modelagem cinemática de tais mecanismos, porém, existem muitos trabalhos na obtenção das relações cinemáticas inversa e direta de mecanismos com cadeias fechadas usando diferentes métodos e notações.

Assim, não foi escopo deste trabalho apresentar uma nova técnica ou notação para o desenvolvimento do modelo cinemático inverso do mecanismo estudado, mas sim obter o modelo dinâmico direto deste mecanismo a partir do modelo cinemático inverso obtido por um método consagrado, como o da cadeia vetorial. O método de fluxo de potência para obtenção do modelo dinâmico já foi usado por diversos autores, contudo, neste trabalho este modelo dinâmico direto é acoplado com a solução analítica fechada do modelo cinemático inverso do mecanismo e integrado ao modelo do sistema de atuação.

A validação de uma estratégia de controle baseada no uso de centrais inerciais de baixo custo, além de trazer vantagens no projeto mecânico destes mecanismos, pode contribuir na redução dos custos com instrumentação, dependendo do número de atuadores. Além disso, este trabalho contribui no estudo do uso de tais mecanismos para a calibração destas centrais inerciais, tema também estudado por diversos autores atualmente.

A bancada experimental desenvolvida neste trabalho também poderá servir como objeto de ensino de diversas disciplinas dos cursos de Graduação em Engenharia Mecânica e Engenharia de Controle e Automação e Pós-Graduação 
em Engenharia Mecânica da PUC-Rio, além de poder ser usada por alunos de Iniciação Científica, Projeto de Fim de Curso, Mestrado e Doutorado. Por exemplo, a empresa canadense Quanser Innovate Educate, produz aparatos de auxílio ao Ensino e Pesquisa. As Figuras 8.2.1.a e 8.2.1.b apresentam dois destes aparatos, um mecanismo de quatro barras com duas juntas atuadas (a) e um hexapod com atuação elétrica (b). Entre as universidades que usaram aparatos desta empresa em pesquisas acadêmicas estão: University of Toronto, Western University e University of Victoria, no Canadá, e State University of New York at Buffalo, University of Central Florida e Rice University, nos Estados Unidos (quanser.com, acesso em Junho de 2017).

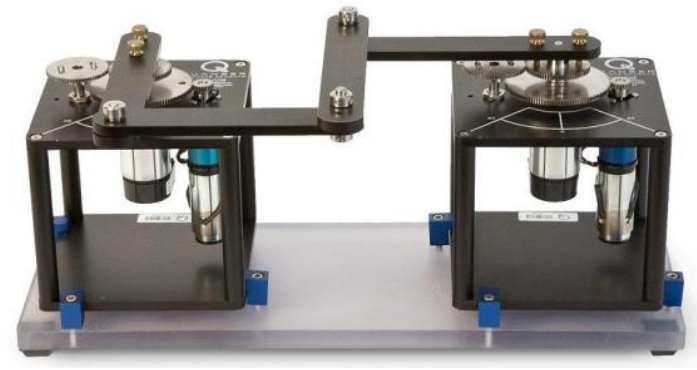

(a)

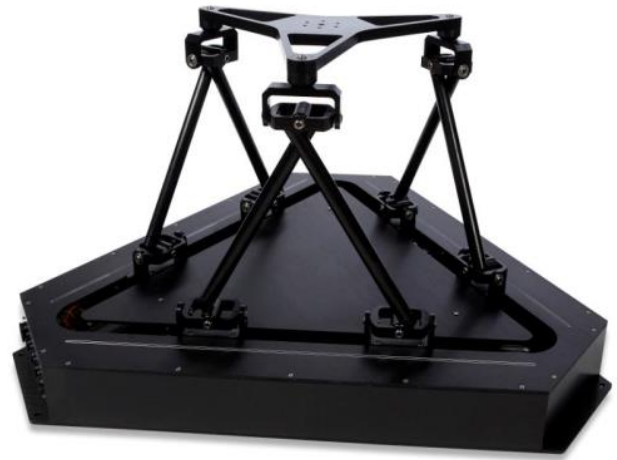

(b)

Figura 8.2.1: Aparatos desenvolvidos pela Quanser: mecanismo de quatro barras (a) e hexapod (b).

O equipamento desenvolvido, por ter rigidez e capacidade de carga relativamente altas (em comparação com arquiteturas em série, por exemplo), pode ser adaptado para ser usado em outras aplicações, como em usinagem, fabricação aditiva e ensaios mecânicos.

\subsection{Trabalhos futuros}

Neste trabalho foi desenvolvida uma bancada de testes que consiste em um manipulador paralelo plano de três graus de liberdade cujas aplicações diretas em pesquisas futuras podem ser diversas, tais como seu uso no processo de calibração de centrais inerciais, como descrito na Seção 7.4.2, seu uso como simulador de movimentos de veículos em escala, como é exemplificado na Figura 8.3.1 e como ferramenta de auxílio ao ensino de engenharia, como outros equipamentos 
desenvolvidos no Laboratório de Desenvolvimento de Sistemas Mecatrônicos. Estes aparatos são em escala reduzida e de baixo custo, com o intuito de auxiliar a prática do ensino, aprendizado e pesquisa em engenharia. Equipamentos deste tipo podem ser usados por outras instituições como kits educacionais, além de serem usados para ilustrar conceitos de Física e Matemática, por exemplo, gerando um ganho de qualidade no treinamento de futuros técnicos e engenheiros (Speranza Neto, M. et al., 2016).

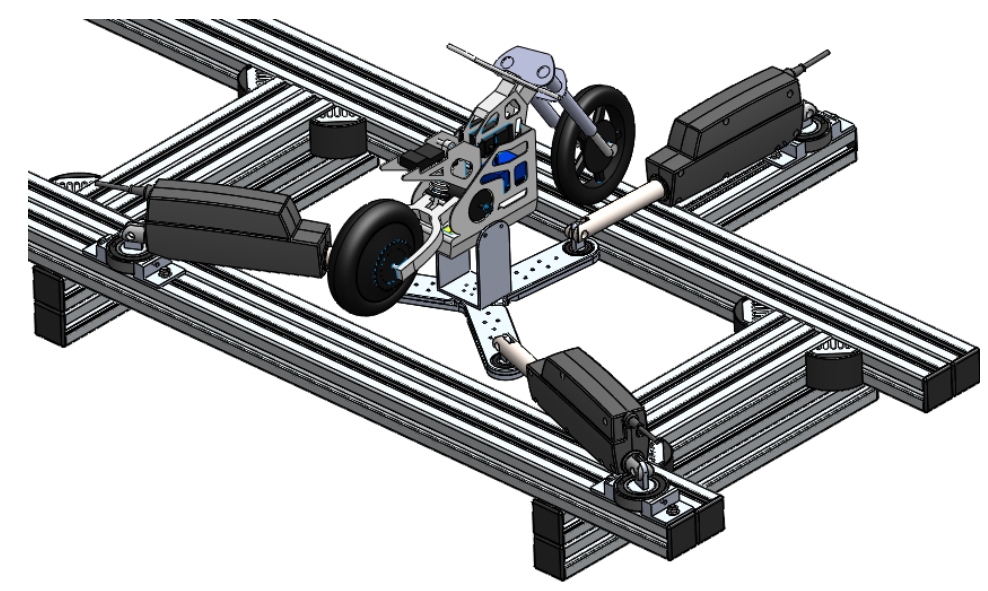

Figura 8.3.1: Uso do mecanismo paralelo desenvolvido como simulador de movimentos.

O acoplamento do modelo analítico fechado da cinemática inversa e da dinâmica direta para mecanismos de cadeia cinemática fechada desenvolvido neste trabalho não foi observado em outro trabalho da área e isto abre espaço para novas análises. Um trabalho subsequente a este é o de aplicar a metodologia proposta em outros mecanismos, sejam seriais ou paralelos, para uma validação mais abrangente do método.

Os resultados experimentais envolvendo centrais inerciais de baixo custo indicam que é necessário um melhor tratamento do processo de filtragem destes tipos de sensores usando técnicas como a de fusão de sensores, por exemplo, para um melhor desempenho na aplicação em estratégias de controle como a proposta. Melhores processos de filtragem também podem ser aplicados aos sinais obtidos a partir dos transdutores de deslocamentos. Além disso, podem ser estudadas novas técnicas e procedimentos para o uso de mecanismos paralelos na calibração destas centrais inerciais. 


\section{Referências bibliográficas}

ADI, B. I. e GREVILLE, T. N. E. Generalized inverses: Theory and applications. Springer-Verlag, second edition, ISBN 0-387-00293-6. 2003.

ALBUQUERQUE, A. N. Desenvolvimento de um simulador vertical com atuação pneumática. Departamento de Engenharia Mecânica, Pontifícia Universidade Católica do Rio de Janeiro. Projeto Final de Graduação. Rio de Janeiro, Brasil. Agosto de 2009.

ALBUQUERQUE, A. N. Modelagem e simulação de uma plataforma de Stewart controlada usando sensores inerciais. Departamento de Engenharia Mecânica, Pontifícia Universidade Católica do Rio de Janeiro. Dissertação de Mestrado. Rio de Janeiro, Brasil. Agosto de 2012.

AKIMA, H. A New Method of Interpolation and Smooth Curve Fitting Based on Local Procedures. J.ACM, vol. 17, no. 4, pp. 589-602. Boulder, EUA. Outubro de 1970.

ASADA, H., SLOTINE, E. Robot Analysis and Control. Massachusetts Institute of Technology. John Wiley \& Sons, Inc. 1986.

ASADA, H., YOUCEF-TOUMI, K. Analysis and design of a direct-drive arm with a five-bar-link parallel drive mechanism. ASME Journal of Dynamic Systems, Measurements and Control, Vol. 106, No. 3, pp. 225-230. 1984.

ASSAD, M. M. Cinemática direta e inversa de mecanismos paralelos Modelagem de um simulador de movimentos. Departamento de Engenharia de 
Controle e Automação, Pontifícia Universidade Católica do Rio de Janeiro. Projeto Final de Graduação. Rio de Janeiro, Brasil. Dezembro de 2010.

ASSAD, M. M. Estratégias de controle em tempo real para compensação das não linearidades de um sistema de atuação pneumático. Departamento de Engenharia Mecânica, Pontifícia Universidade Católica do Rio de Janeiro. Dissertação de Mestrado. Rio de Janeiro, Brasil. Março de 2013.

ASSAD, M. M. Implementação e validação experimental de estratégias de controle para estabilização e acompanhamento de trajetórias de motocicletas autônomas. Departamento de Engenharia de Controle e Automação, Pontifícia Universidade Católica do Rio de Janeiro. Tese de Doutorado (em andamento). Rio de Janeiro, Brasil. Dezembro de 2017 (previsão).

BACIC, M. On hardware-in-the-loop simulation. European Control Conference, Seville, Spain. Dezembro de 2005.

BAJPAI, A., ROTH, B. Workspace and mobility of a closed-loop manipulator. The International Journal of Robotics Research, Vol. 5, No. 2, pp. 131-142. 1986.

BAR-COHEN, Y. Automation, miniature robotics, and sensors for nondestructive testing and evaluation. American Society for Nondestructive Testing. Columbus, USA. 2000.

BENNETT, D. J., HOLLERBACH, J. M. Autonomous calibration of singleloop closed kinematic chains formed by manipulators with passive endpoint constraints. IEEE Transactions on Robotics and Automation, vol. 7, $\mathrm{n}^{\circ} 5$. Outubro de 1991. 
BOUDREAU, R., TURKKAN, N. Solving the forward kinematics of parallel manipulators with a genetic algorithm. École de genie, Université de Moncton. Moncton, New Brunswick, E1A 3E9, Canada. Outubro de 2009.

CHAI, W. H., CHEN, Y. The line-symmetric octahedral Bricard linkage and its structural closure. School of Mechanics and Aerospace Engineering, Nanyang Technological University, Singapore. 2009.

COSTA, M. S. M., MEgGIOLARO, M. A., SPERAnZA NETO, M., ALBUQUERQUE, A. N., ASSAD, M. M.. Performance evaluation of a sensor fusion algorithm for atitude estimation using commercial IMU and scale Stewart Platform. $23^{\text {rd }}$ ABCM International Congress of Mechanical Engineering. Rio de Janeiro, Brasil. Dezembro de 2015.

COSTA NETO, R. T. Modelagem e integração dos mecanismos de suspensão e direção de veículos terrestres através do fluxo de potência. Departamento de Engenharia Mecânica, Pontifícia Universidade Católica do Rio de Janeiro. Tese de Doutorado. Rio de Janeiro, Brasil. Abril de 2008.

CRAIG, J. J. Introduction to robotics - Mechanics and control. AddisonWesley, Silma, Inc, Second Edition. USA. 1989.

CUNHA, R. T. Caracterização, calibração do modelo e aferição de um atuador elétrico linear. Departamento de Engenharia de Controle e Automação, Pontifícia Universidade Católica do Rio de Janeiro. Projeto Final de Graduação. Rio de Janeiro, Brasil. Junho de 2016.

DASSAULT SYSTÈMES SOLIDWORKS CORP. Understanding Motion Simulation. 2008. 
DENAVIT, J., HARTENBERG, R. A kinematic notation for lower pair mechanisms based on matrices. Journal of Applied Mechanics, vol. 22, $\mathrm{n}^{\circ} 215$. USA. Junho de 1955.

DUTRÉ, S., BRUYNINCKX, H., DE SHUTTER, J. The analytical jacobian and its derivative for a parallel manipulator. Department of Mechanical Engineering, Katholieke Universiteit Leuven. Heverlee, Belgium. Abril de 2007.

EL-FATATRY, A. Inertial Measurement Units - IMU. BAE SYSTEMS Advanced Technology Centre. Chelmsford, United Kingdom. 2003.

EVANS, M. B., SCHILLING, L. J. The role of simulation in the development and flight test of the HiMAT vehicle. NASA TM-84912. 1984.

FERREIRA, F. G., DA SILVA, F. R. Proposta de uma metodologia modular para a modelagem e simulação de sistemas mecânicos. $16^{\circ}$ POSMEC Simpósio de Pós-Graduação em Engenharia Mecânica. Uberlândia, Brasil. 2006.

FICHTER, E. F. A Stewart platform-based manipulator: general theory and practical construction. The International Journal of Robotics Research, Vol. 5, No. 2, pp. 157-182. 1986.

FISCHER, I. S., CHU, T. Numerical analysis of the displacement in multi-loop mechanisms. Mechanics Research Communication, vol. 28, ${ }^{\circ}$ 2. USA. Janeiro de 2001.

FLÜCKIGER, L., PIGUET, L., BAUR, C. Generic robotic kinematic generator for virtual environment interfaces. SPIE Telemanipulator and Telepresence Technologies III, Vol. 2901, pp. 186-195. Boston, USA. Novembro de 1996. 
GANS, N. R., DIXON, W. E., LIND, R., KURDILA, A. A hardware in the loop simulation platform for vision-based control of unmanned air vehicles. Mechatronics 19 1043-1056, DOI: 10.1016/j.mechatronics.2009.06.014. 2009.

GOSSELIN, C. Kinematic analysis, optimization and programming of parallel robotic manipulators. Doctoral dissertation. Department of Mechanical Engineering, McGill University. Montréal, Canada. Junho de 1988.

GOSSElin, C., ANGELES, J. The optimum kinematic design of a planar three-degree-of-freedom parallel manipulator. Transactions of the ASME. Journal of Mechanisms, Transmissions, and Automation in Design. Vol. 110/41. Março de 1988.

GUTIERREZ, E. Numerical analysis for engineering - Kinematic analysis of a four-bar crank mechanism with a redundant constraint. Rensselaer at Hartford. USA. 1999.

HANIEH, A. A. Active Isolation and Control of Vibrations via Stewart Platform. Free University of Brussels. Publisher: VDM Verlag Dr.Müller Aktiengesellschaft\& Co. KG. Brussels, Belgium. 2009.

HARAKAWA, M., YAMASAKI, H., NAGANO, T., ABOURIDA, S., DUFOUR, C., BÉLANGER, J. Real-time simulation of a complete PMSM drive at $10 \mu$ s time step. 2005 International Power Electronics Conference. Niigata, Japan. 2005.

HARRINGTON, A. M., KRONINGER, C. Characterization of small DC brushed ans brushless motors. Army Research Laboratory, Aberdeen Proving Ground, MD 21005-5066, ARL-TR-6389. Aberdeen, USA. Março de 2013. 
HUANG, C. I., CHANG, C. F., YU, M Y. e FU, L. C. Sliding-mode tracking control of the Stewart Platform. Department of Electrical Engineering and Department of Computer Science and Information Engineering, National Taiwan University. Taipei, Taiwan, R.O.C. 2004.

ISERMANN， R., SCHAFFNIT， J., SINSEL， S. Hardware-in-the-loop simulation for the design and testing of engine-control systems. Control Engineering Practice, vol. 7, pp. 643-653. 1999.

JALON, J. G., BAYO, E. Kinematic and dynamic simulation of multibody systems - The real-time challenge. Springer-Verlag. New York, USA. 1994.

JAZAR, R. N. Theory of applied robotics - Kinematics, dynamics, and control. Springer, $2^{\text {nd }}$ Edition. ISBN 978-1-4419-1749-2. 2010.

KARNOPP, D. C., MARGOLIS, D. L., ROSENBERG, R. C. System dynamics: Modeling and simulation of mechatronic systems. $4^{\text {th }}$ Edition, Wiley. 2006.

KHALIL, W., KLEINFINGER, J. F. A new geometric notation for open and closed-loop robots. Laboratoire d'Automatique de Nantes. Nantes, France. 1986.

KHANDELWAL, S., CHEVALLEREAU, C. Estimate of the trunk attitude of a humanoid by data fusion of inertial sensors and joint encoders. Proceedings of the Sixteenth International Conference on Climbing and Walking Robots. Sydney, Australia. Julho de 2013.

KIM, J., KIM, K., LEE, J. Y. Solving 3D geometric constraints for closed-loop assemblies. The $5^{\text {th }}$ International Conference on Engineering Design \& Automation. Las Vegas, USA. 2001. 
KLEIJN, C. Introduction to Hardware-in-the-Loop Simulation. Controllab

Products B. V. - Model Based Design. Enschede, Netherlands. Acesso em 2016.

KRISHNAN, R. Permanent magnet synchronous and brushless DC motor drives. CRC/Taylor \& Francis. Boca Raton, USA. 2010.

LLERENA, R. W. A. Modelagem para um simulador de movimentos para um veículo terrestre em escala. Departamento de Engenharia Mecânica, Pontifícia Universidade Católica do Rio de Janeiro. Dissertação de Mestrado. Rio de Janeiro, Brasil. Fevereiro de 2000.

MAGNUSSEN, O., OTTESTAD, M., HOVLAND, G. Calibration procedure for an inertial measurement unit using a 6-degree-of-freedom hexapod. Faculty of Engineering and Science, Departmente of Engineering, University of Agder, Norway. 2012.

MARTINS, G. C. P. Modelagem e simulação de um atuador elétrico linear. Departamento de Engenharia de Controle e Automação, Pontifícia Universidade Católica do Rio de Janeiro. Projeto Final de Graduação. Rio de Janeiro, Brasil. Junho de 2016.

MARTINS, G. N. Concepção e modelagem de objetos educacionais para compreensão da dinâmica de motocicletas/ bicicletas em projetos de engenharia. Departamento de Engenharia Mecânica, Pontifícia Universidade Católica do Rio de Janeiro. Tese de Doutorado. Rio de Janeiro, Brasil. Outubro de 2016.

MAVROIDIS, C., BEDDOWS, M. A spatial overconstrained mechanism that can be used in practical applications. Department of Mechanical and Aerospace Engineering. Rutgers University, The State University of New Jersey. New Jersey, USA. 1995. 
MAVROIDIS, C., ROTH, B. Analysis of overconstrained mechanisms.

Department of Mechanical Engineering. Rutgers University, Massachusetts Institute of Technology. Cambridge, USA. 1995.

MAVROIDIS, C., ROTH, B. New and revised overconstrained mechanisms. Department of Mechanical Engineering. Rutgers University, Massachusetts Institute of Technology. Cambridge, USA. 1995.

MOHAMED, M. G., DUFFY, J. A direct determination of the instantaneous kinematics of fully parallel robot manipulators. ASME Journal of Mechanisms, Transmissions, and Automation in Design, Vol. 107, No. 2, pp. 226229. 1985.

MOHAMED, M. G., GOSSELIN, C. M. Design and analysis of kinematically redundant parallel manipulators with configurable platforms. IEEE Transactions on Robotics, vol. 21, $\mathrm{n}^{\circ}$ 3. USA. Junho de 2005.

MOLINA, F. A. L. Ambiente de simulação de manipuladores paralelos: modelagem, simulação e controle de uma Plataforma Stewart. Faculdade de Engenharia Mecânica, Universidade Estadual de Campinas. Dissertação de Mestrado. Campinas, Brasil. Junho de 2008.

NAKAMURA, Y., GHODOUSSI, M. Dynamics computation of closed-link robot mechanisms with nonredundant and redundant actuators. IEEE Transactions on Robotics, vol. 5, n 3 . USA. Junho de 1989.

NIKRAVESH, P. E. Computer-aided analysis of mechanical systems. PrenticeHall. Nova Jersey, EUA. 1988.

NIZAR, M. H. M. SolidWorks Motion Study Tutorial. South Dakota School of Mines \& Technology. Dakota do Sul, EUA, Agosto, 2013. 
ÖMÜRLÜ, V. E., YILDIZ, I. A Stewart platform as a FBW flight control unit. Journal of Electrical Engineering, vol. 62, n 4. Turquia. 2011.

PAWLUS. W., INOUVA, I. C., OYDNA, S., WROLDSEN, T. K., HOVLAND, G. Next generation hardware -in-the-loop simulation enables advanced testing of offshore hydraulic systems. IADC Advanced Rig Technology Conference 2015. Amsterdam, Netherlands. Outubro de 2015.

PEDERSEN, M. M., HANSEN, M. R., BALLEBYE, M. A cost-effective approach to hardware-in-the-loop simulation. In Mechatronics: Recent Technological and Scientific Advances, Part V (pp. 553-560). Springer. DOI: 10.1007/978-3-642-23244-2_67. Aalborg, Denmark. Abril de 2012.

PRITSKER, D. Hardware in the loop from the MatLab/Simulink environment. Altera Corporation, WP-01208-1.0. Setembro de 2013.

QUANSER. Quanser Innovate Educate: user case studies. http://www.quanser.com/case_studies. Ontario, Canada. Acesso em Junho de 2017.

RAGHAVAN, M., ROTH, B. A general solution for the inverse kinematics of all series chain. Proceedings of the 8th CISM-IFToMM Symposium on Robots and Manipulators. Cracóvia, Polônia. 1990.

RAMASWAMY, D., MCGEE, R., SILVASHANKAR, S., DESHPANDE, A., ALlEN, J., RZEMIEN, K., STUART, W. A case study in Hardware-in-theLoop testing: development of an ECU for a Hybrid Electric Vehicle. SAE World Congress, Detroit, Michigan. Março de 2004. 
RIBEIRO, J. G. T., CASTRO, J. T. P., FREIRE, J. L. F. Experimental results of the FFT-DDI method with ICP and piezoresistive accelerometers. $16^{\text {th }}$ Brazilian Congress of Mechanical Engineering, ABCM. 2001.

RODRIGUES, F. H., SIQUEIRA, E. B., MÓR, J. L., OLIVEIRA, V. M. An alternative methodology for modeling the kinematics of bifurcated robotic system. Universidade Federal do Rio Grande do Sul. Rio Grande do Sul, Brasil. 2013.

SAHAWNEH, L., JARRAH, M. A. Development and calibration of low cost MEMS IMU for UAV applications. Proceeding of the $5^{\text {th }}$ International Symposium on Mechatronics and its Applications (ISMA08). Amman, Jordânia. Maio de 2008.

SERRANO, F., CABAllERO, A. A., YEN, K. K., BREZINA ,T. Control of a Stewart Platform used in Biomechanical Systems. Florida International University. Miami, Florida, EUA. Maio de 2007.

SHETH, P. N., UICKER, J. J. A Generalized Symbolic Notation for Mechanisms. Transactions of ASME. EUA. Fevereiro de 1971.

SHIRMER, L. Modelagem do Robothron - Um manipulador de barras paralelas. Departamento de Engenharia Elétrica, Universidade do Estado de Santa Catarina - UDESC. Dissertação de Mestrado. Santa Catarina, Brasil. Fevereiro de 2005.

SILVA, J. C. C. Modelagem de um simulador de Movimentos. Instituto Militar de Engenharia. Dissertação de Mestrado. Rio de Janeiro, Brasil. 1991.

SIMAAN, N., SHOHAM, M. Geometric interpretation of the derivatives of parallel robots jacobian matrix with application to stiffness control. Robotics 
Laboratory, Department of Mechanical Engineering, Technion - Israel Institute of Technology. Haifa 32000, Israel. Março de 2003.

SOUZA, I. D. T., SILVA, S. N., FERNANDES, M. A. C. Plataforma para simulação em tempo real de sistemas dinâmicos e hardware-in-the-loop em sistemas embarcados do tipo PSOC. Proceeding Series of the Brazilian Society of Computational and Applied Mathematics. Natal, Brasil. Outubro de 2015.

SPERANZA NETO, M., ALBUQUERQUE, A. N., ASSAD, M. M. Small scale mechatronics devices as educational and research engineering tools. 11th IFAC Symposium on Advances in Control Education. Bratislava, Slovakia. Junho de 2016.

SPERANZA NETO, M. Dinâmica de um corpo rígido através do fluxo de potência. Departamento de Engenharia Mecânica, Pontifícia Universidade Católica do Rio de Janeiro. Notas de aula. Rio de Janeiro, Brasil. 2007.

SPERANZA NETO, M. Procedimento para acoplamento de modelos dinâmicos através do fluxo de potência. XV Congresso Brasileiro de Engenharia Mecânica. São Paulo, Brasil. Novembro de 1999.

STAMPER, R. E., TSAI, L. W., WALSH, G. C. Optimization of a three DOF translational platform for well-conditioned workspace. Mechanical Engineering Department and Institute for Systems Research, University of Maryland. College Park, MD 20742, Maryland, Estados Unidos. Agosto de 1997.

STEWART, D. A platform with six degrees of freedom. Proceedings of the Institution of Mechanical Engineers. Vol. 180, No. 5, pp. 371-378. 1965. 
TAPIA, B. C. e MÉNDEZ, S. J. T. Robot paralelo planar para ensamble. División de Estudios de Posgrado e Investigación, Instituto Tecnológico de Puebla. Maravillas, Colombia. 2009.

TAYLOR, J. C. Correction of general deformity with the Taylor spatial frame fixator. http://www.jcharlestaylor.com, acessado em Novembro de 2011. Memphis, Tennessee, USA. 2002.

TSAI, L. W. Robot analysis - The mechanical of serial and parallel manipulators. John Wiley \& Sons, Inc. 1999.

VARGAS, M. V. Controle de uma plataforma de movimento de um simulador de voo. Escola de Engenharia de São Carlos, Universidade de São Paulo. Tese de Doutorado. São Carlos, Brasil. Outubro de 2009.

WANG, L., WANG, F. Intelligent calibration method of low cost MEMS inertial measurement unit for an FPGA-based navigation system. International Journal of Intelligent Engineering and Systems, Vol. 4, No. 2. 2011.

WANG, Y. Symbolic dynamics and controls of a parallel manipulator - A case study of Stewart Platform. State University of New York. Publisher: VDM Verlag Dr.Müller Aktiengesellschaft \& Co. KG. Buffalo, USA. 2009.

WANG, Y. Symbolic kinematics and dynamics analysis and control of a general Stewart parallel manipulator. Master's thesis. Department of Mechanical and Aerospace Engineering, State University of New York. Buffalo, USA. 2008.

WEBER, H. I. Raciocinando dinâmica de rotação - Bases para o entendimento do movimento de rotação. Notas de aula. Departamento de 
Engenharia Mecânica, Pontifícia Universidade Católica do Rio de Janeiro. Rio de Janeiro, Brasil. 2009.

YANG, D. C. H., LEE, T. W. Feasibility study of a platform type of robotic manipulators from a kinematic viewpoint. ASME Journal of Mechanisms, Transmissions, and Automation in Design, Vol. 106, No. 2, pp. 191-198. 1984.

YILDIZ, I., ÖMÜRLÜ, V. E., SAGIRLI, A. Dynamic modeling of a generalized Stewart platform by bond graph method utilizing a novel spatial visualization technique. International Review of Mechanical Engineering. Turquia. 2007.

YILDIZ, I., ÖMÜRLÜ, V. E., SAGIRLI, A. A novel visualization technique in bond-graph method for modeling of a generalized Stewart platform. School of Mechanical Engineering, Yildiz Technical University. Istambul, Turquia. 2009.

YILDIZ, I., ÖMÜRLÜ, V. E., SAGIRLI, A. Modeling and experimental validation of a generalized Stewart platform by bond-graph method. Arabian Journal of Science and Engineering, Vol. 38, n 10. Turquia. 2012.

ZHANG, L., GUO, F., YONGQUAN, L. I., WENJUAN, L. U. Global dynamic modeling of electro-hydraulic 3-UPS/S parallel stabilized platform by bond graph. Chinese Journal of Mechanical Engineering. Vol. 29, No. 6. DOI: 10.3901/CJME.2016.0623.078. 2016.

ZHAO, Q., GAO, F. Bond graph modelling of hydraulic six-degree-offreedom motion simulator. Proceedings of the Institution of Mechanical Engineers, Part C: Journal of Mechanical Engineering Science. EUA. 2012. 


\section{Apêndice A \\ Análise cinemática de um mecanismo de quatro barras usando o método de Denavit-Hartenberg}

Neste estudo será descrita uma forma de obtenção da cinemática direta e inversa de um mecanismo paralelo pelo uso do método de Denavit-Hartenberg. O objeto deste estudo se trata de um mecanismo de quatro barras como mostra a Figura A.1. O ângulo $\theta_{4}$ é o ângulo do atuador. Já $p_{x}, p_{z}$ e $\theta$ denotam a posição e orientação da plataforma móvel.

Para obter as matrizes Jacobianas direta e inversa deste mecanismo de quatro barras usando o método de Denavit-Hartenberg, primeiramente este será dividido em dois mecanismos serias com dois graus de liberdade, como mostram as Figuras A.2 e A.3. Na Figura A.2 é apresentada a parte esquerda do mecanismo de três barras. O ponto de divisão escolhido foi o centro do sistema de referencia da plataforma móvel (ponto P).

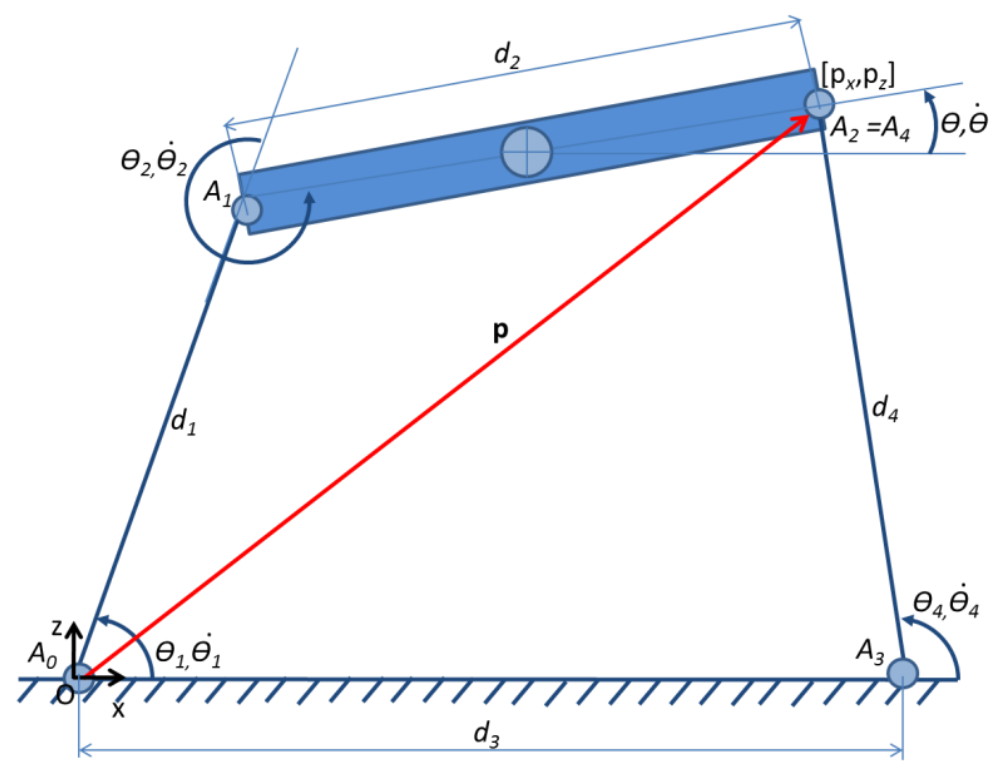

Figura A.1: Mecanismo de quatro barras. 


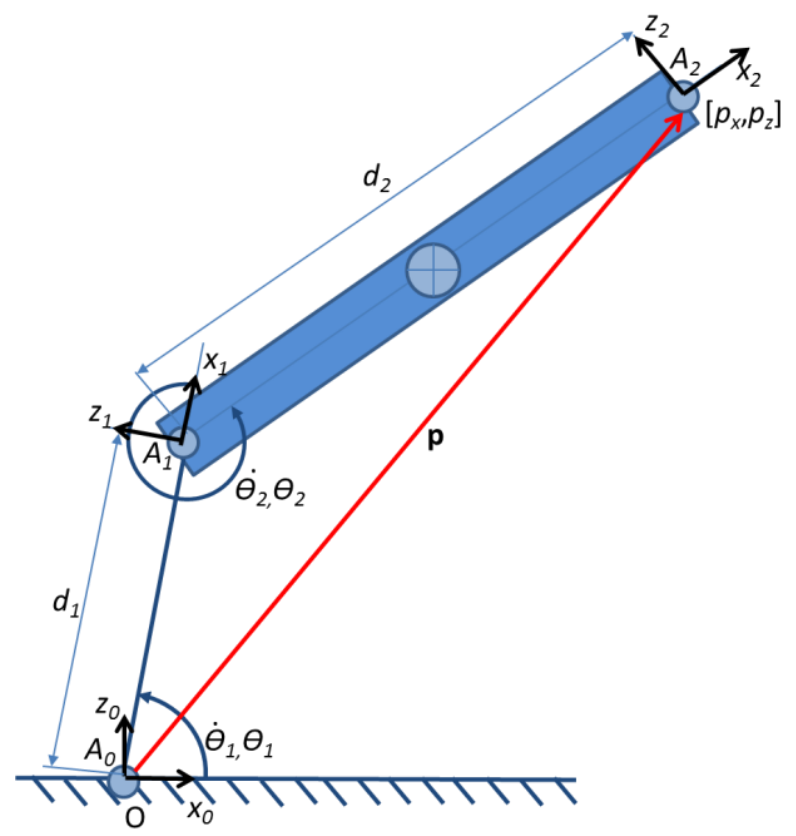

Figura A.2: Seção esquerda do mecanismo de quatro barras apresentado e seus parâmetros de Denavit-Hartenberg.

Uma vez definidos os sistemas de referência em cada uma das juntas do mecanismo, constrói-se a tabela de parâmetros de Denavit-Hartenberg (H. Asada, 1986). A Tabela A.1 apresenta o conjunto de parâmetros para o mecanismo serial da parte esquerda. Com estes parâmetros montam-se as matrizes de transformação $A_{1}^{0}$ e $A_{2}^{1}$ (Equações A.1 e A.2).

Tabela A.1: Parâmetros de Denavit-Hartenberg do mecanismo serial da esquerda.

$$
\begin{aligned}
& \begin{array}{ccccc}
\text { Elo } & \boldsymbol{a}_{\boldsymbol{i}} & \boldsymbol{\alpha}_{\boldsymbol{i}} & \boldsymbol{d}_{\boldsymbol{i}} & \boldsymbol{\theta} \\
\hline 1 & d_{1} & 0 & 0 & \theta_{1} \\
2 & d_{2} & 0 & 0 & \theta_{2}
\end{array} \\
& A_{1}^{0}=\left[\begin{array}{cccc}
\cos \left(\theta_{1}\right) & -\operatorname{sen}\left(\theta_{1}\right) & 0 & d_{1} \cos \left(\theta_{1}\right) \\
0 & 1 & 0 & 0 \\
\operatorname{sen}\left(\theta_{1}\right) & \cos \left(\theta_{1}\right) & 0 & d_{1} \operatorname{sen}\left(\theta_{1}\right) \\
0 & 0 & 0 & 1
\end{array}\right]=T_{1}^{0} \\
& A_{2}^{1}=\left[\begin{array}{cccc}
\cos \left(\theta_{2}\right) & -\operatorname{sen}\left(\theta_{2}\right) & 0 & \left(d_{2}\right) \cos \left(\theta_{2}\right) \\
0 & 1 & 0 & 0 \\
\operatorname{sen}\left(\theta_{2}\right) & \cos \left(\theta_{2}\right) & 0 & \left(d_{2}\right) \operatorname{sen}\left(\theta_{2}\right) \\
0 & 0 & 0 & 1
\end{array}\right]
\end{aligned}
$$


Para obter a matriz de transformação do sistema de referência fixo na primeira junta (centrado no ponto $\mathrm{A}_{0}$ ) até o sistema de referência da extremidade do mecanismo (centrado no ponto $\mathrm{A}_{2}$ e definido por $\mathbf{p}$ ), multiplicam-se as matrizes de transformação obtidas como mostra a Equação A.3.

$$
\begin{aligned}
& T_{2}^{0}=A_{1}^{0} A_{2}^{1} \\
& =\left[\begin{array}{cccc}
\cos \left(\theta_{1}+\theta_{2}\right) & -\operatorname{sen}\left(\theta_{1}+\theta_{2}\right) & 0 & d_{1} \cos \left(\theta_{1}\right)+\left(d_{2}\right) \cos \left(\theta_{1}+\theta_{2}\right) \\
0 & 1 & 0 & 0 \\
\operatorname{sen}\left(\theta_{1}+\theta_{2}\right) & \cos \left(\theta_{1}+\theta_{2}\right) & 0 & d_{1} \operatorname{sen}\left(\theta_{1}\right)+\left(d_{2}\right) \operatorname{sen}\left(\theta_{1}+\theta_{2}\right) \\
0 & 0 & 0 & 1
\end{array}\right]
\end{aligned}
$$

Dos termos desta matriz de transformação obtêm-se aqueles que relacionam as velocidades das juntas com as velocidades da extremidade do mecanismo (Equação A.4). Estes termos formam a matriz Jacobiana direta do mecanismo serial da esquerda denominada $J_{e}$ (Equação A.5).

$$
\left[\begin{array}{c}
\dot{x}_{2} \\
\dot{\mathrm{z}}_{2}
\end{array}\right]=\left[\begin{array}{c}
\mathrm{v}_{x} \\
\mathrm{v}_{z}
\end{array}\right]=\left[\begin{array}{cc}
-d_{1} \operatorname{sen}\left(\theta_{1}\right)-\left(d_{2}\right) \operatorname{sen}\left(\theta_{1}+\theta_{2}\right) & -\left(d_{2}\right) \operatorname{sen}\left(\theta_{1}+\theta_{2}\right) \\
d_{1} \cos \left(\theta_{1}\right)+\left(d_{2}\right) \cos \left(\theta_{1}+\theta_{2}\right) & \left(d_{2}\right) \cos \left(\theta_{1}+\theta_{2}\right)
\end{array}\right]\left[\begin{array}{c}
\dot{\theta}_{1} \\
\dot{\theta}_{2}
\end{array}\right]
$$

$$
J_{e}=\left[\begin{array}{cc}
-d_{1} \operatorname{sen}\left(\theta_{1}\right)-\left(d_{2}\right) \operatorname{sen}\left(\theta_{1}+\theta_{2}\right) & -\left(d_{2}\right) \operatorname{sen}\left(\theta_{1}+\theta_{2}\right) \\
d_{1} \cos \left(\theta_{1}\right)+\left(d_{2}\right) \cos \left(\theta_{1}+\theta_{2}\right) & \left(d_{2}\right) \cos \left(\theta_{1}+\theta_{2}\right)
\end{array}\right]
$$

A Figura A.3 apresenta a parte direita do mecanismo de três barras. O ponto de divisão escolhido foi a extremidade direita da plataforma móvel (ponto $\mathrm{A}_{4}$; também definido por $\left.\mathbf{p}\right)$. 


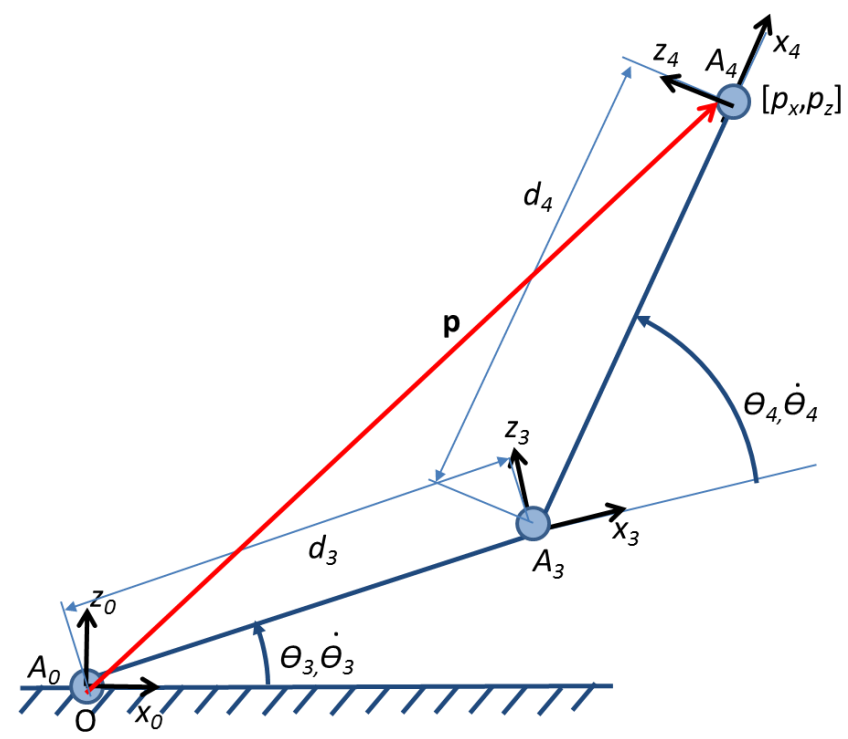

Figura A.3: Seção direita do mecanismo de quatro barras apresentado e seus parâmetros de Denavit-Hartenberg.

Uma vez definidos os sistemas de referência em cada uma das juntas do mecanismo, constrói-se a tabela de parâmetros de Denavit-Hartenberg (H. Asada, 1986). A Tabela A.2 apresenta o conjunto de parâmetros para o mecanismo serial da parte direita. Com estes parâmetros montam-se as matrizes de transformação $A_{3}^{0}$ e $A_{4}^{3}$ (Equações A.6 e A.7).

Tabela A.2: Parâmetros de Denavit-Hartenberg do mecanismo serial da direita.

$$
\begin{aligned}
& \begin{array}{ccccc}
\text { Elo } & \boldsymbol{a}_{\boldsymbol{i}} & \boldsymbol{\alpha}_{\boldsymbol{i}} & \boldsymbol{d}_{\boldsymbol{i}} & \boldsymbol{\theta} \\
\hline 3 & d_{3} & 0 & 0 & \theta_{3}
\end{array} \\
& \begin{array}{llllll}
4 & d_{4} & 0 & 0 & \theta_{4}
\end{array} \\
& A_{3}^{0}=\left[\begin{array}{cccc}
\cos \left(\theta_{3}\right) & -\operatorname{sen}\left(\theta_{3}\right) & 0 & d_{3} \cos \left(\theta_{3}\right) \\
0 & 1 & 0 & 0 \\
\operatorname{sen}\left(\theta_{3}\right) & \cos \left(\theta_{3}\right) & 0 & d_{3} \operatorname{sen}\left(\theta_{3}\right) \\
0 & 0 & 0 & 1
\end{array}\right]=T_{3}^{0} \\
& A_{4}^{3}=\left[\begin{array}{cccc}
\cos \left(\theta_{4}\right) & -\operatorname{sen}\left(\theta_{4}\right) & 0 & \left(d_{4}\right) \cos \left(\theta_{4}\right) \\
0 & 1 & 0 & 0 \\
\operatorname{sen}\left(\theta_{4}\right) & \cos \left(\theta_{4}\right) & 0 & \left(d_{4}\right) \operatorname{sen}\left(\theta_{4}\right) \\
0 & 0 & 0 & 1
\end{array}\right]
\end{aligned}
$$


Para obter a matriz de transformação do sistema de referência fixo na primeira junta (centrado no ponto $\mathrm{A}_{0}$ ) até o sistema de referência da extremidade do mecanismo (centrado no ponto $\mathrm{A}_{4}$ e definido por $\mathbf{p}$ ), multiplicam-se as matrizes de transformação obtidas como mostra a Equação A.8.

$$
\begin{aligned}
& T_{4}^{0}=A_{3}^{0} A_{4}^{3} \\
& =\left[\begin{array}{cccc}
\cos \left(\theta_{3}+\theta_{4}\right) & -\operatorname{sen}\left(\theta_{3}+\theta_{4}\right) & 0 & d_{3} \cos \left(\theta_{3}\right)+\left(d_{4}\right) \cos \left(\theta_{3}+\theta_{4}\right) \\
0 & 1 & 0 & 0 \\
\operatorname{sen}\left(\theta_{3}+\theta_{4}\right) & \cos \left(\theta_{3}+\theta_{4}\right) & 0 & d_{3} \operatorname{sen}\left(\theta_{3}\right)+\left(d_{4}\right) \operatorname{sen}\left(\theta_{3}+\theta_{4}\right) \\
0 & 0 & 0 & 1
\end{array}\right]
\end{aligned}
$$

Dos termos desta matriz de transformação tiram-se os termos que relacionam as velocidades das juntas com as velocidades da extremidade do mecanismo (Equação A.9). Estes termos formam a matriz Jacobiana direta do mecanismo serial da direita denominada $J_{d}$. Sabendo que $\theta_{3}=\dot{\theta}_{3}=0, J_{d}$ fica como mostrado na Equação A.10.

$$
\left[\begin{array}{c}
\dot{x}_{4} \\
\dot{\mathrm{z}}_{4}
\end{array}\right]=\left[\begin{array}{c}
\mathrm{v}_{x} \\
\mathrm{v}_{z}
\end{array}\right]=\left[\begin{array}{cc}
-d_{3} \operatorname{sen}\left(\theta_{3}\right)-\left(d_{4}\right) \operatorname{sen}\left(\theta_{3}+\theta_{4}\right) & -\left(d_{4}\right) \operatorname{sen}\left(\theta_{3}+\theta_{4}\right) \\
d_{3} \cos \left(\theta_{3}\right)+\left(d_{4}\right) \cos \left(\theta_{3}+\theta_{4}\right) & \left(d_{4}\right) \cos \left(\theta_{3}+\theta_{4}\right)
\end{array}\right]\left[\begin{array}{c}
\dot{\theta}_{3} \\
\dot{\theta}_{4}
\end{array}\right]
$$

$$
J_{d}=\left[\begin{array}{cc}
-\left(d_{4}\right) \operatorname{sen}\left(\theta_{4}\right) & -\left(d_{4}\right) \operatorname{sen}\left(\theta_{4}\right) \\
d_{3}+\left(d_{4}\right) \cos \left(\theta_{4}\right) & \left(d_{4}\right) \cos \left(\theta_{4}\right)
\end{array}\right]
$$

As Equações A.11 e A.12 apresentam as relações entre as velocidades angulares das juntas rotativas e as velocidades da plataforma móvel. Na Figura A.4 é apresentado um detalhe do mecanismo de três barras para esclarecer a notação usada na denominação dos ângulos.

$$
\begin{aligned}
& {\left[\begin{array}{c}
\dot{x}_{2} \\
\dot{\mathrm{z}}_{2} \\
\dot{\theta}
\end{array}\right]=J_{e}\left[\begin{array}{l}
\dot{\theta}_{1} \\
\dot{\theta}_{2}
\end{array}\right]} \\
& {\left[\begin{array}{l}
\dot{x}_{4} \\
\dot{\mathrm{z}}_{4}
\end{array}\right]=J_{d}\left[\begin{array}{l}
\dot{\theta}_{3} \\
\dot{\theta}_{4}
\end{array}\right]}
\end{aligned}
$$




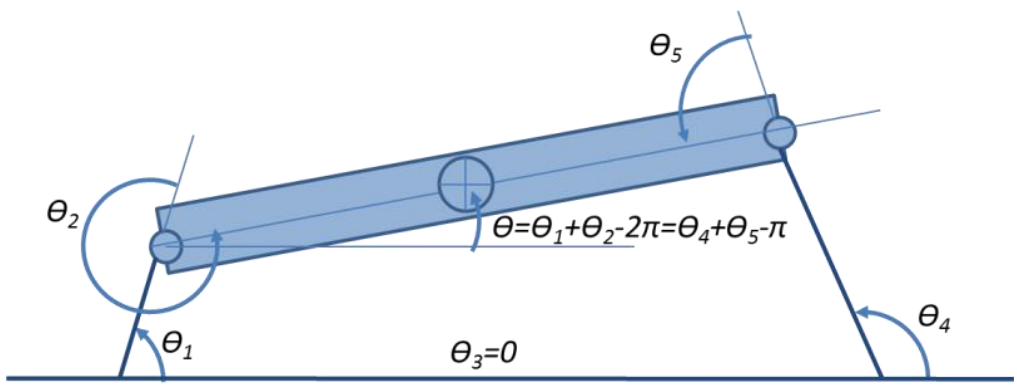

Figura A.4: Definição dos ângulos no mecanismo de quatro barras.

Por se tratar de um mecanismo simples, com poucos graus de liberdade, estas matrizes Jacobianas também podem ser obtidas pela geometria. Definindo as posições dos pontos das extremidades e a orientação da plataforma móvel, tanto do mecanismo à esquerda, quanto do mecanismo à direita, chega-se às relações apresentadas nas Equações A.13 e A.14, respectivamente.

$$
\begin{gathered}
\left\{\begin{array}{c}
x_{2}=d_{1} \cos \left(\theta_{1}\right)+\left(d_{2}\right) \cos \left(\theta_{1}+\theta_{2}\right) \\
z_{2}=d_{1} \operatorname{sen}\left(\theta_{1}\right)+\left(d_{2}\right) \operatorname{sen}\left(\theta_{1}+\theta_{2}\right) \\
\theta=\theta_{1}+\theta_{2}-2 \pi
\end{array}\right. \\
\left\{\begin{array}{c}
x_{4}=d_{3} \cos \left(\theta_{3}\right)+\left(d_{4}\right) \cos \left(\theta_{3}+\theta_{4}\right) \\
z_{4}=d_{3} \operatorname{sen}\left(\theta_{3}\right)+\left(d_{4}\right) \operatorname{sen}\left(\theta_{3}+\theta_{4}\right) \\
\theta=\theta_{4}+\theta_{5}-\pi
\end{array}\right.
\end{gathered}
$$

Derivando cada termo em relação às variáveis das juntas, obtêm-se as mesmas matrizes Jacobianas apresentadas nas Equações A.5 e A.10.

\section{Como}

$$
\left\{\begin{array}{c}
x_{2}=x_{4}=p_{x} \\
z_{2}=z_{4}=p_{z} \\
\theta_{1}+\theta_{2}-2 \pi=\theta_{4}+\theta_{5}-\pi=\theta
\end{array}\right.
$$

tem-se que

$$
\left[\begin{array}{c}
\dot{x}_{2} \\
\dot{\mathrm{z}}_{2}
\end{array}\right]=\left[\begin{array}{c}
\dot{x}_{4} \\
\dot{\mathrm{z}}_{4}
\end{array}\right]=\left[\begin{array}{l}
\mathrm{v}_{x} \\
\mathrm{v}_{z}
\end{array}\right]
$$


$\mathrm{e}$

$$
\dot{\theta}=\dot{\theta}_{1}+\dot{\theta}_{2}=\dot{\theta}_{4}+\dot{\theta}_{5}
$$

Deste modo, igualando os termos à direita das Equações A.11 e A.12, obtém-se

$$
J_{e}\left[\begin{array}{c}
\dot{\theta}_{1} \\
\dot{\theta}_{2}
\end{array}\right]=J_{d}\left[\begin{array}{c}
\dot{\theta}_{3} \\
\dot{\theta}_{4}
\end{array}\right]=J_{d}\left[\begin{array}{c}
0 \\
\dot{\theta}_{4}
\end{array}\right]
$$

Daí segue que

$$
\left[\begin{array}{c}
\dot{\theta}_{1} \\
\dot{\theta}_{2}
\end{array}\right]=J_{e}^{-1}\left[\begin{array}{c}
J_{d(1,2)} \\
J_{d(2,2)}
\end{array}\right]\left[\dot{\theta}_{4}\right]=J_{a}\left[\dot{\theta}_{4}\right]
$$

Substituindo as relações da Equação A.17 na Equação A.19, tem-se

$$
\left[\begin{array}{c}
\dot{\theta}_{1} \\
\dot{\theta}-\dot{\theta}_{1}
\end{array}\right]=\left[\begin{array}{cc}
1 & 0 \\
-1 & 1
\end{array}\right]\left[\begin{array}{c}
\dot{\theta}_{1} \\
\dot{\theta}
\end{array}\right]=J_{a}\left[\begin{array}{c}
\dot{\theta}_{3} \\
\dot{\theta}_{4}
\end{array}\right]=\left[\begin{array}{c}
J_{a(1,2)} \\
J_{a(2,2)}
\end{array}\right]\left[\dot{\theta}_{4}\right]
$$

Rearranjando, tem-se

$$
\left[\begin{array}{c}
\dot{\theta}_{1} \\
\dot{\theta}
\end{array}\right]=\left[\begin{array}{cc}
1 & 0 \\
-1 & 1
\end{array}\right]^{-1}\left[\begin{array}{l}
J_{a(1,2)} \\
J_{a(2,2)}
\end{array}\right]\left[\dot{\theta}_{4}\right]=\left[\begin{array}{c}
J_{a(1,2)} \\
J_{a(1,2)}+J_{a(2,2)}
\end{array}\right]\left[\dot{\theta}_{4}\right]
$$

Substituindo as relações da Equação A.17 na Equação A.18, tem-se

$$
\left[\begin{array}{c}
\mathrm{v}_{x} \\
\mathrm{v}_{z}
\end{array}\right]=J_{e}\left[\begin{array}{c}
\dot{\theta}_{1} \\
\dot{\theta}_{2}
\end{array}\right]=J_{e}\left[\begin{array}{c}
\dot{\theta}_{1} \\
\dot{\theta}-\dot{\theta}_{1}
\end{array}\right]=\left[\begin{array}{cc}
J_{e(1,1)}-J_{e(1,2)} & J_{e(1,2)} \\
J_{e(2,1)}-J_{e(2,2)} & J_{e(2,2)}
\end{array}\right]\left[\begin{array}{c}
\dot{\theta}_{1} \\
\dot{\theta}
\end{array}\right]
$$

Substituindo a Equação A.21 na Equação A.22 segue que 
$\left[\begin{array}{c}\mathrm{v}_{x} \\ \mathrm{v}_{z}\end{array}\right]=\left[\begin{array}{cc}J_{e(1,1)}-J_{e(1,2)} & J_{e(1,2)} \\ J_{e(2,1)}-J_{e(2,2)} & J_{e(2,2)}\end{array}\right]\left[\begin{array}{c}J_{a(1,2)} \\ J_{a(1,2)}+J_{a(2,2)}\end{array}\right]\left[\dot{\theta}_{4}\right]$

Substituindo os valores de $J_{e}$ segue que

$$
\left[\begin{array}{l}
\mathrm{v}_{x} \\
\mathrm{v}_{z}
\end{array}\right]=\left[\begin{array}{cc}
-d_{1} \operatorname{sen}\left(\theta_{1}\right) & -d_{2} \operatorname{sen}\left(\theta_{1}+\theta_{2}\right) \\
d_{1} \cos \left(\theta_{1}\right) & d_{2} \cos \left(\theta_{1}+\theta_{2}\right)
\end{array}\right]\left[\begin{array}{c}
J_{a(1,2)} \\
J_{a(1,2)}+J_{a(2,2)}
\end{array}\right]\left[\dot{\theta}_{4}\right]
$$

Já o problema da cinemática direta consiste em encontrar a posição (vetor p) e orientação do mecanismo a partir de um dos ângulos de entrada. O método empregado nesta etapa é o mesmo usado em Tsai, L. W. (1999) para um mecanismo serial plano com dois graus de liberdade em rotação. Substituindo as relações da Equação A.15 nas Equações A.13 e A.14 e sabendo que, para este mecanismo $\theta_{3}=\dot{\theta}_{3}=0$, tem-se

$$
\begin{gathered}
\left\{\begin{array}{l}
p_{x}=d_{1} \cos \left(\theta_{1}\right)+d_{2} \cos \left(\theta_{1}+\theta_{2}\right) \\
p_{z}=d_{1} \operatorname{sen}\left(\theta_{1}\right)+d_{2} \operatorname{sen}\left(\theta_{1}+\theta_{2}\right)
\end{array}\right. \\
\left\{\begin{array}{c}
p_{x}=d_{3}+d_{4} \cos \left(\theta_{4}\right) \\
p_{z}=d_{3} \operatorname{sen}\left(\theta_{4}\right)
\end{array}\right.
\end{gathered}
$$

O quadrado do módulo de p pela cadeia da esquerda (Equação A.25) é

$$
\begin{aligned}
& p_{x}^{2}+p_{z}^{2}=d_{1}{ }^{2} c^{2} \theta_{1}+d_{2}{ }^{2} c^{2} \theta_{12}+2 d_{1} d_{2} c \theta_{1} c \theta_{12}+d_{1}{ }^{2} s^{2} \theta_{1}+ \\
& d_{2}{ }^{2} s^{2} \theta_{12}+2 d_{1} d_{2} s \theta_{1} s \theta_{12}
\end{aligned}
$$

Usando as relações trigonométricas das Equações A.28 e A.29, chega-se a Equação A.30.

$$
\begin{aligned}
& \left\{\begin{array}{c}
c^{2} \theta_{1}+s^{2} \theta_{1}=1 \\
c^{2} \theta_{12}+s^{2} \theta_{12}=1
\end{array}\right. \\
& \left\{\begin{array}{l}
\cos \left(\theta_{1}+\theta_{2}\right)=c \theta_{12}=c \theta_{1} c \theta_{2}-s \theta_{1} s \theta_{2} \\
\operatorname{sen}\left(\theta_{1}+\theta_{2}\right)=s \theta_{12}=s \theta_{1} c \theta_{2}+s \theta_{2} c \theta_{1}
\end{array}\right.
\end{aligned}
$$




$$
\begin{gathered}
p_{x}^{2}+p_{z}^{2}=d_{1}{ }^{2}+d_{2}{ }^{2}+2 d_{1} d_{2}\left(c \theta_{1} c \theta_{12}+s \theta_{1} s \theta_{12}\right)= \\
=d_{1}{ }^{2}+d_{2}{ }^{2}+2 d_{1} d_{2}\left(c^{2} \theta_{1} c \theta_{2}-c \theta_{1} s \theta_{1} s \theta_{2}+s^{2} \theta_{1} c \theta_{2}+s \theta_{1} s \theta_{2} c \theta_{1}\right)= \\
=d_{1}{ }^{2}+d_{2}{ }^{2}+2 d_{1} d_{2} c \theta_{2}
\end{gathered}
$$

A partir da Equação A.30, obtém-se o ângulo $\theta_{2}$ (Equação A.31).

$$
\theta_{2}=\cos ^{-1}\left[\frac{p_{x}^{2}+p_{z}^{2}-d_{1}{ }^{2}-d_{2}{ }^{2}}{2 d_{1} d_{2}}\right]
$$

O quadrado do módulo de $\mathbf{p}$ pela cadeia da direita do manipulador (Equação A.26) é

$$
p_{x}^{2}+p_{z}^{2}=d_{3}{ }^{2}+d_{4}{ }^{2} c^{2} \theta_{4}+2 d_{3} d_{4} c \theta_{4}+d_{4}{ }^{2} s^{2} \theta_{4}
$$

Usando as relações trigonométricas da Equação A.28, chega-se a Equação A.34.

$$
p_{x}^{2}+p_{z}^{2}=d_{3}^{2}+d_{4}^{2}+2 d_{3} d_{4} c \theta_{4}
$$

A partir da Equação A.34, obtém-se o ângulo $\theta_{4}$ (Equação A.35).

$$
\theta_{4}=\cos ^{-1}\left[\frac{p_{x}^{2}+p_{z}^{2}-d_{3}{ }^{2}-d_{4}{ }^{2}}{2 d_{3} d_{4}}\right]
$$

Para obter o ângulo $\theta_{1}$, serão reescritas as Equações A.25 usando as relações da Equação A.29.

$$
\left\{\begin{array}{l}
p_{x}=d_{1} \cos \left(\theta_{1}\right)+d_{2}\left(c \theta_{1} c \theta_{2}-s \theta_{1} s \theta_{2}\right) \\
p_{z}=d_{1} \operatorname{sen}\left(\theta_{1}\right)+d_{2}\left(s \theta_{1} c \theta_{2}+s \theta_{2} c \theta_{1}\right)
\end{array}\right.
$$


Resolvendo para $\cos \left(\theta_{1}\right)$ e $\operatorname{sen}\left(\theta_{1}\right)$, tem-se as Equações A.37 e A.38, respectivamente.

$$
\begin{aligned}
& c \theta_{1}=\frac{p_{x}+s \theta_{1}\left(d_{2} s \theta_{2}\right)}{d_{1}+d_{2} c \theta_{2}} \\
& s \theta_{1}=\frac{p_{z}-c \theta_{1}\left(d_{2} s \theta_{2}\right)}{d_{1}+d_{2} c \theta_{2}}
\end{aligned}
$$

Substituindo $\operatorname{sen}\left(\theta_{1}\right)$ da Equação A.38 na Equação A.37 tem-se

$$
\begin{aligned}
& c \theta_{1}=\frac{p_{x}}{d_{1}+d_{2} c \theta_{2}}+\frac{\left[p_{z}-c \theta_{1}\left(d_{2} s \theta_{2}\right)\right]\left(d_{2} s \theta_{2}\right)}{\left(d_{1}+d_{2} c \theta_{2}\right)^{2}}= \\
& =\frac{p_{x}\left(d_{1}+d_{2} c \theta_{2}\right)+p_{z}\left(d_{2} s \theta_{2}\right)-c \theta_{1}\left(d_{2} s \theta_{2}\right)^{2}}{\left(d_{1}+d_{2} c \theta_{2}\right)^{2}}
\end{aligned}
$$

Rearranjando, tem-se

$$
c \theta_{1}\left(d_{1}+d_{2} c \theta_{2}\right)^{2}+c \theta_{1}\left(d_{2} s \theta_{2}\right)^{2}=p_{x}\left(d_{1}+d_{2} c \theta_{2}\right)+p_{z}\left(d_{2} s \theta_{2}\right)
$$

Substituindo a Equação A.28 no lado esquerdo da Equação A.40, chega-se a

$$
c \theta_{1}\left(d_{1}^{2}+2 d_{1} d_{2} c \theta_{2}+d_{2}^{2} c^{2} \theta_{2}+d_{2}^{2} s^{2} \theta_{2}\right)=c \theta_{1}\left(d_{1}^{2}+2 d_{1} d_{2} c \theta_{2}+d_{2}^{2}\right)
$$

Substituindo a Equação A.41 na Equação A.44, tem-se

$$
c \theta_{1}=\frac{p_{x}\left(d_{1}+d_{2} c \theta_{2}\right)+p_{z}\left(d_{2} s \theta_{2}\right)}{d_{1}^{2}+2 d_{1} d_{2} c \theta_{2}+d_{2}^{2}}
$$


Substituindo $\cos \left(\theta_{1}\right)$ da Equação A.37 na Equação A.38, tem-se

$$
\begin{aligned}
& s \theta_{1}=\frac{p_{z}}{d_{1}+d_{2} c \theta_{2}}-\frac{\left[p_{x}-s \theta_{1}\left(d_{2} s \theta_{2}\right)\right]\left(d_{2} s \theta_{2}\right)}{\left(d_{1}+d_{2} c \theta_{2}\right)^{2}}= \\
& =\frac{p_{z}\left(d_{1}+d_{2} c \theta_{2}\right)-p_{x}\left(d_{2} s \theta_{2}\right)-s \theta_{1}\left(d_{2} s \theta_{2}\right)^{2}}{\left(d_{1}+d_{2} c \theta_{2}\right)^{2}}
\end{aligned}
$$

Rearranjando, tem-se

$$
s \theta_{1}\left(d_{1}+d_{2} c \theta_{2}\right)^{2}+s \theta_{1}\left(d_{2} s \theta_{2}\right)^{2}=p_{z}\left(d_{1}+d_{2} c \theta_{2}\right)-p_{x}\left(d_{2} s \theta_{2}\right)
$$

Substituindo a Equação A.28 no lado esquerdo da Equação A.44, chega-se a

$$
s \theta_{1}\left(d_{1}^{2}+2 d_{1} d_{2} c \theta_{2}+d_{2}^{2} c^{2} \theta_{2}+d_{2}^{2} s^{2} \theta_{2}\right)=s \theta_{1}\left(d_{1}^{2}+2 d_{1} d_{2} c \theta_{2}+d_{2}^{2}\right)
$$

Substituindo a Equação A.45 na Equação A.44, tem-se

$$
s \theta_{1}=\frac{p_{z}\left(d_{1}+d_{2} c \theta_{2}\right)-p_{x}\left(d_{2} s \theta_{2}\right)}{d_{1}^{2}+2 d_{1} d_{2} c \theta_{2}+d_{2}^{2}}
$$

Assim, o ângulo $\theta_{1}$ pode ser determinado de acordo com as Equações A.47 e A.48.

$$
t \theta_{1}=\frac{s \theta_{1}}{c \theta_{1}}=\frac{p_{z}\left(d_{1}+d_{2} c \theta_{2}\right)-p_{x}\left(d_{2} s \theta_{2}\right)}{p_{x}\left(d_{1}+d_{2} c \theta_{2}\right)+p_{z}\left(d_{2} s \theta_{2}\right)}
$$




$$
\theta_{1}=\tan ^{-1}\left[\frac{p_{z}\left(d_{1}+d_{2} c \theta_{2}\right)-p_{x}\left(d_{2} s \theta_{2}\right)}{p_{x}\left(d_{1}+d_{2} c \theta_{2}\right)+p_{z}\left(d_{2} s \theta_{2}\right)}\right]
$$

Unindo as equações do modelo cinemático direto (Equação A.24) e do modelo cinemático inverso (Equações A.31, A.35 e A.48), é possível calcular as velocidades, posição e orientação da plataforma móvel do mecanismo de quatro barras a partir de uma entrada de velocidade angular de uma das barras do mecanismo $\left(\dot{\theta}_{4}\right)$. A Figura A.5 apresenta um diagrama resumindo a metodologia empregada. Já A Figura A.6 apresenta este esquema com mais detalhes.

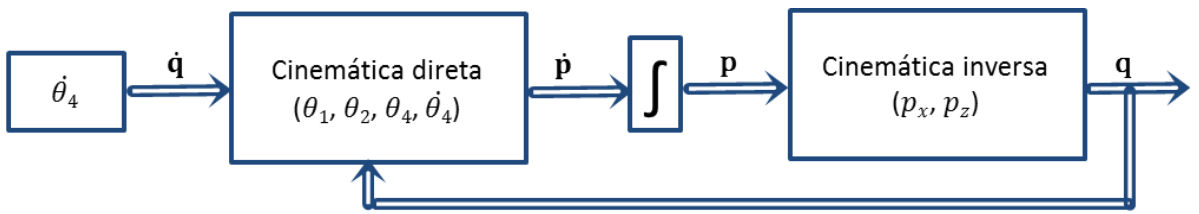

Figura A.5: Modelo cinemático do mecanismo de quatro barras.

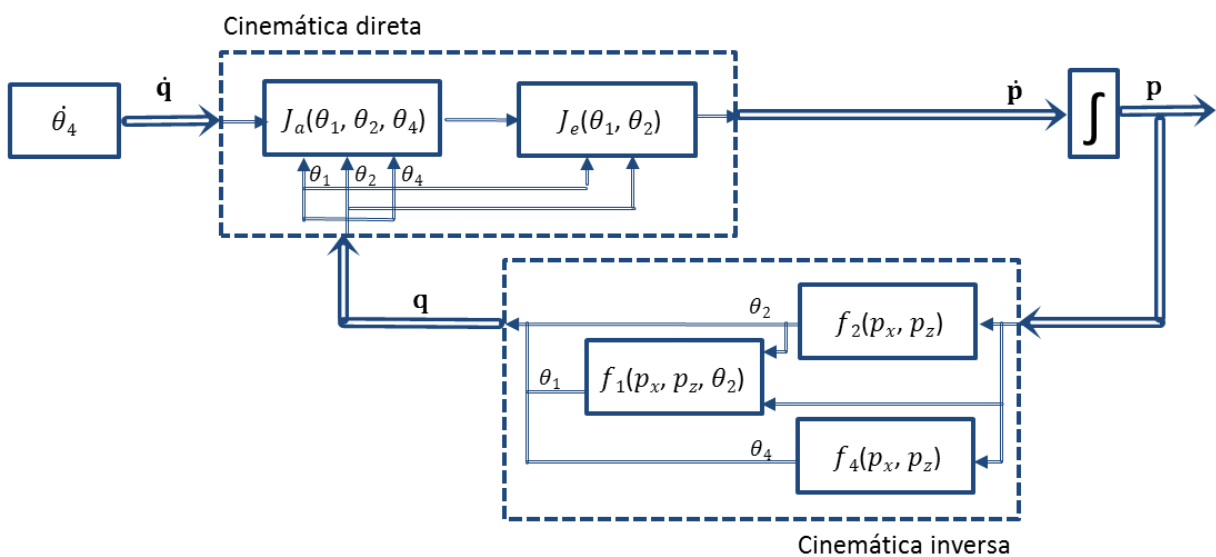

Figura A.6: Detalhes do modelo cinemático do mecanismo de quatro barras.

A Figura A.7 apresenta a configuração final do mecanismo de quatro barras (em azul) para uma entrada de $-30 \%$ s (30 \% no sentido horário) na barra $d_{4}$ após 1 segundo de simulação. A configuração original do mecanismo (em vermelho) foi $A_{0}=[0,0]^{T}, A_{1}=[20,50]^{T}, A_{2}=[60,40]^{T}$ e $A_{3}=[80,0]^{T}$. As Figuras A.8 a A.10 mostram, respectivamente, os deslocamentos do ponto $A_{2}$, as velocidades deste ponto e a variação dos ângulos $\theta_{1}, \theta_{2}$ e $\theta_{4}$. 


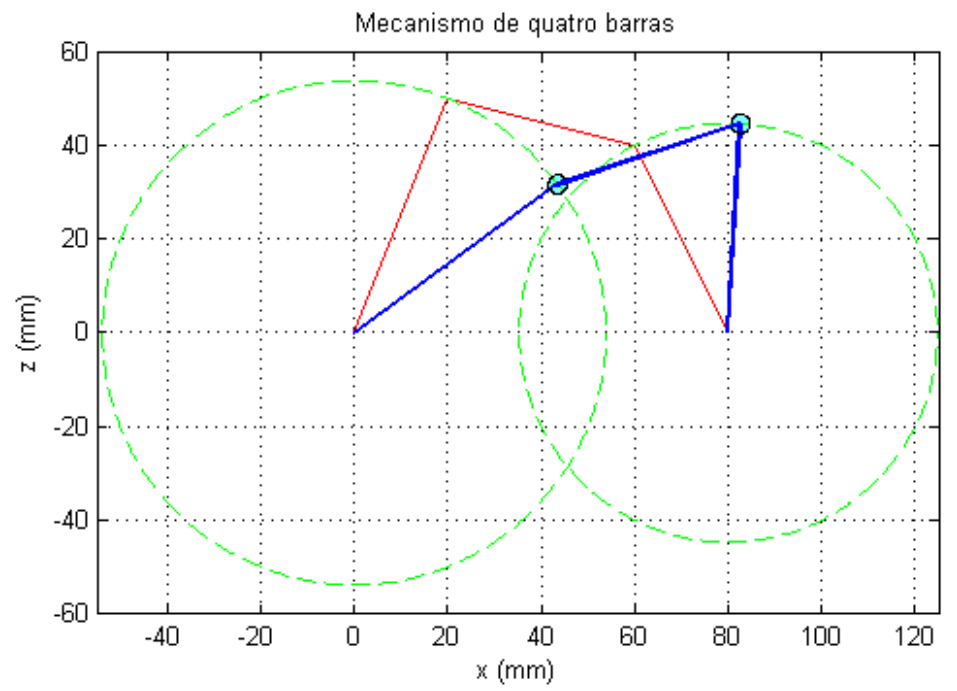

Figura A.7: Entrada de -30 \% na barra $d_{4}$ após $1 \mathrm{~s}$.

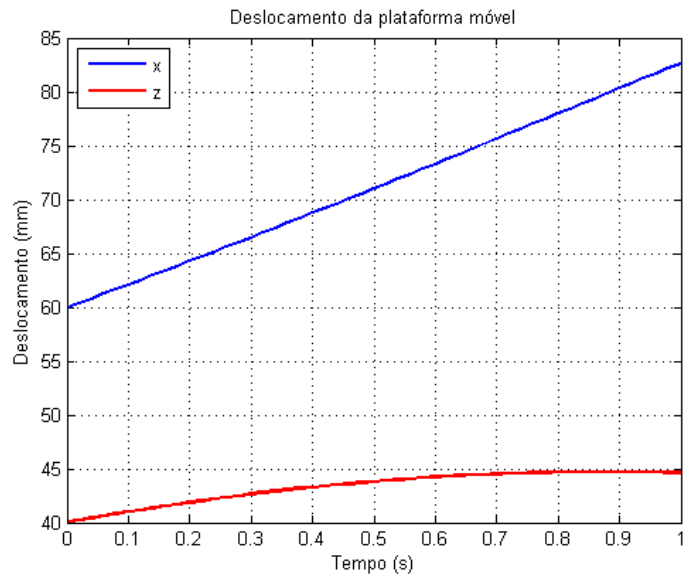

Figura A.8: Deslocamentos do ponto $A_{2}$ para entrada de $-30 \%$ em $d_{4}$.

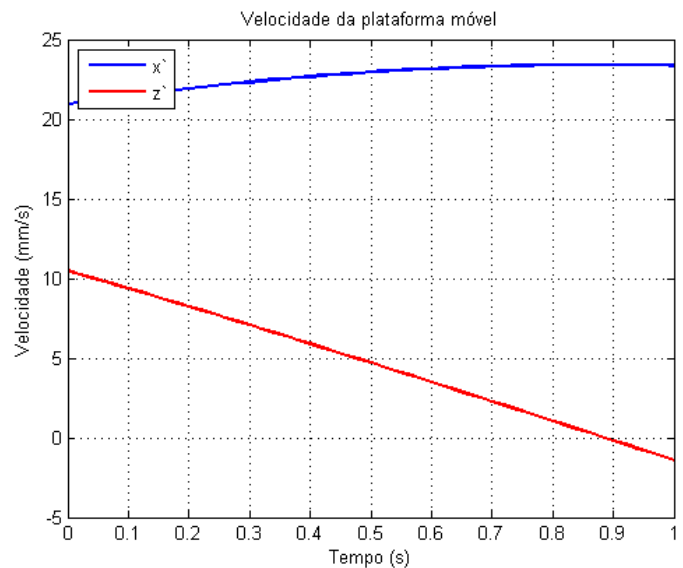

Figura A.9: Velocidades do ponto $A_{2}$ para entrada de $-30 \% \mathrm{~s} \mathrm{em} d_{4}$. 


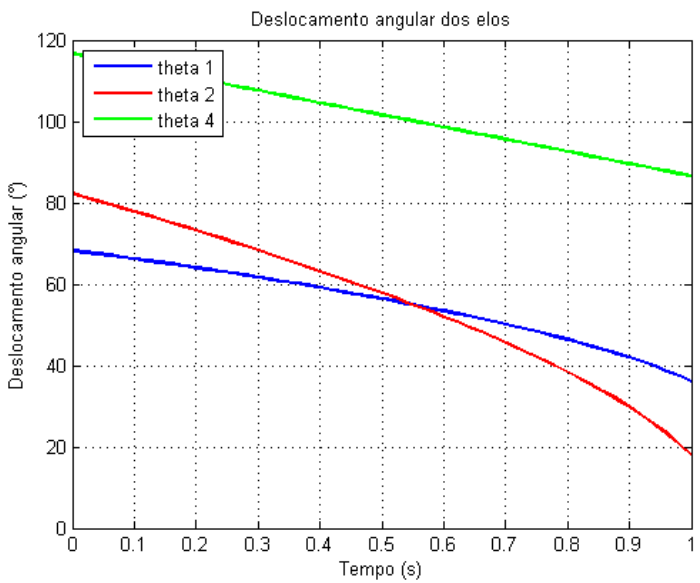

Figura A.10: Variação dos ângulos $\boldsymbol{\theta}_{\mathbf{1}}, \boldsymbol{\theta}_{\mathbf{2}} e \boldsymbol{\theta}_{\mathbf{4}}$ para entrada de $-30 \%$ em $d_{4}$.

A Figura A.11 apresenta a configuração final do mecanismo de quatro barras (em azul) para as mesmas condições, porém, usando a solução com o "cotovelo" para baixo no ponto $A_{l}$.

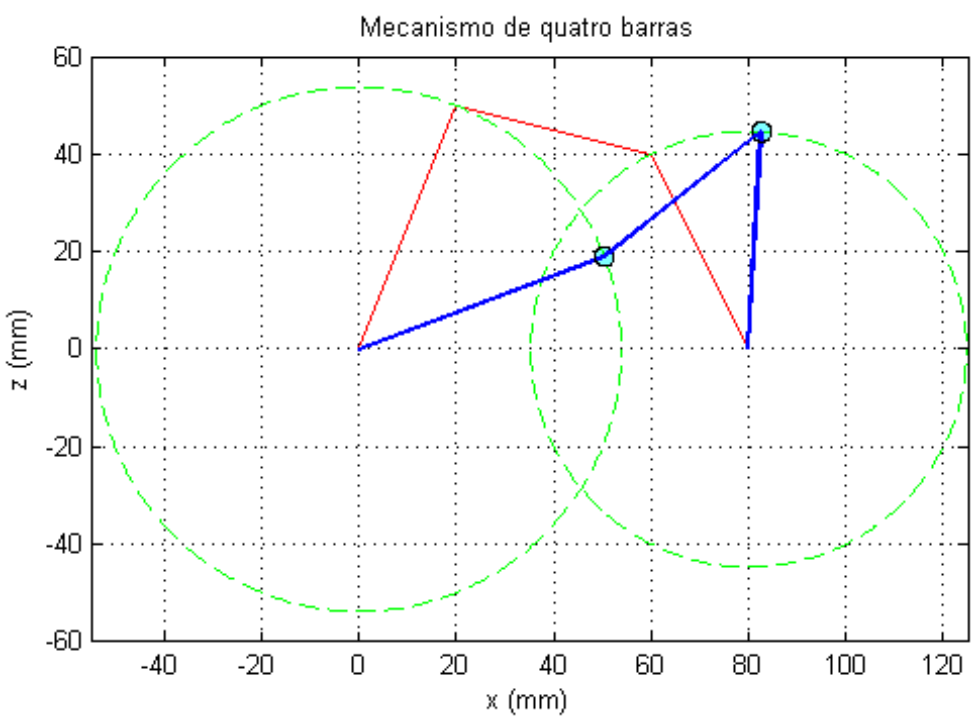

Figura A.11: Entrada de -30 \%s na barra $d_{4}$ após $1 \mathrm{~s} \mathrm{("cotovelo"} \mathrm{para} \mathrm{baixo).}$ 


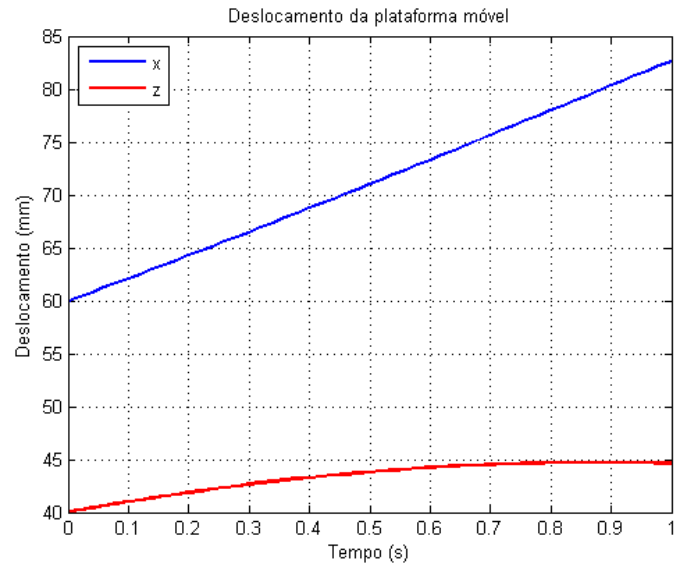

Figura A.12: Deslocamentos do ponto $A_{2}$ para entrada de $-30 \%$ em $d_{4}$ ("cotovelo" para baixo).

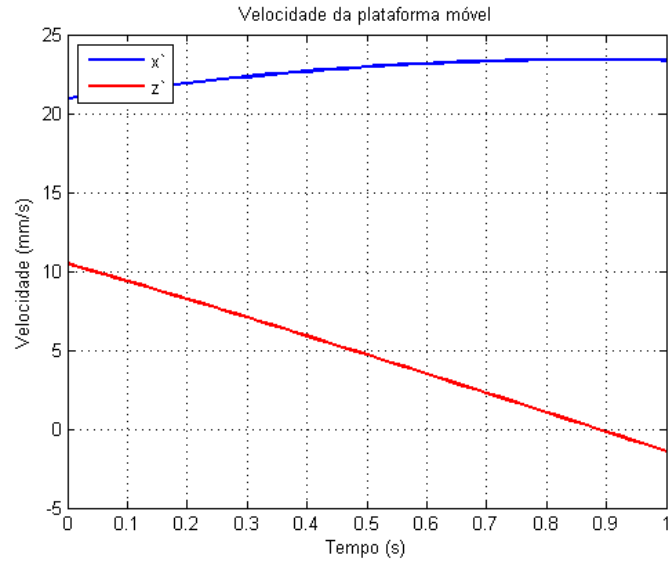

Figura A.13: Velocidades do ponto $A_{2}$ para entrada de $-30 \%$ em $d_{4}$ ("cotovelo" para baixo).

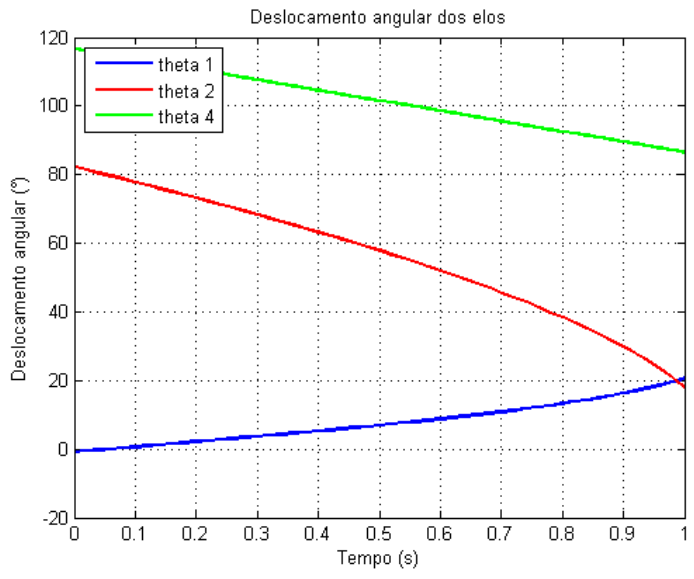

Figura A.14: Variação dos ângulos $\boldsymbol{\theta}_{\mathbf{1}}, \boldsymbol{\theta}_{\mathbf{2}}$ e $\boldsymbol{\theta}_{\mathbf{4}}$ para entrada de $-30 \%$ em $d_{4}$ ("cotovelo" para baixo). 
A Figura A.15 apresenta a configuração final do mecanismo de quatro barras (em azul) para uma entrada de $30 \%$ s (30\% no sentido anti-horário) na barra $d_{4}$ após 1 segundo de simulação. Já a Figura A.16 apresenta a solução com o "cotovelo" para baixo no ponto $A_{l}$.

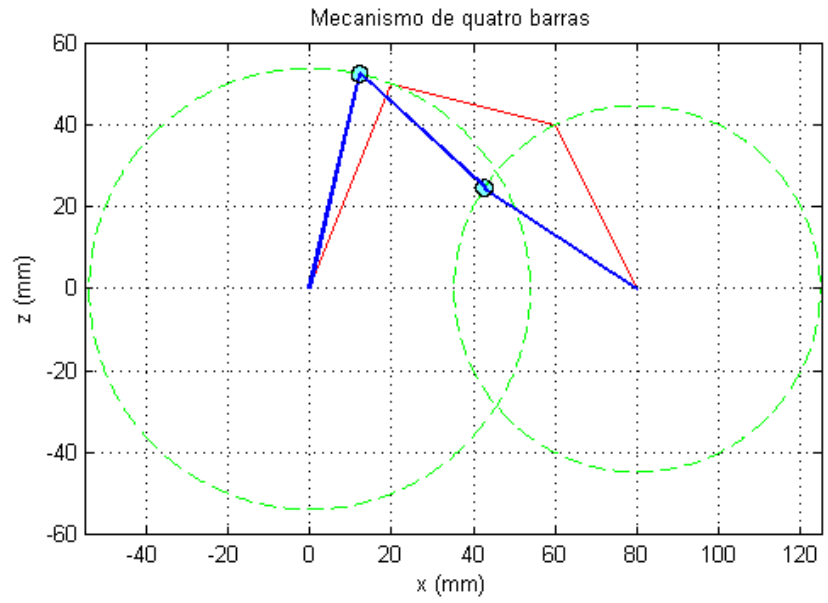

Figura A.15: Entrada de $30 \% \mathrm{~s}$ na barra $d_{4}$ após $1 \mathrm{~s}$.

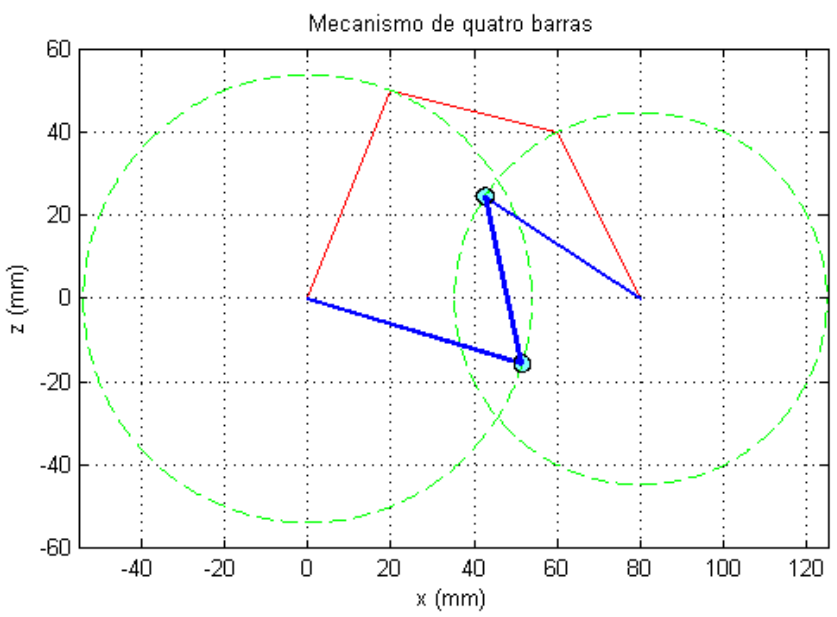

Figura A.16 Entrada de 30 \%s na barra $d_{4}$ após $1 \mathrm{~s}$ ("cotovelo" para baixo).

Desta vez, foi dada uma entrada $45 . \operatorname{sen}(6 \pi . t)-30 \%$ (frequência de $3 \mathrm{~Hz}$ ) em $\dot{\theta_{4}}$ com 1 segundo de simulação no modelo com a solução do "cotovelo" para cima. As Figuras A.17 a A.19 mostram, respectivamente, os deslocamentos do ponto $A_{2}$, as velocidades deste ponto e a variação dos ângulos $\theta_{1}, \theta_{2}$ e $\theta_{4}$ para esta entrada. 


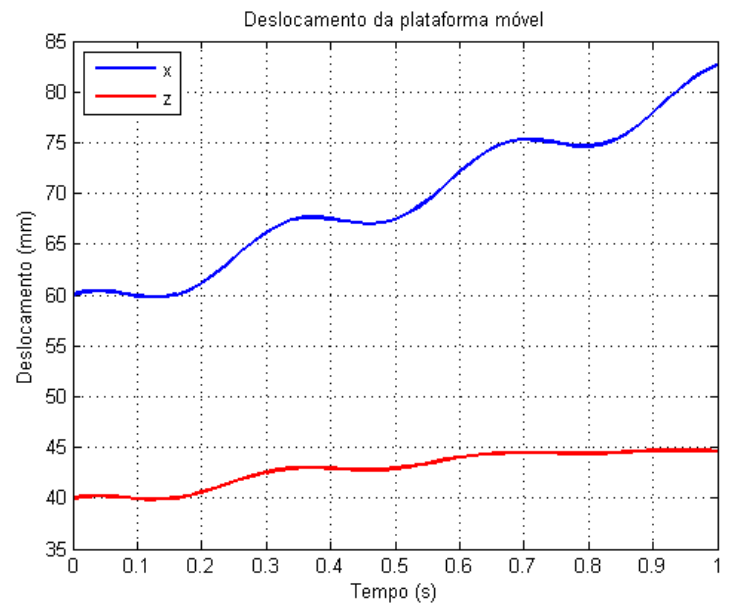

Figura A.17: Deslocamentos do ponto $A_{2}$ para entrada senoidal em $\dot{\boldsymbol{\theta}_{4}}$.

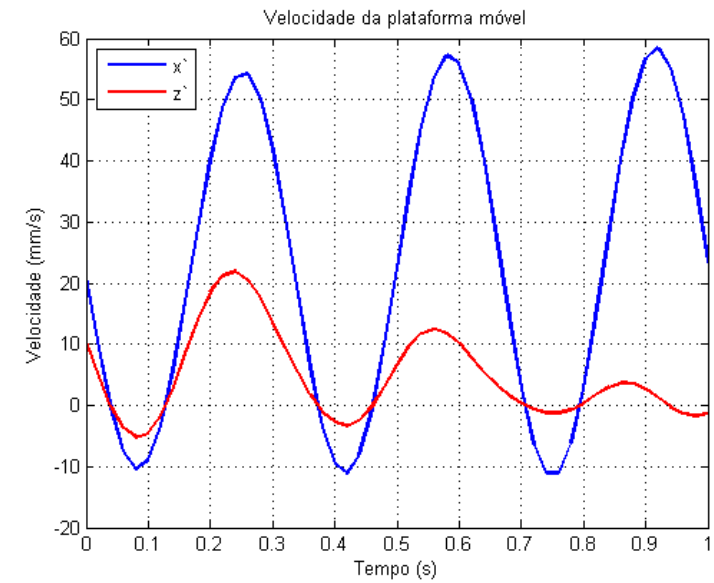

Figura A.18: Velocidades do ponto $A_{2}$ para entrada senoidal em $\dot{\boldsymbol{\theta}_{4}}$.

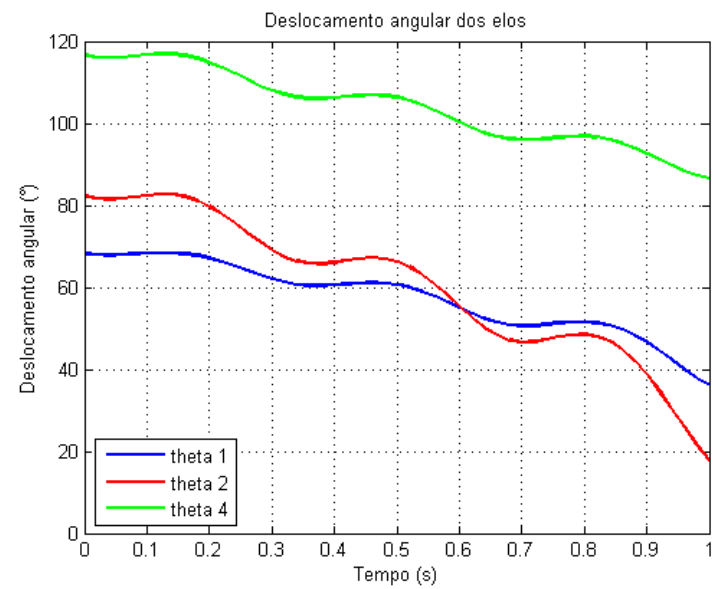

Figura A.19: Variação dos ângulos $\boldsymbol{\theta}_{\mathbf{1}}, \boldsymbol{\theta}_{\mathbf{2}}$ e $\boldsymbol{\theta}_{\mathbf{4}}$ para entrada senoidal em $\dot{\boldsymbol{\theta}}_{\mathbf{4}}$. 
Índice do CD Anexo

I Códigos usados nas simulações

I.1 Sistema de atuação

I.2 Plataforma plana com três graus de liberdade

I.2.1 Parâmetros (função principal)

I.2.2 Geometria inversa

1.2.3 Cinemática inversa (modelo da matriz Jacobiana)

I.2.4 Cinemática inversa (modelo dos derivativos da matriz Jacobiana)

I.2.5 Dinâmica direta

1.2.6 Estratégias de controle

1.2.7 Gráficos e animações 
Índice do CD Anexo

II CAD e desenhos técnicos

II.1 Atuador linear elétrico

II.2 Plataforma móvel

II.3 Rolamentos

II.4 Bancada completa

II.5 Desenhos técnicos

II.6 Animações 
Índice do CD Anexo

III Virtual Instruments (.vi) do programa LabView

III.1 Testes no dinamômetro

III.2 Testes na plataforma plana 3-RPR

III.2.1 Geometria inversa

III.2.2 Cinemática inversa (modelo da matriz Jacobiana)

III.2.3 Cinemática inversa (modelo dos derivativos da matriz Jacobiana)

III.2.4 Calibração da IMU

III.2.5 Estratégia de controle via transdutores de deslocamento

III.2.6 Estratégia de controle via IMU 
Índice do CD Anexo

IV Catálogos dos elementos da plataforma plana 3-RPR

IV.1 Atuadores e sensores

IV.1.1 Atuador linear elétrico

IV.1.2 Central inercial

IV.2 Componentes mecânicos

IV.2.1 Rolamento da base

IV.2.2 Rolamento da plataforma móvel

IV.3 Componentes do sistema de controle

IV.3.1 Controlador de motor

IV.3.2 Fonte 24 VDC

IV.3.3 Fonte 12 VDC

IV.3.4 Regulador de tensão 5 VDC

IV.4 Módulos de aquisição de dados e controle

IV.4.1 NI 9172

IV.4.2 NI 9205

IV.4.3 NI 9264 
CD Anexo

Este trabalho possui um CD anexado à versão impressa disponível na Divisão de Bibliotecas e Documentação PUC-Rio. 